\title{
EXPLORING TRANSIT RIDERSHIP USING CENSUS, ROUTING \& SCHEDULING, AND STOP CHARACTERISTIC DATA
}

\author{
A Thesis \\ presented to \\ the Faculty of California Polytechnic State University, \\ San Luis Obispo
}

In Partial Fulfillment

of the Requirements for the Degree

Master of Science in Civil and Environmental Engineering (MSCEEN)

by

Douglas Harvey Moody

March 2016 
(C) 2016

Douglas Harvey Moody

ALL RIGHTS RESERVED 


\section{COMMITTEE MEMBERSHIP}

TITLE:

AUTHOR:

DATE SUBMITTED:

COMMITTEE CHAIR:

COMMITTEE MEMBER:

COMMITTEE MEMBER:
Exploring Transit Ridership Using Census, Routing \& Scheduling, and Stop Characteristic Data

Douglas Harvey Moody

March 2016

Anurag Pande, Ph.D.

Associate Professor of Civil and Environmental Engineering

Robert Bertini, Ph.D.

Associate Professor of Civil and Environmental Engineering

Phil Moores

San Luis Obispo Regional Transit Authority (RTA)

Manager of Operations 


\begin{abstract}
Exploring Transit Ridership Using Census, Routing \& Scheduling, and Stop Characteristic Data Douglas Harvey Moody
\end{abstract}

This study develops, analyzes, and applies transit-system-specific regression tree models that identify and prioritize transit system improvements through analysis and application of ridership, Census, routing and scheduling, and transit stop characteristic data. Regression trees identify and rank independent variables that split dependent variable datasets into meaningful subsets according to significant relationships with independent variable datasets, and regression tree models can be used to identify and prioritize transit system improvements. In this study, ridership datatypes are the dependent variables (i.e., boardings and alightings) and Census, routing and scheduling, and transit stop characteristic datatypes are the independent variables. Data associated with the San Luis Obispo Regional Transit Authority (RTA) is the basis of this study.

The literature review for this study identified no other studies that use regression trees to identify and/or prioritize transit system improvements. The analysis method herein can help identify and prioritize improvements to any transit system. The findings of this study may be applicable to other transit systems if assumptions can be made about the similarity of other systems to the San Luis Obispo Regional Transit Authority system.

Relationships between transit ridership and independent variables that may be effective predictors of transit ridership are evaluated in this study. Traditional independent variables used to forecast transit ridership include population and employment densities, land use types, income distributions, service frequencies, and transit stop accessibility; other independent variables that may be significant predictors of transit ridership include transit stop amenities, characteristics, and connecting and nearby infrastructure.

Ridership data needed for the analysis presented in this study can be obtained from transit agencies. Census data needed for the analysis presented in this study is available through the United States Census Bureau. Routing and scheduling data needed for the analysis presented in this study can be extracted from local transit system schedules. Transit stop characteristic data needed for the analysis presented in this study can be gathered by using a survey instrument during field-visits. 
The regression tree models developed in this study show a positive relationship in the RTA system between transit ridership and population density (specifically Asian and twenty to twenty-four years old residential population densities), the number of trips serving transit stops, and transit stop characteristics (specifically the presence of a trash can). According to these findings, this study offers recommendations for improvements to RTA's transit system and marketing and planning strategies. More general conclusions that could be applicable to more transit systems could be drawn if the analysis method used in this study were performed with more and/or larger datasets (e.g., other transit agency, regional, statewide, national, and/or global datasets) comprised of more robust, accurate, and precise datatypes, and this concept is the basis for the future work recommended by this study. 


\section{ACKNOWLEDGMENTS}

First, thank you to the good people of the San Luis Obispo Regional Transit Authority (RTA) for the all the great times. Working with the people of RTA to get the people of San Luis Obispo County to school, work, and everywhere else they wanted and needed to go was one of the most rewarding experiences of my life. Thank you Aimee Wyatt for your good-natured spirit, having faith in me, and helping me get my start in transportation and government. Thank you Phil Moores for being a cool dude with a ton of experience and empathy who is always willing to talk things through. Thank you Geoff Straw for assigning me to the project that was the kernel for this thesis, and thank you for sharing some of your wealth of transit experience and expertise with me while I developed this thesis and the two RTA reports that are attached as appendices. Thank you Tania Arnold for having faith in me and helping to keep me working with RTA. There are so many more people with RTA to thank, and I can't list you all here, but you know who you are, and thank you.

Thank you Geoffrey Chiapella and James Worthley of the San Luis Obispo Council of Governments (SLOCOG) for taking the time to offer some key feedback on this thesis at a crucial juncture.

Thank you Dr. Anurag Pande for your thoughtful and very useful guidance and feedback. Thank you Dr. Robert Bertini for helping keep this process on-track and me sane.

Thank you Chris Clark for your ability and willingness to listen, sense of humor, and steady flow of sage advice.

And thank you Brandi Stansbury for being there for me throughout this whole process. 


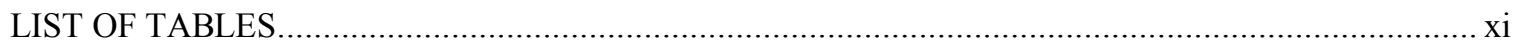

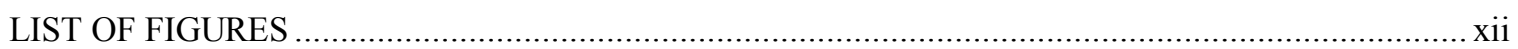

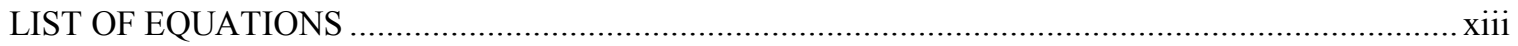

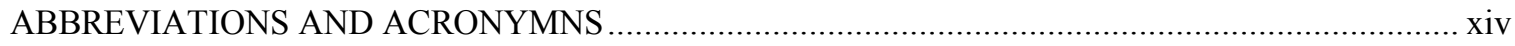

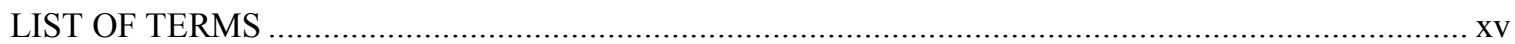

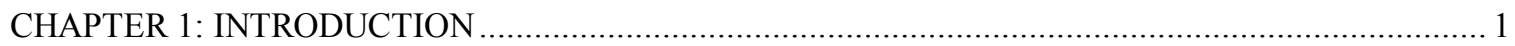

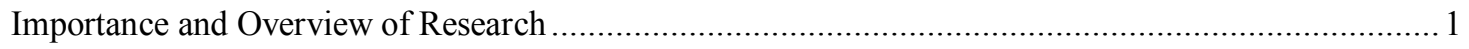

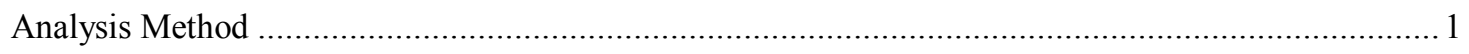

Dependent Variables - Ridership Data ……....................................................................... 2

Independent Variables - Census, Routing and Scheduling, and Transit-Stop Characteristics............. 2

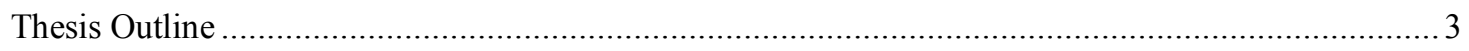

CHAPTER 2: LITERATURE REVIEW AND BACKGROUND ............................................................. 4

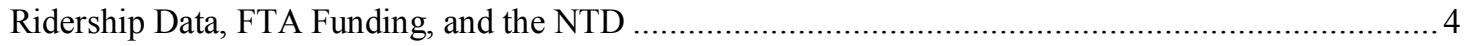

National Transit Database Fixed-route Ridership Data Collection Requirements ............................ 4

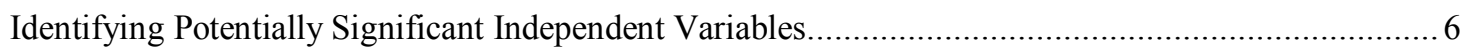

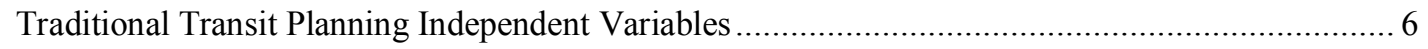

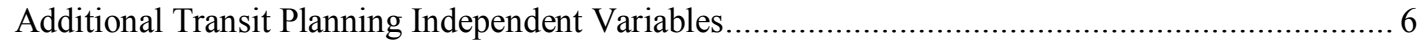

Ridership Data and Transit-specific Intelligent Transportation Systems (ITS) ..................................... 7

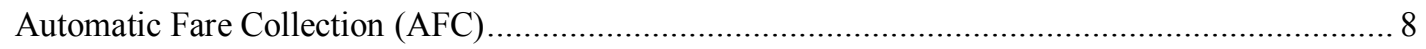

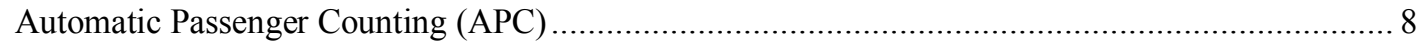

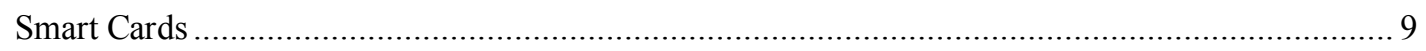

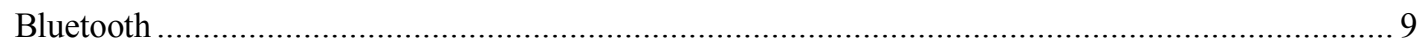

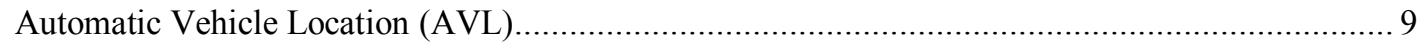

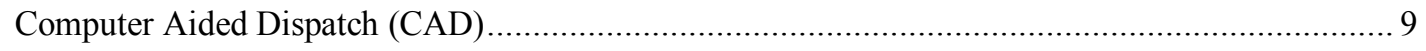

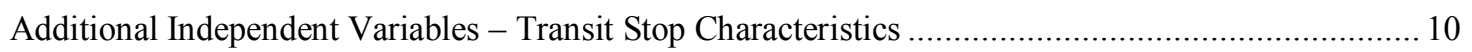

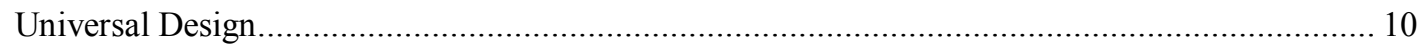




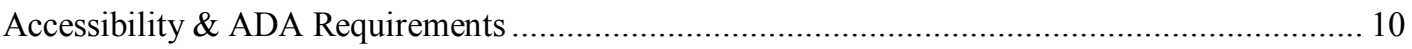

Using Regression Trees to Identify and Prioritize Transit Improvements............................................ 11

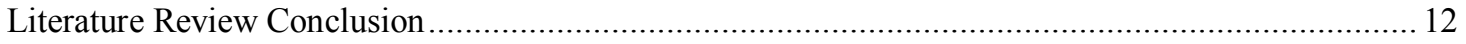

CHAPTER 3: DATA COLLECTION, AGGREGATION, AND ANALYSIS METHODOLOGY ............. 13

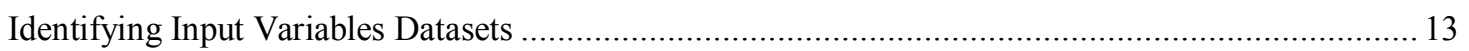

Dependent Variables: Boardings and Alightings by Transit Stop …........................................... 13

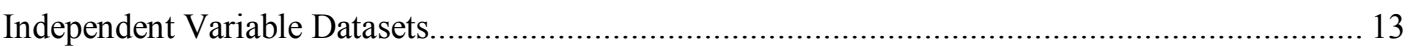

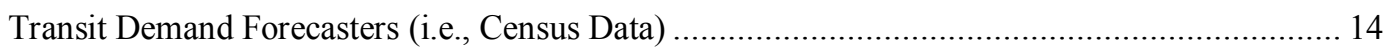

Transit Demand Obstructers and Inducers (Policy-based Variables) ........................................... 14

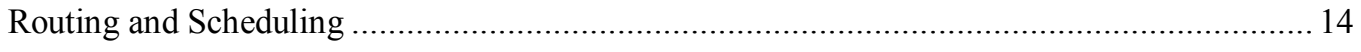

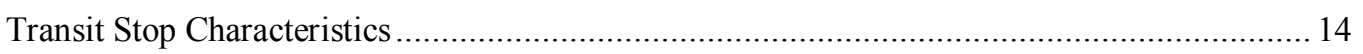

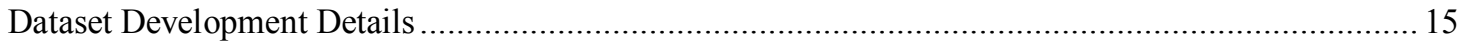

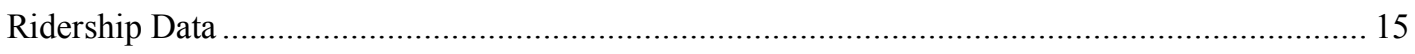

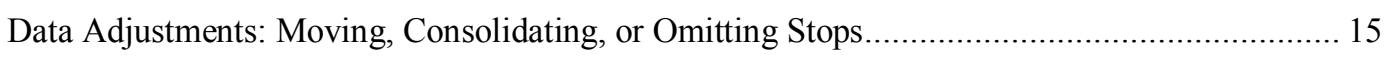

Currently Operating Bus Stops with no Ridership Data ......................................................... 16

Moved, Consolidated, and Omitted Bus Stops since last Ridership Surveys ............................ 17

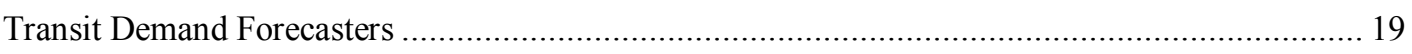

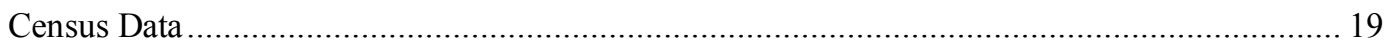

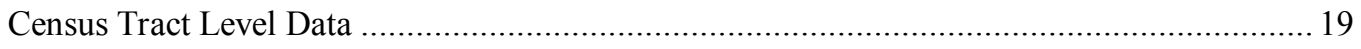

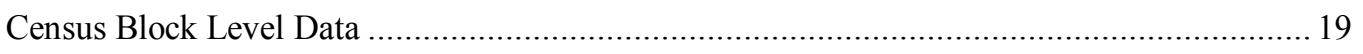

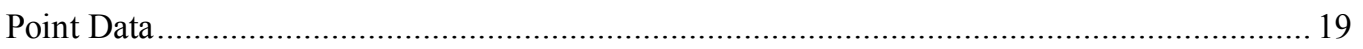

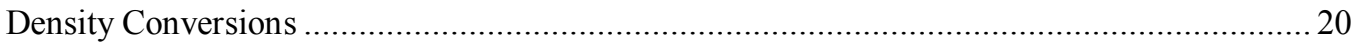

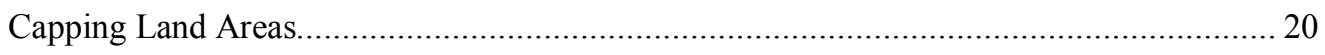

Capping Residential Density in the California Men's Colony Census Tract ........................ 21

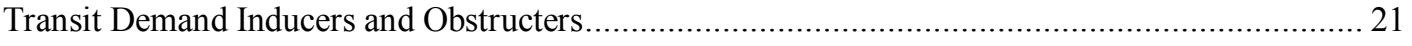

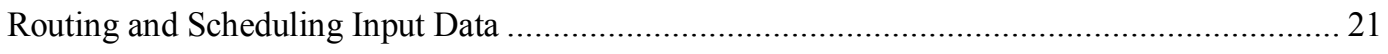

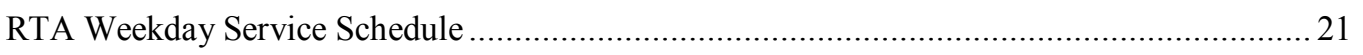

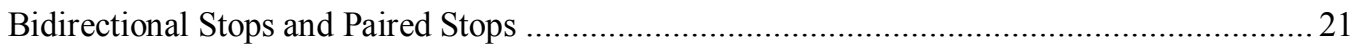




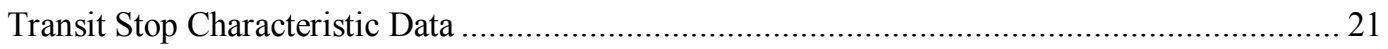

Capping Twin Cities Hospital Shelter Area ........................................................................... 22

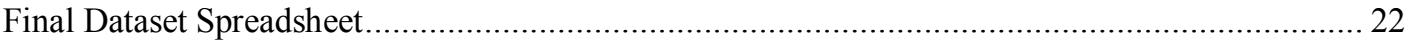

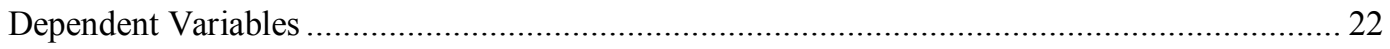

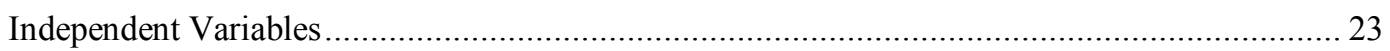

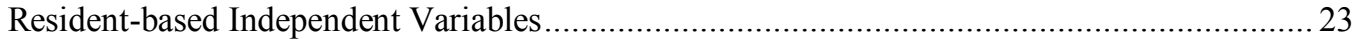

Employment-based Independent Variables ...................................................................... 25

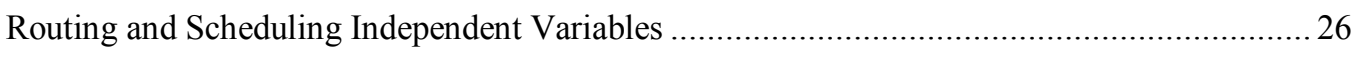

Transit Stop Characteristic Independent Variables …….......................................................... 26

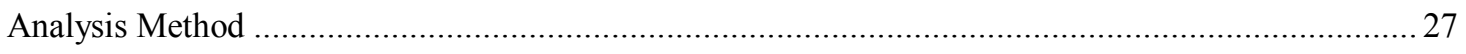

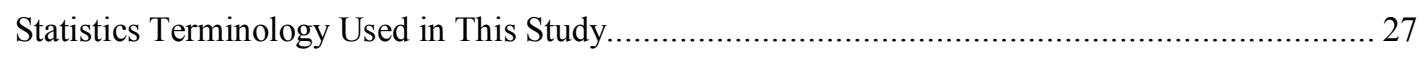

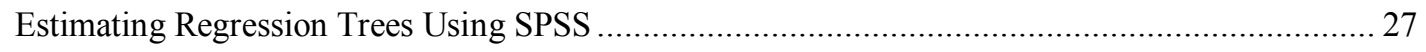

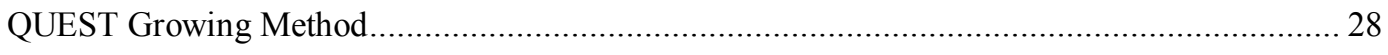

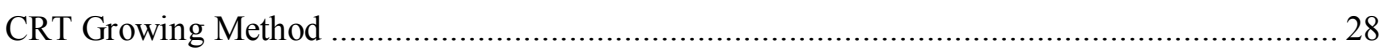

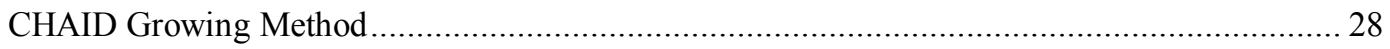

Growing Regression Tress in SPSS through Exhaustive CHAID ............................................ 28

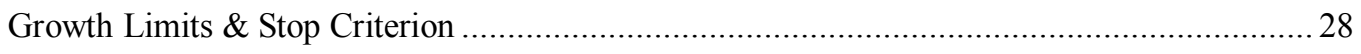

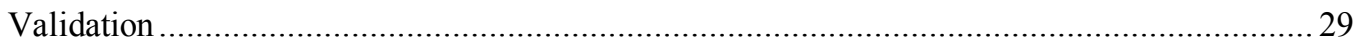

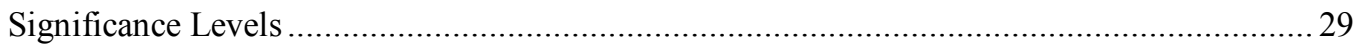

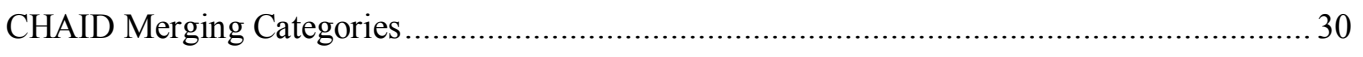

Resplitting Merged Categories with a Node ……............................................................... 30

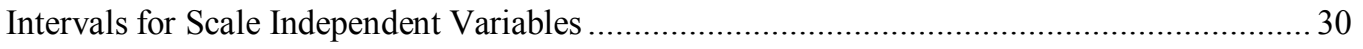

CHAPTER 4: ANALYSIS, RESULTS, AND DISCUSSION USING REGRESSION TREE METHOD.. 31

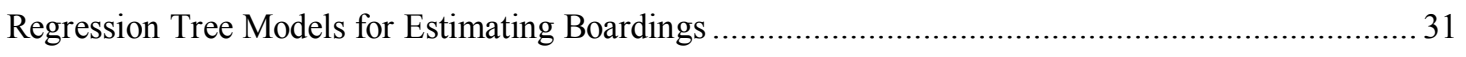

Regression Tree Models for Estimating Boardings: Census Data Only ....................................... 31

Regression Tree Models for Boardings: Routing, Scheduling \& Stop Characteristic Data Only...... 33

Regression Tree Models for Estimating Boardings: Full Dataset ................................................ 34

Regression Tree Models for Estimating Alightings..................................................................... 35 
Regression Tree Models for Estimating Alightings: Census Data Only

Regression Tree Models for Alightings: Routing, Scheduling \& Stop Characteristic Data Only ..... 36

Regression Tree Models for Estimating Alightings: Full Dataset ................................................ 37

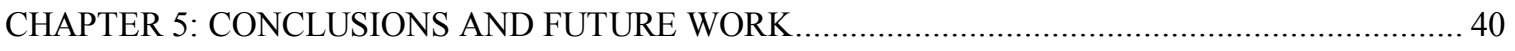

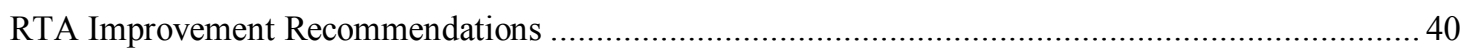

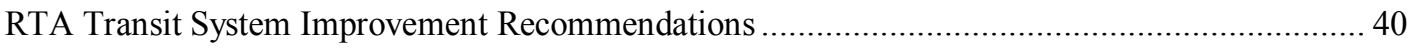

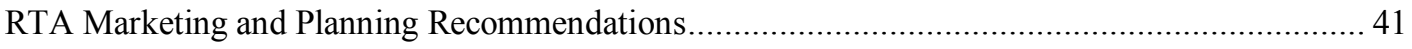

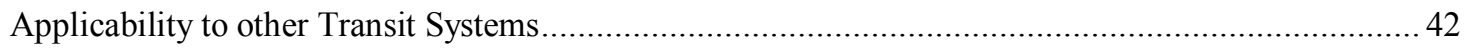

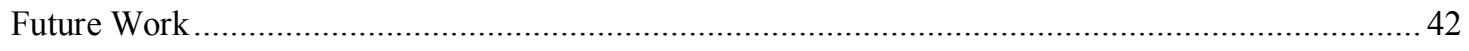

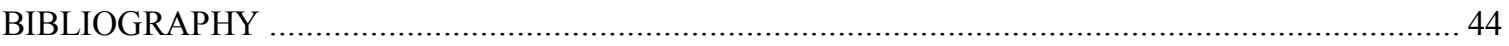

APPENDICES

A. Prioritizing RTA Fixed-route Bus Stop Improvements Report ............................................. 46

B. Draft Prioritizing RTA and Paso Express Fixed-route Bus Stop Improvements Report ............ 91

C. RTA Fixed-route Schedules (timetables, bus stop maps and diagrams) ................................. 145

D. Timetables used to Populate Google with RTA Route and Schedule Information .................. 152

E. Final Dataset Spreadsheet (Basis of Analysis) ….............................................................. 162 


\section{LIST OF TABLES}

Table

Page

Table 1: Moved, Consolidated, and Omitted Bus Stops since last Ridership Surveys 18

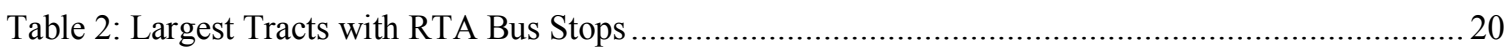

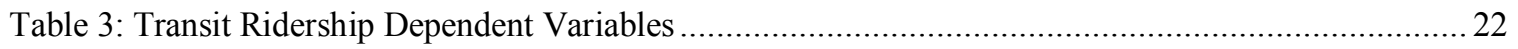

Table 4: Resident-based Census Tract Density Independent Variables ................................................... 24

Table 5: Employment-based Census Tract Density Independent Variables ............................................ 25

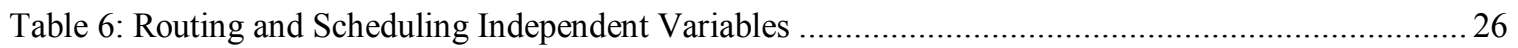

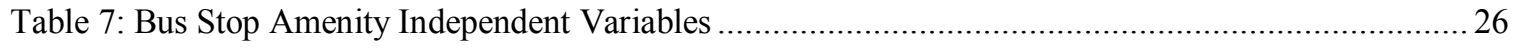

Table 8: Census Tracts in RTA Service Area with Highest Asian Residential Population Densities .......... 41

Table 9: Census Tracts in RTA Service Area with Highest 20 to 24 Year Old Residential Densities ......... 41 


\section{LIST OF FIGURES}

Figure

Page

Figure 1: Ons - Census Data Only Regression Tree.. 32

Figure 2: Ons - Routing, Scheduling \& Stop Characteristic Data Only Regression Tree........................... 33

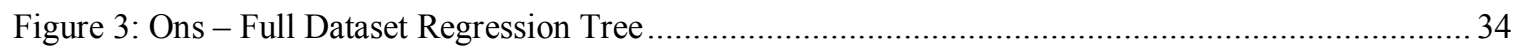

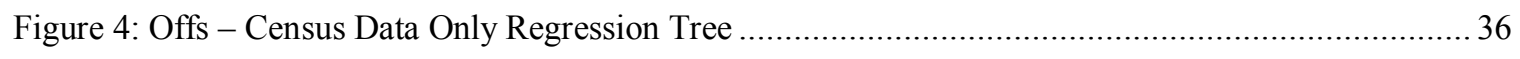

Figure 5: Offs - Routing, Scheduling \& Stop Characteristic Data Only Regression Tree .......................... 37

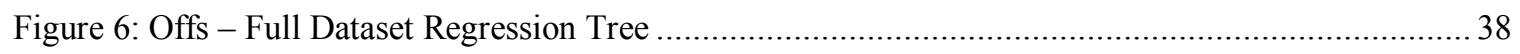




\section{LIST OF EQUATIONS}

Equation

Page

Equation 1: Census Tract Count Variable Density ... 


\section{ABBREVIATIONS AND ACRONYMNS}

$\begin{array}{ll}\text { TcTS } & \text { Transit-centric transportation system } \\ \text { CHAID } & \text { Chi-squared Automatic Interaction Detection } \\ \text { FTA: } & \text { Federal Transit Administration } \\ \text { NTD: } & \text { National Transit Database } \\ \text { TCRP: } & \text { Transit Cooperative Research Program } \\ \text { SLOCOG: } & \text { San Luis Obispo Council of Governments } \\ \text { SLORTA: } & \text { San Luis Obispo Regional Transit Authority } \\ \text { UZA: } & \text { Urbanized Area } \\ \text { PMT: } & \text { Passenger Miles Traveled } \\ \text { AFC: } & \text { Automatic fare collection } \\ \text { APC: } & \text { Automatic passenger counting } \\ \text { AVL: } & \text { Automatic vehicle location } \\ \text { GPS: } & \text { Global positioning system } \\ \text { GIS: } & \text { Geographic information system } \\ \text { CAD: } & \text { Computer aided dispatch }\end{array}$




\section{LIST OF TERMS}

\section{CATEGORICAL VARIABLES}

Sometimes called nominal variables, categorical variables have two or more categories, and there is no intrinsic ordering to the categories (e.g., land use types).

ORDINAL VARIABLES

Similar to categorical variables, but there is a clear ordering of the variables (e.g., low, medium, and high), and the interval between categories is inconsistent.

\section{INTERVAL VARIABLES}

Similar to ordinal variables but the interval between categories is equal (e.g., 5, 10, 20, 25).

\section{SCALE VARIABLES}

Scale variable values represent ordered categories with meaningful metrics so that distance comparisons between values are appropriate. Examples of scale variables include number of boardings, number of alightings, and trips per day. This study treats both interval and continuous variables as scale variables.

\section{GLOBAL Positioning SYSTEM (GPS)}

A U.S.-owned utility that provides users with positioning, navigation, and timing (PNT) services. This system consists of three segments: the space segment, the control segment, and the user segment. The U.S. Air Force develops, maintains, and operates the space and control segments. (National Coordination Office for Space-Based Positioning, Navigation, 2014)

UNIVERSAL DESIGN

Design that meets the needs of all.

AMERICANS WITH DISABILITIES ACT

Civil rights law that prohibits, under certain circumstances, discrimination based on disability.

\section{ACCESSIBILITY}

The availability of a product, device, service, or environment to all.

\section{ASSISTIVE TECHNOLOGY}

Umbrella term for assistive, adaptive, and rehabilitative devices for people with Disabilities. 


\section{CHAPTER 1: INTRODUCTION}

This study seeks to answer the following questions: What changes to a transit system's stop characteristics and routes and schedules are significantly related to changes in transit ridership? How can transit agencies use these relationships to prioritize improvements to their systems? Which demographics have significant relationship to transit ridership? Towards which demographics should transit agencies focus their marketing and planning efforts? To answer these questions, this study develops, interprets, and applies transit-system-specific regression tree models that can be used to identify and prioritize system improvements through analysis and application of ridership, Census, routing and scheduling, and transit stop characteristic data.

\section{Importance and Overview of Research}

Transit-centric transportation systems (TcTSs) provide many advantages: TcTSs can reduce congestion, reduce greenhouse gas emissions, improve air quality and public respiratory health, provide increased mobility to the non-driving public (including seniors, youth and people with disabilities), encourage decreased travel demand, utilize space efficiently, provide fast alternatives in congested areas, and uphold economic health. Furthermore, TcTS can encourage walking and biking to and from stops, which can add exercise, tranquility, and flavor to daily commutes. Effective TcTSs can be desirable transportation solutions - they can decrease environmental degradation, increase mobility, increase public health, and contribute to a healthy economy.

Transit is currently thriving in the United States. There are over 140,000 vehicles that serve over 48 billion passenger-miles and collect over $\$ 8.5$ billion in passenger fares each year, and in the past 10 years, the transit travel has increased by more than $20 \%$, which is more than either highway or air travel. (National Transit Database, 2014)

Identifying changes to transit systems and policies that may lead to increases in transit ridership by making transit systems more desirable and efficient is a critical research question.

\section{Analysis Method}

This study develops, interprets, and applies transit-system-specific regression trees that can be used to identify and prioritize system improvements through analysis and application of ridership, Census, routing 
and scheduling, and transit stop characteristic data. Regression trees identify and rank the strongest relationships between dependent and independent variables. Advantages of regression trees over traditional statistical approaches (including linear regression models) is that regression trees can account for correlated independent variables, and they are distribution agnostic, so they don't require restrictive assumptions that are typical of more traditional statistical analysis methods. Furthermore, regression tree data mining techniques are suitable for analysis of observational data collected outside the purview of designed experiments. (Hand et al., 2001)

\section{Dependent Variables - Ridership Data}

Most transit agencies already collect substantial transit usage data, and, hence, this data is available to develop transit-ridership-estimating models. One reason transit agencies collect ridership data is that they are required to report performance data to the National Transit Database (NTD) in order to receive their share of the over $\$ 5$ billion of Federal Transit Administration (FTA) funds apportioned to transit agencies in urbanized areas (UZAs) annually. It is not uncommon for transit agencies to hire on-board ride-checkers to gather ridership data, but gathering robust data through this method is time-consuming and expensive, so transit agencies have been turning to transit intelligent transportation systems (ITS) technologies for more accurate, robust, and cost-effective data gathering, storage, interpretation, and communication. Transit-

specific ITS technologies that can gather ridership data include automatic fare collection (AFC), automatic passenger counting (APC), transit user smart cards, Bluetooth, automatic vehicle location (AVL), and computer aided dispatch (CAD) technologies.

In addition to the challenges of cost-effectively collecting robust and accurate ridership data, transit agencies may be wary to share ridership data they collect, but ridership data that was reported to the NTD should generally be accessible. For this reason, the ridership data analysis approach proposed herein should be applicable to several transit systems.

\section{Independent Variables - Census, Routing and Scheduling, and Transit-Stop Characteristics}

Census data is available through the U.S. Census Bureau, routing and scheduling data can be extracted from local transit system schedules, and transit stop characteristic data can be gathered by using a survey instrument during field-visits. 
Identifying the appropriate scale of Census data (e.g., block, block group, tract, county, voting district, traffic analysis zone, zip code, school district, congressional district, places, etc...) can be a challenge. Extracting Census data into a format that is useful for analysis in a time-efficient manner can also be a challenge. In addition, full data from local transit system schedules can also be difficult to obtain - published schedules may provide only a partial representation, and transit agencies may be wary to provide full timetables. Gathering transit stop characteristic data through field visits may be cumbersome, but this may be the only option if the transit agency being studied does not have the desired data, or if they are not willing to share it. In the subsequent chapters of this thesis, processes to overcome data-related challenges are described, the regression tree modeling process is described, and results are discussed.

\section{Thesis Outline}

The next chapter, chapter 2 , is a literature review that identifies generally accepted indicators of transit ridership, methods used to collect transit data, synergies between transit data collection and funding, and methods to use regression trees to analyze and apply transit data. Chapter 3 identifies sources for input variable datasets and describes methods used to in this study to analyze and apply the final dataset developed for this study. Chapter 4 models the number of boardings and alightings at bus stops according to characteristics of the stops identified by regression tree analysis. Chapter 5 offers recommendations to increase ridership of the RTA system and presents ideas for future work to expand on this study. 


\section{CHAPTER 2: LITERATURE REVIEW AND BACKGROUND}

This chapter is a literature review that identifies generally accepted (and other) indicators of transit ridership, methods used to collect transit data, and synergies between transit data collection and funding. This review also explores application of regression tree models, the data-mining method used in this study to analyze and apply data in order to identify and prioritize transit system improvements.

\section{Ridership Data, FTA Funding, and the NTD}

This section is a summary of FTA and National Transit Database (NTD) funding requirements, as they relate to collection of ridership data. These NTD data collection requirements generate data that should be available for researchers to analyze.

\section{National Transit Database Fixed-route Ridership Data Collection Requirements}

To be eligible for FTA Funding through NTD Reporting, transit agencies must meet specific ridership data collection requirements. The following summarizes and outlines NTD fixed-route ridership data collection requirements as specified in $\S 60$ - Data Collection. (U.S. Department of Transportation Federal Transit Administration, 2009) Transit agencies should evaluate these requirements diligently and consider them carefully when selecting NTD ridership data collection methods and transit ITS investments.

- Data collected with any instrument that records data correctly is acceptable.

- Samples must be randomly selected and selection methods should be designed to identify and correct errors when they occur; recorded errors must be corrected.

- Samples must cover all service units, and no service unit shall be selected more than once in the random sample.

- All service units expected to operate must be reported; this includes all service units on the schedule and others that are expected to operate (i.e., trippers, shuttles, and other operations). Service units shall be reported as one-way trips in terms of the amount of revenue service that each is expected to generate.

- All service unit data reported must include the date and type of service. If the sampling plan is based on the PPMT option, route identification data is also required. If sampling plan is based on 
service grouping, the group membership determination method of each service unit in the random sample is required.

- Data may be collected using on-board ride-checkers and/or automatic passenger counters (APCs). Ridership data collected through other methods must be obtained from direct measurement or direct observation without passenger intercept (i.e., no passenger interviews).

- When determining distances between stops, odometers readings recorded at the pick-up and/or drop-off site that are accurate to $1 / 10$ of mile are always acceptable; no distance estimations may be taken from maps.

- Passenger miles travelled (PMT) for each fixed-route service unit may be determined using the load-based approach or the distance based approach.

- To use the load-based approach, the following data is required for each service unit:

- Number of boardings and number of alightings

- Distance between any pair of consecutive stops at which boardings or alightings occurred

- Number of people onboard the vehicle between any pair of consecutive stops

- Number of people who stayed on from the previous one-way vehicle trip

- Number of people who remained on the vehicle at the last stop

- To use the distance-based approach, origins, destinations, and corresponding odometer readings of each transit rider in the service unit must be recorded.

- All data reported must meet the requirements of measurement accuracy in the NTD Reporting Manual. 


\section{Identifying Potentially Significant Independent Variables}

This section reviews literature to identity independent variables that may be effective predictors of transit ridership.

\section{Traditional Transit Planning Independent Variables}

Traditional independent variables used to forecast transit ridership in order to plan for ridershipmaximizing routing and scheduling include population and employment densities, land use types, income distributions, service frequencies, and transit stop accessibility. In addition to route and frequency planning, transit agencies have also successfully increased ridership using marketing and planning methods that include community involvement, market segmentation, and price adjustment strategies. External economic factors outside of a transit agency's direct control (e.g., local wages and GDP) have also been strongly correlated to transit ridership. The studies summarized below support these claims.

Based on data collected in urban areas of Maryland, a study of transit ridership reported that "land use type, transit accessibility, income, and density are strongly significant and robust predictors of transit ridership.” (Chakraborty \& Mishra, 2013)

A Transit Cooperative Research Program (TCRP) study identified service adjustments, fare and pricing adaptations, market information initiatives, planning orientation (community and customer based approaches), and service coordination, consolidation, and market segmentation as sources of increased ridership. (U.S. Department of Transportation Federal Transit Administration Transit Cooperative Research Program, 1998)

A Mineta Transportation Institute study found "extraordinarily strong correlations between transit ridership and three external factors related to economic activity [in the U.S. between 1995 and 1999]," and these are factors were hourly wage, GDP, and GDP per capita. This study also identified that transit professionals generally accept that traditional transit territories (i.e., dense corridors, urban cores, suburbs to cities configurations, and low-auto ownership areas) are good predictors of ridership growth. (Taylor et al., 2002)

\section{$\underline{\text { Additional Transit Planning Independent Variables }}$}

Additional independent variables that may be significant predictors of transit ridership are transit stop amenities, characteristics, and connecting and nearby infrastructure; if these variables are found to be 
significant predictors, they may be used to prioritize ridership-maximizing improvements to the built environment. Transit agencies may also be able to increase ridership by using marketing and planning strategies that consider competing costs and benefits of different modes, including costs of travel (e.g., fuel, maintenance, insurance, payments, fees, etc...), costs of travel time (e.g., lost productivity), and benefits while traveling (e.g., effects of stress, health, productivity, etc...). The studies summarized below support these claims:

A study of the Triangle Transit Authority (TTA) in North Carolina found that a bus stop index score comprised of "bus stop environment" information (i.e., bus stop amenities and bi-directional stop pairing information) had high statistical significance. Of the stop amenities studied, bus stop signs, shelters, schedules, lighting, paved landing areas, and sidewalks were found to be significantly correlated. Sidewalk completeness and connectivity were also identified as "important elements in predicting ridership," and pedestrian signals, signs, and crosswalk pavement markings were also "associated with higher ridership." This study also identified that adjacent architectural features (i.e., building orientations and setbacks) are correlated with transit ridership. This study did not indicate discovery of significant correlations between TTA ridership and the presence of maps, real-time information displays, trash cans, or bike racks at bus stops; nor did this study identify significant correlation between transit ridership and roadway widths. This study also supports the traditional transit planning assumptions that land uses and frequency of service are strongly correlated with transit ridership. (University of North Carolina Department of City and Regional Planning, 2006)

A study of Broward County, Florida's transit system identifies the "generalised price of transit travel" (i.e., the time to reach employment) as "more important than land use variables for explaining transit patronage, at least for a bus-only transit system with a large number of transit-dependent riders." (Thompson, Brown, \& Bhattacharya, 2012)

\section{Ridership Data and Transit-specific Intelligent Transportation Systems (ITS)}

Obviously, local real-world correlations are best identified by using input data that most accurately represents local real-world conditions. Local bus stop characteristic data can, rather simply, be gathered through one-time field-visits to bus stops. However, robust passenger usage data is harder to collect. 
As stated previously, to meet NTD requirements, it is common for transit agencies to hire onboard ride-checkers to count passenger boardings and alightings at specified locations (i.e., transit stops). However, gathering robust data through this method is expensive, so datasets collected by on-board ridecheckers are usually relatively small, and they are typically only collected intermittently. Furthermore, this type of data collection is very susceptible to human error. As a result, transit agencies are more frequently turning to transit ITS for more accurate, robust, and cost-effective data gathering, storage, interpretation, and communication. This section of the literature review explores the following transit ITS technologies: automatic fare collection (AFC), automatic passenger counting (APC), transit user smart cards, automatic vehicle location (AVL), Bluetooth for passenger-tracking, and computer aided dispatch (CAD).

\section{$\underline{\text { Automatic Fare Collection (AFC) }}$}

The main purpose of automatic fare collection (AFC) devices is to collect revenue, and they can also be used to count boardings, but, unfortunately, they do not collect alighting data. AFCs can also collect data about payment method (e.g., cash fare paid or type of pass used).

\section{Automatic Passenger Counting (APC)}

Automatic passenger counting (APC) systems can count both boardings and alightings. Automatic passenger counters (APCs) can also be used to report annual ridership data to the National Transit Database (NTD). APC data can also be very useful for local planning. Video surveillance systems can be used to validate the accuracy and precision of data collected using APCs. (Kimpel, Strathman, Griffin, Callas, \& Gerhart, 2002)

More robust transit user data can be gathered when APCs are used in combination with "smart cards" that can track long-term registration, transaction, and travel behaviors of transit users. For example, a study of Chicago Transit Authority smart card holders presents an analysis of access and usage patterns and discusses other analyses that are made possible by using smart card registration and transaction data. The study also discusses difficulties that may be encountered when conducting such analyses and recommends methods to improve and expand smart card data sets. (Utsunomiya, Attanucci, \& Wilson, 2006) Smart cards also come with privacy and legal issues related to encryption, storage, and dissemination of data. (Pelletier, Trépanier, \& Morency, 2011) 


\section{$\underline{\text { Smart Cards }}$}

Current smart card system technologies include (Pelletier et al., 2011):

- Readers and credentials, including both contactless credentials and credentials that require contact

- In-card memory and a microprocessors

- Data encryption or non-encryption

- Usage (i.e., boardings and alightings) data collection and storage technology

- Ability to collect and store card-holder travel behavior and registration, transaction, financial, and personal data

\section{Bluetooth}

Bluetooth is an emerging transit ITS technology (Moshe, Hadas, \& Levi, 2014), and it could allow transit users to employ their mobile devices in ways similar to smart cards.

\section{Automatic Vehicle Location (AVL)}

Automatic Vehicle Location (AVL) systems can track, log, and report real-time locations of transit vehicles. AVL systems are usually integrated with communications systems - they can track and communicate transit vehicle locations and schedule adherence information, which can be communicated amongst drivers, dispatchers, transit users, and transit agency staff. When AVL systems are used effectively, transit users receive real-time information, and they view their transit systems as more modern and reliable. (U.S. Department of Transportation Federal Transit Administration Transit Cooperative Research Program, 2008)

Early AVL systems used radio and wheel odometer technologies to determine and report bus locations. (U.S. Department of Transportation Federal Transit Administration Transit Cooperative Research Program, 1997) Modern AVL systems use Global Positioning System (GPS) technology.

\section{Computer Aided Dispatch (CAD)}

Computer aided dispatch (CAD) systems can collect and store data from each of the abovementioned transit ITS methods. Furthermore, by integrating, interpreting, and strategically communicating this data to transit agency staff and transit users, the data can be used to inform decisions. (U.S. Department of Transportation Federal Transit Administration Transit Cooperative Research Program, 2008) 
When used in fixed-route operations, CAD software can transmit AFC data, APC data, and AVL data, on-board emergency notifications, and other information - CAD software can generally improve situational awareness. CAD software can also improve the accuracy of information communicated to transit riders by transmitting schedule adherence information, ensuring the correctness of head-signs, and announcing upcoming stops. (U.S. Department of Transportation Federal Transit Administration Transit Cooperative Research Program, 2008)

\section{Additional Independent Variables - Transit Stop Characteristics}

Generally, transit stop designs and improvements focus on accessibility and/or universal design, and, in this study, both will be tested for correlations with transit ridership originating and terminating at the stop. Universal design measures focus on meeting the wants and needs of all users, and accessibility focuses on making the stop accessible for all users, including those with physical disabilities.

\section{Universal Design}

Most scholarly literature that discusses transit system improvements also discusses some aspects of universal design. Universal design is a design philosophy focused on social inclusion that was stimulated by disability civil rights legislation, an aging population, the information revolution, and evolving markets. Universal design focuses on improving accessible routes, improving assistive technology, and improving quality-of-life for people of all ages and abilities. (Audirac, 2008)

\section{Accessibility \& ADA Requirements}

In the U.S., transit accessibility usually focuses on minimum transit-specific requirements of the Americans with Disabilities Act (ADA); accordingly, Easter Seals Project ACTION created the Toolkit for the Assessment of Bus Stop Accessibility and Safety as a guide primarily for "staff at transit agencies and public works departments who are responsible for bus stop design and placement." The Toolkit interprets the Americans with Disabilities Act to develop minimum ADA requirements for bus stops. The Toolkit identifies the following as minimum ADA requirements for bus stops (Easter Seals Project ACTION, 2006):

Providing accessible bus stops requires choosing appropriate locations or improving the existing location. Coordination and cooperation with public works agencies, municipal government and 
business owners can enhance the connectivity between the land use and the bus stop. To ensure optimum bus stop placement, coordination should occur during the planning/development phase."

Bus stop sites must have the following:

- A firm, stable surface;

- A minimum clear length of 96 inches, measured from the curb or vehicle roadway edge, and a minimum clear width of 60 inches, measured parallel to the vehicle roadway;

- A maximum slope of 1:50 (2\%) for water drainage; and

- Connection to streets, sidewalks or pedestrian paths by an accessible route

\section{Using Regression Trees to Identify and Prioritize Transit Improvements}

Regression trees split datasets into subsets that represent meaningful differences in dependent variable values that correspond to significant differences in independent variable values, and regression trees rank independent variables according to the strength of their contribution to the dependent variable data splits. (Pande, 2005) Regression trees are relatively easy to program, and they produce results that are easy to understand. Also, because they are non-parametric, regression trees do not require independent variables being tested for strength of contribution to the dependent variable data splits to follow any particular probability distribution, and the independent variables being tested can have overlapping significance. (Tuffery, 2011)

Regression trees also have disadvantages. For example, because they evaluate the independent variables sequentially (not simultaneously) they detect only local (not global) optima, and the choice to divide a node into more branches is never revised subsequently — this gives greater importance to independent variables assigned nearer to the top of the tree, and it can give preference to variables that have more categories. (Tuffery, 2011) Several of these disadvantages can be overcome by using large datasets and robust validation methods. Dependent and independent variables analyzed using regression trees can be nominal, ordinal, or scale. (IBM, n.d.) 


\section{Literature Review Conclusion}

Regression trees can identify and rank independent variables with significant relationships to transitridership dependent variables, and independent variables with significant relationships to transit-ridership dependent variables contained within regression trees can be used to identify and prioritize transit system improvements.

This literature review identified many transit datatypes and sources that can be used to develop regression trees that can, in turn, be used to identify and prioritize transit system improvements, but no studies were discovered that used regression trees to identify and prioritize transit system improvements according to expected increases in transit ridership.

This study develops regression trees that can be used to identify and prioritize transit system improvements using the datatypes identified in the literature review. The findings of this study may be applicable to any transit agency, but may be especially applicable to transit agencies that are similar to the San Luis Obispo Regional Transit Authority (e.g., a regional commuter transit system in a somewhat rural area with a temperate climate). The analysis method that this study develops is expected to be useful for any transit agency seeking a method to identify and prioritize improvements to their system. The next chapter describes the methods used by this study to gather and analyze the requisite dependent and independent variables for analysis. 


\section{CHAPTER 3: DATA COLLECTION, AGGREGATION, AND ANALYSIS METHODOLOGY}

This chapter describes the collection and assembly of datatypes used in this study, including Census data and transit ridership, routing and scheduling, and stop characteristic data. Input variable dataset sources, and methods used to aggregate and analyze this study's dataset, are described in this chapter.

\section{Identifying Input Variables Datasets}

This section describes methods used by this study to identify dependent and independent variables to be analyzed.

\section{Dependent Variables: Boardings and Alightings by Transit Stop}

This study uses RTA ridership data collected in 2010 and 2011 as a basis, and this ridership data is discussed in greater detail below.

One source of ridership data used in this study is ridership data collected by RTA staff in midApril 2010; this data includes counts of weekday boardings and alightings at every stop served by at least one of the five main RTA fixed-routes (i.e., RTA 9, 10, 12/14, and 15). The "Prioritizing RTA Fixed-route Bus Stop Improvements" report in APPENDIX A includes more detailed descriptions of this data and associated collection methods.

The other source of ridership data used in this study is the draft report titled "Prioritizing RTA and Paso Express Fixed-route Bus Stop Improvements" in APPENDIX B. This report uses the abovementioned ridership data and additional ridership data collected by Nelson\Nygaard as part of the 2012 San Luis Obispo Council of Governments (SLOCOG) North County Transit Plan. This data was collected through on-board surveys on Tuesday, May 3 and Wednesday, May 4, 2011 at every stop served by one of the five main RTA fixed-routes. The ridership data presented in the "Prioritizing RTA and Paso Express Fixedroute Bus Stop Improvements" in APPENDIX B is used as a basis of this study.

\section{$\underline{\text { Independent Variable Datasets }}$}

This section describes the methods used by this study to identify independent variables that are included in the boardings and alightings regression tree models. 


\section{Transit Demand Forecasters (i.e., Census Data)}

Robust data for numerous population and economic characteristics is available at state, county, county subdivision, city, place, and Census tract, block, and block group levels (to name a few) from the Census. (United States Census Bureau, 2014c) For reasons that will be discussed in the following sections, this study uses Census tract level data and assigns it fully to each transit stop within the tract.

\section{$\underline{\text { Transit Demand Obstructers and Inducers (Policy-based Variables) }}$}

Within existing contexts, transit demand can either be obstructed or induced according to the actions of transit entities, transit entity partners, and others; these obstructers and inducers form a set of independent variables that are generally within transit agency control.

\section{Routing and Scheduling}

Routing and scheduling data can be extrapolated from transit timetables and maps. This analysis extrapolated RTA routing and scheduling data from the most current versions of the printed RTA fixedroute schedules at the time of this writing and from RTA schedule and route information used to populate Google Transit using a software called Urbineris. The most current versions of all the RTA fixed-route schedules included in this study are in Appendix C. The timetables RTA used to populate Google Transit at the time of this writing using the Urbineris software are included in Appendix D (some calculations used for analysis in this study are also included).

\section{Transit Stop Characteristics}

To identify local characteristics of San Luis Obispo Regional Transit Authority (RTA) bus stops, in 2013 and 2014, every bus stop served by an RTA fixed-route was visited to collect bus stop characteristic data. The data was collected by filling out a form developed in collaboration with RTA after reviewing existing professionally accepted bus stop improvement surveys. (Easter Seals Project ACTION, 2006) (Nabors, Schneider, Leven, Lieberman, \& Mitchell, 2008)

The data collected with this instrument was used to create the Prioritizing RTA Fixed-route Bus Stop Improvements report, and on March 5th, 2014, the RTA Board of Directors (comprised of greater San Luis Obispo area City Mayors and County Supervisors) voted unanimously to direct staff to submit the Prioritizing RTA Fixed-route Bus Stop Improvements report to local jurisdictions and use it to guide bus stop improvements. The report seeks to prioritize RTA fixed-route bus stop improvements so that, to the 
extent possible, “every stop served by an RTA fixed-route becomes ADA accessible, safe, convenient, and comfortable for citizens and visitors of all ages and abilities, including those who use mobility devices like wheelchairs, scooters, rolling luggage, and strollers." The version of the report that was approved by the RTA board is APPENDIX A.

On June $1^{\text {st }}$, 2014, RTA absorbed Atascadero Transit and Paso Express, and RTA now operates additional routes and serves additional stops, so an updated report was in order. The most current draft of the Prioritizing RTA and Paso Express Fixed-route Bus Stop Improvements report is APPENDIX B. As the data included in this report best represents current transit stop conditions, the transit stop characteristic data it contains is used as a basis of this study.

\section{Dataset Development Details}

This section describes how the dataset that is the basis of this study was built by using ridership, Census, routing and scheduling, and bus stop characteristic data associated with RTA and the RTA service area.

\section{Ridership Data}

This section presents the ridership data that will be used in this study as the dependent variables.

\section{Data Adjustments: Moving, Consolidating, or Omitting Stops}

RTA does not currently serve the same stops as those for which ridership data was collected in 2010 and 2011, and, as a result, this study makes judgments to make best and appropriate use of available data. At the time of this writing, 149 stops are served by the five main RTA fixed-routes (i.e., RTA 9, 10, 12/14, and 15). As RTA has streamlined routes and discontinued service to out-of-the-way and/or low performing stops since the ridership data that is the basis of this study was collected, this study consolidates around thirty-five stops for which ridership data was collected into sixteen stops that are currently served. This study also omits ridership data associated with twenty stops that could not be reasonably consolidated into currently operating stops. Eight stops for which ridership data was not collected are also omitted. These adjustments are not expected to have a significant effect on the outcome of this study for the reasons discussed in the following paragraphs, and the following rules were used by this study when making data adjustment judgments: 
Since the ridership data that is a basis for this study was collected, some bus stops have been closed, some new stops have been opened, and some stops have been moved. Where stops have been moved to a nearby location, this study assigns ridership data to the new stop location. Where stops have been closed, if the stop is reasonably close to another operating stop that is reasonably accessible from the closed stop, ridership data has been attributed to the nearest operating stop.

Ridership data from stops that could not be reasonably attributed to another operating stop has been not been attributed to any stops included in this study, and because the statistical analyses in this study depends primarily on the differences between ridership at stops that are included in the analysis, ridership data from closed stops that is not attributed to currently operating stops should not have a significant effect on the outcome of this study. This approach was selected because this study assumes that the majority of RTA users who previously used RTA stops that are now closed still ride RTA and use other stops if they are reasonably close and easy and comfortable to access. This study also assumes that bus stop characteristics (i.e., amenities, design, and nearby and connecting infrastructure) of operational bus stops are generally at least as desirable to most transit users as characteristics of closed bus stops.

The following sections highlight distinct adjustments made to the ridership data used in this study.

\section{Currently Operating Bus Stops with no Ridership Data}

Currently operating stops that do not have associated ridership data have been omitted from this analysis. These stops do not have associated ridership data because they were not included in the ridership surveys that produced the data that is a basis of this study. The stops without ridership data that have been omitted from this study are:

- Santa Rosa at Murray NB

- Grand at McCollum NB \& SB

- Grand at Wilson NB

- Grand at Abbott SB

- $\quad 1^{\text {st }}$ at Oak

- Theatre at Gahan SB

- Theatre Drive at Rancho Paso

- Burton at Burton Cir. 


\section{Moved, Consolidated, and Omitted Bus Stops since last Ridership Surveys}

The table below shows adjustments made by this study to account for service changes since the last RTA ridership surveys were conducted: 
Table 1: Moved, Consolidated, and Omitted Bus Stops since last Ridership Surveys

\begin{tabular}{|c|c|c|}
\hline Rte. & Moved and/or Consolidated Stops & Omitted Stops \\
\hline $\begin{array}{l}\text { RTA } \\
9\end{array}$ & $\begin{array}{l}\text { Spring at } 6^{\text {th }} \mathrm{SB} \rightarrow \text { Spring at } 4^{\text {th }} \mathrm{SB} \\
\text { Las Tablas at Posada NB \& SB } \rightarrow \text { Twin Cities Hospital } \\
\text { ECR at Santa Cruz SB } \rightarrow \text { ECR at Atalaya SB } \\
\text { Paloma Park NB \& SB } \rightarrow \text { Viejo Camino at Bocina NB \& SB }\end{array}$ & $\begin{array}{l}\text { Creston at Melody SB } \\
\text { Main at } 1^{\text {st }} N B \& S B \\
\text { Main at } 6^{\text {th }} \text { NB \& SB }\end{array}$ \\
\hline $\begin{array}{l}\text { RTA } \\
10\end{array}$ & $\begin{array}{l}\text { NoRTHBOUND } \\
\text { Higuera at Prado, Higuera at Chumash } \rightarrow \text { Higuera at Margarita NB } \\
\text { Higuera at Hind } \rightarrow \text { Higuera at Suburban NB } \\
\text { South at Beebee, South at High, Higuera at Elks Lane, South at } \\
\text { Meadow, South at King, South at Exposition } \rightarrow \text { Higuera at South NB } \\
\text { Santa Rosa at Higuera } \rightarrow \text { Marsh at Broad NB } \\
\text { SouTHBOUND } \\
\text { South at Beebee, South at Broad, Higuera at Bridge, South at } \\
\text { Exposition, South at King } \rightarrow \text { Higuera at South SB } \\
\text { Higuera at Prado, Higuera at Granada } \rightarrow \text { Higuera at Margarita SB } \\
\text { Higuera at Hind, Higuera at Silver City } \rightarrow \text { Higuera at Suburban }\end{array}$ & $\begin{array}{l}\text { Greyhound NB \& SB } \\
\text { (near other stops, but this } \\
\text { study assumes Greyhound bus } \\
\text { service was generating } \\
\text { overwhelming majority of } \\
\text { trips to and from this stop) } \\
\text { E. Main St. at College Dr. NB } \\
\text { Santa Barbara at High } \\
\text { Santa Barbara at Church }\end{array}$ \\
\hline $\begin{array}{l}\text { RTA } \\
12\end{array}$ & $\begin{array}{l}\text { All Cuesta College stops } \rightarrow \text { Cuesta College } \\
\text { (except for the Achievement House stop which remains in operation } \\
\text { and is still counted as a unique stop) } \\
\text { Highland at Hwy } 1 \rightarrow \text { Santa Rosa at Foothill SB } \\
\text { Men's Colony NB \& SB } \rightarrow \text { Men's Colony at HWY } 1 \mathrm{NB} \\
\text { (The Men's Colony used to be served in both directions; now it is only } \\
\text { served on NB trips) } \\
\text { Kansas at HWY } 1 \mathrm{NB} \& \mathrm{SB} \rightarrow \text { Kansas at HWY } 1 \mathrm{SB} \\
\text { (Kansas at HWY } 1 \text { used to be served in both directions; now it is only } \\
\text { served on SB trips) }\end{array}$ & $\begin{array}{l}\text { Patricia at Foothill NB \& SB } \\
\text { LOVR at Buckskin NB \& SB }\end{array}$ \\
\hline $\begin{array}{l}\text { RTA } \\
15\end{array}$ & Ocean@Cayucos $\rightarrow$ Cayucos@Ash & $\begin{array}{l}\text { Main@Errol NB \& SB } \\
\text { Main@ Elena } \\
\text { Main@Bonita } \\
\text { Main@ Jamaica } \\
\text { Main at San Joaquin }\end{array}$ \\
\hline
\end{tabular}




\section{Transit Demand Forecasters}

This sections presents data that will be evaluated as independent variables in this study to determine if they are effective indicators of transit ridership within the RTA system.

\section{Census Data}

The Census makes available robust data that can be used for transit planning (United States Census Bureau, 2014c), and Census data that is applicable to this study is discussed below.

\section{Census Tract Level Data}

Population, ethnicity, race, age, and household count data from the 2010 Census down to the Census tract level can be easily accessed using the 2010 Census Interactive Population Map. (United States Census Bureau, 2014a) Median household income, worker population, commute time, and automobile ownership data collected through the 2012 American Community Survey down to the Census tract level can be easily accessed using Census Explorer "Commuting Edition" and "People, Education, and Income." (United States Census Bureau, 2014b) This data is a basis of this study.

\section{Census Block Level Data}

Population, ethnicity, race, age, and household count data from the 2010 Census down to the Census block level can also be easily accessed using the 2010 Census Interactive Population Map (United States Census Bureau, 2014a), but, because Census blocks are often small and can be oddly-shaped, analysis that focuses on individual Census block data associated with the bus stop(s) that lie(s) within the Census block may be thrown-off because it is too granular. So, for the purposes of this study, data down to the Census tract level appears appropriate and will be used in the analysis conducted in this study.

\section{$\underline{\text { Point Data }}$}

Census employment data is available down to the location of the employer, and it can be accessed using the OnTheMap tool available on the Longitudinal Employer-Household Dynamics (LEHD) website. (United States Census Bureau, 2015a) For the reasons mentioned above in the Census block level data section, this study will use this data at the Census tract level. Because it is the most recent data available, employment data used in this study comes from 2011 LEHD Origin Destination Employment Statistics (LODES). (United States Census Bureau, 2015a) 


\section{Density Conversions}

Density is generally accepted as an important indicator of transit demand and ridership; so, in this study, when testing for independent variables with statistically significant relationship to stop-level transit ridership, Census tract data is converted into densities. For example, rather than testing the number of renter-occupied units per Census tract, this study will test the average number of renter-occupied units per square mile of the Census tract. To convert raw Census data into densities, this study uses land areas of Census tracts that were obtained by using geographic information system (GIS) 2014 Census tract shapefile data that is available through the TIGER/Line website. (United States Census Bureau, 2015b)

\section{Equation 1: Census Tract Count Variable Density}

$$
\text { Census Tract Count Variable Density }=\frac{\text { Census Tract Count Variable }}{\text { Census Tract Area }}
$$

\section{Capping Land Areas}

Overwhelmingly, RTA routes travel from/to residential/employment center from/to residential/employment center, but, largely because San Luis Obispo County is home to vast agricultural and open space lands, a few Census tracts analyzed in this study have land-areas that skew the desired results of this study, and, for this reason, maximum upper limits for Census tract land areas are set in this study. Of the tracts where RTA bus stops are located, the table below shows the four the largest land areas.

Table 2: Largest Tracts with RTA Bus Stops

\begin{tabular}{|l|l|l|}
\hline Tract Number & Area [Square Miles] & Locations of RTA Bus Stops \\
\hline 127.02 & 1111 & Santa Margarita and Atascadero \\
\hline 103 & 650 & San Miguel \\
\hline 123.02 & 365 & Nipomo \\
\hline 127.04 & 45 & Templeton and Paso Robles \\
\hline
\end{tabular}

The next largest Census tract is 101.02; it includes part of Paso Robles, and it is seventeen square miles. So that the analysis is not skewed by including geographically large but sparsely populated land areas outside RTA's service area, in this study, any tract land area that exceeds twenty square miles will be set equal to twenty square miles. This only affects four census tracts out of the thirty-six census tracts that contain a bus stop served by at least one of the main RTA fixed-routes. 


\section{Capping Residential Density in the California Men's Colony Census Tract}

Because the CA Men's Colony has the greatest residential density, and its residents have little to no access to RTA service, all residential densities datatypes for the CA Men's Colony greater than 34.7 residents per square-mile have been set equal to 34.7 residents per square-mile, which is equal to the renter occupied population density [renters per square-mile] of the Census tract.

\section{Transit Demand Inducers and Obstructers}

This sections presents data that will be evaluated as independent variables in this study to determine if they are effective indicators transit demand stimulation or obstruction within the RTA system.

\section{Routing and Scheduling Input Data}

Routing and scheduling input data has been gathered from maps, straight-line diagrams, and timetables in the published RTA schedules that are in effect at the time of this writing; these schedules are in APPENDIX C. Data that is intended to match the published schedules sent to Google Transit using Urbineris software is used in this study, and these spreadsheets are included in APPENDIX D.

\section{$\underline{\text { RTA Weekday Service Schedule }}$}

Down to the bus stops served, all RTA fixed-routes operate on the same schedule every weekday, and this study evaluates the number of bus trips per day serving the stop

\section{Bidirectional Stops and Paired Stops}

Stops served by a route, or routes, in both directions are considered bidirectional (e.g., served by both NB and SB or Clockwise and Counterclockwise). Corresponding stops served by routes in both directions within reasonable walking distance of one another, and that are reasonably accessible from one another, are considered to be part of a stop pair. Stop pairs are not limited to two stops; for example, two closely spaced stops on one side of the road can both be paired with a single stop on the other side of the road if they are both accessible from, and within reasonable walking distance to, the stop on the other side of the road. If a stop is considered bidirectional, it is also considered a paired stop.

\section{Transit Stop Characteristic Data}

Bus stop characteristic data used in this study was gathered through field-visits to every bus stop served by the RTA fixed-route system. Data regarding many characteristics of RTA bus stops was collected, and 
information about all of the data collected can be found in the RTA and Paso Express fixed-route improvement prioritization reports in APPENDIX A and APPENDIX B. This study evaluates the presence (or not) of ADA-compliant landing pads, the number of benches, shelter area, presence of a shelter, presence of a bike rack, presence of a trash can, the number of trash cans, presence of a recycling receptacle, and the percent of routes that serve a stop that are indicated as serving the stop at the stop as independent variables with potential relationship to transit ridership dependent variables. The minimum and maximum values of these independent variables within the RTA system are summarized in tables in the following sections, and counts and percentages of stops with these stop amenities are discussed in greater detail in the RTA and Paso Express fixed-route improvement prioritization reports in APPENDIX A and APPENDIX B

\section{Capping Twin Cities Hospital Shelter Area}

Since the area of the shelter at Twin Cities Hospital is an outlier because it is a covered walkway that connects to the hospital, this study will set the area of the shelter at twin cities hospital equal to the area of the next largest shelter; which is 552 square-feet - the combined area of the two shelters at Atascadero Transit Center.

\section{Final Dataset Spreadsheet}

The final dataset spreadsheet that is used as the basis of this analysis is in Appendix E. This spreadsheet includes ridership, Census, routing and scheduling, and bus stop characteristics data corresponding to each bus stop currently served by the main RTA fixed-routes, and the variables included in this spreadsheet are summarized in the following sections:

\section{Dependent Variables}

The dependent variables that will be tested in this study are the number of weekly boardings at each bus stop and the number of weekly alightings at each bus stop, and the table below shows how these variables are labeled during analysis.

Table 3: Transit Ridership Dependent Variables

\begin{tabular}{|l|c|}
\hline Variable & SPPS Variable Name \\
\hline Number of weekly boardings at bus stop & Ons \\
\hline Number of weekly alightings at bus stop & Offs \\
\hline
\end{tabular}




\section{Independent Variables}

Census, routing and scheduling, and transit stop characteristic data will be analyzed in this study as independent variables, and the independent variables that will be tested in this study can be divided into four broad datatypes:

- Resident-based

- Employment-based

- Routing- and scheduling-based

- Transit-stop-characteristic-based

The tables in the sections below show how these variables will be labeled during analyses.

\section{$\underline{\text { Resident-based Independent Variables }}$}

The resident-based independent variables that will be tested for statistically significant relationships with the dependent ridership variables are summarized in the table below. All Census data in this study is presented on the Census tract scale. 
Table 4: Resident-based Census Tract Density Independent Variables

\begin{tabular}{|c|c|c|c|c|}
\hline $\begin{array}{l}\text { Density } \\
\text { Category }\end{array}$ & Density Variable & $\begin{array}{l}\text { SPSS Density } \\
\text { Variable } \\
\text { Name }\end{array}$ & $\begin{array}{l}\text { Minimum } \\
\text { Value } \\
{\left[\text { per mile }{ }^{2}\right]}\end{array}$ & $\begin{array}{c}\text { Maximum } \\
\text { Value } \\
\left.\text { [per mile }^{2}\right]\end{array}$ \\
\hline $\begin{array}{l}\text { Total } \\
\text { population }\end{array}$ & Total residential population & ResPop & 34.7 residents & 7248.5 residents \\
\hline \multirow[t]{2}{*}{ Gender cohort } & Male residential population & ResMale & 34.7 residents & 3668.2 residents \\
\hline & Female residential population & ResFemale & 1.9 residents & 3580.3 residents \\
\hline \multirow[t]{7}{*}{ Age cohort } & 18 and under & $\operatorname{Res}<18$ & 0 residents & 2163.5 residents \\
\hline & Over 18 & Res $>18$ & 34.7 residents & 5315.8 residents \\
\hline & $20-24$ & Res20to24 & 6.3 residents & 1938.1 residents \\
\hline & $25-34$ & Res25to34 & 10.9 residents & 1360.6 residents \\
\hline & $35-49$ & Res35to49 & 7.8 residents & 1304.5 residents \\
\hline & $50-64$ & Res50to64 & 4.1 residents & 1300.1 residents \\
\hline & 65 and over & Res $>65$ & 2.3 residents & 683.0 residents \\
\hline \multirow{6}{*}{$\begin{array}{l}\text { Home } \\
\text { ownership and } \\
\text { rental cohort }\end{array}$} & Occupied housing unit & OccUnits & 11.6 units & 3032.6 units \\
\hline & Owner-occupied housing unit & OwnOccUnits & 0 units & 1267.7 units \\
\hline & Owner-occupied population & OwnOccPop & 0 residents & 3079.2 residents \\
\hline & Renter-occupied housing unit & RentOccUnits & 4.0 units & 2609.2 units \\
\hline & Renter-occupied population & RentOccPop & 8.6 residents & 5100.0 residents \\
\hline & Housing with minors & $\begin{array}{l}\text { HousingWith } \\
\text { Minors }\end{array}$ & 0 units & 954.5 units \\
\hline \multirow{8}{*}{$\begin{array}{l}\text { Race/ethnicity } \\
\text { cohort }\end{array}$} & Hispanic or Latino density & ResLatino & 17.5 residents & 4523.6 residents \\
\hline & White & ResWhite & 34.7 residents & 4987.2 residents \\
\hline & African American & ResBlack & 0.5 residents & 198.4 residents \\
\hline & Asian & ResAsian & 0.7 residents & 262.2 residents \\
\hline & $\begin{array}{l}\text { American Indian or Alaska } \\
\text { Native (AIAN) }\end{array}$ & ResAIAN & 0.5 residents & 140.4 residents \\
\hline & $\begin{array}{l}\text { Native Hawaiian or Other } \\
\text { Pacific Islander (NHPI) }\end{array}$ & ResNHPI & 0.1 residents & 15.0 residents \\
\hline & Some other race & ResOtherRace & 5.3 residents & 1506.6 residents \\
\hline & Two or more races & $\begin{array}{l}\text { ResTwoOr } \\
\text { MoreRaces }\end{array}$ & 1.9 residents & 479.1 residents \\
\hline \multirow{2}{*}{$\begin{array}{l}\text { Other } \\
\text { resident-based } \\
\text { cohort data }\end{array}$} & Over 16 years of age (worker) & ResWorkers & 0 residents & 4021.6 residents \\
\hline & $\begin{array}{l}\text { Worker without personal } \\
\text { vehicle }\end{array}$ & $\begin{array}{l}\text { ResWorkers_ } \\
\text { NoAuto }\end{array}$ & 0 residents & 1279.8 residents \\
\hline
\end{tabular}




\section{Employment-based Independent Variables}

The employment-based by independent variables that will be tested for statistically significant relationships with the dependent ridership variables are summarized in the table below. All Census data in this study is presented on the Census tract scale

Table 5: Employment-based Census Tract Density Independent Variables

\begin{tabular}{|c|c|c|c|c|}
\hline $\begin{array}{l}\text { Density } \\
\text { Category }\end{array}$ & Density Variable & $\begin{array}{l}\text { SPSS Density } \\
\text { Variable Name }\end{array}$ & $\begin{array}{r}\text { Minimum } \\
\text { Value } \\
\text { [workers } / \text { mile }^{2} \text { ] }\end{array}$ & $\begin{array}{r}\text { Maximum } \\
\text { Value } \\
\text { [workers/mile }{ }^{2} \text { ] }\end{array}$ \\
\hline Total jobs & Total jobs & AllJobs & 18.2 & 14343.2 \\
\hline \multirow{2}{*}{ Gender cohort } & Male workers & WorkMale & 3.6 & 6678.7 \\
\hline & Female workers & WorkFemale & 2.9 & 7664.5 \\
\hline \multirow{3}{*}{$\begin{array}{l}\text { Worker age } \\
\text { cohort }\end{array}$} & 29 and under & Work $<29$ & 1.8 & 4673.5 \\
\hline & 30 to 54 & Work30to54 & 3.2 & 6932.8 \\
\hline & 55 and over & Work $>55$ & 1.5 & 2737.0 \\
\hline \multirow{4}{*}{$\begin{array}{l}\text { Worker } \\
\text { education } \\
\text { cohort }\end{array}$} & $\begin{array}{l}\text { No high school } \\
\text { diploma }\end{array}$ & Work $<$ HS & 0.7 & 1545.1 \\
\hline & $\begin{array}{l}\text { High school } \\
\text { diploma, but no } \\
\text { college }\end{array}$ & WorkHSDiploma & 1.3 & 2091.5 \\
\hline & $\begin{array}{l}\text { Some college, but no } \\
\text { degree }\end{array}$ & WorkSomeCollege & 1.6 & 3200.3 \\
\hline & College degree & WorkCollegeDegree & 1.2 & 2832.9 \\
\hline \multirow{3}{*}{$\begin{array}{l}\text { Worker } \\
\text { monthly } \\
\text { income cohort }\end{array}$} & Less than $\$ 1250$ & Work $<\$ 1250$ & 2.4 & 4574.4 \\
\hline & $\$ 1251$ to $\$ 3333$ & Work $\$ 1251$ to $\$ 3333$ & 2.6 & 5483.6 \\
\hline & More than $\$ 3333$ & Work $>\$ 3333$ & 1.5 & 4285.2 \\
\hline \multirow{7}{*}{$\begin{array}{l}\text { Worker } \\
\text { race/ethnicity } \\
\text { cohort }\end{array}$} & $\begin{array}{l}\text { Hispanic or Latino } \\
\text { density }\end{array}$ & WorkLatino & 1.4 & 3797.9 \\
\hline & White & WorkWhite & 6.0 & 12817.4 \\
\hline & African American & WorkBlack & 0.1 & 324.3 \\
\hline & Asian & WorkAsian & 0.2 & 688.6 \\
\hline & $\begin{array}{l}\text { American Indian or } \\
\text { Alaska Native } \\
\text { (AIAN) }\end{array}$ & WorkAIAN & 0.1 & 172.6 \\
\hline & $\begin{array}{l}\text { Native Hawaiian or } \\
\text { Other Pacific } \\
\text { Islander (NHPI) }\end{array}$ & WorkNHPI & 0.0 & 36.7 \\
\hline & Two or more races & WorkTwoOrMoreRaces & 0.1 & 303.6 \\
\hline
\end{tabular}




\section{$\underline{\text { Routing and Scheduling Independent Variables }}$}

The routing- and scheduling-based independent variables that will be tested for statistically significant relationships with the dependent ridership variables are summarized in the table below.

Table 6: Routing and Scheduling Independent Variables

\begin{tabular}{|l|l|l|c|c|}
\hline Category & Variable & $\begin{array}{l}\text { SPSS Variable } \\
\text { Name }\end{array}$ & $\begin{array}{c}\text { Minimum } \\
\text { Value }\end{array}$ & $\begin{array}{c}\text { Maximum } \\
\text { Value }\end{array}$ \\
\hline $\begin{array}{l}\text { Trips per } \\
\text { Day }\end{array}$ & $\begin{array}{l}\text { Number of bus trips per day serving the } \\
\text { stop }\end{array}$ & BusTripsPerDay & 2 & 116 \\
\hline Stop Pairing & $\begin{array}{l}\text { Paired stop? (i.e., is there another stop } \\
\text { within easy walking distance that serves } \\
\text { another bus in the opposite direction?) }\end{array}$ & BusPairedStop & $0=$ no & $1=$ yes \\
\hline
\end{tabular}

\section{Transit Stop Characteristic Independent Variables}

The bus stop characteristic-based independent variables that will be tested for statistically significant relationships with the dependent ridership variables are summarized in the table below.

Table 7: Bus Stop Amenity Independent Variables

\begin{tabular}{|c|c|c|c|c|}
\hline Category & Variable & $\begin{array}{l}\text { SPSS Variable } \\
\text { Name }\end{array}$ & $\begin{array}{l}\text { Minimum } \\
\text { Value }\end{array}$ & $\begin{array}{l}\text { Maximum } \\
\text { Value }\end{array}$ \\
\hline $\mathrm{ADA}$ & $\begin{array}{l}\text { Is there an accessible } 5^{\prime} \text { by } 8^{\prime} \text { (minimum) } \\
\text { mobility device landing pad at the bus } \\
\text { stop? }\end{array}$ & ADALandingPad & $0=$ no & $1=$ yes \\
\hline \multirow{3}{*}{$\begin{array}{l}\text { Seating } \\
\text { and } \\
\text { Shelter }\end{array}$} & Number of benches at the stop & Benches & 0 & 10 \\
\hline & Is there a shelter at the stop? & Shelter & $0=$ no & $1=$ yes \\
\hline & Shelter area $[\mathrm{sqft}]$ of the stop & ShelterArea & 0 & 4200 \\
\hline Bike & Bike Rack or Storage at the stop? & BikeRack & $0=$ no & $1=$ yes \\
\hline \multirow{3}{*}{$\begin{array}{l}\text { Trash and } \\
\text { Recycle }\end{array}$} & Is there a trash receptacle at the stop? & TrashCan & $0=$ no & $1=$ yes \\
\hline & Number of trash receptacles at the stop & \#ofTrash & 0 & 3 \\
\hline & Is there a recycle receptacle at the stop? & Recycle & $0=$ no & $1=$ yes \\
\hline Signage & $\begin{array}{l}\text { Percent of routes serving the stop that are } \\
\text { indicated at the stop }\end{array}$ & $\%$ routesIndicated & $0 \%$ & $100 \%$ \\
\hline
\end{tabular}




\section{Analysis Method}

This analysis will develop regression trees through a method that identifies independent variables with significant relationships to transit ridership dependent variables. The independent variables used in this study are discussed in the previous chapter, and they can be categorized as Census, routing and scheduling, and transit stop characteristic datatypes. This chapter explores, determines, and describes how this study will conduct regression tree analysis.

\section{Statistics Terminology Used in This Study}

Prior to statistical analysis, it is helpful to understand some terminology. The UCLA Institute for Digital Research and Education (IDRE) offers the following definitions of categorical (or nominal), ordinal, and interval variables. (UCLA Institute for Digital Research and Education, 2015b) Categorical variables (also called nominal variables) have two or more categories, and there is no intrinsic ordering to the categories (e.g., land use types). Ordinal variables are similar to categorical variables, but there is a clear ordering of the variables (e.g., low, medium, and high), and the interval between categories is inconsistent. Interval variables are similar to ordinal variables, but the interval between categories is equal (e.g., 5, 10, 20, 25).

Also, this study will use SPSS for statistical analysis, and IBM offers a definition of scale variables that is similar to IDRE's definition of interval variables, which is: "a variable can be treated as scale (continuous) when its values represent ordered categories with a meaningful metric, so that distance comparisons between values are appropriate. Examples of scale variables include age in years and income in thousands of dollars." (IBM, n.d.) This study will treat both interval and continuous variables as scale variables.

\section{Estimating Regression Trees Using SPSS}

In SPSS, regression trees can be "grown" using Chi-squared Automatic Interaction Detection (CHAID), exhaustive CHAID, Classification and Regression Trees (CRT), or a Quick, Unbiased, Efficient Statistical Tree (QUEST) (IBM, n.d.); to determine the appropriate regression tree method for this study, these methods are briefly described and explored below. 


\section{QUEST Growing Method}

QUEST is a "method that is fast and avoids other methods' bias in favor of predictors with many categories. QUEST can be specified only if the dependent variable is nominal.” (IBM, n.d.) The dependent variables analyzed in this study are transit ridership, which are not nominal, so QUEST will not be used in this study.

\section{CRT Growing Method}

CRT "splits the data into segments that are as homogeneous as possible with respect to the dependent variable. A terminal node in which all cases have the same value for the dependent variable is a homogeneous, 'pure' node.” (IBM, n.d.) The dependent variables tested in this analysis are transit boardings and alightings, and because the values of the dependent variables vary widely, homogenous terminal nodes are not sought, and CRT seeks terminal nodes with homogeneous dependent variables in the terminal node, this analysis will not use the CRT growing method.

\section{CHAID Growing Method}

CHAID "chooses the independent (predictor) variable that has the strongest interaction with the dependent variable. Categories of each predictor are merged if they are not significantly different with respect to the dependent variable." (IBM, n.d.) Exhaustive CHAID is a modification of CHAID that examines all possible splits for each predictor. Due to this characteristic, exhaustive CHAID will be explored in this analysis.

\section{Growing Regression Tress in SPSS through Exhaustive CHAID}

The following is a discussion of SPSS 22 settings used in this study to grow regression trees using the Exhaustive CHAID method:

\section{Growth Limits \& Stop Criterion}

Once a stop criterion is reached, regression trees stop attempting to find further significant variables along their "branches" beyond the significant variable identified in the current nodes. In SPSS 22, stop criterion can be reached two ways: 1) achieving a pre-specified maximum tree depth, and 2) not having enough cases with nodes to further split the data.

For data files with a small number of cases, the default values of 100 cases for parent nodes and 50 cases for child nodes may sometimes result in trees with no nodes below the root node; in this case, 
lowering the minimum values may produce more useful results. (IBM, n.d.) Furthermore, stop criterion can be set by specifying the minimum quantity of samples within each node, and then, if the quantity in the node is less than the specified value, the regression tree stops trying to find further significant variables along that branch. The fixed value for this stop criterion is usually between 10 and 30, but, for larger sample sizes, stop criterion between 75 and 100 are more appropriate. (Tuffery, 2011) Tuffery further recommends, to avoid over fitting the sample, at least 30 to 50 cases should be in each node. (Tuffery, 2011) Because the dataset analyzed in this study is relatively small $(n=149)$, this study will require 40 minimum cases in the parent node and 20 minimum cases in the child nodes.

\section{Validation}

SPSS 22 has two validation options: cross-validation and split-sample validation. (IBM, n.d.) Split-sample Validation generates a model using a training sample and tests the model on a hold-out sample. Because there may not be enough cases to adequately grow the tree, small training sample sizes may yield poor models (IBM, n.d.), and because the dataset that is the basis of this analysis is relatively small, split-sample validation will not be used in this study.

"Crossvalidation divides the sample into a number of subsamples, or folds. Tree models are then generated, excluding the data from each subsample in turn. The first tree is based on all of the cases except those in the first sample fold, the second tree is based on all of the cases except those in the second sample fold, and so on. For each tree, misclassification risk is estimated by applying the tree to the subsample excluded in generating it. You can specify a maximum of 25 sample folds. The higher the value, the fewer the number of cases excluded for each tree model. Crossvalidation produces a single, final tree model. The crossvalidated risk estimate for the final tree is calculated as the average of the risks for all of the trees." (IBM, n.d.) Because the dataset is relatively small and computing power is available, this analysis will perform cross-validation with the maximum number of sample folds allowed by SPPS 22 (i.e., 25 folds) specified.

\section{Significance Levels}

For splitting nodes, the value must be greater than 0 and less than 1 . Lower values tend to produce trees with fewer nodes. (IBM, n.d.) The analysis in this study will be performed using the default 0.05 
significance level for splitting nodes; that is, this analysis is looking for independent variables that have a statistically significant relationship to transit usage boarding variables at a $95 \%$ confidence level.

\section{CHAID Merging Categories}

For merging categories, the value must be greater than 0 and less than or equal to 1 . To prevent merging of categories, IBM suggests specifying a "Splitting Nodes" value of 1. (IBM, n.d.) This study is exploring exhaustive CHAID, not CHAID, and when performing exhaustive CHAID, because exhaustive CHAID explores all possible splits for each predictor, the merging category option is fixed.

\section{Resplitting Merged Categories with a Node}

So that data is well distributed at each stage of analysis, this study will build regression trees that allow for re-splitting of merged categories within nodes.

\section{Intervals for Scale Independent Variables}

Prior to CHAID analysis, "scale independent (predictor) variables are always banded into discrete groups (for example, $0-10,11-20,21-30$, etc.)." The initial/maximum number of groups can be specified to be a fixed number that initially bands all scale independent variables into the same number of groups, or a custom number of groups can be specified for each scale independent variable. (IBM, n.d.) This analysis will use the default fixed-value of 10 number of groups for every scale independent variable.

This chapter identified sources for input variable datasets and described methods used to build and analyze the dataset. The next chapter performs the analysis described in this chapter using the dataset built using the methods described in this chapter. Results of analysis are also presented and discussed in the next chapter. 


\section{CHAPTER 4: ANALYSIS, RESULTS, AND DISCUSSION USING REGRESSION TREE METHOD}

The analysis in this chapter models the number of boardings and alightings at bus stops according to characteristics of the stops, and the modeling tool used is regression trees. Regression tree models for boardings and alightings are first developed using only Census data associated with individual stops. Next, boarding and alighting regression tree models are developed using only stop-specific routing, scheduling, and stop characteristic data. Finally, boarding and alighting regression tree models are developed using the full dataset (i.e., Census, routing and scheduling, and stop characteristic data). Boarding regression tree models are developed and analyzed first, followed by alighting regression tree models.

The "Bidirectional" independent variable was omitted from this analysis because it was observed that many bidirectional stops were also transit hubs near city-centers, and, as such, these stops had some of the highest numbers of boardings and alightings, regardless of the other stop characteristics. Hence, the significant relationship between the "Bidirectional" variable and boardings and alightings wasn't useful in gaining understanding of what nearer-term transit system improvements may lead to higher ridership. In total, sixteen "Bidirectional" stops were omitted from analysis.

\section{Regression Tree Models for Estimating Boardings}

This section models the number of boardings at RTA bus stops according to characteristics of the stops identified by regression tree analysis. Boarding regression trees are first developed using Census data only; then developed using routing, scheduling, and stop characteristic data only; then developed using the full dataset.

\section{Regression Tree Models for Estimating Boardings: Census Data Only}

The first boardings regression tree model uses only Census data. In this regression tree, the density of the residential Asian population is the independent variable that splits the RTA boardings data first, and the density of the total population splits the RTA boardings data second.

As can be seen in the second level of the regression tree below, when there is less than or equal to 4.5 Asian residents per square-mile in the Census tract in which a bus stop is located, on average there are 5.2 boardings per week at these bus stops. When there is between 4.5 and 13.4 Asian residents per squaremile in the Census tract in which a bus stop is located, on average there are 11.8 boardings per week at 
these bus stops. Bus stops with between 13.4 and 123.2 Asian residents per square-mile have an average of 29.0 boardings per week, and bus stops with more than 123.2 Asian residents per square-mile have an average of 64.2 boardings per week. One can observe that, as the Asian Population density rises, so does transit ridership.

At the next level, when the residential Asian population is between 13.4 and 123.2 residents per square-mile and there is less than or equal to 1493.9 total residents per square-mile in the Census tract in which a bus stop is located, on average there are 36.9 boardings per week at these bus stops. In the same scenario, bus stops with greater than 1493.9 total residents per square-mile have an average of 17.9 boardings per week.

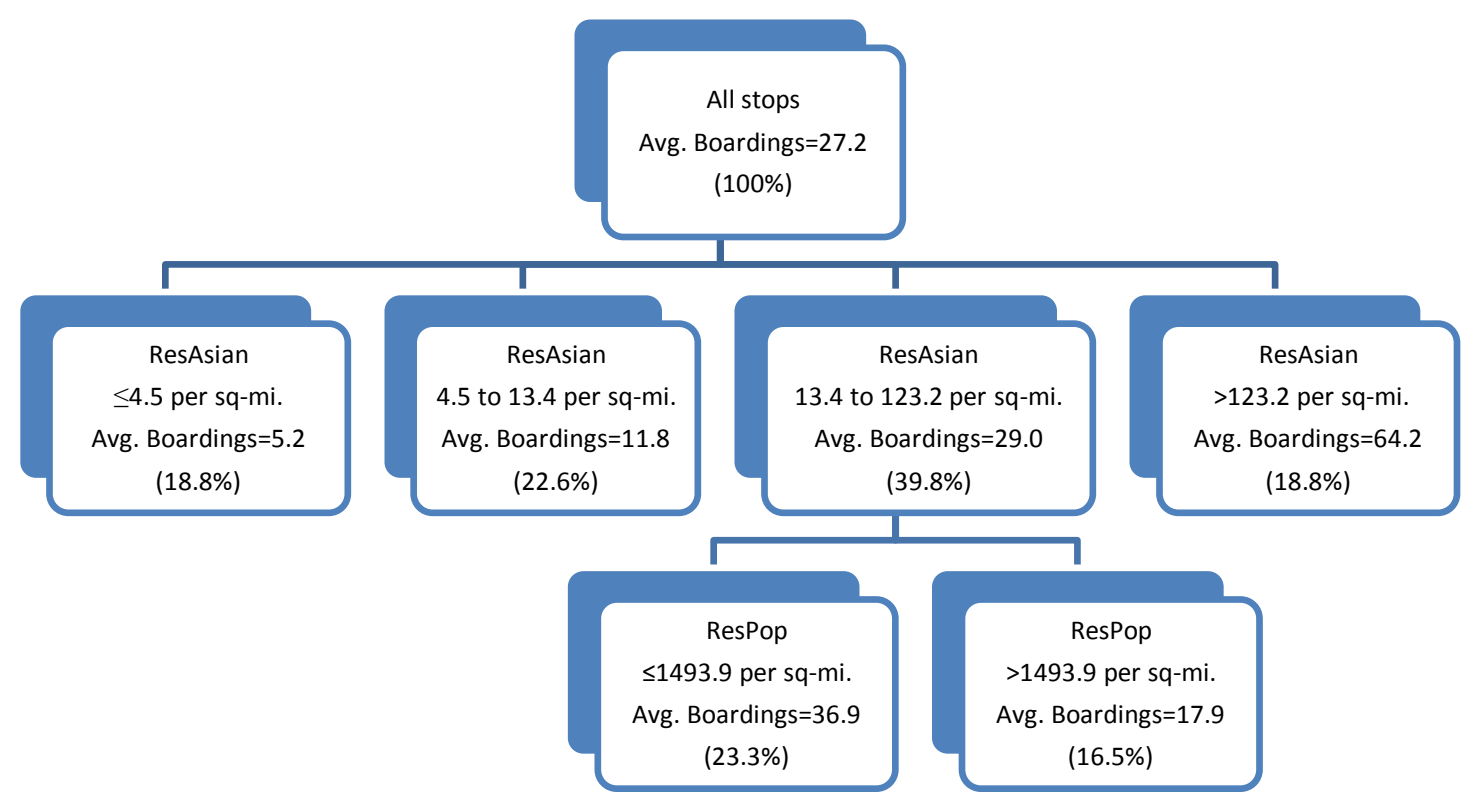

Figure 1: Ons - Census Data Only Regression Tree

Generally, transit ridership is expected to increase as population density increases, and this is exactly what happens in the regression tree above as the Asian residential population density increases. However, in the third level of the tree, as total resident population density increases, the average number of boardings decreases - this is probably due to the strength of the relationship between Asian resident population density and RTA boardings that is accounted for in the second level of the regression tree. 


\section{Regression Tree Models for Boardings: Routing, Scheduling \& Stop Characteristic Data $\underline{\text { Only }}$}

The regression tree below models boardings using only routing, scheduling, and stop characteristic data. In this regression tree, the presence of a trash can is the first independent variable that splits the RTA boardings data, and the number of trips per day serving the bus stop is the second independent variable that splits the RTA boardings data.

As can be seen in the figure below, when a trash can is present at a stop, on average there are 51.4 boardings per week, and bus stops without a trash can have an average of 15.4 boardings per week.

At the next level, when there is no trash can at a bus stop and there is less than or equal to five trips per day serving a stop, on average there are 5.6 boardings per week at the bus stop. In the same scenario, bus stops with between five and fourteen trips per day serving the stop have an average of 21.4 boardings per week, and bus stops with more than fourteen trips per day serving the stop have an average of 22.8 boardings per day.

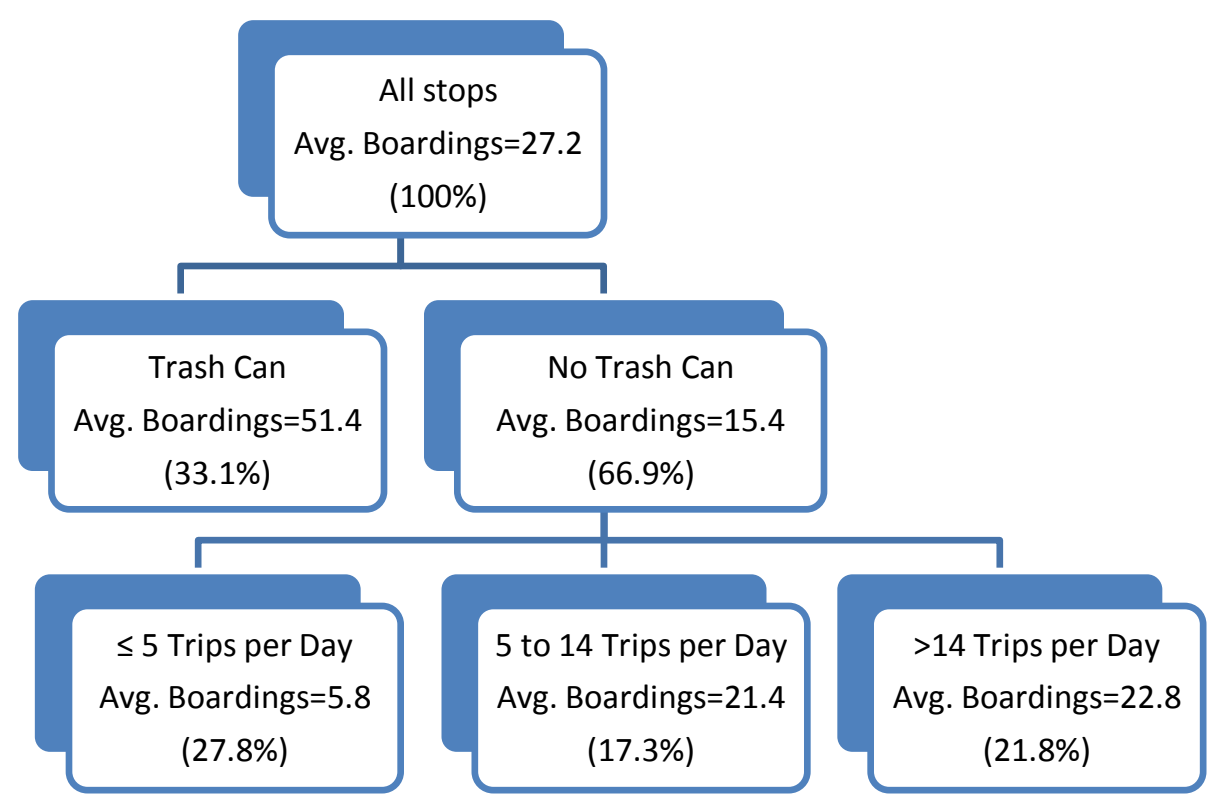

Figure 2: Ons - Routing, Scheduling \& Stop Characteristic Data Only Regression Tree

Generally, transit ridership is expected to be higher at stops with trash cans because they can create a sense of place, make stops more desirable by reducing the amount of trash, and transit agency policies will place trash cans at higher-use stops before lower-use stops - the regression tree model 
captures this relationship. It is also generally expected that the number of boardings increases as the number of trips serving a transit stop increase, and this is also modeled in the regression tree above.

\section{$\underline{\text { Regression Tree Models for Estimating Boardings: Full Dataset }}$}

The regression tree below models RTA boardings using the full dataset (i.e., Census, routing and scheduling, and stop characteristic data). As expected, independent variables included in the previous two models are again included in the model below that was developed using the full dataset. In the model below, the density of the residential Asian population is the independent variable that splits the RTA boardings data first, and the presence of a trach can at a bus stop splits the RTA boardings data second.

Because the density of the residential Asian population remains in the second level of the regression tree, its dataset classification boundaries and associated boardings estimates remain the same as in the previous Census-data-only tree.

Because the presence of a trash can at a bus stop has dropped to the third level of the RTA boardings regression tree model, its dataset classification boundaries and associated boardings estimates have changed. In the regression tree model below, when the residential Asian population is between 13.4 and 123.2 residents per square-mile and there is a trash can at a bus stop, the average number of weekly boardings at a stop is 39.3. In the same scenario, when there is not a trash can at a bus stop, the average number of weekly boardings is 19.8 .

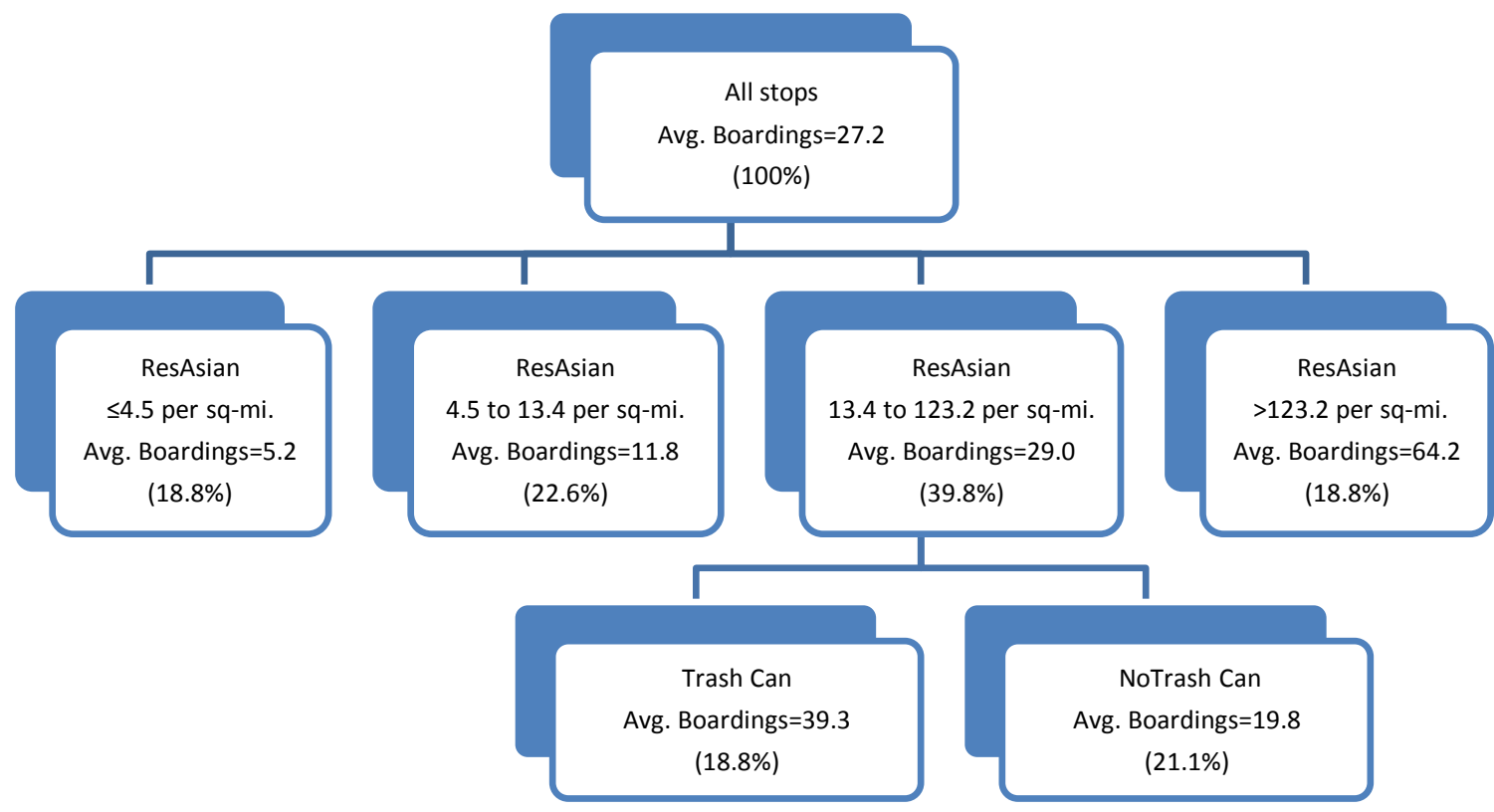

Figure 3: Ons - Full Dataset Regression Tree 
Generally, transit ridership is expected to increase as population density increases, and this is exactly what happens in the regression tree above as the Asian residential population density increases. Furthermore, transit ridership is generally expected to be higher at stops with trash cans because they can create a sense of place, make stops more desirable by reducing the amount of trash, and transit agency policies will place trash cans at higher-use stops before lower-use stops, and the regression tree model above also captures this relationship.

\section{Regression Tree Models for Estimating Alightings}

This section models the number of alightings at RTA bus stops according to characteristics of the stops identified by regression tree analysis. Alighting regression trees are first developed using Census data only; then developed using routing, scheduling, and stop characteristic data only; then developed using the full dataset.

\section{$\underline{\text { Regression Tree Models for Estimating Alightings: Census Data Only }}$}

The regression tree below models alightings using only Census data. In this regression tree, the density of residents twenty to twenty-four years old is the independent variable that splits the RTA alightings data first, and the density of the Native Hawaiian / Pacific Islander residential population splits the RTA alightings data second.

As can be seen in the second level of the regression tree, when there is less than or equal to 17.2 residents twenty to twenty-four years old per square-mile in the Census tract in which a bus stop is located, on average there are 5.2 alightings per week at these bus stops. When there is between 17.2 and 87.3 residents twenty to twenty-four years old per square-mile, on average there are 13.6 alightings per week at these bus stops. Bus stops with between 87.3 and 226.2 residents twenty to twenty-four years old per square-mile have an average of 57.3 alightings per week, and bus stops with more than 226.2 residents twenty to twenty-four years old per square-mile have an average of 65.5 alightings per week. One can observe that, as the residents twenty to twenty-four population density rises, so does transit ridership.

At the next level, when residents twenty to twenty-four years old per square-mile is between 17.2 and 87.3, the density of the Native Hawaiian / Pacific Islander residential population splits the RTA alightings data next. In this scenario, when there is less than or equal to 0.68 Native Hawaiian / Pacific 
Islander residents per square-mile in the Census tract in which a bus stop is located, on average there are 22.1 alightings per week at these bus stops. In the same scenario, bus stops with greater than 0.68 Native Hawaiian / Pacific Islander residents per square-mile in the Census tract have an average of 9.2 alightings per week.

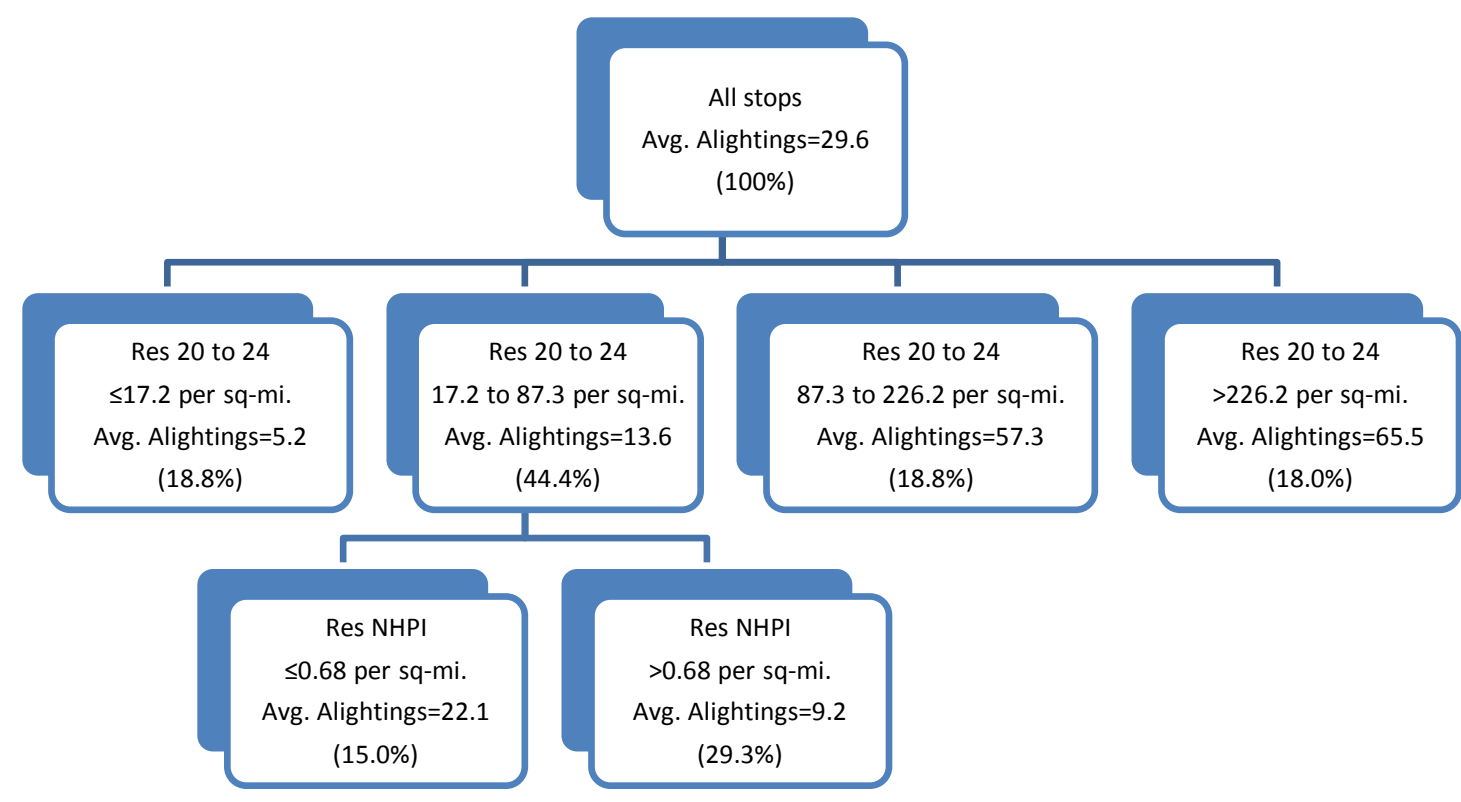

Figure 4: Offs - Census Data Only Regression Tree

Generally, transit ridership is expected to increase as population density increases, and this is exactly what happens in the regression tree below as the residents twenty to twenty-four years old population density increases. However, in the third level of the tree, as Native Hawaiian / Pacific Islander resident density increases, the average number of alightings decreases - this is probably due to the strength of the relationship between twenty to twenty-four years old population density and RTA alightings that is accounted for in the second level of the regression tree.

\section{Regression Tree Models for Alightings: Routing, Scheduling \& Stop Characteristic Data $\underline{\text { Only }}$}

The regression tree below models alightings using only routing, scheduling, and stop characteristic data. In this regression tree, the presence of a trash can is the independent variable that splits the RTA alightings data first, and the number of trips per day serving the bus stop splits the RTA alightings data second - the same routing, scheduling, and stop characteristic independent variables split the alightings data in the same order as in the earlier boardings regression tree model. 
As can be seen in the second level of the regression tree, when a trash can is present at a stop, on average there are 54.3 alightings per week, and bus stops without a trash can have an average of 17.4 alightings per week.

At the next level, when there is no trash can at a bus stop, the number of trips per day serving the bus stop splits the RTA alightings data next. In this scenario, when there is less than or equal to five trips per day serving a stop, on average there are 3.9 alightings per week at the stop. In the same scenario, bus stops with more than five trips per day serving the stop have an average of 26.9 alightings per week.

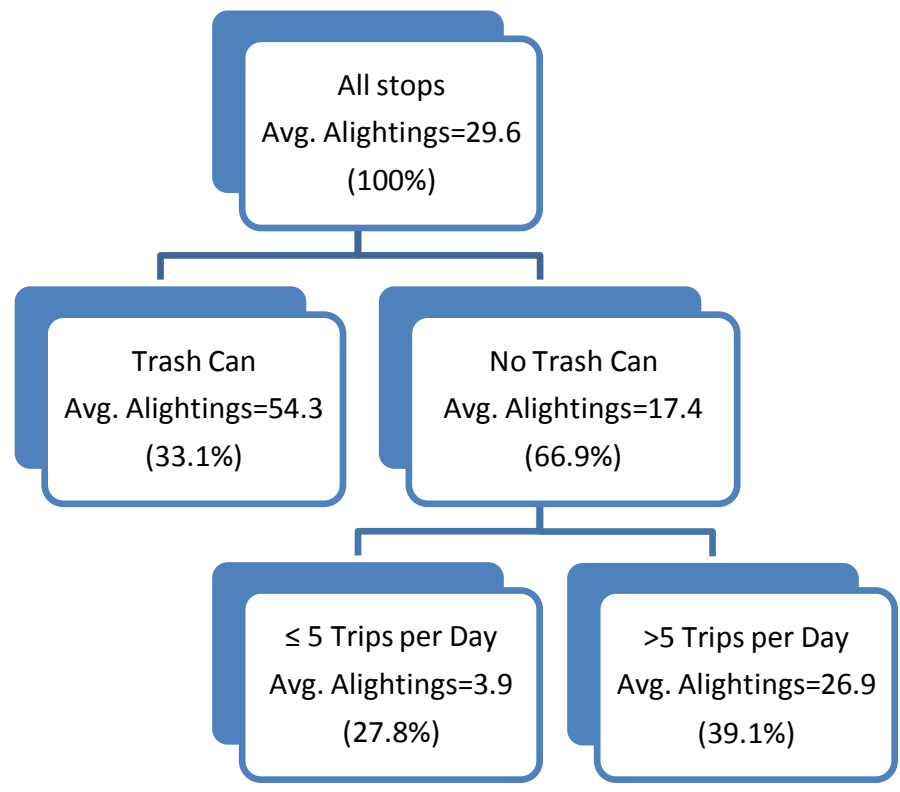

Figure 5: Offs - Routing, Scheduling \& Stop Characteristic Data Only Regression Tree

Generally, transit ridership is expected to be higher at stops with trash cans because they can create a sense of place, make stops more desirable by reducing the amount of trash, and transit agency policies will place trash cans at higher-use stops before lower-use stops, and the regression tree model above captures this relationship. It is also generally expected that the number of alightings increases as the number of trips serving a transit stop increase, and this is also modeled in the regression tree above.

\section{$\underline{\text { Regression Tree Models for Estimating Alightings: Full Dataset }}$}

The regression tree below models RTA alightings using the full dataset (i.e., Census, routing and scheduling, and stop characteristic data). As expected, independent variables included in the previous two models are again included in the model below that was developed using the full dataset. In fact, the 
alighting model developed in this study using the full dataset is the same as the alighting model developed using only Census data, which indicates that the Census data used has more significant relationship to alightings than the routing, scheduling, and stop characteristics data used.

Because the alighting regression tree in this section is the same as the alighting regression tree developed using only Census data in the previous section, please see the previous section for a discussion of this regression tree.

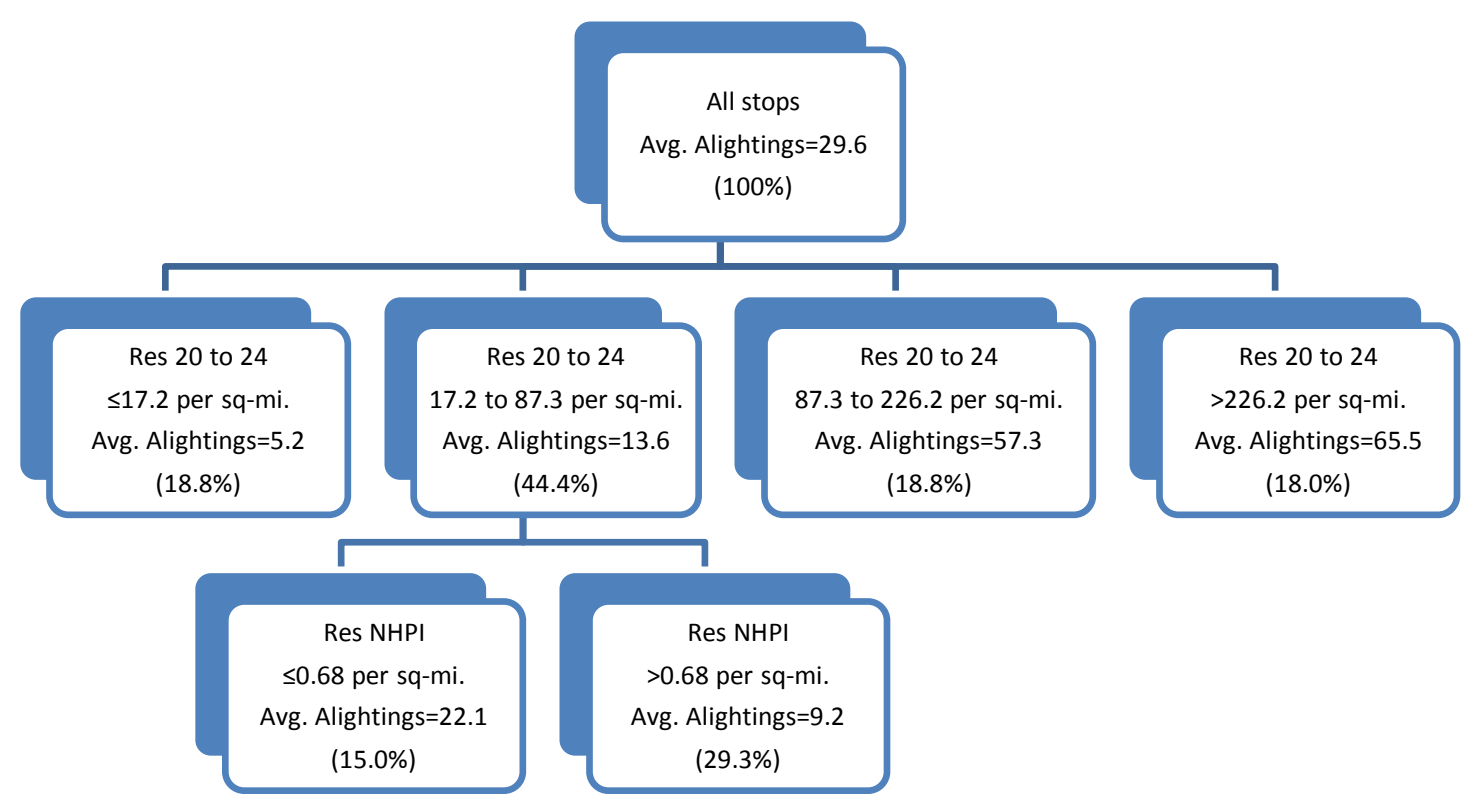

Figure 6: Offs - Full Dataset Regression Tree

This chapter developed and analyzed boardings and alightings regression tree models. Both the boardings and alightings regression tree models used population density independent variables to split the ridership data, and all models showed a positive relationship between higher population densities (specifically Asian and twenty to twenty-four year old residential population densities) and higher RTA ridership. Both the boarding and alighting regression tree models also used the presence of a trash can and the number of trips per day serving a stop to split the data, and the models showed positive relationships between these independent variables and increased RTA ridership. It is generally expected that transit ridership increases as population density and the number of trips serving a transit stop increases, and transit ridership is expected to be higher at stops with trash cans because they can create a sense of place, reduce trash, and policies will place trash cans at higher-use stops before lower-use stops. 
It is interesting that the independent variables used to split the RTA ridership data did not vary more than they did between boardings and alightings; this is especially surprising for transit stop characteristic independent variables. One would expect that transit stop characteristics that contribute to a more desirable waiting experience (e.g., benches, shelters, trash cans, signage, etc...) would be more related to increases in boardings than alightings, but this was not identified by this study. These types of relationships may have been identified if the presence of a trash can was not included as an independent variable.

The results of the regression tree model analysis conducted in this chapter are applied as recommendations to increase RTA ridership through RTA system improvements and RTA marketing and planning focuses in the next chapter. 


\section{CHAPTER 5: CONCLUSIONS AND FUTURE WORK}

This chapter offers recommendations to increase ridership of the RTA system and presents ideas for future work that could expand on this study. First, the data analysis conducted in chapter 4 is summarized, and the results are used to develop recommendations that are expected to increase ridership; two types of recommendations are offered:

1) Improvements to the RTA system

2) Potential focus areas for RTA marketing and planning efforts

Next, the applicability of the findings of this study to other transit systems is discussed. Finally, future work that would expand on the findings of this study is discussed.

\section{RTA Improvement Recommendations}

This section summarizes the key conclusions from the regression tree analysis in chapter 4 and offers recommendations to increase ridership of the RTA system. Both boarding and alighting regression tree models showed a positive relationship between higher RTA ridership and denser populations (specifically Asian and twenty to twenty-four year old residential population densities), more trips serving the stop, and the presence of a trash can. This is in-line with common sense expectations that transit ridership increases as population density increases, transit service increases, and transit stop characteristics improve. Keeping these findings in mind, the following sections offer recommendations for improvements to RTA's transit system and marketing and planning efforts.

\section{RTA Transit System Improvement Recommendations}

As RTA ridership generally increases as population density and transit service increase, RTA should study the feasibility of serving stops in areas with denser populations with more trips. Also, because RTA ridership is generally higher at stops with trash cans, RTA should also study the feasibility of adding (and servicing) trash cans at stops that do not have them, especially at stops that are already used heavily, served by many trips, and/or are in densely populated areas. It is possible that presence of trash cans alone will not drastically increase ridership (because correlation isn’t necessarily causation), but trash cans can be attractive amenities for riders. 


\section{$\underline{\text { RTA Marketing and Planning Recommendations }}$}

Because Census tracts with higher population densities (specifically Asian and twenty to twenty-four year old residential population densities) are associated with higher RTA ridership, RTA should focus some of their marketing and planning efforts towards areas with denser residential populations. The tables below summarize the top eleven Census tracts in the RTA service area with the highest Asian residential population densities and the highest twenty to twenty-four year old residential population densities; population densities are presented in descending order. As can be seen in the tables below, Census tracts in San Luis Obispo, northern Los Osos, Santa Maria, Cal Poly, and southern Atascadero all have relatively high Asian and twenty to twenty-four year old residential population densities.

Table 8: Census Tracts in RTA Service Area with Highest Asian Residential Population Densities

\begin{tabular}{|c|c|l|}
\hline $\begin{array}{c}\text { ResAsian Density } \\
\text { [Resident/sq-mi] }\end{array}$ & Tract Number & City/Place (Area of City/Place) \\
\hline 262.2 & 107.01 & Los Osos (Northern) \\
\hline 207.7 & 111.01 & San Luis Obispo (Downtown) \\
\hline 202.9 & 107.03 & Los Osos (North-East) \\
\hline 190.2 & 111.02 & San Luis Obispo (Downtown) \\
\hline 153.7 & 115.01 & San Luis Obispo (South Higuera) \\
\hline 153.2 & 21.02 & Santa Maria \\
\hline 137.3 & 109.01 & Cal Poly \\
\hline 123.3 & 125.03 & Atascadero (Southern) \\
\hline 121.7 & 21.01 & Santa Maria \\
\hline 93.0 & 22.11 & Santa Maria \\
\hline 64.2 & 110.02 & San Luis Obispo (Uptown, Eastern) \\
\hline
\end{tabular}

Table 9: Census Tracts in RTA Service Area with Highest 20 to 24 Year Old Residential Densities

\begin{tabular}{|c|c|l|}
\hline $\begin{array}{c}\text { Res20to24 Density } \\
\text { [Resident/sq-mi] }\end{array}$ & Tract Number & City/Place (Area of City/Place) \\
\hline 1938.1 & 111.01 & San Luis Obispo (Downtown) \\
\hline 1346.1 & 111.02 & San Luis Obispo (Downtown) \\
\hline 681.2 & 21.01 & Santa Maria \\
\hline 497.2 & 112.00 & San Luis Obispo (Northwest) \\
\hline 470.9 & 110.02 & San Luis Obispo (Uptown, Eastern) \\
\hline 407.3 & 115.01 & San Luis Obispo (South Higuera) \\
\hline 383.2 & 109.01 & Cal Poly \\
\hline 306.4 & 21.02 & Santa Maria \\
\hline 301.0 & 107.01 & Los Osos (Northern) \\
\hline 280.0 & 101.02 & Paso Robles (Downtown) \\
\hline 226.2 & 125.03 & Atascadero (Southern) \\
\hline & & \\
\hline
\end{tabular}




\section{Applicability to other Transit Systems}

The analysis method this study developed can help identify and prioritize improvements to any transit system, and the findings of this study can be applicable to any transit system if assumptions can be made about the similarity of the system to the San Luis Obispo Regional Transit Authority system (e.g., a regional commuter transit system in a somewhat rural area with a temperate climate).

More general conclusions that could be applicable to more transit systems could be drawn if the analysis method used in this study were performed with more and/or larger datasets (e.g., other transit agencies, regional, statewide, national and/or global datasets), and this concept is a basis for the future work recommended in the next section.

\section{Future Work}

To expand on the work in this study, future work should seek to apply appropriate analysis methods using more and larger datasets comprised of more robust, accurate, and precise data. Furthermore, as is almost always the case, the datasets used as the basis of this study's analysis, and the accuracy, precision, and usefulness of the outcomes of the analysis could have been improved by using more robust, accurate, and precise data. This study would probably have benefited most from more robust and current ridership data.

More robust ridership data could be data collected over longer periods of time (e.g., collected all the time using transit ITS, instead of over a few days using on-board ride-checkers). More robust ridership data could also be data that is tied to rider characteristics (e.g., datasets that could be available if smart-card systems are in place). More robust stop characteristic data could include more stop characteristic datatypes (e.g., transit service schedule-adherence information collected with transit ITS, weather conditions, and/or the presence of an automated pass vending machine) that are collected at more precise levels (e.g., the number of seats, instead of the number of benches).

It should be noted that since this study was conducted, RTA has implemented automatic passenger counting (APC) and automatic vehicle location (AVL) transit ITS technologies, and the ridership and schedule-adherence data generated by these technologies should be available for future analyses.

Lastly, Census data is regularly updated and available for analyses, and methods to efficiently and effectively gather, aggregate, analyze, and apply Census data should continually be refined. For example, in the method presented in this study, Census data could be applied more effectively by tying it to individual 
stops using tools like GIS. Using GIS, Census data could be allocated to stops according to travel-distances (or travel-times) from stops. The most effective way to do this is probably through use of the Network Analyst feature in ArcGIS, which can determine the distance (or travel time) of data points from transit stops according to travel-routes, by mode - this method would almost certainly be more effective than spatial radii methods that do not take travel-route options into consideration. This approach could also be applied to other datatypes (beyond Census data), like land use types and associated zoning regulations.

Findings of the future work described above should be shared with the public through appropriate channels. 
Audirac, I. (2008). Accessing Transit as Universal Design. Journal of Planning Literature, 23(May), 4-16. doi: $10.1177 / 0885412208318558$

Chakraborty, A., \& Mishra, S. (2013). Land use and transit ridership connections: Implications for statelevel planning agencies. Land Use Policy, 30, 458-469. doi:10.1016/j.landusepol.2012.04.017

Easter Seals Project ACTION. (2006). Toolkit for Bus Stop Accessibility and Safety Assessment. Washington, DC.

Hand, D., Hand, D., Mannila, H., Mannila, H., Smyth, P., \& Smyth, P. (2001). Principles of data mining. The MIT Press. doi:10.2165/00002018-200730070-00010

IBM. (n.d.). Creating Decision Trees. Retrieved January 12, 2015, from http://www01.ibm.com/support/knowledgecenter/SSLVMB_22.0.0/com.ibm.spss.statistics.help/spss/tree/idh_id d_treegui_main.htm?lang=en

Kimpel, T. J., Strathman, J. G., Griffin, D., Callas, S., \& Gerhart, R. L. (2002). Implications for National Transit Database Reporting, (03), 2089.

Moshe, B. Ben, Hadas, Y., \& Levi, H. (2014). Energy-Efficient Framework for Indoor and Outdoor Public transit Passengers Tracking using Bluetooth-Enabled Devices (pp. 1-16). Washington, DC.

Nabors, D., Schneider, R. J., Leven, D., Lieberman, K., \& Mitchell, C. (2008). Pedestrian Safety Guide for Transit Agencies. Washington, DC. Retrieved from http://trid.trb.org/view.aspx?id=863651

National Coordination Office for Space-Based Positioning, Navigation, and T. (2014). The Global Positioning System. Retrieved November 22, 2014, from http://www.gps.gov/systems/gps/

Pande, A. (2005). ESTIMATION OF HYBRID MODELS FOR REAL-TIME CRASH RISK ASSESSMENT ON FREEWAYS. University of Central Florida.

Pelletier, M.-P., Trépanier, M., \& Morency, C. (2011). Smart card data use in public transit: A literature review. Transportation Research Part C, 19, 557-568. doi:10.1016/j.trc.2010.12.003

Taylor, B., Haas, P., Boyd, B., Hess, D., Iseki, H., \& Yoh, A. (2002). Increasing transit ridership: lessons from the most successful transit systems in the 1990s. Retrieved from http://ntl.bts.gov/lib/19000/19600/19677/PB2002109122.pdf

Thompson, G., Brown, J., \& Bhattacharya, T. (2012). What Really Matters for Increasing Transit Ridership: Understanding the Determinants of Transit Ridership Demand in Broward County, Florida. Urban Studies, 49. doi:10.1177/0042098012443864

Tuffery, S. (2011). Data Mining for Decision Making. (P. Giudici, G. H. Givens, \& B. K. Mallick, Eds.). Rennes, France: John Wiley \& Sons, Ltd.

U.S. Department of Transportation Federal Transit Administration. (2009). NATIONAL TRANSIT DATABASE SAMPLING MANUAL.

U.S. Department of Transportation Federal Transit Administration Transit Cooperative Research Program. (1997). TCRP Synthesis 24 AVL Systems for Bus Transit A Synthesis of Transit Practice.

U.S. Department of Transportation Federal Transit Administration Transit Cooperative Research Program. (1998). Continuing Examination of Successful Transit Ridership Initiatives. REASEARCH RESULTS DIGEST, (29).

U.S. Department of Transportation Federal Transit Administration Transit Cooperative Research Program. (2008). TCRP SYNTHESIS 73 - AVL Systems for Bus Transit: Update.

United States Census Bureau. (2014a). Census 2010 Interactive Population Map. Retrieved December 20, 2014, from http://www.census.gov/2010census/popmap/

United States Census Bureau. (2014b). Census Explore. Retrieved December 20, 2014, from http://www.census.gov/censusexplorer/

United States Census Bureau. (2014c). Data Tools and Apps. Retrieved December 20, 2014, from 
http://www.census.gov/data/data-tools.html

United States Census Bureau. (2015a). Longitudinal Employer-Household Dynamics. Retrieved March 23, 2015, from http://lehd.ces.census.gov/applications/

United States Census Bureau. (2015b). TIGER/Line ${ }^{\circledR}$ Shapefiles and TIGER/Line ${ }^{\circledR}$ Files. Retrieved March 23, 2015, from https://www.census.gov/geo/maps-data/data/tiger-line.html

University of North Carolina Department of City and Regional Planning. (2006). Understanding How the Built Environment Around TTA Stops Affects Ridership.

Utsunomiya, M., Attanucci, J., \& Wilson, N. (2006). Potential Uses of Transit Smart Card Registration and Transaction Data to Improve Transit Planning. Transportation Research Record: Journal of the Transportation Research Board, 1971, 119-126. doi:10.3141/1971-16 
APPENDIX A: Prioritizing RTA Fixed-route Bus Stop Improvements Report 


\title{
Prioritizing RTA Fixed-route Bus Stop Improvements
}

\author{
RTA Mission
}

The Mission of RTA is to provide safe, reliable and efficient transportation services that improve and enhance the quality of life for the citizens and visitors of San Luis Obispo County.

\section{Goal}

Develop a plan to make every fixed-route bus stop served by RTA ADA accessible, safe, convenient and comfortable for citizens and visitors of all ages and abilities, including those who use mobility devices like wheelchairs, scooters, rolling luggage, and strollers. 


\section{Table of Contents}

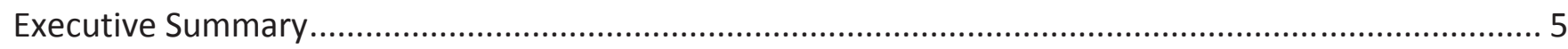

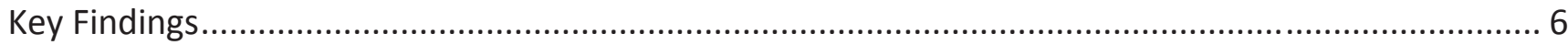

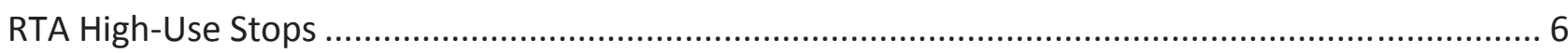

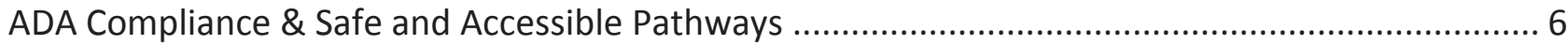

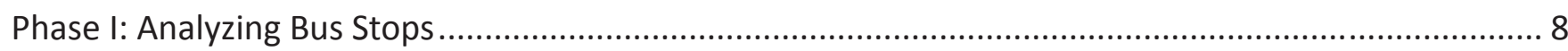

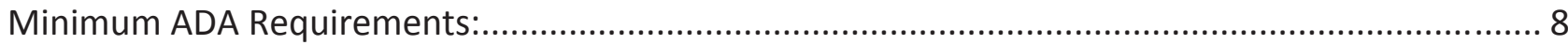

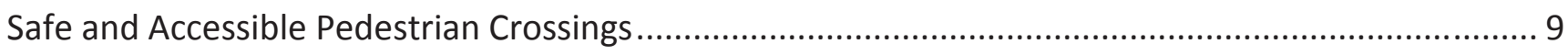

Traffic Impact, Sight Distance, Pull-Out Space, and Safety............................................................. 10

Bus Stop Location Prioritization and Bus Pull-Out Space................................................................... 10

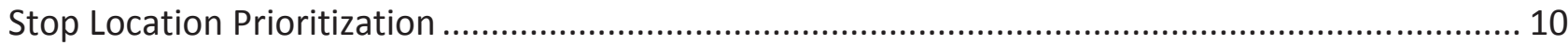

Bus Pull-Out Space: Road Operation and Safety ......................................................................... 11

Cost of Improvements \& Available Funding Sources ................................................................... 11

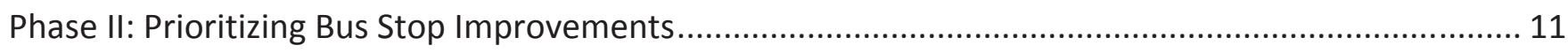

Bus Stop Improvement Prerequisite I: Mobility Device Landing Pad(s) ............................................. 12

Bus Stop Improvement Prerequisite II: Safe and Accessible Pathways ................................................. 12

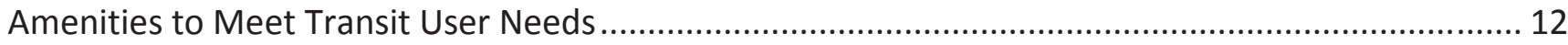

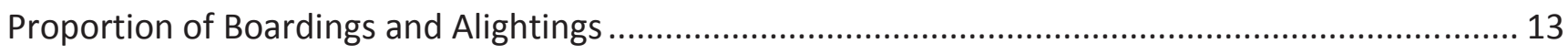

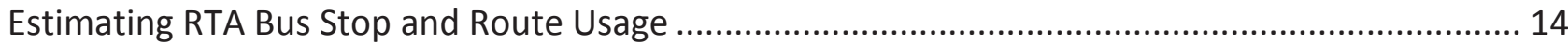

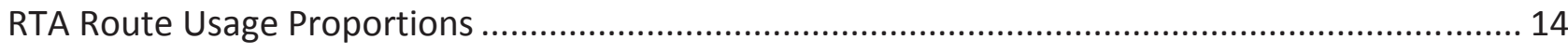

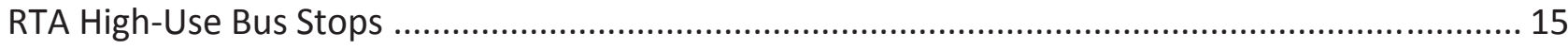

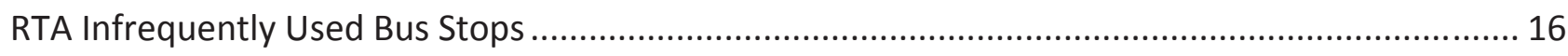

Assessment of RTA Multi-route Transit Hubs...................................................................................... 17

RTA Multi-Route Transit Passenger Facilities: Existing Amenities at High-Use Bus Stops ................... 17

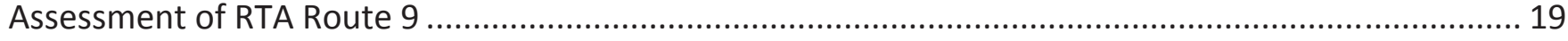

RTA Route 9 Bus Stop Usage: Proportion of Boardings and Alighting ................................................ 19

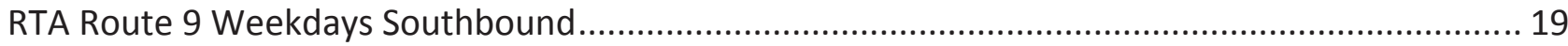




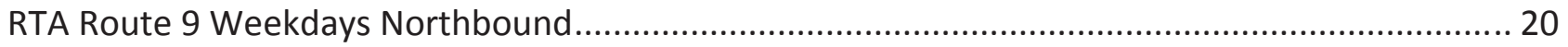

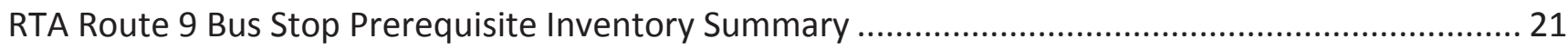

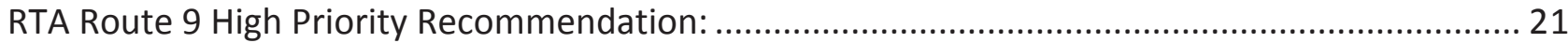

RTA Route 9 Bus Stop Prerequisites: Mobility Device Landing Pads with Safe and Accessible

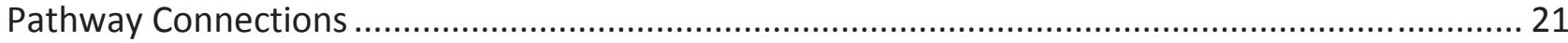

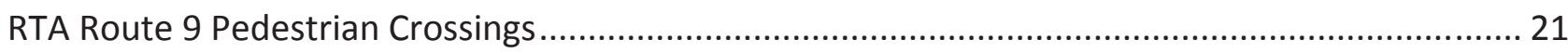

RTA Route 9 Pull-Out Space, Traffic Impact, and Sight Distance ....................................................... 22

RTA Route 9 Existing Amenities at High-Use Bus Stops ......................................................................... 22

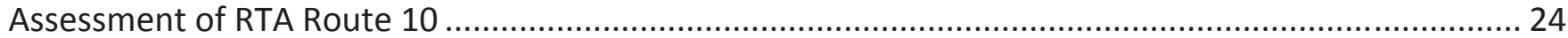

RTA Route 10 Bus Stop Usage: Proportion of Boardings and Alightings .............................................. 24

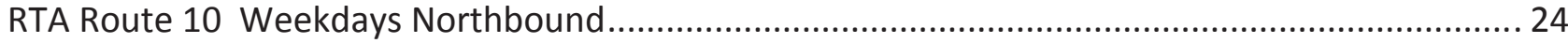

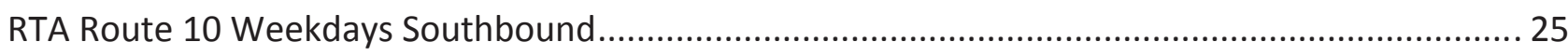

RTA Route 10 Bus Stop Prerequisite Inventory Summary ……......................................................... 26

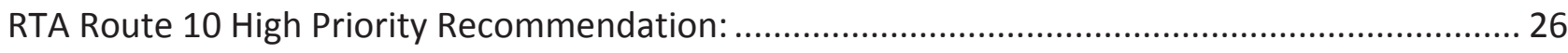

RTA Route 10 Bus Stop Prerequisites: Mobility Device Landing Pads with Safe and Accessible

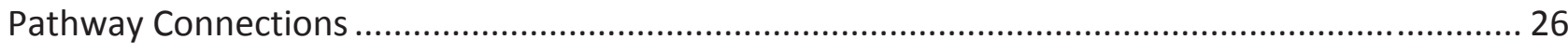

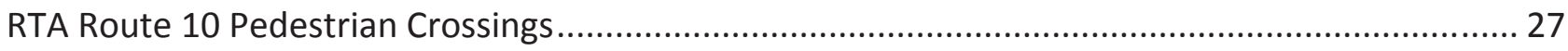

RTA Route 10 Pull-Out Space, Traffic Impact, and Sight Distance ..................................................... 27

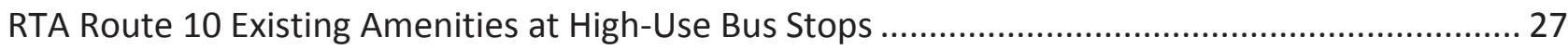

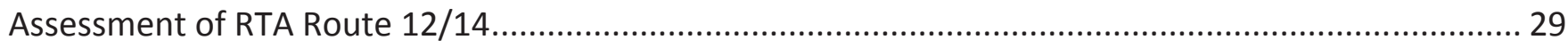

RTA Route 12/14 Bus Stop Usage: Proportion of Boardings and Alightings.......................................... 29

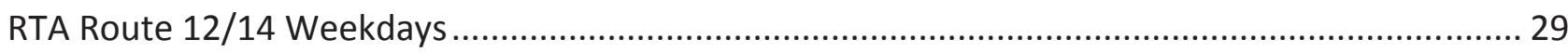

RTA Route 12/14 Bus Stop Prerequisite Inventory Summary............................................................ 30

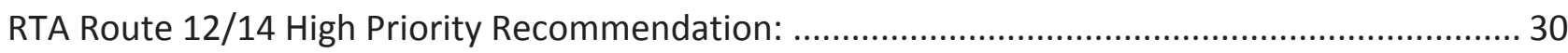

RTA Route 12/14 Bus Stop Prerequisites: Mobility Device Landing Pads with Safe and Accessible

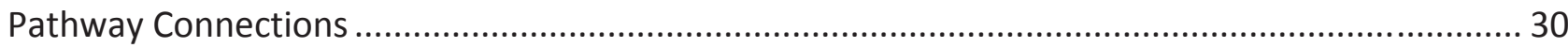

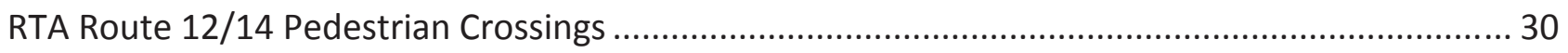

RTA Route 12/14 Pull-Out Space, Traffic Impact, and Sight Distance................................................ 31

RTA Route 12/14 Existing Amenities at High-Use Bus Stops ............................................................ 31 


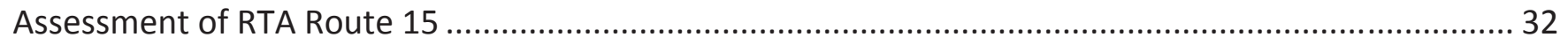

RTA Route 15 Bus Stop Usage: Proportion of Boardings and Alightings ............................................. 32

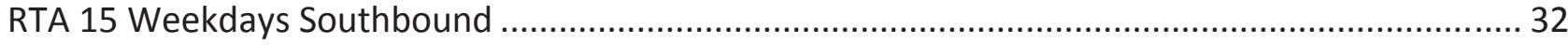

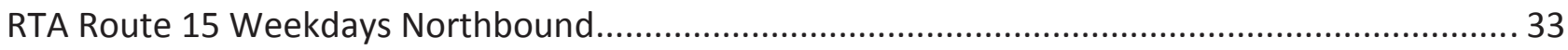

RTA Route 15 Existing Amenities at High-Use Bus Stops ........................................................................ 34

RTA Route 15 Bus Stop Prerequisite Inventory Summary ................................................................... 34

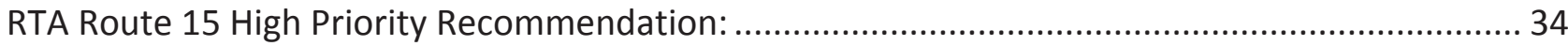

RTA Route 15 Bus Stop Prerequisites: Mobility Device Landing Pads with Safe and Accessible

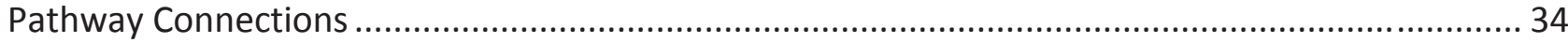

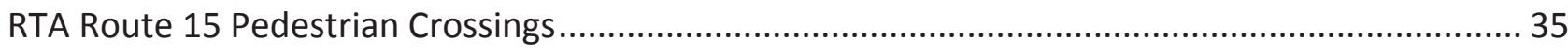

RTA Route 15 Pull-Out Space, Traffic Impact, and Sight Distance ..................................................... 35

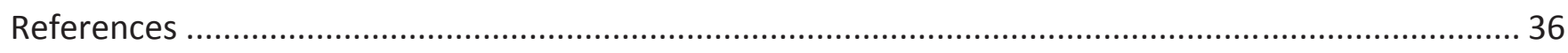

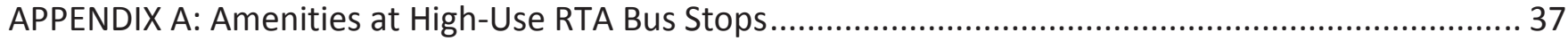

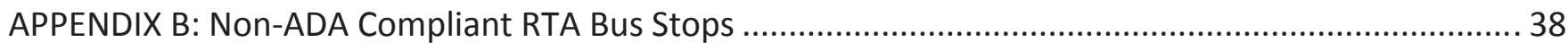

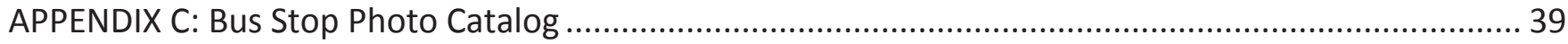




\section{Executive Summary}

To further develop a safe, reliable, and efficient transit-centric transportation system in the greater San Luis Obispo area, this report seeks to prioritize RTA fixed-route bus stop improvements. The goal of this report is to ensure that, to the extent possible, every bus stop served by an RTA fixed-route bus is ADA accessible, safe, convenient, and comfortable for citizens and visitors of all ages and abilities, including those who use mobility devices like wheelchairs, scooters, rolling luggage, and strollers.

This report discusses existing conditions at RTA bus stops and presents some potential improvement options. The analysis considers safety, long-term locations, minimum ADA access requirements, access to nearby activity centers exceeding minimum ADA requirements, passenger amenities, pedestrian connections, traffic impacts, sight distance, and the potential for bus pull-out space. The report also evaluates passenger utilization by route at each individual bus stop. As such, high-use and relatively infrequently used bus stops are categorized to help prioritize potential improvements based on demand.

Local decision-makers should keep in mind that optimal solutions, including bus stop related improvements, depend on context. Optimal bus stop location and design solutions require local jurisdictions to consider how the environment surrounding each bus stop affects the attractiveness of using public transportation. For example, passenger amenities (bench, shade, etc.) may already exist immediately adjacent to a bus stop in an urban setting, yet it might be appropriate to add ambient lighting and a passenger shelter in a rural setting. In addition, transit user characteristics (e.g., people with disabilities, seniors, mothers with young children, homeless persons, business travelers, vacationers, cyclists, etc...) may dictate that local jurisdictions consider expanded passenger amenities to attract riders. Local land uses and traffic patterns can also affect optimal bus stop placement and design. Existing nearby public amenities like shelter, seating, lighting, trash receptacles, and/or bike parking effect optimal bus stop design.

Additionally, when considering potential RTA bus stop improvements, local decision-makers must consider financial feasibility and cost-effectiveness of potential solutions. It would be unwise to attempt to implement costly and complex urban solutions (e.g., a concrete bus pull-out, passenger shelter, and bus arrival prediction signs) at a rural bus stop that would have little chance of attracting a sufficient number of riders to justify the cost. In any case, RTA and the local officials should seek robust community input when prioritizing bus stop improvements in any given community. 
To identify existing conditions, every bus stop served by RTA was inventoried by an RTA employee from June 2013 through October 2013. The Appendices A \& B of this report include tables that summarize key findings for each fixed-route.

\section{Key Findings}

\section{RTA High-Use Stops}

- Over $75 \%$ of RTA fixed-route boardings and alightings occur at less than $20 \%$ of bus stops served by RTA.

- Of the approximately 125 current RTA bus stops, 21 are considered high-use RTA bus stops. High-use bus stops are defined as has having more than 1\% of RTA system-wide boardings or alightings.

- All of the 21 high-use bus stops are ADA compliant.

- Of the five high-use multi-route transit passenger facilities served by RTA (and other fixed-route providers), three permit multiple buses to board and alight passengers simultaneously. However, of the three high-use stops served by multiple buses simultaneously, only one ADA compliant landing pad is present at both Pismo Premium Outlets and Morro Bay Park passenger facilities. These high-use passenger facilities lack sufficient landing area to simultaneously board or alight mobility devices from more than one bus at a time.

- Santa Rosa @ Mustang Village \& Stenner Glen Apartments is the only high-use RTA stop used primarily for boarding that has no amenities for waiting passengers (e.g., no shelter and no seating).

- Of the 21 high-use RTA stops: 9 do not have RTA bus stop signs, 2 do not have RTA map/schedule holders, and 12 do not have Braille pads. Only eight have bike racks. Only three do not have trash receptacles.

\section{ADA Compliance \& Safe and Accessible Pathways}

- To meet minimum ADA requirements, fixed-route bus stops must have a mobility device landing pad that is a firm and stable surface at least 5' wide by $8^{\prime}$ deep (with no greater than a $2 \%$ slope) that connects to an accessible route. 
- Of the approximately 125 bus stops served by RTA fixed-routes, 77 bus stops (greater than 60\%) lack an acceptable mobility device landing pad.

- A total of 49 bus stops served by RTA fixed-routes do not connect to nearby sidewalks.

- Regarding safe pedestrian crossings, out of the 77 ADA non-compliant bus stops, 2 are adjacent to an at-grade railroad crossing, 10 are adjacent to streets with speed limits greater than 45 $\mathrm{mph}, 3$ are adjacent to roadways with 4 or more lanes, and 38 do not have a labeled pedestrian crossing within sight. Obviously, RTA fixed-routes operate on many corridors with $45 \mathrm{mph}$ or greater speed limits and no feasible adjacent travel options. As such, RTA must work closely with local jurisdictions when considering the placement of and improvements to bus stops. Nonetheless, transit authorities have been held liable for incidents involving transit users crossing busy streets while accessing bus stops that the agency knew or should have known caused their riders to face unacceptable risks. The Darlene Bonanno v. Central Contra Costa Transit Authority case is discussed in this report. 


\section{Phase I: Analyzing Bus Stops}

For RTA to offer ADA accessible, safe, convenient and comfortable fixed-route transit services to users and residents of all ages and abilities, riders should be able to safely access all fixed-route bus stops, and to safely board and alight at every fixed-route bus stop. To access the bus stop safely, mobility device users require a safe and accessible pathway (ideally, a sidewalk separated from rail, high-speed automobile and bicycle traffic) that connects the bus stop to surrounding transit trip generators. To safely board and alight a bus, mobility device users require an ADA compliant mobility device landing pad at least five feet wide and eight feet deep positioned adjacent to the front door of a stopped bus.

Prior to investing in fixed-route bus stop improvements, RTA and local jurisdiction officials must evaluate existing conditions at the bus stop and develop a realistic improvement plan.

\section{Minimum ADA Requirements:}

Minimum ADA requirements for bus stops according to ADA Accessibility Guidelines for Buildings and Facilities (ADAAG) Section 10 are below ${ }^{1}$ :

\section{Minimum ADA Requirements}

Providing accessible bus stops requires choosing appropriate locations or improving the existing location. Coordination and cooperation with public works agencies, municipal government and business owners can enhance the connectivity between the land use and the bus stop. To ensure optimum bus stop placement, coordination should occur during the planning/development phase.

Bus stop sites must have the following:

- A firm, stable surface;

- A minimum clear length of 96 inches (eight feet), measured from the curb or vehicle roadway edge and a minimum clear width of 60 inches (five feet), measured parallel to the vehicle roadway;

- A maximum slope of 1:50 (2\%) for water drainage; and

- $\quad$ Connection to streets, sidewalks or pedestrian paths by an accessible route. 


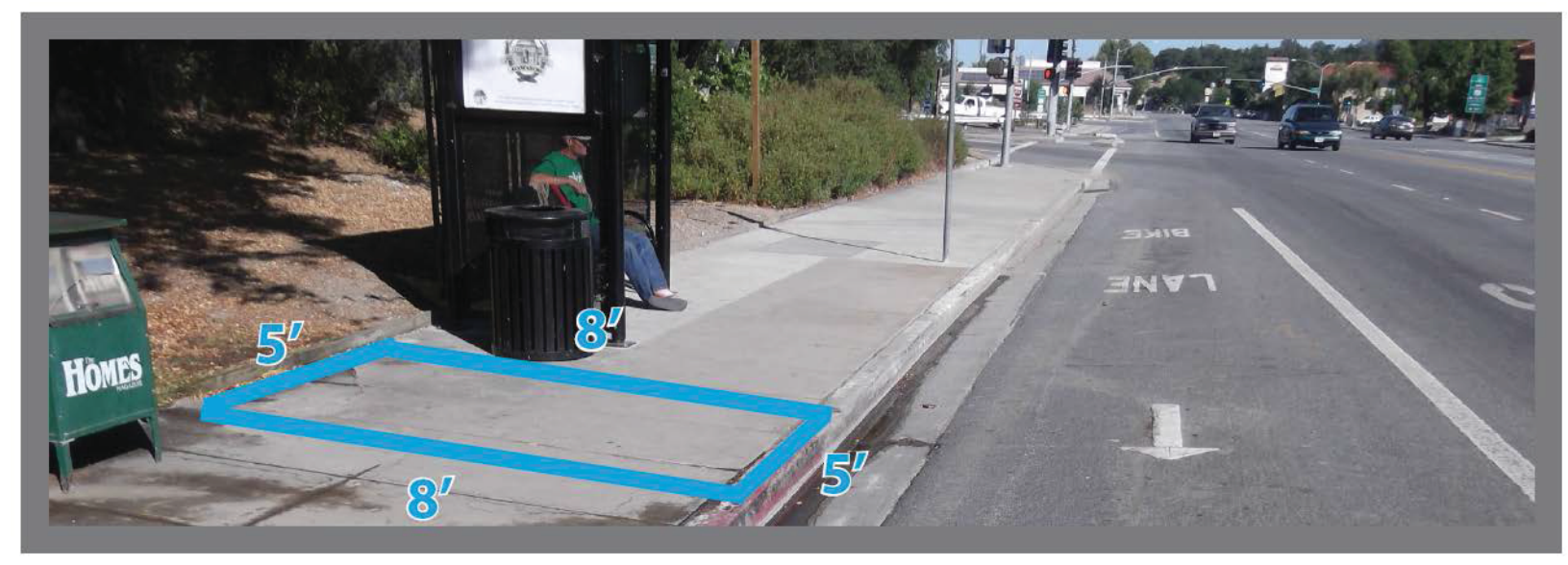

Minimum dimensions of a mobility device landing pad

\section{Safe and Accessible Pedestrian Crossings}

The provision of accessible and safe pedestrian crossings that connect bus stops to nearby pedestrian paths of travel is essential to ensure transit user safety. Factors like proximity to railroad crossings, speed limits on adjacent streets, width of adjacent roadways and proximity to protected pedestrian crossings are important to transit user safety.

Transit authorities have been held liable for passenger incidents involving transit users crossing streets to access bus stops. For example, in 1993, while on her way to a bus stop, Darlene Bonanno entered a crosswalk at a 3-leg intersection that had no traffic controls for through traffic, and she was struck by a car and seriously injured. Ms. Bonanno sued the driver of the car that struck her, as well as the Central Contra Costa Transit Authority (CCCTA), Contra Costa County, and entities that treated her after the accident. In 1999, the Supreme Court of California found CCCTA and Contra Costa County each $1 \%$ liable. All parties except for CCCTA settled outside of court. CCCTA was ultimately held liable for over $\$ 1.5$ million dollars. ${ }^{3}$

Prior to Ms. Bonanno being struck, there were indicators that accessing this particular bus stop was hazardous. In 1986, on her way to the same bus stop and crossing the same street (although midblock, not at the intersection) as Ms. Bonanno, Kimberly Chittock was struck by a car and killed. In 1987, 15 students complained that it was too dangerous to cross the same street to access the same bus stop. Later in 1987, Contra Costa County installed traffic signals with pedestrian push buttons at an intersection about 500 feet away from the bus stop. Although 
pedestrians could now cross the street safely, the route to the bus stop was still hazardous, since it was not relocated to better access the safe street crossing. ${ }^{3}$

Safe crossings for transit users should be considered when developing a transit bus stop improvement plan.

\section{Traffic Impact, Sight Distance, Pull-Out Space, and Safety}

Ideally, a stopped bus does not unduly obstruct traffic or impair sight distance for nearby pedestrians or drivers. An ideal bus stop also affords space that allows buses to easily enter the bus-loading zone while decelerating, stop parallel to the bus-loading zone, and safely accelerate when exiting the bus-loading zone. Furthermore, an ideal bus stop provides ample space around a parked bus for passengers to safely enter and exit the stop and/or load or remove bikes from racks. It is also important for busses to be able to adequately reenter traffic after servicing a bus stop. Obviously, it would not be feasible - or even advisable - to provide a bus pull-out at every bus stop in San Luis Obispo County. Local decision-makers must decide if the surrounding uses, traffic levels, sight-lines, etc. warrant such a complex and costly solution.

\section{Bus Stop Location Prioritization and Bus Pull-Out Space}

The first step to prioritize bus stop improvements is to determine if current bus stop locations are optimal. Prior to prioritizing bus stop improvements, consensus should be reached by RTA and local jurisdiction officials regarding planned new or improved fixed-route bus stop locations. Factors to consider when identifying, evaluating, and selecting bus stop locations include:

\section{Stop Location Prioritization}

- Comfort, and convenience for transit route passengers (e.g., travel time, distance, out of direction travel, and cost)

- Accessibility, safety, comfort, and convenience of bus stops and pathway connections to adjacent developments

- Context sensitivity of bus stop with surrounding environment 


\section{Bus Pull-Out Space: Road Operation and Safety}

- Effects of stopped bus on adjacent traffic and sight distance

- Ability of bus to decelerate to, stop at, and accelerate from bus stop

- Adequateness of space around stopped busses for transit user safety

\section{Cost of Improvements \& Available Funding Sources}

RTA does not own any bus stops or adjacent land, so improvements to bus stops and surrounding areas typically requires partnerships with other agencies and/or adjacent property owners. This should be considered when evaluating potential new bus stop locations and estimating improvement costs related to a bus stop (e.g., expected grant availability and expected improvements along the RTA Route 9 in south Atascadero and the RTA Route 10 in Nipomo).

\section{Phase II: Prioritizing Bus Stop Improvements}

Once consensus of long-range bus stop locations has been reached by RTA and local jurisdiction officials, the next step is to prioritize stop improvements. This report seeks to prioritize installation of ADA accessible mobility device landing pads, safe and accessible connecting pathways, and passenger amenities that meet transit user needs. Factors to consider when prioritizing bus stop improvements include:

- Presence of mobility device landing pads.

- Presence accessible pathways between the bus stop and nearby transit trip generators.

- Presence of passenger amenities not required by ADA but are important for generating ridership. These amenities include safe pathways, benches, shelters, lighting, bicycle parking and passenger information.

- Proportion of boardings and alightings in relationship to the RTA system as a whole.

- Potential use by school buses and other forms of shared-ride transportation.

- Jurisdictional control of the bus stop.

- Cost to install ADA mobility device landing pad at stop (if not already provided)

- Cost to install accessible pathways connecting to the bus stop (if not already provided).

- Cost to install amenities not required by ADA. 


\section{Bus Stop Improvement Prerequisite I: Mobility Device Landing Pad(s)}

If a fixed-route bus stop does not have a mobility device landing pad, by ADA requirements, RTA should not implement improvements to the bus stop before one is installed (or planned). Repair, replacement, and updated transit user information are exempt from this recommendation.

\section{Bus Stop Improvement Prerequisite II: Safe and Accessible Pathways}

This document defines safe and accessible pathways between the bus stop and nearby transit trip generators as an RTA bus stop planning prerequisite. It should be noted that ADA only requires a compliant mobility device landing pad that connects to any type of accessible pathway (e.g., an accessible but busy street). If a fixed-route bus stop is not connected to an accessible pathway, by ADA requirements, no improvements should implemented by RTA to the bus stop before an accessible pathway is installed (or planned).

\section{Amenities to Meet Transit User Needs}

On March 3 ${ }^{\text {rd }}$, 2010, RTA staff proposed minimum standards for amenities that will create "safe, clean, comfortable, accessible stops with amenities that attract and retain customers" to the RTA Board of Directors. These are the minimum bus stop standards as proposed in 2010:

- All RTA bus stops will include a bus stop sign and information kiosk.

- Bus stops that have at least fifteen (15) boardings per day shall include a bus bench and trash receptacle.

- Bus stops that have at least twenty-five (25) boardings per day shall include a 13-foot passenger shelter with solar lighting or sufficient ambient light and a bike rack or bike locker.

- Bus stops that have at least forty (40) boardings per day shall include a 16-foot passenger shelter with solar lighting or sufficient ambient light and all amenities as noted above.

- New bus stops may also include a passenger shelter based upon the local jurisdiction requirements for new commercial or residential development in the corridor. 
- RTA staff will work with local jurisdiction staff to incorporate local design requirements and develop a process for providing conditions to new commercial or residential development in the corridor.

- RTA staff will also work with the local arts councils on the development of an "Arts@Stops" program where local artists could incorporate their artwork at bus stops, as appropriate.

Re-evaluating these standards may be a worthwhile exercise. Factors to consider when prioritizing bus stops amenities include:

- Presence of bus stop sign and information kiosk.

- Presence of other amenities (e.g. seating, shelter, bike storage, trash, Braille pads).

- Passenger boarding proportion ranking (boarding passengers typically wait at stops, while alighting passengers rarely dwell at a bus stop).

- Typical wait times of users at bus stops.

- Travel characteristics of transit users at bus stops (e.g., mobility device users, people with disabilities, cyclists, etc.).

- Environment surrounding bus stop (e.g., adjacent land use, shelter, shade, lighting, interaction with sun, wind, and water, bike lanes, trash, public art, etc.).

- Number of seats needed at bus stops, based on typical passenger activity.

- Number of bike racks needed at bus stops.

From a purely liability avoidance perspective, implementing passenger amenities at bus stops should not be considered unless the bus stop meets minimum ADA requirements.

\section{Proportion of Boardings and Alightings}

The majority of RTA passenger trips are provided during weekday commute hours, so this analysis uses boarding and alighting (on/off) data collected on weekdays to prioritize improvements. If other overarching needs of community members suggest that certain bus stops should receive special consideration, then local officials could alter the priority to meet those needs. For example, construction of a low-income and/or accessible housing project adjacent to a deficient bus stop could warrant special consideration to meet community member needs. 


\section{Estimating RTA Bus Stop and Route Usage}

To estimate proportion of weekday "ons/offs" for stops served by RTA fixed-routes, a useful data source exists from mid-April 2010 when RTA collected "on/off" data. This report uses this data to calculate percentage of boardings and alightings along each RTA route and at each RTA bus stop in relationship to the entire RTA fixed-route system. During this study period, 9,429 boardings and 9,299 alighting were recorded.

This "on/off" transit usage data was collected for all RTA bus stops and routes and was used to create RTA usage proportion tables used throughout this report.

\section{RTA Route Usage Proportions}

Proportions of passengers per RTA route are summarized in the table below.

\begin{tabular}{|l|c|c|}
\cline { 2 - 3 } & $\begin{array}{c}\text { PCT of } \\
\text { System } \\
\text { ONS }\end{array}$ & $\begin{array}{c}\text { PCT of } \\
\text { System } \\
\text { OFFS }\end{array}$ \\
\hline RTA 10 Weekdays & $33 \%$ & $33 \%$ \\
\hline RTA 9 Weekdays & $32 \%$ & $33 \%$ \\
\hline RTA 12 Weekdays & $32 \%$ & $32 \%$ \\
\hline RTA 15 Weekdays & $2 \%$ & $2 \%$ \\
\hline Total (Check for correctness) & $100 \%$ & $100 \%$ \\
\hline
\end{tabular}




\section{RTA High-Use Bus Stops}

A table summarizing high use bus stops (i.e., bus stops with greater than $1 \%$ of the total RTA system boardings or alightings during the study period) is shown below. Notably, of the approximately 125 bus stops served by RTA fixed-route buses, over $77 \%$ of both boardings and alightings take place at the 21 bus stops listed below.

Where bus stops have moved or been renamed since "on/off" data was collected in 2010, names of stops serviced in 2013 nearest the discontinued 2010 stops are indicated in parentheses.

\begin{tabular}{|l|l|}
\hline & PCT of System ONS $\geq 1 \%$ \\
\hline & PCT of System OFFS $\geq 1 \%$ \\
\hline
\end{tabular}

\begin{tabular}{|l|r|r|}
\hline High-Use Stops & \multicolumn{1}{|c|}{ Ons } & \multicolumn{1}{c|}{ Offs } \\
\hline Government Center & $24.6 \%$ & $22.1 \%$ \\
\hline Cuesta College & $7.9 \%$ & $10.4 \%$ \\
\hline Morro Bay Park & $5.6 \%$ & $4.9 \%$ \\
\hline Atascadero City Hall & $5.3 \%$ & $4.3 \%$ \\
\hline Cal Poly Kennedy Library (NB) & $4.8 \%$ & $1.2 \%$ \\
\hline Pismo Prime Outlets & $4.7 \%$ & $4.0 \%$ \\
\hline Pine Street @ 8th (Train Station) (Paso Robles Transit Center) & $4.3 \%$ & $5.1 \%$ \\
\hline Town Center Mall (Santa Maria Transit Center) & $3.7 \%$ & $3.2 \%$ \\
\hline Halcyon Park and Ride & $2.8 \%$ & $2.2 \%$ \\
\hline Foothill @ Casa (NB) (Santa Rosa @ Mustang Village @ Stnr Gle & $2.6 \%$ & $0.2 \%$ \\
\hline Las Tablas Park and Ride & $2.2 \%$ & $1.9 \%$ \\
\hline E. Grand @ El Camino Real & $1.9 \%$ & $2.7 \%$ \\
\hline Alan Hancock College (S. Bradley at Jones) & $1.9 \%$ & $2.3 \%$ \\
\hline Tefft St. @ Carillo St. (NB) & $1.7 \%$ & $0.8 \%$ \\
\hline Cal Poly Performing Arts center (NB) & $1.1 \%$ & $0.1 \%$ \\
\hline Tefft St. @ Carillo St. (SB) & $1.0 \%$ & $1.2 \%$ \\
\hline 10th at LOVR & $0.9 \%$ & $1.0 \%$ \\
\hline Cal Poly Kennedy Library (SB) & $0.1 \%$ & $4.2 \%$ \\
\hline Foothill @ Casa (SB) (Santa Rosa @ Foothill) & $0.1 \%$ & $1.8 \%$ \\
\hline Cal Poly Performing Arts Center (SB) & $0.1 \%$ & $2.0 \%$ \\
\hline Monterey @ Grand & $0.0 \%$ & $1.4 \%$ \\
\hline Total & $77.5 \%$ & $77.1 \%$ \\
\hline
\end{tabular}


Transit users typically spend more time at the bus stop when boarding because they wait at the bus stop for the bus to arrive; alighting passengers typically leave the bus stop upon exiting the bus (unless they are waiting to transfer to another bus or waiting to be picked up by a friend or relative). Transit user wait time and appropriate bus stop waiting amenities should be taken into consideration when planning and prioritizing bus stop improvements based on passenger activity.

Existing amenities beyond minimum ADA requirements for high use stops are shown in the table in APPENDIX A.

\section{RTA Infrequently Used Bus Stops}

A table summarizing infrequently used bus stops (i.e., bus stops with no recorded boardings or alightings during the study period) is below.

\begin{tabular}{|l|c|c|}
\hline Unused Stops & ON & OFF \\
\hline Moonstone @ Castle Inn & 0 & 0 \\
\hline Moonstone @ Mariner's Inn (SB) & 0 & 0 \\
\hline Main @ Jamaica & 0 & 0 \\
\hline Main @ Bluebird Inn & 0 & 0 \\
\hline Moonstone @ Mariner's Inn (NB) & 0 & 0 \\
\hline Moonstone @ Firesiede Inn & 0 & 0 \\
\hline
\end{tabular}

RTA staff recommends considering ending service to these bus stops. 


\section{Assessment of RTA Multi-route Transit Hubs}

\section{RTA Multi-Route Transit Passenger Facilities: Existing Amenities at High-Use Bus Stops}

Of the 21 high-use bus stops listed in the previous section, 5 are served by multiple RTA fixedroutes, as follows:

- Government Center is served by RTA Route 9, RTA Route 10, and RTA Routes 12/14.

- Morro Bay Park is served by RTA Route 12 and RTA Route 15.

- Cal Poly Kennedy Library NB is served by RTA Route 9NB, RTA Route 12NB and RTA Route 10x.

- Santa Rosa at Mustang Village \& Stenner Glen Apartments is served by RTA Route 9NB and RTA Route 12/14NB.

- $\quad$ Santa Rosa at Foothill is served by RTA Route 9SB and RTA Route 12/14SB.

The table in APPENDIX A summarizes amenities and limitations at these high-use multi-route transit passenger facilities served by RTA. Key high-use multi-route transit passenger facilities findings include:

- The Santa Rosa at Mustang Village bus stop is the only high-use bus stop that lacks amenities for waiting passengers (i.e., no shelter and no seating).

- All five high-use passenger facilities have at least one ADA compliant mobility device landing pad and safe and accessible sidewalks and/or routes connecting the bus stop to nearby developments.

- At Pismo Premium Outlets and Morro Bay Park high-use passenger facilities, multiple buses stop simultaneously, but only one ADA compliant landing pad is present. These highuse passenger facilities lack sufficient landing area to simultaneously board or alight mobility devices from more than one bus at a time. 
- Cal Poly Kennedy Library NB is the only high-use passenger facility that lacks an RTA bus stop sign.

- All five high-use passenger facilities have RTA information kiosks.

- All five high-use passenger facilities have sufficient lighting.

- Morro Bay Park and Cal Poly Kennedy Library NB are the high-use only passenger facilities with payphones within sight.

- Only Government Center and Morro Bay Park high-use passenger facilities have bike racks.

- Only Cal Poly Kennedy Library NB and Santa Rosa at Foothill high-use passenger facilities are directly connected to designated bike lanes.

- Government Center is the only high-use passenger facility with a Braille pad.

- Santa Rosa at Mustang Village and Santa Rosa at Foothill are the only high-use passenger facilities without a trash receptacle.

Existing amenities at high-use bus stops served by single RTA routes are discussed in the next sections. 


\section{Assessment of RTA Route 9}

\section{RTA Route 9 Bus Stop Usage: Proportion of Boardings and Alighting}

\section{RTA Route 9 Weekdays Southbound}

\begin{tabular}{|l|c|c|c|c|c|}
\hline \multicolumn{1}{c|}{$\begin{array}{c}\text { Weekday Southbound } \\
\text { WEEKDAY TOTALS }\end{array}$} & \multicolumn{2}{c|}{ TOTAL } & $\begin{array}{c}\text { Total } \\
\text { Stop } \\
\text { Activity }\end{array}$ & $\begin{array}{c}\text { PCT of } \\
\text { System } \\
\text { ONS }\end{array}$ & $\begin{array}{c}\text { PCT of } \\
\text { System } \\
\text { OFFS }\end{array}$ \\
\cline { 2 - 5 } Atascadero City Hall & 435 & 56 & 491 & $4.61 \%$ & $0.60 \%$ \\
\hline Pine Street @ 8th (Train Station) & 402 & 22 & 424 & $4.26 \%$ & $0.24 \%$ \\
\hline Las Tablas Park and Ride & 193 & 13 & 206 & $2.05 \%$ & $0.14 \%$ \\
\hline ECR @ Car Wash & 92 & 7 & 99 & $0.98 \%$ & $0.08 \%$ \\
\hline ECR @ Encina & 86 & 62 & 148 & $0.91 \%$ & $0.67 \%$ \\
\hline ECR @ El Bordo & 52 & 31 & 83 & $0.55 \%$ & $0.33 \%$ \\
\hline Viejo Camino @ Bocina & 44 & 50 & 94 & $0.47 \%$ & $0.54 \%$ \\
\hline Mission @ 14th St. & 44 & 0 & 44 & $0.47 \%$ & $0.00 \%$ \\
\hline ECR @ Plata & 41 & 12 & 53 & $0.43 \%$ & $0.13 \%$ \\
\hline ECR @ Patria Circle & 29 & 15 & 44 & $0.31 \%$ & $0.16 \%$ \\
\hline ECR @ Maple & 23 & 23 & 46 & $0.24 \%$ & $0.25 \%$ \\
\hline Viejo Camino @ Santa Barbara & 23 & 13 & 36 & $0.24 \%$ & $0.14 \%$ \\
\hline ECR @ Carrows & 16 & 4 & 20 & $0.17 \%$ & $0.04 \%$ \\
\hline ECR @ Pueblo & 14 & 8 & 22 & $0.15 \%$ & $0.09 \%$ \\
\hline ECR @ Santa Margarita & 9 & 7 & 16 & $0.10 \%$ & $0.08 \%$ \\
\hline Kennedy Library (SB) & 8 & 205 & 213 & $0.08 \%$ & $2.20 \%$ \\
\hline Performing Arts center (SB) & 7 & 189 & 196 & $0.07 \%$ & $2.03 \%$ \\
\hline ECR @ Maria & 6 & 11 & 17 & $0.06 \%$ & $0.12 \%$ \\
\hline Foothill @ Casa (SB) & 5 & 65 & 70 & $0.05 \%$ & $0.70 \%$ \\
\hline ECR @ Carmel & 5 & 7 & 12 & $0.05 \%$ & $0.08 \%$ \\
\hline Creston @ Melody & 5 & 0 & 5 & $0.05 \%$ & $0.00 \%$ \\
\hline ECR @ Garden Farms & 3 & 10 & 13 & $0.03 \%$ & $0.11 \%$ \\
\hline ECR @ Viejo Camino & 3 & 8 & 11 & $0.03 \%$ & $0.09 \%$ \\
\hline Monterey @ Grand & 2 & 131 & 133 & $0.02 \%$ & $1.41 \%$ \\
\hline Government Center & 1547 & 1552 & 3099 & $16.41 \%$ & $16.69 \%$ \\
\hline
\end{tabular}




\section{RTA Route 9 Weekdays Northbound}

\begin{tabular}{|c|c|c|c|c|c|}
\hline \multirow{2}{*}{$\begin{array}{l}9 \text { Weekday Northbound } \\
\text { WEEKDAY TOTALS }\end{array}$} & \multicolumn{2}{|c|}{ TOTAL } & \multirow{2}{*}{$\begin{array}{c}\text { Total } \\
\text { Stop } \\
\text { Activity }\end{array}$} & \multirow{2}{*}{$\begin{array}{c}\text { PCT of } \\
\text { System } \\
\text { ONS }\end{array}$} & \multirow{2}{*}{$\begin{array}{c}\text { PCT of } \\
\text { System } \\
\text { OFFS }\end{array}$} \\
\hline & ON & OFF & & & \\
\hline Government Center & 780 & 0 & 780 & $8.27 \%$ & $0.00 \%$ \\
\hline Kennedy Library (NB) & 239 & 30 & 269 & $2.53 \%$ & $0.32 \%$ \\
\hline Performing Arts center (NB) & 106 & 12 & 118 & $1.12 \%$ & $0.13 \%$ \\
\hline Atascadero City Hall & 63 & 343 & 406 & $0.67 \%$ & $3.69 \%$ \\
\hline Viejo Camino @ Bocina & 60 & 54 & 114 & $0.64 \%$ & $0.58 \%$ \\
\hline Monterey @ Peach Tree Inn & 56 & 5 & 61 & $0.59 \%$ & $0.05 \%$ \\
\hline ECR @ Encina & 50 & 69 & 119 & $0.53 \%$ & $0.74 \%$ \\
\hline Foothill @ Casa (NB) & 39 & 6 & 45 & $0.41 \%$ & $0.06 \%$ \\
\hline ECR @ Musselman & 20 & 18 & 38 & $0.21 \%$ & $0.19 \%$ \\
\hline Las Tablas Park and Ride & 17 & 164 & 181 & $0.18 \%$ & $1.76 \%$ \\
\hline ECR @ El Bordo & 10 & 31 & 41 & $0.11 \%$ & $0.33 \%$ \\
\hline ECR @ Avenida Maria & 9 & 35 & 44 & $0.10 \%$ & $0.38 \%$ \\
\hline ECR @ Solano & 9 & 29 & 38 & $0.10 \%$ & $0.31 \%$ \\
\hline Pine Street @ 8th (Train Station) & 8 & 455 & 463 & $0.08 \%$ & $4.89 \%$ \\
\hline ECR @ Santa Margarita & 8 & 8 & 16 & $0.08 \%$ & $0.09 \%$ \\
\hline ECR @ Pueblo & 7 & 22 & 29 & $0.07 \%$ & $0.24 \%$ \\
\hline ECR @ Maria & 7 & 12 & 19 & $0.07 \%$ & $0.13 \%$ \\
\hline ECR @ Highway 41 & 6 & 65 & 71 & $0.06 \%$ & $0.70 \%$ \\
\hline ECR @ Garden Farms & 6 & 6 & 12 & $0.06 \%$ & $0.06 \%$ \\
\hline ECR @ Palomar & 5 & 31 & 36 & $0.05 \%$ & $0.33 \%$ \\
\hline ECR @ Adobe Plaza & 3 & 35 & 38 & $0.03 \%$ & $0.38 \%$ \\
\hline ECR @ Principal & 3 & 7 & 10 & $0.03 \%$ & $0.08 \%$ \\
\hline ECR @ Junipero & 2 & 12 & 14 & $0.02 \%$ & $0.13 \%$ \\
\hline Viejo Camino @ Santa Barbara & 2 & 11 & 13 & $0.02 \%$ & $0.12 \%$ \\
\hline ECR @ Viejo Camino & 1 & 8 & 9 & $0.01 \%$ & $0.09 \%$ \\
\hline Mission @ 14th Street & 0 & 25 & 25 & $0.00 \%$ & $0.27 \%$ \\
\hline \multirow[t]{2}{*}{ ECR @ Carmel } & 0 & 6 & 6 & $0.00 \%$ & $0.06 \%$ \\
\hline & 1516 & 1499 & 3015 & $16.08 \%$ & $16.12 \%$ \\
\hline
\end{tabular}




\section{RTA Route 9 Bus Stop Prerequisite Inventory Summary}

A table in APPENDIX B provides a summary of bus stops served by RTA Route 9 that lack ADA accessible mobility device landing pads and/or safe and accessible pathways. Corresponding proportions of RTA system boardings and alightings are also presented for each of these bus stops. The table in APPENDIX B identifies improvement opportunities associated with these bus stops and provides staff recommendations for next steps to create a bus stop improvement plan.

\section{RTA Route 9 High Priority Recommendation:}

Remove landing pad obstructions: Mobility device landing pads at three relatively safe and accessible bus stops (Cal Poly Kennedy Library NB, Cal Poly Performing Arts SB, and ECR at Encina NB) exist but are obstructed by bus stop amenities.

RTA staff recommends removing obstructions to create ADA compliant landing pads all three of these stops.

\section{RTA Route 9 Bus Stop Prerequisites: Mobility Device Landing Pads with Safe and Accessible Pathway Connections}

Of the 51 RTA Route 9 bus stops, ten lack ADA accessible landing pads, so they are not ADA compliant. Twelve RTA Route 9 bus stops lack connected sidewalks. Six bus stops without landing pads are under San Luis Obispo County's jurisdiction, and all are found along El Camino Real and Santa Barbara Road from Maria Avenue in Santa Margarita to Bordeaux Apartments in South Atascadero. Four bus stops without landing pads are under San Luis Obispo City jurisdiction.

Six RTA Route 9 ADA compliant stops under San Luis Obispo County jurisdiction found in Santa Margarita and South Atascadero have landing pads, but no connecting sidewalks.

\section{RTA Route 9 Pedestrian Crossings}

At all six of the ADA non-compliant bus stops under San Luis Obispo County jurisdiction in Santa Margarita and South Atascadero, the speed limit of the adjacent street is 45 miles per hour or higher, and at five of the six stops, the speed limit of the adjacent street is 55 miles per hour. 
Roadway widths are two to three lanes. None of these six bus stops have a protected pedestrian crossing within sight. Of these six bus stops, two are near an at-grade railroad crossing. Given the rural nature of these stops, installing pedestrian protection features like those typically found in urban settings is not feasible nor advisable at this time. If development patterns change, or if local officials become aware of undue hazards, RTA should work with local officials to potentially relocate these bus stops.

\section{RTA Route 9 Pull-Out Space, Traffic Impact, and Sight Distance}

Each of the six ADA non-compliant bus stops in Santa Margarita and South Atascadero under San Luis Obispo County jurisdiction is on a road shoulder. A parked bus at each bus stop temporarily obstructs sight distance for traffic entering the roadway. None have an adequate "No Parking" zone. At two of these stops, a stopped bus obstructs traffic (Viejo Camino at Santa Barbara SB and ECR at Pine SB). At one of these stops, a stopped bus blocks a business driveway (ECR at Pine SB). Based on the rural nature and relatively low traffic volumes in this area, it is not recommended at this time that the bus stops be relocated or altered.

\section{RTA Route 9 Existing Amenities at High-Use Bus Stops}

The following list provides a summary of existing passenger amenities at high-use RTA Route 10 bus stops. Corresponding proportions of RTA system boardings and alightings are also presented for each of these bus stops. The table of existing amenities at high-use stops is included in APPENDIX A.

- All seven high-use bus stops are ADA compliant, and have safe and accessible sidewalks and/or pathways connecting the bus stop to nearby transit trip generators.

- As can be seen in the table in APPENDIX A, of the seven high use bus stops served by RTA Route 9 exclusively, five high-use bus stops lack a bus stop sign (Atascadero City Hall, Cal Poly Performing Arts Center NB \& AB, Cal Poly Kennedy Library NB \& SB, and Monterey@ Grand)

- All seven of the bus stops with a high proportion of passenger boardings have both shelters and benches for waiting passengers. 
- All three high-use bi-directional bus stops have bike racks, plus one has bike lockers (Las Tablas Park and Ride).

- Two high-use bi-directional bus stops lack designated bicycle lanes connecting to the bus stop (Paso Robles Transit Center and Cal Poly Performing Arts Center NB).

- All seven high-use bus stops have sufficient ambient lighting.

- One bus stop with a high proportion of passenger alightings lacks an RTA information kiosk (Monterey @ Grand).

- Six high use bus stops lack Braille pads.

- Two high-use bus stops have payphones or call-boxes within sight of the bus stop (Cal Poly Performing Arts Center NB and Cal Poly Performing Arts Center SB).

- All seven high-use bus stops have trash receptacles. 


\section{Assessment of RTA Route 10}

RTA Route 10 Bus Stop Usage: Proportion of Boardings and Alightings

RTA Route 10 Weekdays Northbound

\begin{tabular}{|c|c|c|c|c|c|}
\hline \multirow{2}{*}{$\begin{array}{l}10 \text { Daily Northbound } \\
\text { WEEKDAY TOTALS }\end{array}$} & \multicolumn{2}{|c|}{ TOTAL } & \multirow{2}{*}{$\begin{array}{l}\text { Total } \\
\text { Stop } \\
\text { Activity }\end{array}$} & \multirow{2}{*}{$\begin{array}{l}\text { PCT of } \\
\text { System } \\
\text { ONS }\end{array}$} & \multirow{2}{*}{$\begin{array}{c}\text { PCT of } \\
\text { System } \\
\text { OFFS }\end{array}$} \\
\hline & ON & OFF & & & \\
\hline Town Center Mall (Santa Maria Transit Center) & 342 & 0 & 342 & $3.63 \%$ & $0.00 \%$ \\
\hline Prime Outlets & 339 & 77 & 416 & $3.60 \%$ & $0.83 \%$ \\
\hline Allan Hancock & 171 & 2 & 173 & $1.81 \%$ & $0.02 \%$ \\
\hline Tefft St. @ Carillo St. (NB) & 163 & 79 & 242 & $1.73 \%$ & $0.85 \%$ \\
\hline Halcyon Park and Ride & 142 & 118 & 260 & $1.51 \%$ & $1.27 \%$ \\
\hline E. Grand @ El Camino Real & 100 & 115 & 215 & $1.06 \%$ & $1.24 \%$ \\
\hline Thompson Ave @ Branch St. & 62 & 31 & 93 & $0.66 \%$ & $0.33 \%$ \\
\hline Greyhound (no longer served) & 53 & 0 & 53 & $0.56 \%$ & $0.00 \%$ \\
\hline Marian Hospital & 46 & 2 & 48 & $0.49 \%$ & $0.02 \%$ \\
\hline Nicholson St. @ Cypress St & 38 & 0 & 38 & $0.40 \%$ & $0.00 \%$ \\
\hline Thompson Ave @ Nipomo HS & 37 & 22 & 59 & $0.39 \%$ & $0.24 \%$ \\
\hline E. Main St. @ College Dr. & 37 & 1 & 38 & $0.39 \%$ & $0.01 \%$ \\
\hline S Higuera St. @ Suburban Rd. & 27 & 65 & 92 & $0.29 \%$ & $0.70 \%$ \\
\hline Thompson Ave @ Los Berros & 16 & 18 & 34 & $0.17 \%$ & $0.19 \%$ \\
\hline S. Higuera @ Prado (no longer served) & 13 & 39 & 52 & $0.14 \%$ & $0.42 \%$ \\
\hline South St. @ Beebee St (no longer served) & 11 & 34 & 45 & $0.12 \%$ & $0.37 \%$ \\
\hline S. Higuera St. @ Margarita Ave & 11 & 27 & 38 & $0.12 \%$ & $0.29 \%$ \\
\hline S. Higuera @ Hind (no longer served) & 9 & 16 & 25 & $0.10 \%$ & $0.17 \%$ \\
\hline South St. @ High (no longer served) & 6 & 12 & 18 & $0.06 \%$ & $0.13 \%$ \\
\hline S. Higuera @ Elks Lane (no longer served) & 6 & 11 & 17 & $0.06 \%$ & $0.12 \%$ \\
\hline S. Higuera @ Chumash (no longer served) & 6 & 10 & 16 & $0.06 \%$ & $0.11 \%$ \\
\hline South St. @ Meadow St. (no longer served) & 4 & 28 & 32 & $0.04 \%$ & $0.30 \%$ \\
\hline South Street @ King (no longer served) & 3 & 4 & 7 & $0.03 \%$ & $0.04 \%$ \\
\hline Santa Barbara @ Church (no longer served) & 1 & 17 & 18 & $0.01 \%$ & $0.18 \%$ \\
\hline Government Center & 0 & 740 & 740 & $0.00 \%$ & $7.96 \%$ \\
\hline Cal Poly @ Kennedy Library (NB) & 0 & 63 & 63 & $0.00 \%$ & $0.68 \%$ \\
\hline Santa Rosa@ @iguera (no longer served) & 0 & 46 & 46 & $0.00 \%$ & $0.49 \%$ \\
\hline Cal Poly @ Performing Arts & 0 & 32 & 32 & $0.00 \%$ & $0.34 \%$ \\
\hline Marsh St @ Broad St. & 0 & 25 & 25 & $0.00 \%$ & $0.27 \%$ \\
\hline \multirow[t]{2}{*}{ South St. @ Exposition (no longer served) } & 0 & 9 & 9 & $0.00 \%$ & $0.10 \%$ \\
\hline & 1643 & 1643 & 3286 & $17.42 \%$ & $17.67 \%$ \\
\hline
\end{tabular}




\section{RTA Route 10 Weekdays Southbound}

\begin{tabular}{|c|c|c|c|c|c|}
\hline \multirow{2}{*}{$\begin{array}{l}10 \text { Daily Southbound } \\
\text { WEEKDAY TOTALS }\end{array}$} & \multicolumn{2}{|c|}{ TOTAL } & \multirow{2}{*}{$\begin{array}{c}\text { Total } \\
\text { Stop } \\
\text { Activity } \\
\end{array}$} & \multirow{2}{*}{$\begin{array}{c}\text { PCT of } \\
\text { System } \\
\text { ONS }\end{array}$} & \multirow{2}{*}{$\begin{array}{c}\text { PCT of } \\
\text { System } \\
\text { OFFS }\end{array}$} \\
\hline & ON & OFF & & & \\
\hline Government Center & 708 & 0 & 708 & $7.51 \%$ & $0.00 \%$ \\
\hline Halcyon Park \& Ride & 126 & 82 & 208 & $1.34 \%$ & $0.88 \%$ \\
\hline Prime Outlets & 104 & 299 & 403 & $1.10 \%$ & $3.22 \%$ \\
\hline Tefft St. @ Carillo St. (SB) & 90 & 111 & 201 & $0.95 \%$ & $1.19 \%$ \\
\hline E. Grand @ El Camino Real & 80 & 138 & 218 & $0.85 \%$ & $1.48 \%$ \\
\hline South Higuera St. @ Suburban & 59 & 22 & 81 & $0.63 \%$ & $0.24 \%$ \\
\hline Cal Poly @ Mott Gym & 49 & 0 & 49 & $0.52 \%$ & $0.00 \%$ \\
\hline South St. @ Beebee St. (Higuera at South) & 41 & 7 & 48 & $0.43 \%$ & $0.08 \%$ \\
\hline S.Higuera St. @ Margarita & 38 & 30 & 68 & $0.40 \%$ & $0.32 \%$ \\
\hline Thompson Ave @ Branch & 35 & 47 & 82 & $0.37 \%$ & $0.51 \%$ \\
\hline South St. @ Broad St (no longer served) & 24 & 7 & 31 & $0.25 \%$ & $0.08 \%$ \\
\hline Santa Barbara @ Church (no longer served) & 24 & 1 & 25 & $0.25 \%$ & $0.01 \%$ \\
\hline S. Higuera @ Bridge St. (no longer served) & 9 & 6 & 15 & $0.10 \%$ & $0.06 \%$ \\
\hline South Street @ Exposition (no longer served) & 8 & 0 & 8 & $0.08 \%$ & $0.00 \%$ \\
\hline Thompson Ave @ HS & 7 & 46 & 53 & $0.07 \%$ & $0.49 \%$ \\
\hline Marion Medical Center & 7 & 28 & 35 & $0.07 \%$ & $0.30 \%$ \\
\hline S. Higuera @ Prado (no longer served) & 7 & 11 & 18 & $0.07 \%$ & $0.12 \%$ \\
\hline Santa Barbara @ High (no longer served) & 6 & 1 & 7 & $0.06 \%$ & $0.01 \%$ \\
\hline Town Center Mall (Santa Maria Transit Center) & 5 & 301 & 306 & $0.05 \%$ & $3.24 \%$ \\
\hline Allan Hancock & 4 & 212 & 216 & $0.04 \%$ & $2.28 \%$ \\
\hline S. Higuera @ Silver City Mobile (no longer served) & 3 & 5 & 8 & $0.03 \%$ & $0.05 \%$ \\
\hline S. Higuera @ Granada (no longer served) & 3 & 1 & 4 & $0.03 \%$ & $0.01 \%$ \\
\hline Nipomo St. @ Higuera St & 2 & 0 & 2 & $0.02 \%$ & $0.00 \%$ \\
\hline South Street @ King St. (no longer served) & 1 & 0 & 1 & $0.01 \%$ & $0.00 \%$ \\
\hline Greyhound (no longer served) & 0 & 37 & 37 & $0.00 \%$ & $0.40 \%$ \\
\hline Thompson Ave @ Los Berros & 0 & 11 & 11 & $0.00 \%$ & $0.12 \%$ \\
\hline \multirow[t]{2}{*}{ Nicholson St. @ Cypress } & 0 & 7 & 7 & $0.00 \%$ & $0.08 \%$ \\
\hline & 1440 & 1410 & 2850 & $15.27 \%$ & $15.16 \%$ \\
\hline
\end{tabular}




\section{RTA Route 10 Bus Stop Prerequisite Inventory Summary}

A table in APPENDIX B provides a summary of bus stops served by RTA Route 10 that lack ADA accessible mobility device landing pads and/or safe and accessible connecting pathways. Corresponding proportions of RTA system boardings and alightings are also presented for each of these bus stops. The table in APPENDIX B also identifies improvement opportunities associated with these bus stops and provides staff recommendations for next steps to create a bus stop improvement plan.

\section{RTA Route 10 High Priority Recommendation:}

Remove landing pad and sidewalk obstructions: A mobility device landing pad at one relatively safe and accessible bus stop (S. Higuera at Suburban NB) exists but is obstructed by bus stop amenities. An ADA compliant sidewalk at one relatively safe and accessible bus stop (Higuera at South SB) exists but is obstructed by bus stop amenities.

RTA staff recommends removing obstructions to create ADA compliant landing pads and sidewalks at both of these stops.

\section{RTA Route 10 Bus Stop Prerequisites: Mobility Device Landing Pads with Safe and Accessible Pathway Connections}

Of the 24 RTA Route 10 bus stops, six lack ADA accessible landing pads. Four of these bus stops are under San Luis Obispo County jurisdiction (Nipomo High School, Thompson at Branch, $\mathbf{N}$. Thompson at Hwy 101 NB, and N. Thompson at Hwy 101 SB). One of these bus stops is under Santa Maria jurisdiction (Nicholson at E. Cypress). The last of these six bus stops that lacks an ADA compliant landing pad is under San Luis Obispo City jurisdiction-it meets the five-foot width requirement but is technically one-inch shy of the eight-foot depth requirement (Higuera at South SB).

Of the five RTA Route 10 fixed-route bus stops that lack ADA compliant landing pads, five also lack connected sidewalks - four of these bus stops are under San Luis Obispo County's jurisdiction (Nipomo High School NB, Thompson at Branch SB, N. Thompson at Hwy 101 NB, and N. 
Thompson at Hwy 101 SB) and one is under Santa Maria's jurisdiction (Nicholson at E. Cypress).

Two bus stops meet ADA requirements but have noteworthy operational deficiencies. At the Alan Hancock College bus stop (S. Bradley at Jones) under Santa Maria jurisdiction, a bus can access an ADA compliant landing pad only if it stops awkwardly between the bus stop pole and the bus bay. At a bus stop under Pismo Beach jurisdiction, multiple buses stop simultaneously at the Pismo Beach Premium Outlets bus stop, but only one ADA compliant landing pad is present.

\section{RTA Route 10 Pedestrian Crossings}

At three ADA non-compliant bus stops, the speed limit of the adjacent street is at least 45 miles per hour (Nipomo High School NB, N. Thompson at Hwy 101 NB, and N. Thompson at Hwy 101 SB). At two non-ADA compliant stops, roadway widths are greater than four lanes, (Nipomo High School NB and Higuera at South SB). Four of the ADA non-compliant bus stops do not have a protected pedestrian crossing opportunity within sight (Nipomo High School NB, Nicholson at E. Cypress, N. Thompson at Hwy 101 NB, and N. Thompson at Hwy 101 SB).

\section{RTA Route 10 Pull-Out Space, Traffic Impact, and Sight Distance}

Four of the six ADA non-compliant bus stops are on the road shoulder; all of which are in Nipomo under San Luis Obispo County jurisdiction (Nipomo High School NB, Thompson at Branch SB, N. Thompson at Hwy 101 NB, and N. Thompson at Hwy 101 SB). A parked bus in each of the six ADA non-compliant bus stops obstruct traffic. A parked bus in four ADA non-compliant bus stops obstruct sight distance for traffic entering the roadway. None have an adequate "No Parking" zone.

\section{RTA Route 10 Existing Amenities at High-Use Bus Stops}

The following list provides a summary of existing amenities at high-use RTA Route 10 bus stops. Corresponding proportions of RTA system boardings and alightings are also presented for each of these bus stops. The table of existing amenities at high-use stops is included in APPENDIX A. 
- Two high-use bus stops lack safe and accessible sidewalks and/or routes connecting the bus stop to nearby transit trip generators (Pismo Prime Outlets and Teft st. @ Carillo St. NB).

- Of the seven high-use bus stops served by RTA Route 10 exclusively, three lack RTA bus stop signs (Santa Maria Transit Center, Halcyon Park and Ride, and Alan Hancock College). * Notes: Santa Maria does not allow RTA bus stop signs at SMAT bus stops. Halcyon Park and Ride has a large highly-visible RTA logo in the 4'x6' shelter display.

- One bus stop with a high proportion of passenger boardings lacks an RTA information kiosk (Santa Maria Transit Center).

- Five bus stops lack Braille pads.

- All seven of the high-use bus stops have both shelters and benches for waiting passengers.

- At two of the high-use bus stops, passengers could be hidden from view of an approaching bus (Halycyon Park and Ride and Pismo Prime Outlets).

- All seven high-use bus stops have sufficient ambient lighting.

- Except for the Alan Hancock College bus stop, all five bi-directional high-use bus stops have bike racks.

- Four high-use bi-directional bus stops lack designated bicycle lanes connecting to the bus stop.

- All seven high-use bus stops have trash receptacles. 


\section{Assessment of RTA Route 12/14}

\section{RTA Route 12/14 Bus Stop Usage: Proportion of Boardings and Alightings}

\section{RTA Route 12/14 Weekdays}

\begin{tabular}{|c|c|c|c|c|c|}
\hline \multirow{2}{*}{$\begin{array}{c}\text { 12A Daily } \\
\text { WEEKDAY TOTALS }\end{array}$} & \multicolumn{2}{|c|}{ TOTAL } & \multirow{2}{*}{$\begin{array}{l}\text { Total } \\
\text { Stop } \\
\text { Activity }\end{array}$} & \multirow{2}{*}{$\begin{array}{c}\text { PCT of } \\
\text { System } \\
\text { ONS }\end{array}$} & \multirow{2}{*}{$\begin{array}{c}\text { PCT of } \\
\text { System } \\
\text { OFFS }\end{array}$} \\
\hline & ON & OFF & & & \\
\hline Government Center & 831 & 0 & 831 & $8.81 \%$ & $0.00 \%$ \\
\hline Cuesta Parking Lot 3 (SB) & 421 & 175 & 596 & $4.46 \%$ & $1.88 \%$ \\
\hline Morro Bay Park (SB) & 334 & 91 & 425 & $3.54 \%$ & $0.98 \%$ \\
\hline Kennedy Library (NB) & 216 & 20 & 236 & $2.29 \%$ & $0.22 \%$ \\
\hline Foothill @ Casa (NB) (Santa Roas at Mstng / Stnr Glen) & 205 & 9 & 214 & $2.17 \%$ & $0.10 \%$ \\
\hline Morro Bay Park (NB) & 122 & 288 & 410 & $1.29 \%$ & $3.10 \%$ \\
\hline Cuesta Parking Lot 3 (NB) & 116 & 676 & 792 & $1.23 \%$ & $7.27 \%$ \\
\hline 10th @ LOVR & 87 & 95 & 182 & $0.92 \%$ & $1.02 \%$ \\
\hline 10th @ Santa Ynez & 77 & 90 & 167 & $0.82 \%$ & $0.97 \%$ \\
\hline Cuesta Building 1400 (no longer served) & 67 & 47 & 114 & $0.71 \%$ & $0.51 \%$ \\
\hline Pine @ LOVR & 63 & 46 & 109 & $0.67 \%$ & $0.49 \%$ \\
\hline Cuesta West Side (no longer served) & 58 & 12 & 70 & $0.62 \%$ & $0.13 \%$ \\
\hline Ramona @ 7th & 46 & 27 & 73 & $0.49 \%$ & $0.29 \%$ \\
\hline Cuesta Building 1400 (no longer served) & 44 & 42 & 86 & $0.47 \%$ & $0.45 \%$ \\
\hline Cuesta West Side (no longer served) & 43 & 14 & 57 & $0.46 \%$ & $0.15 \%$ \\
\hline Pine @ Loma & 42 & 29 & 71 & $0.45 \%$ & $0.31 \%$ \\
\hline Santa Ysabel @ 15th & 32 & 3 & 35 & $0.34 \%$ & $0.03 \%$ \\
\hline Santa Ysabel @ 7th & 29 & 9 & 38 & $0.31 \%$ & $0.10 \%$ \\
\hline 11th @ Ramona & 28 & 48 & 76 & $0.30 \%$ & $0.52 \%$ \\
\hline 11th @ El Morro & 27 & 51 & 78 & $0.29 \%$ & $0.55 \%$ \\
\hline LOVR @ Palisades & 25 & 20 & 45 & $0.27 \%$ & $0.22 \%$ \\
\hline 7th @ El Morro & 23 & 16 & 39 & $0.24 \%$ & $0.17 \%$ \\
\hline 2nd @ Santa Maria & 21 & 17 & 38 & $0.22 \%$ & $0.18 \%$ \\
\hline South Bay Boulevard @ Quintana & 18 & 12 & 30 & $0.19 \%$ & $0.13 \%$ \\
\hline Kansas Avenue & 16 & 8 & 24 & $0.17 \%$ & $0.09 \%$ \\
\hline Santa Ysabel @ 15th & 14 & 39 & 53 & $0.15 \%$ & $0.42 \%$ \\
\hline Kansas Avenue & 13 & 6 & 19 & $0.14 \%$ & $0.06 \%$ \\
\hline Kennedy Library (SB) & 6 & 187 & 193 & $0.06 \%$ & $2.01 \%$ \\
\hline Highland @ HWY 1 & 6 & 56 & 62 & $0.06 \%$ & $0.60 \%$ \\
\hline Patricia @ Foothill (no longer served) & 6 & 0 & 6 & $0.06 \%$ & $0.00 \%$ \\
\hline Foothill @ Casa (SB) (Santa Rosa at Foothill) & 5 & 102 & 107 & $0.05 \%$ & $1.10 \%$ \\
\hline South Bay Boulevard @ Quintana & 5 & 10 & 15 & $0.05 \%$ & $0.11 \%$ \\
\hline Achievement House & 3 & 4 & 7 & $0.03 \%$ & $0.04 \%$ \\
\hline LOVR @ Buckskin (no longer served) & 2 & 0 & 2 & $0.02 \%$ & $0.00 \%$ \\
\hline Men's Colony & 1 & 7 & 8 & $0.01 \%$ & $0.08 \%$ \\
\hline Government Center & 0 & 709 & 709 & $0.00 \%$ & $7.62 \%$ \\
\hline LOVR @ Buckskin (no longer served) & 0 & 6 & 6 & $0.00 \%$ & $0.06 \%$ \\
\hline Patricia @ Foothill (no longer served) & 0 & 5 & 5 & $0.00 \%$ & $0.05 \%$ \\
\hline \multirow[t]{2}{*}{ Men's Colony } & 0 & 1 & 1 & $0.00 \%$ & $0.01 \%$ \\
\hline & 3052 & 2977 & 6029 & $32.37 \%$ & $32.01 \%$ \\
\hline
\end{tabular}




\section{RTA Route 12/14 Bus Stop Prerequisite Inventory Summary}

A table in APPENDIX B provides a summary of bus stops served by RTA Route 12/14 that lack ADA accessible mobility device landing pads and/or safe and accessible connecting pathways. Corresponding proportions of RTA system boardings and alightings are also presented for each of these stops. The table in APPENDIX B also identifies improvement opportunities associated with these bus stops and provides staff recommendations for next steps to create a bus stop improvement plan.

\section{RTA Route 12/14 High Priority Recommendation:}

The lowest use RTA Route 12/14 bus stops that lack mobility device landing pads (Kansas at Highway 1 and California Men's Colony) are currently served as call stops.

RTA staff recommends no immediate actions to stops served by RTA Route 12/14.

\section{RTA Route 12/14 Bus Stop Prerequisites: Mobility Device Landing Pads with Safe and Accessible Pathway Connections}

Of the 21 RTA Route 12/14 bus stops, twelve lack ADA accessible landing pads: all are under San Luis Obispo County jurisdiction. Eleven of these ADA non-compliant bus stops lack connecting pathways. Eleven of the twelve bus stops that lack landing pads are in Los Osos, except for Kansas at Highway 1, which is already a call stop and technically not considered part of fixed-route service.

Two ADA compliant bus stops under Morro Bay jurisdiction have landing pads but no connecting pathways (South Bay at Quintana SB and South Bay at Quintana NB).

\section{RTA Route 12/14 Pedestrian Crossings}

None of the non-ADA compliant bus stops have speed limits on adjacent streets that exceed 40 miles per hour or roadway widths greater than two lanes. Seven of the twelve ADA non-compliant 
bus stops lack a protected pedestrian crossing opportunity within sight, and they are all under San Luis Obispo County jurisdiction (two are on the Highway 1 corridor and the other five are in Los Osos).

\section{RTA Route 12/14 Pull-Out Space, Traffic Impact, and Sight Distance}

Eleven of the twelve ADA non-compliant bus stops are on the road shoulder; ten of these bus stops are in Los Osos, and one is Kansas at Highway 1; all are under San Luis Obispo County jurisdiction. A bus temporarily parked in eleven of the twelve ADA non-compliant bus stops obstructs traffic; six obstruct sight distance for traffic entering the roadway, three obstruct residential driveways and one obstructs sightlines for parked vehicles. None have an adequate "No Parking" zone.

\section{RTA Route 12/14 Existing Amenities at High-Use Bus Stops}

The table in APPENDIX A provides a summary of existing amenities at high-use RTA Route 12/14 bus stops. Corresponding proportions of RTA system boardings and alightings are also presented for each of these bus stops.

Cuesta College is the only high-use bus stop served by RTA Route 12/14 exclusively; it is ADA compliant and has a sidewalk with a safe and accessible pathway to the campus core. The bus stop has an RTA bus stop sign, an RTA information kiosk, and a Braille pad. It also has passenger shelters, benches, ambient lighting, and trash and recycle receptacles. There are no bike racks, no bike lane is directly connected to the stop, nor is there a payphone within sight of the bus stop. 


\section{Assessment of RTA Route 15}

\section{RTA Route 15 Bus Stop Usage: Proportion of Boardings and Alightings}

\section{RTA 15 Weekdays Southbound}

\begin{tabular}{|c|c|c|c|c|c|}
\hline \multirow{2}{*}{$\begin{array}{c}\text { 12B Weekday Southbound } \\
\text { WEEKDAY TOTALS }\end{array}$} & \multicolumn{2}{|c|}{ TOTAL } & \multirow{2}{*}{$\begin{array}{c}\text { Total } \\
\text { Stop } \\
\text { Activity }\end{array}$} & \multirow{2}{*}{$\begin{array}{c}\text { PCT of } \\
\text { System } \\
\text { ONS }\end{array}$} & \multirow{2}{*}{$\begin{array}{c}\text { PCT of } \\
\text { System } \\
\text { OFFS } \\
\end{array}$} \\
\hline & ON & OFF & & & \\
\hline Burton @ Ardath & 16 & 0 & 16 & $0.17 \%$ & $0.00 \%$ \\
\hline Burton @ Main & 13 & 0 & 13 & $0.14 \%$ & $0.00 \%$ \\
\hline Ocean @ Cayicos Dr. & 11 & 7 & 18 & $0.12 \%$ & $0.08 \%$ \\
\hline Ocean @ 9th & 11 & 1 & 12 & $0.12 \%$ & $0.01 \%$ \\
\hline Hearst Castle & 10 & 0 & 10 & $0.11 \%$ & $0.00 \%$ \\
\hline Highway $1 @$ San Jacinto & 9 & 6 & 15 & $0.10 \%$ & $0.06 \%$ \\
\hline Ocean @ 3rd & 9 & 3 & 12 & $0.10 \%$ & $0.03 \%$ \\
\hline Ardath @ Green (Ardath @ Hwy 1) & 8 & 0 & 8 & $0.08 \%$ & $0.00 \%$ \\
\hline Main @ Arlington & 7 & 0 & 7 & $0.07 \%$ & $0.00 \%$ \\
\hline Moonstone @ Windsor & 6 & 0 & 6 & $0.06 \%$ & $0.00 \%$ \\
\hline Burton @ Cambria Pines Lodge & 6 & 0 & 6 & $0.06 \%$ & $0.00 \%$ \\
\hline Main @ Tamson & 5 & 0 & 5 & $0.05 \%$ & $0.00 \%$ \\
\hline Main @ Errol (no longer served) & 4 & 9 & 13 & $0.04 \%$ & $0.10 \%$ \\
\hline Ocean @ Old Creek Rd. & 4 & 5 & 9 & $0.04 \%$ & $0.05 \%$ \\
\hline Main @ Bluebird & 3 & 1 & 4 & $0.03 \%$ & $0.01 \%$ \\
\hline Main @ Veterans Hall & 3 & 0 & 3 & $0.03 \%$ & $0.00 \%$ \\
\hline Morro Bay Park & 0 & 76 & 76 & $0.00 \%$ & $0.82 \%$ \\
\hline Moonstone @ San Simeon Pines & 0 & 7 & 7 & $0.00 \%$ & $0.08 \%$ \\
\hline Hearst Drive @ San Simeon & 0 & 0 & 0 & $0.00 \%$ & $0.00 \%$ \\
\hline Moonstone @ Castle Inn & 0 & 0 & 0 & $0.00 \%$ & $0.00 \%$ \\
\hline \multirow[t]{2}{*}{ Moonstone @ Mariner's Inn (SB) } & 0 & 0 & 0 & $0.00 \%$ & $0.00 \%$ \\
\hline & 125 & 115 & 240 & $1.33 \%$ & $1.24 \%$ \\
\hline
\end{tabular}




\section{RTA Route 15 Weekdays Northbound}

\begin{tabular}{|l|c|c|c|c|c|}
\hline \multicolumn{1}{c|}{$\begin{array}{c}\text { 12B Weekday Northbound } \\
\text { WEEKDAY TOTALS }\end{array}$} & ON & OFF & $\begin{array}{c}\text { Total } \\
\text { Stop } \\
\text { Activity }\end{array}$ & $\begin{array}{c}\text { PCT of } \\
\text { System } \\
\text { ONS }\end{array}$ & $\begin{array}{c}\text { PCT of } \\
\text { System } \\
\text { OFFS }\end{array}$ \\
\hline MORRO BAY & 75 & 0 & 75 & $0.81 \%$ & $0.00 \%$ \\
\hline Morro Bay Park & 8 & 3 & 11 & $0.08 \%$ & $0.03 \%$ \\
\hline Ocean @ Cayucos Dr. (Cayucos @ Ash) & 7 & 0 & 7 & $0.07 \%$ & $0.00 \%$ \\
\hline Main @ Errol (no longer served) & 4 & 3 & 7 & $0.04 \%$ & $0.03 \%$ \\
\hline Main @ Elena (no longer served) & 3 & 7 & 10 & $0.03 \%$ & $0.07 \%$ \\
\hline Main @ Veterans Hall (Main @ Skate Park) & 3 & 4 & 7 & $0.03 \%$ & $0.04 \%$ \\
\hline Main @ San Joaquin & 2 & 5 & 7 & $0.02 \%$ & $0.05 \%$ \\
\hline Burton @ Yorkshire & 2 & 2 & 4 & $0.02 \%$ & $0.02 \%$ \\
\hline Main @ Bonita (no longer served) & 1 & 9 & 10 & $0.01 \%$ & $0.10 \%$ \\
\hline Moonstone @ Windsor & 1 & 4 & 5 & $0.01 \%$ & $0.04 \%$ \\
\hline Ardath @ Green (Ardath @ Hwy 1) & 0 & 17 & 17 & $0.00 \%$ & $0.18 \%$ \\
\hline Burton @ Ardath & 0 & 15 & 15 & $0.00 \%$ & $0.16 \%$ \\
\hline Burton @ Main & 0 & 9 & 9 & $0.00 \%$ & $0.10 \%$ \\
\hline Hearst Castle & 0 & 7 & 7 & $0.00 \%$ & $0.07 \%$ \\
\hline Ocean @ 8th St & 0 & 6 & 6 & $0.00 \%$ & $0.06 \%$ \\
\hline Ocean @ 4th (Ocean @ 3rd (NB)) & 0 & 4 & 4 & $0.00 \%$ & $0.04 \%$ \\
\hline Main @ Tamson & 0 & 3 & 3 & $0.00 \%$ & $0.03 \%$ \\
\hline Castillo @ Otter & 0 & 2 & 2 & $0.00 \%$ & $0.02 \%$ \\
\hline Ocean @ Old Creek Rd & 0 & 2 & 2 & $0.00 \%$ & $0.02 \%$ \\
\hline Moonstone @ San Simeon Pines & 0 & 1 & 1 & $0.00 \%$ & $0.01 \%$ \\
\hline Cornwall @ Arlington (Main @ Cornwall) & 0 & 0 & 0 & $0.00 \%$ & $0.00 \%$ \\
\hline Main @ Jamaica (no longer served) & 0 & 0 & 0 & $0.00 \%$ & $0.00 \%$ \\
\hline Main @ Bluebird Inn & 0 & 0 & 0 & $0.00 \%$ & $0.00 \%$ \\
\hline Moonstone @ Mariner's Inn (NB) & 0 & 0 & 0 & $0.00 \%$ & $0.00 \%$ \\
\hline Moonstone @ Firesiede Inn & 106 & 103 & 209 & $1.14 \%$ & $1.09 \%$ \\
\hline
\end{tabular}




\section{RTA Route 15 Existing Amenities at High-Use Bus Stops}

Since it lacks a single bus stop with greater than $1 \%$ of the total RTA system boardings and alightings, RTA Route 15 alone serves no high-use bus stops.

Morro Bay Park is a high-use stop, and it is discussed in the high-use multi-route passenger facility section above. Morro Bay Park is served by RTA Route 12, RTA Route 15, and Morro Bay Transit services.

\section{RTA Route 15 Bus Stop Prerequisite Inventory Summary}

A table in APPENDIX B provides a summary of bus stops served by RTA Route 15 that lack ADA accessible mobility device landing pads and/or safe and accessible connecting pathways. Corresponding proportions of RTA system boardings and alightings are also presented for each of these bus stops. The table in APPENDIX B also identifies improvement opportunities associated with these stops and provides staff recommendations for next steps to create a bus stop improvement plan.

\section{RTA Route 15 High Priority Recommendation:}

Remove landing pad and sidewalk obstructions: A mobility device landing pad at one relatively safe and accessible stop (MAIN at CORNWALL in Cambria) exists but is obstructed by a bench connected to the "Old Station Store."

RTA staff recommends working with the "Old Station Store" property owner to remove obstructions to create an ADA compliant landing pad.

\section{RTA Route 15 Bus Stop Prerequisites: Mobility Device Landing Pads with Safe and Accessible Pathway Connections}

Of the 37 RTA Route 15 bus stops, 31 lack ADA accessible landing pads. One of these ADA noncompliant bus stops (Highway 1 at SAN JACINTO) is under Morro Bay jurisdiction. The rest of the 30 bus stops are under San Luis Obispo County jurisdiction. 
Of the 31 RTA Route 15 stops without landing pads, 23 also lack connecting pathways; all of these bus stops are under San Luis Obispo County jurisdiction.

Two ADA compliant stops under Morro Bay jurisdiction have landing pads but lack connecting pathways (South Bay at Quintana SB and South Bay at Quintana NB).

\section{RTA Route 15 Pedestrian Crossings}

At one ADA non-compliant bus stop, the speed limit of the adjacent street exceeds 45 miles per hour and the roadway is five lanes wide (Highway 1 @ SAN JACINTO).

A total of 20 of the ADA non-compliant bus stops along the north coast lack a protected pedestrian crossing opportunity.

\section{RTA Route 15 Pull-Out Space, Traffic Impact, and Sight Distance}

A total of 18 of the 31 ADA non-compliant bus stops are on the road shoulder; all of which are under San Luis Obispo County jurisdiction. A bus temporarily parked in 24 of the 31 ADA noncompliant bus stops obstructs traffic; all 24 obstruct sight distance for traffic entering the roadway, 5 obstruct business driveways, and 2 obstruct parked vehicles. A total of 29 lack a "No Parking" zone. 


\section{References}

${ }^{1}$ Easer Seals Project Action (2006). Toolkit for the assessment of Bus Stop Accessibility and Safety, (pp. 6 and pp. 14-15). Washington, DC.

2 U.S. Department of Transportation, Federal Highway Administration (February 2008). Pedestrian Safety Guide for Transit Agencies, (pp. 37). Washington, DC.

${ }^{3}$ Darlene Bonanno v. Central Contra Costa Transit Authority, Supreme Court of California 
APPENDIX A: Amenities at High-Use RTA Bus Stops 


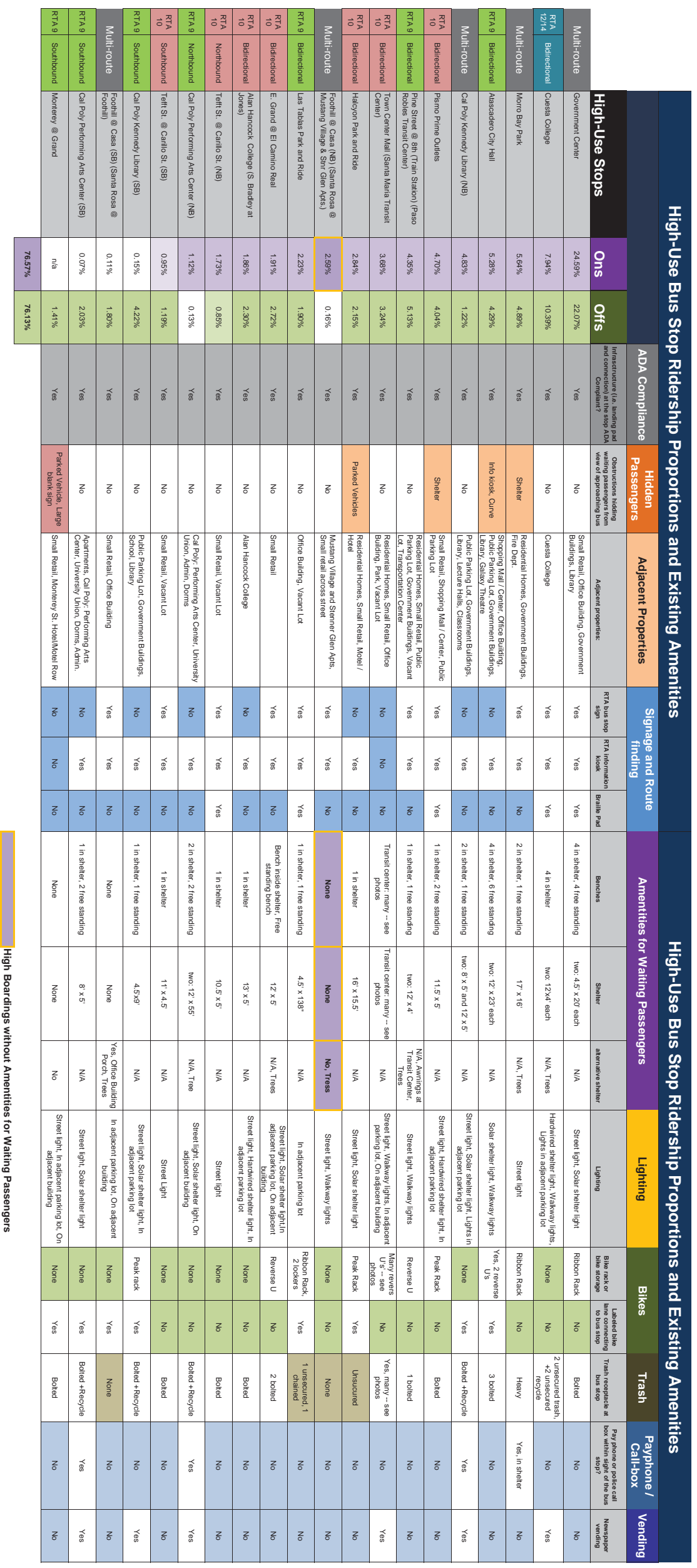


APPENDIX B: Non-ADA Compliant RTA Bus Stops 


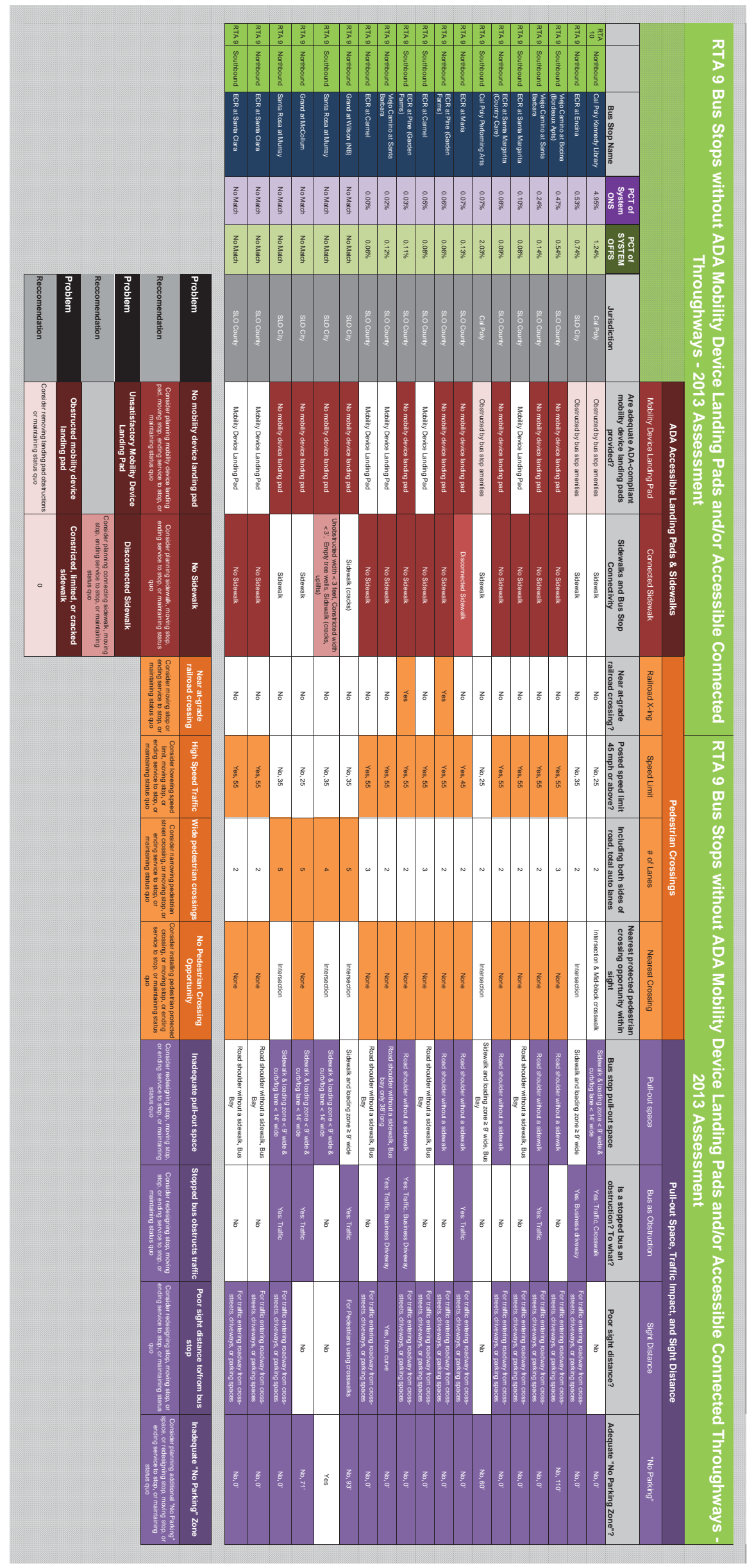




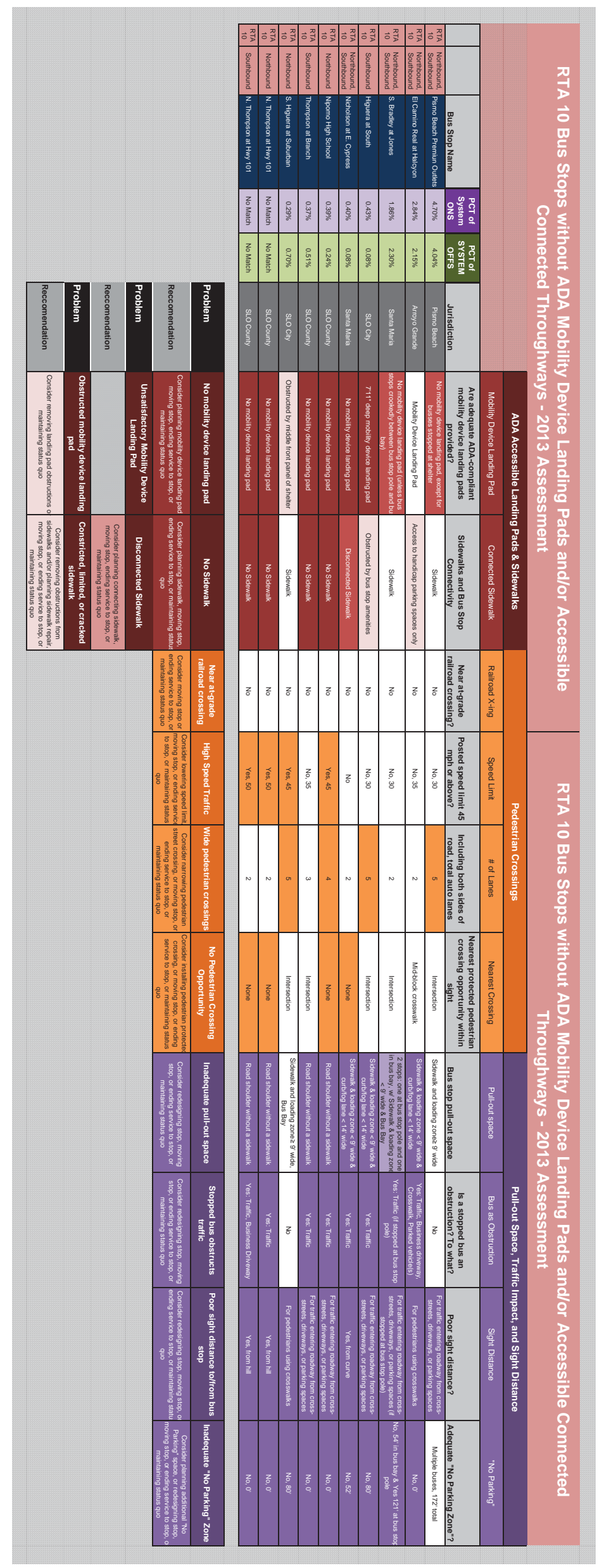




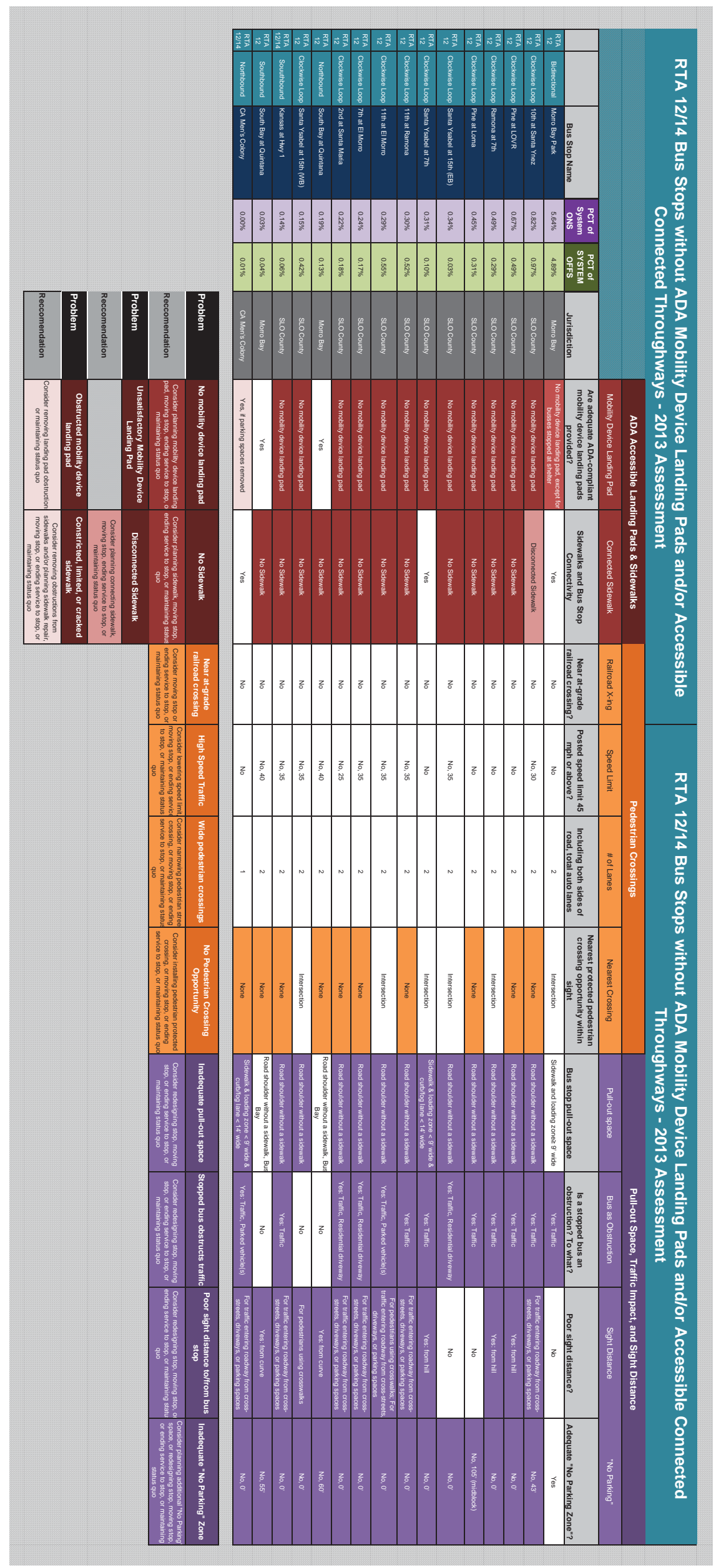




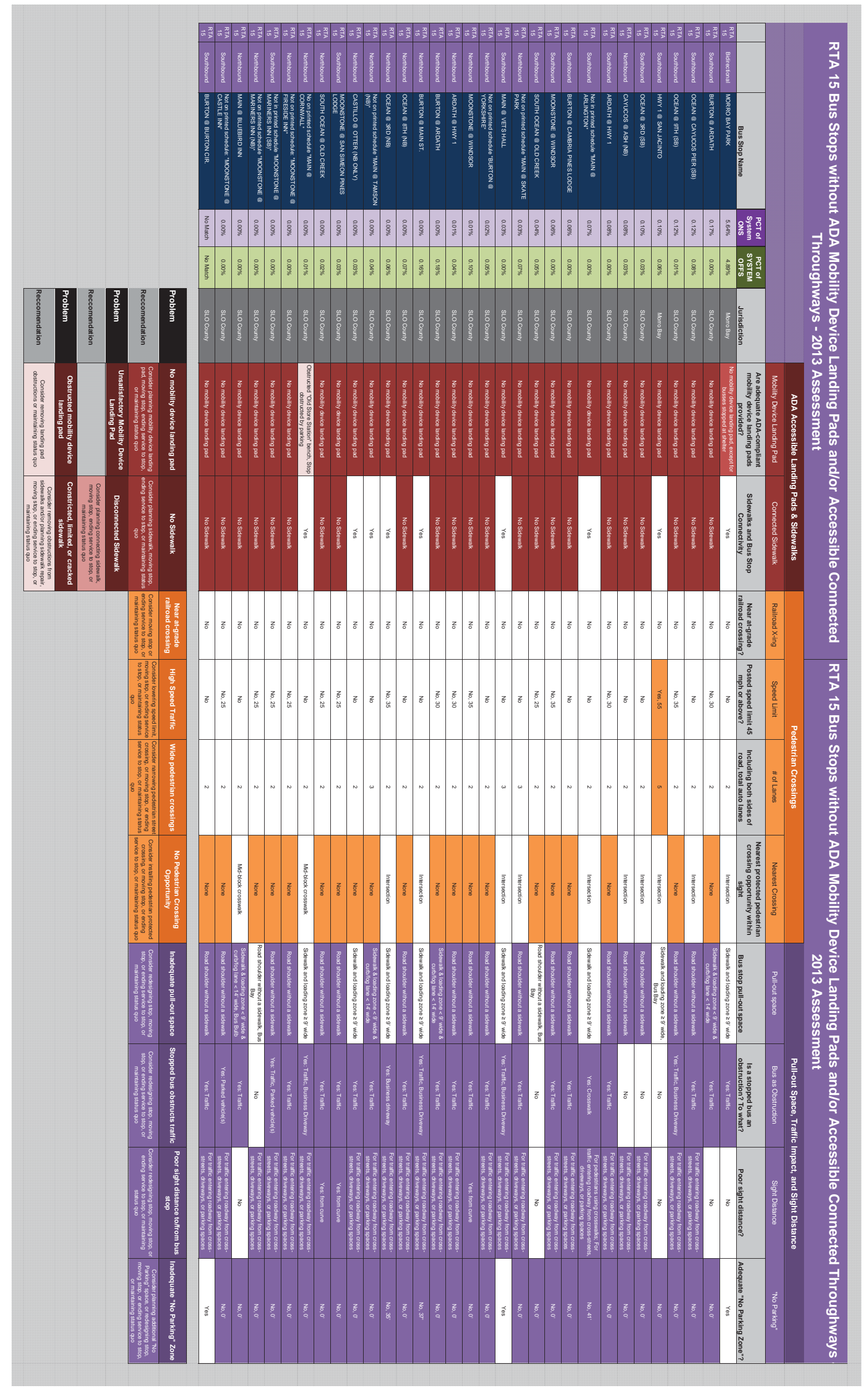




\section{APPENDIX C: Bus Stop Photo Catalog}

A comprehensive bus stop photo catalog has been created for all stops surveyed. Please contact RTA for more information. 
APPENDIX B: Draft Prioritizing RTA and Paso Express Fixed-route Bus Stop

Improvements Report 


\title{
Prioritizing RTA \& Paso Express Fixed-route Bus Stop Improvements
}

\author{
RTA Mission \\ The Mission of RTA is to provide safe, reliable and efficient transportation services that \\ improve and enhance the quality of life for the citizens and visitors of San Luis Obispo County.

\section{Goal} \\ Develop a plan to make every fixed-route bus stop served by RTA and Paso Express ADA \\ accessible, safe, convenient and comfortable for citizens and visitors of all ages and abilities, \\ including those who use mobility devices like wheelchairs, scooters, rolling luggage, and \\ strollers.
}




\section{Table of Contents}

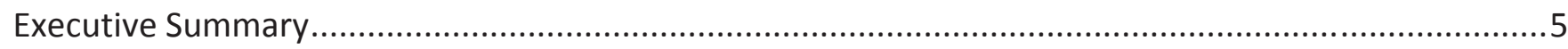

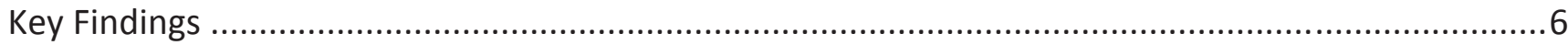

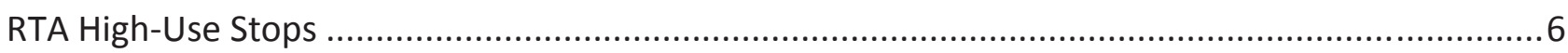

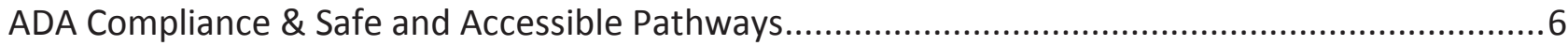

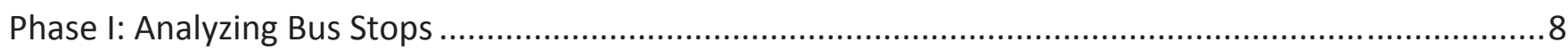

Safe and Accessible Pedestrian Crossings.................................................................................

Traffic Impact, Sight Distance, Pull-Out Space, and Safety ...............................................................10

Bus Stop Location Prioritization and Bus Pull-Out Space ................................................................ 10

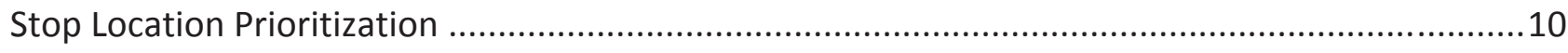

Bus Pull-Out Space: Road Operation and Safety ...................................................................11

Cost of Improvements \& Available Funding Sources ……….......................................................11

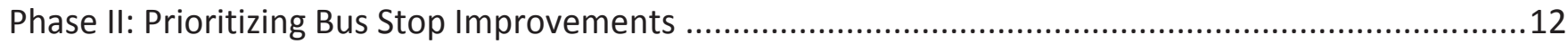

Bus Stop Improvement Prerequisite I: Mobility Device Landing Pad(s) ...........................................12

Bus Stop Improvement Prerequisite II: Safe and Accessible Pathways................................................12

Amenities to Meet Transit User Needs....................................................................................13

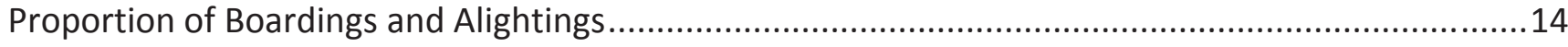

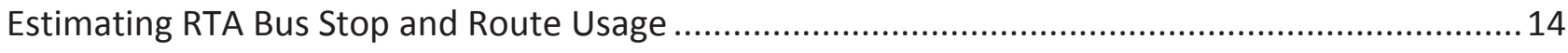

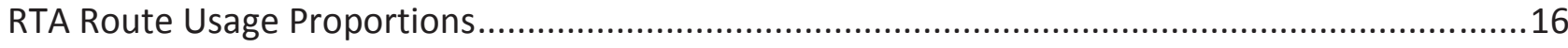

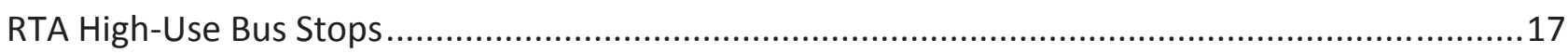

RTA Infrequently Used Bus Stops..........................................................................................

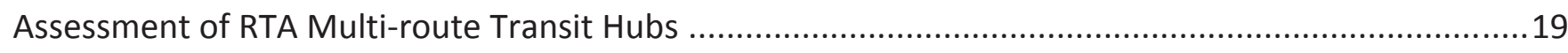

RTA Multi-Route Transit Passenger Facilities: Existing Amenities at High-Use Bus Stops.....................19

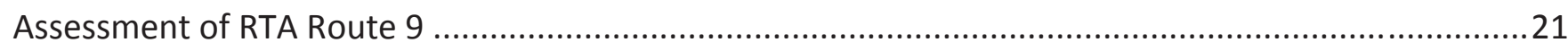

RTA Route 9 Bus Stop Usage: Proportion of Boardings and Alightings ...............................................21

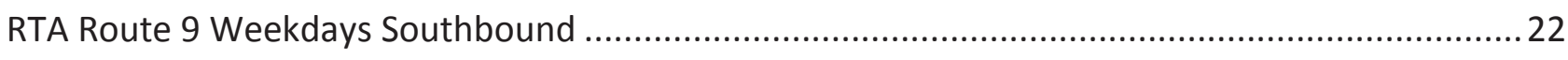

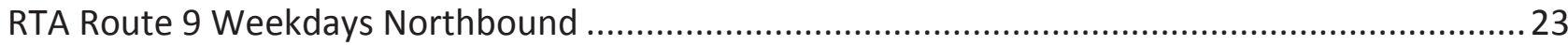




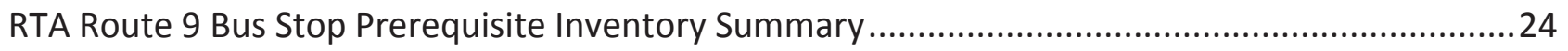

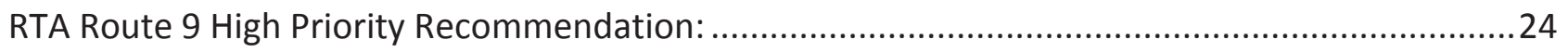

RTA Route 9 Bus Stop Prerequisites: Mobility Device Landing Pads with Safe and Accessible

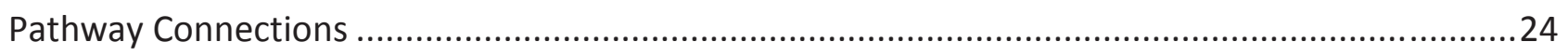

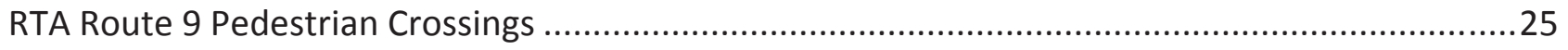

RTA Route 9 Pull-Out Space, Traffic Impact, and Sight Distance .......................................................25

RTA Route 9 Existing Amenities at High-Use Bus Stops .....................................................................26

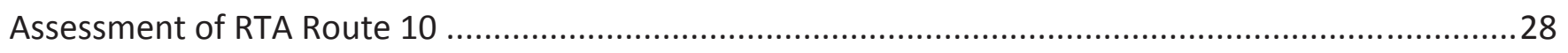

RTA Route 10 Bus Stop Usage: Proportion of Boardings and Alightings ..............................................28

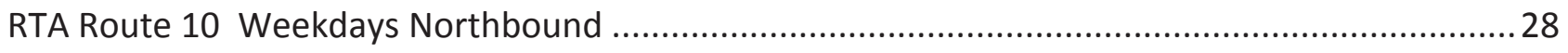

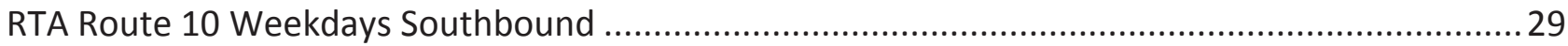

RTA Route 10 Bus Stop Prerequisite Inventory Summary ...............................................................

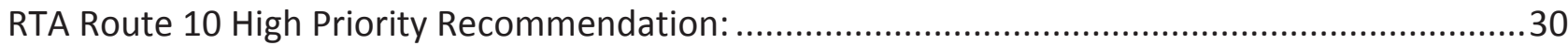

RTA Route 10 Bus Stop Prerequisites: Mobility Device Landing Pads with Safe and Accessible

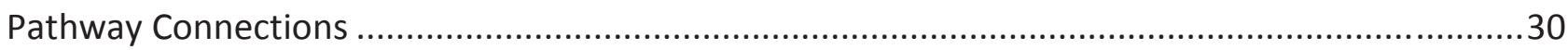

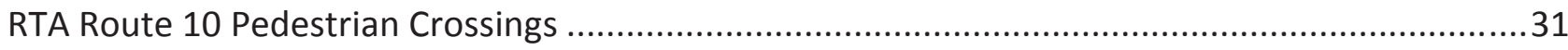

RTA Route 10 Pull-Out Space, Traffic Impact, and Sight Distance ......................................................31

RTA Route 10 Existing Amenities at High-Use Bus Stops ................................................................31

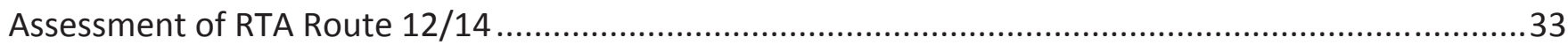

RTA Route 12/14 Bus Stop Usage: Proportion of Boardings and Alightings .......................................33

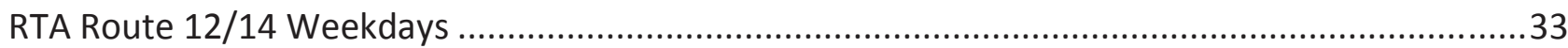

RTA Route 12/14 Bus Stop Prerequisite Inventory Summary ............................................................34

RTA Route 12/14 High Priority Recommendation:....................................................................

RTA Route 12/14 Bus Stop Prerequisites: Mobility Device Landing Pads with Safe and Accessible

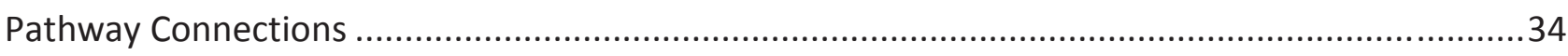

RTA Route 12/14 Pedestrian Crossings ..........................................................................................

RTA Route 12/14 Pull-Out Space, Traffic Impact, and Sight Distance ..............................................35

RTA Route 12/14 Existing Amenities at High-Use Bus Stops.................................................................35

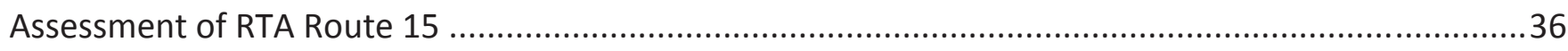


RTA Route 15 Bus Stop Usage: Proportion of Boardings and Alightings ........................................36

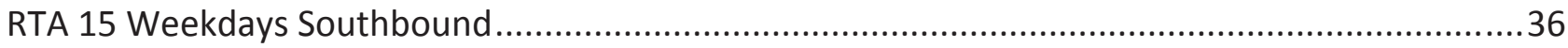

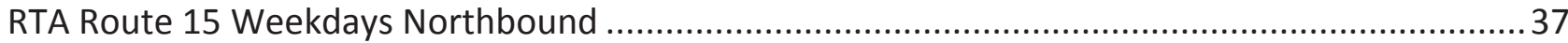

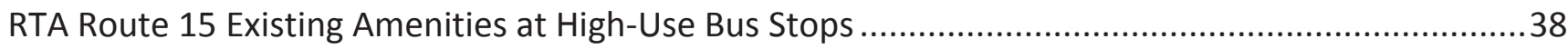

RTA Route 15 Bus Stop Prerequisite Inventory Summary ......................................................38

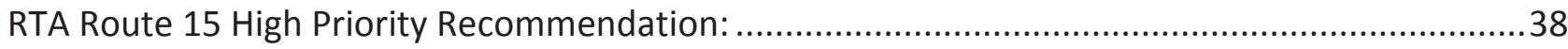

RTA Route 15 Bus Stop Prerequisites: Mobility Device Landing Pads with Safe and Accessible

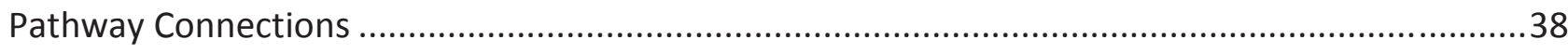

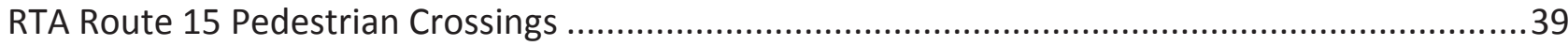

RTA Route 15 Pull-Out Space, Traffic Impact, and Sight Distance ..........................................39

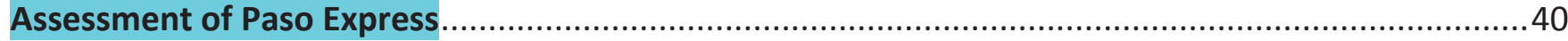

Paso Express Bus Stop Usage: Proportion of Boardings and Alighting ................................... 40

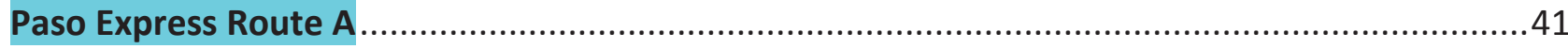

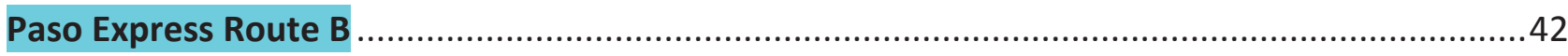

Paso Express Bus Stop Prerequisite Inventory Summary .....................................................4 43

Paso Express High Priority Recommendation:............................................................ 43

Paso Express Bus Stop Prerequisites: Mobility Device Landing Pads with Safe and Accessible

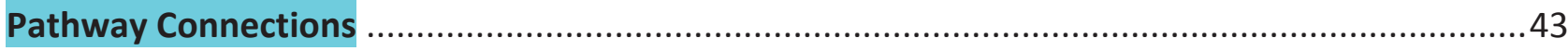

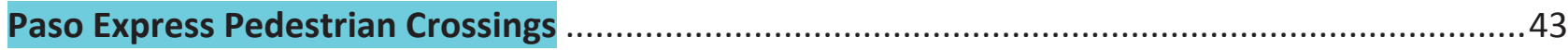

Paso Express Pull-Out Space, Traffic Impact, and Sight Distance........................................44

Paso Express Existing Amenities at High-Use Bus Stops ................................................. 44

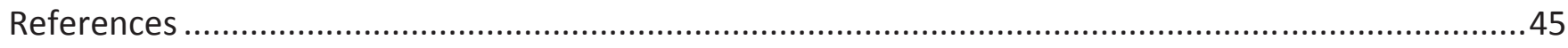

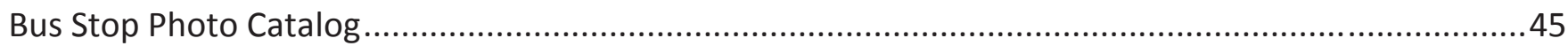

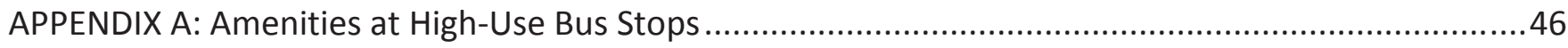

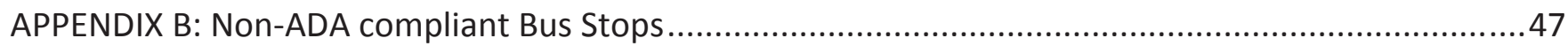




\section{Executive Summary}

To further develop a safe, reliable, and efficient transit-centric transportation system in the greater San Luis Obispo area, this report seeks to prioritize RTA and Paso Express fixed-route bus stop improvements. It is the goal of this report to ensure that, to the extent possible, every bus stop served by an RTA or Paso Express fixed-route bus is ADA accessible, safe, convenient, and comfortable for citizens and visitors of all ages and abilities, including those who use mobility devices like wheelchairs, scooters, rolling luggage, and strollers.

This report discusses existing conditions at RTA and Paso Express bus stops and presents some potential improvement options. The analysis considers safety, long-term locations, minimum ADA access requirements, access to nearby activity centers exceeding minimum ADA requirements, passenger amenities, pedestrian connections, traffic impacts, sight distance, and bus pull-out space. The report also evaluates passenger utilization by route at each bus stop, and high-use and infrequently used bus stops are categorized to help prioritize potential improvements based on demand.

Local decision-makers should keep in mind that optimal solutions, including bus stop related improvements, depend on context. Optimal bus stop location and design solutions require local jurisdictions to consider how the environment surrounding each bus stop affects the attractiveness of using public transportation. For example, passenger amenities (bench, shade, etc.) may already exist immediately adjacent to a bus stop in an urban setting, yet it might be appropriate to add ambient lighting and a passenger shelter in a rural setting. In addition, transit user characteristics (e.g., people with disabilities, seniors, mothers with young children, homeless persons, business travelers, vacationers, cyclists, etc...) may dictate that local jurisdictions consider expanded passenger amenities to attract riders. Local land uses and traffic patterns can also affect optimal bus stop placement and design. Existing nearby public amenities like shelter, seating, lighting, trash receptacles, and/or bike parking effect optimal bus stop design.

Additionally, when considering potential bus stop improvements, local decision-makers must consider financial feasibility and cost-effectiveness of potential solutions. It would be unwise to attempt to implement costly and complex urban solutions (e.g., a concrete bus pull-out, passenger shelter, and bus arrival prediction signs) at a rural bus stop that would have little chance of attracting a sufficient number of riders to justify the cost. In any case, RTA and the local officials should seek robust community input when prioritizing bus stop improvements in any given community. 
To identify existing conditions, every bus stop served by RTA was inventoried by an RTA employee from June 2013 through October 2013 September 2014. This report includes tables that summarize key findings for each fixed-route.

\section{Key Findings}

\section{RTA High-Use Stops}

- Over $75 \% 55 \%$ of RTA fixed-route boardings and alightings occur at less than $20 \% 10 \%$ of bus stops served by RTA.

- Of the approximately 125220 bus stops currently served by an RTA operated fixed-route, $z 120$ are considered high-use bus stops. High-use bus stops are defined as has having more than $1 \%$ of system-wide boardings or alightings.

- Of the five high-use multi-route transit hubs served by RTA and other fixed-route providers, three permit multiple buses to board and alight passengers simultaneously. However, only one ADA compliant landing pad is present at the Pismo Premium Outlets and Morro Bay Park passenger facilities.

- Santa Rosa @ Mustang Village \& Stenner Glen Apartments is the only high-use RTA stop used primarily for boarding that has no amenities for waiting passengers (e.g., no shelter and no seating).

- Of the 2120 high-use RTA stops: 7 do not have RTA bus stop signs, 2 do not have RTA information kiosks, and 13 do not have Braille pads. Only nine have bike racks. Three do not have trash receptacles.

\section{ADA Compliance \& Safe and Accessible Pathways}

- To meet minimum ADA requirements, fixed-route bus stops must have a mobility device landing pad that is a firm and stable surface at least $5^{\prime}$ wide by $8^{\prime}$ deep (with no greater than a $2 \%$ slope) that connects to an accessible route.

- Of the approximately 125220 bus stops served by RTA and Paso Express fixed-routes, 77111 bus stops (greater than $60 \%$ 45\%) lack an acceptable mobility device landing pad. 
- A total of 4961 bus stops served by RTA or Paso Express fixed-routes do not connect to nearby sidewalks.

- Regarding safe pedestrian crossings, out of the 77104 ADA non-compliant bus stops, 2 are adjacent to an at-grade railroad crossing, 1019 are adjacent to streets with speed limits greater than 45 mph or greater, 314 are adjacent to roadways with 4 or more lanes, and 3849 do not have a labeled pedestrian crossing within sight. Obviously, RTA fixed-routes operate on many corridors with $45 \mathrm{mph}$ or greater speed limits and no feasible adjacent travel options. As such, RTA must work closely with local jurisdictions when considering the placement of and improvements to bus stops. Nonetheless, transit authorities have been held liable for incidents involving transit users crossing busy streets while accessing bus stops that the agency knew or should have known caused their riders to face unacceptable risks. The Darlene Bonanno v. Central Contra Costa Transit Authority case is discussed in this report. 


\section{Phase I: Analyzing Bus Stops}

For RTA to offer ADA accessible, safe, convenient and comfortable fixed-route transit services to users and residents of all ages and abilities, riders should be able to safely access all fixed-route bus stops and safely board and alight at every fixed-route bus stop. To access the bus stop safely, mobility device users require a safe and accessible pathway (ideally, a sidewalk separated from rail, high-speed automobile, and bicycle traffic) that connects the bus stop to surrounding transit trip generators. To safely board and alight a bus, mobility device users require an ADA compliant mobility device landing pad at least five feet wide and eight feet deep positioned adjacent to the front door of a stopped bus.

Prior to investing in fixed-route bus stop improvements (i.e., mobility device landing pads with safe and accessible pathways to local developments), RTA and local jurisdiction officials must evaluate existing conditions at the bus stop and develop a realistic improvement plan.

\section{Minimum ADA Requirements:}

Minimum ADA requirements for bus stops according to ADA Accessibility Guidelines for Buildings and Facilities (ADAAG) Section 10 are below ${ }^{1}$ :

\section{Minimum ADA Requirements}

Providing accessible bus stops requires choosing appropriate locations or improving the existing location. Coordination and cooperation with public works agencies, municipal government and business owners can enhance the connectivity between the land use and the bus stop. To ensure optimum bus stop placement, coordination should occur during the planning/development phase.

Bus stop sites must have the following:

- A firm, stable surface;

- A minimum clear length of 96 inches (eight feet), measured from the curb or vehicle roadway edge and a minimum clear width of 60 inches (five feet), measured parallel to the vehicle roadway;

- A maximum slope of 1:50 (2\%) for water drainage; and

- $\quad$ Connection to streets, sidewalks or pedestrian paths by an accessible route. 


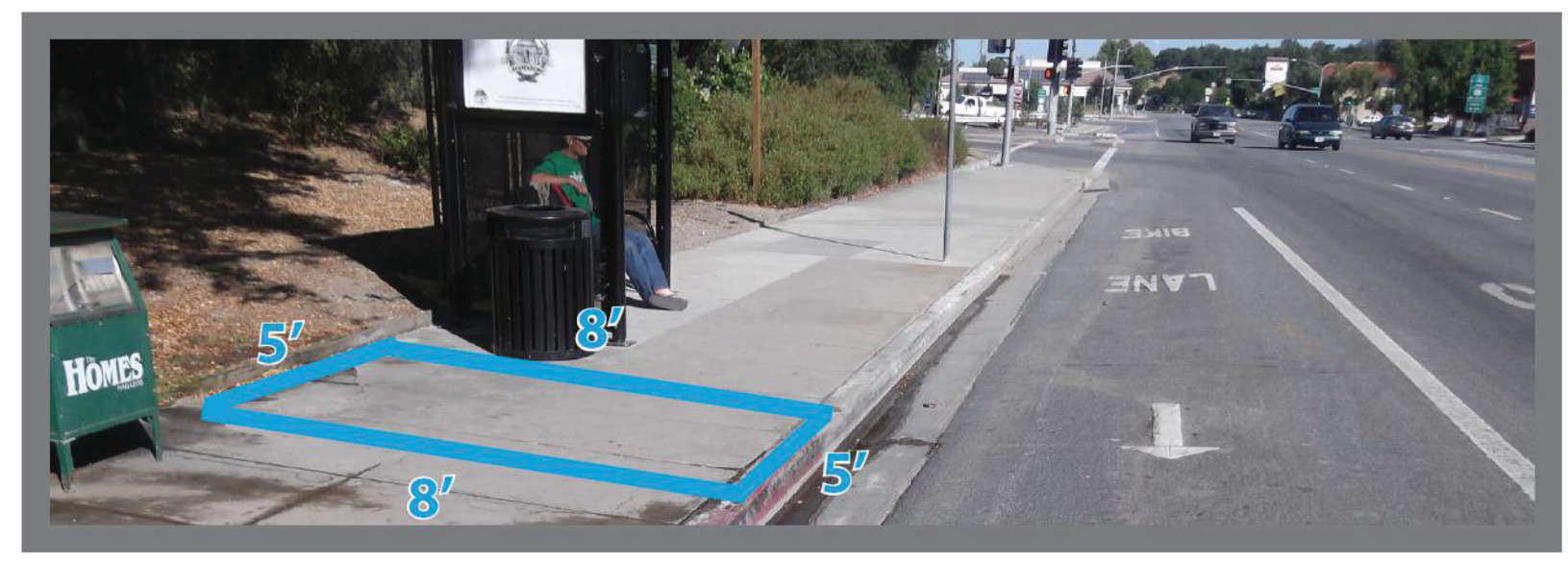

Minimum dimensions of a mobility device landing pad

\section{Safe and Accessible Pedestrian Crossings}

The provision of accessible and safe pedestrian crossings that connect bus stops to nearby pedestrian paths of travel is essential to ensure transit user safety. Factors like proximity to railroad crossings, speed limits on adjacent streets, width of adjacent roadways and proximity to protected pedestrian crossings are important to transit user safety.

Transit authorities have been held liable for passenger incidents involving transit users crossing streets to access bus stops. For example, in 1993, while on her way to a bus stop, Darlene Bonanno entered a crosswalk at a 3-leg intersection that had no traffic controls for through traffic, and she was struck by a car and seriously injured. Ms. Bonanno sued the driver of the car that struck her, as well as the Central Contra Costa Transit Authority (CCCTA), Contra Costa County, and entities that treated her after the accident. In 1999, the Supreme Court of California found CCCTA and Contra Costa County each $1 \%$ liable. All parties except for CCCTA settled outside of court. CCCTA was ultimately held liable for over $\$ 1.5$ million dollars. ${ }^{3}$

Prior to Ms. Bonanno being struck, there were indicators that accessing this particular bus stop was hazardous. In 1986, on her way to the same bus stop and crossing the same street (although midblock, not at the intersection) as Ms. Bonanno, Kimberly Chittock was struck by a car and killed. In 1987, 15 students complained that it was too dangerous to cross the same street to access the same bus stop. Later in 1987, Contra Costa County installed traffic signals with pedestrian push buttons at an intersection about 500 feet away from the bus stop. Although 
pedestrians could now cross the street safely, the route to the bus stop was still hazardous, since it was not relocated to better access the safe street crossing. ${ }^{3}$

Safe crossings for transit users should be considered when developing a transit bus stop improvement plan.

\section{Traffic Impact, Sight Distance, Pull-Out Space, and Safety}

Ideally, a stopped bus does not unduly obstruct traffic or impair sight distance for nearby pedestrians or drivers. An ideal bus stop also affords space that allows buses to easily enter the bus-loading zone while decelerating, stop parallel to the bus-loading zone, and safely accelerate when exiting the bus-loading zone. Additionally, an ideal bus stop provides ample space around a parked bus for passengers to safely enter and exit the stop and/or load or remove bikes from racks. It is also important for busses to be able to adequately reenter traffic after servicing a bus stop. Obviously, it would not be feasible - or even advisable - to provide a bus pull-out at every bus stop in San Luis Obispo County. Furthermore, in many instance, a bus bulb may be preferable to a bus pull-out. Local decision-makers must decide if the surrounding uses, traffic levels, sightlines, etc. warrant such a complex and costly solution.

\section{Bus Stop Location Prioritization and Bus Pull-Out Space}

The first step to prioritize bus stop improvements is to determine if current bus stop locations are optimal. Prior to prioritizing bus stop improvements, consensus should be reached by RTA and local jurisdiction officials regarding planned new or improved fixed-route bus stop locations. Factors to consider when identifying, evaluating, and selecting bus stop locations include:

\section{Stop Location Prioritization}

- Comfort, and convenience for transit route passengers (e.g., travel time, distance, out of direction travel, and cost)

- Accessibility, safety, comfort, and convenience of bus stops and pathway connections to adjacent developments

- Context sensitivity of bus stop with surrounding environment 


\section{Bus Pull-Out Space: Road Operation and Safety}

- Effects of stopped bus on adjacent traffic and sight distance

- Ability of bus to decelerate to, stop at, and accelerate from bus stop

- Adequateness of space around stopped busses for transit user safety

\section{Cost of Improvements \& Available Funding Sources}

RTA does not own any bus stops or adjacent land, so improvements to bus stops and surrounding areas typically requires partnerships with other agencies and/or adjacent property owners. This should be considered when evaluating potential new bus stop locations and estimating improvement costs related to a bus stop (e.g., expected grant availability and expected improvements along the RTA Route 9 in south Atascadero and the RTA Route 10 in Nipomo). 


\section{Phase II: Prioritizing Bus Stop Improvements}

Once consensus of long-range bus stop locations has been reached by RTA and local jurisdiction officials, the next step is to prioritize stop improvements. This report seeks to prioritize installation of ADA accessible mobility device landing pads, safe and accessible connecting pathways, and passenger amenities that meet transit user needs. Factors to consider when prioritizing bus stop improvements include:

- Presence of mobility device landing pads

- Presence accessible pathways between the bus stop and nearby transit trip generators

- Presence of passenger amenities not required by ADA but are important for generating ridership. These amenities include safe pathways, benches, shelters, lighting, bicycle parking and passenger information

- Proportion of boardings and alightings in relationship to the RTA system as a whole.

- Potential use by school buses and other forms of shared-ride transportation

- Jurisdictional control of the bus stop

- Cost to install ADA mobility device landing pad at stop (if not already provided)

- Cost to install accessible pathways connecting to the bus stop (if not already provided)

- Cost to install amenities not required by ADA

\section{Bus Stop Improvement Prerequisite I: Mobility Device Landing Pad(s)}

If a fixed-route bus stop does not have a mobility device landing pad, by ADA requirements, RTA should not implement improvements to the bus stop before one is installed (or planned). Repair, replacement, and updated transit user information are exempt from this recommendation.

\section{Bus Stop Improvement Prerequisite II: Safe and Accessible Pathways}

This document defines safe and accessible pathways between the bus stop and nearby transit trip generators as an RTA bus stop planning prerequisite. It should be noted that ADA only requires a compliant mobility device landing pad that connects to any type of accessible pathway 
(e.g., an accessible but busy street). If a fixed-route bus stop is not connected to an accessible pathway, by ADA requirements, no improvements should implemented by RTA to the bus stop before an accessible pathway is installed (or planned).

\section{Amenities to Meet Transit User Needs}

On March 3rd, 2010, RTA staff proposed minimum standards for amenities that will create "safe, clean, comfortable, accessible stops with amenities that attract and retain customers" to the RTA Board of Directors. These are the minimum bus stop standards as proposed in 2010:

- All RTA bus stops will include a bus stop sign and information kiosk.

- Bus stops that have at least fifteen (15) boardings per day shall include a bus bench and trash receptacle.

- Bus stops that have at least twenty-five (25) boardings per day shall include a 13-foot passenger shelter with solar lighting or sufficient ambient light and a bike rack or bike locker.

- Bus stops that have at least forty (40) boardings per day shall include a 16-foot passenger shelter with solar lighting or sufficient ambient light and all amenities as noted above.

- New bus stops may also include a passenger shelter based upon the local jurisdiction requirements for new commercial or residential development in the corridor.

- RTA staff will work with local jurisdiction staff to incorporate local design requirements and develop a process for providing conditions to new commercial or residential development in the corridor.

- RTA staff will also work with the local arts councils on the development of an "Arts@Stops" program where local artists could incorporate their artwork at bus stops, as appropriate. 
Re-evaluating these standards may be a worthwhile exercise. Factors to consider when prioritizing bus stops amenities include:

- Presence of bus stop sign and information kiosk.

- Presence of other amenities (e.g. seating, shelter, bike storage, trash, Braille pads).

- Passenger boarding proportion ranking (boarding passengers typically wait at stops, while alighting passengers rarely dwell at a bus stop).

- Typical wait times of users at bus stops.

- Travel characteristics of transit users at bus stops (e.g., mobility device users, people with disabilities, cyclists, etc.).

- Environment surrounding bus stop (e.g., adjacent land use, shelter, shade, lighting, interaction with sun, wind, and water, bike lanes, trash, public art, etc.).

- Number of seats needed at bus stops, based on typical passenger activity.

- Number of bike racks needed at bus stops.

From a purely liability avoidance perspective, implementing new passenger amenities at bus stops should not be considered unless the bus stop meets minimum ADA requirements, especially if new amenities significantly alter the built or natural environment.

\section{Proportion of Boardings and Alightings}

The majority of RTA passenger trips are provided during weekday commute hours, so this analysis uses boarding and alighting (on/off) data collected on weekdays to prioritize improvements. If other overarching needs of community members suggest that certain bus stops should receive special consideration, then local officials could alter the priority to meet those needs. For example, construction of a low-income and/or accessible housing project adjacent to a deficient bus stop could warrant special consideration to meet community member needs.

\section{Estimating RTA Bus Stop and Route Usage}

To estimate proportion of weekday "ons/offs" for stops served by RTA and Paso Express fixedroutes, a two useful data sources exist: 
1) In mid-April 2010, RTA collected "on/off" data over five consecutive weekdays along RTA routes.

2) As part of the 2012 SLOCOG North County Transit Plan", during Tuesday May 3 and Wednesday May 4, 2011, Nelson\Nygaard conducted on-board surveys along RTA Route 9, North County Shuttle, and Paso Express routes (to be comparable to the data collected by RTA in 2010, this data has been extrapolated to represent five consecutive weekdays).

This report uses the above-mentioned data sources to calculate percentages of boardings and alightings along each RTA and Paso Express route and at each RTA and Paso Express bus stop in relationship to the entire fixed-route system operated by RTA. This report uses the data collected in 2010 by RTA as the usage data for the RTA routes, and because the RTA Route 9 that became effective on June 1,2014 serves stops previously served by the North County Shuttle, North County Shuttle usage data collected in 2011 by Nelson\Nygaard has been added to the RTA Route 9 usage data. This report also uses the 2011 Nelson\Nygaard data as the usage data for the Paso Express Routes.

This report also uses the data mentioned above to conclude that, in 2010 and 2011, approximately 11,843 boardings and 11,766 alightings could be expected to have occured on the fixed-route transit system operated by RTA (i.e. RTA and Paso Express) during a typical work, and this assumption is used to calculate the proportion of boardings and alightings for each RTA and Paso Express route and at each RTA and Paso Express bus stop in relationship to the entire fixed-route system operated by RTA.

The tables in APPENDIX A show the "on/off" transit user usage data collected for all RTA and Paso Express bus stops and routes. This data was used to create the tables used throughout this report. 


\section{RTA Route Usage Proportions}

Proportions of passengers per RTA route are summarized in the table below.

Route Proportions After to June $1^{\text {st }}, 2014$ Configuration

\begin{tabular}{|l|c|c|}
\hline & $\begin{array}{c}\text { PCT of } \\
\text { System } \\
\text { ONS }\end{array}$ & $\begin{array}{c}\text { PCT of } \\
\text { System } \\
\text { OFFS }\end{array}$ \\
\hline RTA 9 Weekdays & $34 \%$ & $35 \%$ \\
\hline RTA 10 Weekdays & $26 \%$ & $26 \%$ \\
\hline RTA 12 Weekdays & $26 \%$ & $25 \%$ \\
\hline Paso Express Weekdays & $12 \%$ & $12 \%$ \\
\hline RTA 15 Weekdays & $2 \%$ & $2 \%$ \\
\hline Total (Check for correctness) & $100 \%$ & $100 \%$ \\
\hline
\end{tabular}

Route Proportions Prior to June $1^{\text {st }}, 2014$

\begin{tabular}{|l|c|c|}
\cline { 2 - 3 } & $\begin{array}{c}\text { PCT of } \\
\text { System } \\
\text { ONS }\end{array}$ & $\begin{array}{c}\text { PCT of } \\
\text { System } \\
\text { OFFS }\end{array}$ \\
\hline RTA 10 Weekdays & $33 \%$ & $33 \%$ \\
\hline RTA 9 Weekdays & $32 \%$ & $33 \%$ \\
\hline RTA 12 Weekdays & $32 \%$ & $32 \%$ \\
\hline RTA 15 Weekdays & $2 \%$ & $2 \%$ \\
\hline Total (Check for correctness) & $100 \%$ & $100 \%$ \\
\hline
\end{tabular}




\section{RTA High-Use Bus Stops}

A table summarizing high use bus stops (i.e., bus stops with greater than $1 \%$ of the total RTA system boardings or alightings during the study period) is shown below. Notably, of the approximately 125220 bus stops served by RTA fixed-route buses, over 77\% 55\% of both boardings and alightings take place at the 2120 bus stops listed below.

Where bus stops have moved or been renamed since "on/off” data was collected in 2010 or 2011, names of stops serviced in 2014 nearest the discontinued 2010/11 stops are indicated in parentheses.

PCT of System ONS $\geq 1 \%$

PCT of System OFFS $\geq 1 \%$

\begin{tabular}{|l|r|r|}
\hline High-Use Stops & \multicolumn{1}{c|}{ Ons } & \multicolumn{1}{c|}{ Offs } \\
\hline Government Center & $19.58 \%$ & $17.44 \%$ \\
\hline Pine at 8th (North County Transportation Center) (Train Station) & $6.48 \%$ & $6.71 \%$ \\
\hline Cuesta College & $5.35 \%$ & $2.46 \%$ \\
\hline Morro Bay Park & $4.48 \%$ & $3.87 \%$ \\
\hline Atascadero Transit Center & $4.37 \%$ & $5.31 \%$ \\
\hline Cal Poly Kennedy Library (NB) & $3.84 \%$ & $0.96 \%$ \\
\hline Pismo Prime Outlets & $3.74 \%$ & $3.20 \%$ \\
\hline Town Center Mall (Santa Maria Transit Center) & $2.89 \%$ & $2.56 \%$ \\
\hline Halcyon Park and Ride & $2.26 \%$ & $1.70 \%$ \\
\hline Foothill @ Casa (NB) (Santa Rosa @ Mustang Village @ Stnr Glen Apts.) & $2.15 \%$ & $0.22 \%$ \\
\hline Las Tablas Park and Ride & $1.82 \%$ & $1.67 \%$ \\
\hline E. Grand @ El Camino Real & $1.52 \%$ & $2.15 \%$ \\
\hline Alan Hancock College (S. Bradley at Jones) & $1.48 \%$ & $1.82 \%$ \\
\hline Tefft St. @ Carillo St. (NB) & $1.38 \%$ & $0.67 \%$ \\
\hline ECR at Hwy (Carwash) & $1.10 \%$ & $0.18 \%$ \\
\hline Cal Poly Kennedy Library (SB) & $0.07 \%$ & $1.74 \%$ \\
\hline Cal Poly Performing Arts Center (SB) & $0.06 \%$ & $1.61 \%$ \\
\hline Spring at 34th (SB) & $0.25 \%$ & $1.47 \%$ \\
\hline Foothill @ Casa (SB) (Santa Rosa @ Foothill) & $0.08 \%$ & $1.42 \%$ \\
\hline Monterey @ Grand & $0.02 \%$ & $1.11 \%$ \\
\hline Total & $62.93 \%$ & $58.27 \%$ \\
\hline
\end{tabular}


Transit users typically spend more time at the bus stop when boarding because they wait at the bus stop for the bus to arrive; alighting passengers typically leave the bus stop upon exiting the bus (unless they are waiting to transfer to another bus or waiting to be picked up by a friend or relative). Transit user wait time and appropriate bus stop waiting amenities should be taken into consideration when planning and prioritizing bus stop improvements based on passenger activity.

Existing amenities beyond minimum ADA requirements for high use stops are shown in the table in APPENDIX A.

\section{RTA Infrequently Used Bus Stops}

A table summarizing infrequently used bus stops (i.e., bus stops with no recorded boardings or alightings during the study period) is presented below.

\begin{tabular}{|l|c|c|}
\hline Unused Stops & ON & OFF \\
\hline Moonstone @ Castle Inn & 0 & 0 \\
\hline Moonstone @ Mariner's Inn (SB) & 0 & 0 \\
\hline Main @ Jamaica & 0 & 0 \\
\hline Main @ Bluebird Inn & 0 & 0 \\
\hline Moonstone @ Mariner's Inn (NB) & 0 & 0 \\
\hline Moonstone @ Firesiede Inn & 0 & 0 \\
\hline Rambouillet at Nicklaus & 0 & 0 \\
\hline Rambouillet at Wade & 0 & 0 \\
\hline
\end{tabular}

RTA staff recommends considering ending service to these bus stops. 


\section{Assessment of RTA Multi-route Transit Hubs}

\section{RTA Multi-Route Transit Passenger Facilities: Existing Amenities at High-Use Bus Stops}

Of the 20 high-use bus stops listed in the previous section, 56 are served by multiple RTA fixedroutes, as follows:

- Government Center is served by RTA Route 9, RTA Route 10, and RTA Routes 12/14.

The North County Transportation Center is served by RTA Route 9 and the Paso Express

- Morro Bay Park is served by RTA Route 12 and RTA Route 15.

- Cal Poly Kennedy Library NB is served by RTA Route 9NB, RTA Route 12NB and RTA Route 10x.

- Santa Rosa at Mustang Village \& Stenner Glen Apartments is served by RTA Route 9NB and RTA Route 12/14NB.

- $\quad$ Santa Rosa at Foothill is served by RTA Route 9SB and RTA Route 12/14SB.

The table in APPENDIX A summarizes amenities and limitations at these high-use multi-route transit passenger facilities served by RTA:

- The Santa Rosa at Mustang Village bus stop is the only high-use bus stop that lacks amenities for waiting passengers (i.e., no shelter and no seating).

- All six high-use passenger facilities have at least one ADA compliant mobility device landing pad and safe and accessible sidewalks and/or routes connecting the bus stop to nearby developments.

- At Pismo Premium Outlets and Morro Bay Park high-use passenger facilities, multiple buses stop simultaneously, but only one ADA compliant landing pad is present. These highuse passenger facilities lack sufficient space to simultaneously board or alight mobility devices from more than one bus at a time. 
- Cal Poly Kennedy Library NB is the only high-use passenger facility that lacks an RTA bus stop sign.

- All five six high-use passenger facilities have RTA information kiosks.

- All five six high-use passenger facilities have sufficient lighting.

- Only the North County Transportation Center, Government Center and Morro Bay Park high-use passenger facilities have bike racks.

- Only Cal Poly Kennedy Library NB and Santa Rosa at Foothill high-use passenger facilities are directly connected to designated bike lanes.

- Government Center is the only high-use passenger facility with a Braille pad.

- Santa Rosa at Mustang Village and Santa Rosa at Foothill are the only high-use passenger facilities without a trash receptacle.

Existing amenities at high-use bus stops served by single RTA routes are discussed in the next sections. 


\section{Assessment of RTA Route 9}

RTA Route 9 Bus Stop Usage: Proportion of Boardings and Alightings 


\section{RTA Route 9 Weekdays Southbound}

\begin{tabular}{|c|c|c|c|c|c|}
\hline \multirow{2}{*}{$\begin{array}{l}9 \text { Weekday Southbound } \\
\text { WEEKDAY TOTALS } \\
\text { (After June 1st, 2014) }\end{array}$} & \multicolumn{2}{|c|}{ TOTAL } & \multirow{2}{*}{$\begin{array}{l}\text { Total } \\
\text { Stop } \\
\text { Activity } \\
\end{array}$} & \multirow{2}{*}{$\begin{array}{l}\text { PCT of } \\
\text { System } \\
\text { ONS }\end{array}$} & \multirow{2}{*}{$\begin{array}{l}\text { PCT of } \\
\text { System } \\
\text { OFFS }\end{array}$} \\
\hline & ON & OFF & & & \\
\hline Pine at 8th & 455 & 115 & 569 & $3.84 \%$ & $0.97 \%$ \\
\hline Atascadero Transit Center & 450 & 69 & 519 & $3.80 \%$ & $0.58 \%$ \\
\hline Las Tablas Park and Ride & 198 & 16 & 214 & $1.67 \%$ & $0.13 \%$ \\
\hline ECR at Hwy 41 (Carwash) & 131 & 21 & 152 & $1.10 \%$ & $0.18 \%$ \\
\hline ECR at Encina & 86 & 62 & 148 & $0.73 \%$ & $0.53 \%$ \\
\hline ECR at Encina & 86 & 62 & 148 & $0.73 \%$ & $0.53 \%$ \\
\hline ECR at El Bordo (Post Office) & 72 & 31 & 103 & $0.61 \%$ & $0.26 \%$ \\
\hline Viejo Camino at Bocina & 59 & 53 & 112 & $0.50 \%$ & $0.45 \%$ \\
\hline ECR at Maple & 48 & 23 & 71 & $0.41 \%$ & $0.20 \%$ \\
\hline Mission at 14th & 44 & 0 & 44 & $0.37 \%$ & $0.00 \%$ \\
\hline ECR at Plata (Glen Oaks Plaza) & 41 & 15 & 56 & $0.35 \%$ & $0.12 \%$ \\
\hline ECR at Patria Circle & 29 & 15 & 44 & $0.24 \%$ & $0.13 \%$ \\
\hline Target Shopping Center & 28 & 18 & 45 & $0.23 \%$ & $0.15 \%$ \\
\hline ECR at Rosario & 25 & 3 & 28 & $0.21 \%$ & $0.02 \%$ \\
\hline Viejo Camino at Santa Barbara & 23 & 13 & 36 & $0.19 \%$ & $0.11 \%$ \\
\hline ECR at Del Rio (Mission Oaks Plaza) & 23 & 10 & 33 & $0.19 \%$ & $0.08 \%$ \\
\hline ECR at Pueblo & 17 & 18 & 35 & $0.14 \%$ & $0.15 \%$ \\
\hline ECR at San Benito & 15 & 13 & 28 & $0.13 \%$ & $0.11 \%$ \\
\hline ECR at Entrada & 15 & 13 & 28 & $0.13 \%$ & $0.11 \%$ \\
\hline Twin Cities Hospital & 15 & 5 & 20 & $0.13 \%$ & $0.04 \%$ \\
\hline ECR at Cynthia (Kennedy Club) & 13 & 3 & 15 & $0.11 \%$ & $0.02 \%$ \\
\hline ECR at Santa Rosa (Miner's Hardware) & 10 & 3 & 13 & $0.08 \%$ & $0.02 \%$ \\
\hline ECR at Santa Margarita (County Care) & 9 & 7 & 16 & $0.08 \%$ & $0.06 \%$ \\
\hline Cal Poly Library (SB) & 8 & 205 & 213 & $0.07 \%$ & $1.74 \%$ \\
\hline ECR at San Anselmo (Lutheran Church) & 8 & 5 & 13 & $0.06 \%$ & $0.04 \%$ \\
\hline ECR at Curbaril (Albertson's) & 8 & 5 & 13 & $0.06 \%$ & $0.04 \%$ \\
\hline ECR at Del Rio (Mission Oaks Plaza) & 8 & 0 & 8 & $0.06 \%$ & $0.00 \%$ \\
\hline Cal Poly PAC (SB) & 7 & 189 & 196 & $0.06 \%$ & $1.61 \%$ \\
\hline ECR at Maria & 6 & 11 & 17 & $0.05 \%$ & $0.09 \%$ \\
\hline Cuesta College North & 5 & 113 & 118 & $0.04 \%$ & $0.96 \%$ \\
\hline Foothill at Casa (SB) (Santa Rosa at Foothill) & 5 & 65 & 70 & $0.04 \%$ & $0.55 \%$ \\
\hline Main at 6th (no longer served) & 5 & 20 & 25 & $0.04 \%$ & $0.17 \%$ \\
\hline ECR at Carmel & 5 & 7 & 12 & $0.04 \%$ & $0.06 \%$ \\
\hline Main at 1st (no longer served) & 5 & 5 & 10 & $0.04 \%$ & $0.04 \%$ \\
\hline Creston @ Melody & 5 & 0 & 5 & $0.04 \%$ & $0.00 \%$ \\
\hline Paloma Park (no longer served) & 5 & 0 & 5 & $0.04 \%$ & $0.00 \%$ \\
\hline ECR at Pine (Garden Farms) & 3 & 10 & 13 & $0.03 \%$ & $0.08 \%$ \\
\hline ECR at Viejo Camino (no longer served) & 3 & 8 & 11 & $0.03 \%$ & $0.07 \%$ \\
\hline ECR at Atalaya & 3 & 13 & 15 & $0.02 \%$ & $0.11 \%$ \\
\hline Las Tablas at Posada (no longer served) & 3 & 8 & 10 & $0.02 \%$ & $0.06 \%$ \\
\hline ECR at San Anselmo (Kmart) & 3 & 5 & 8 & $0.02 \%$ & $0.04 \%$ \\
\hline Monterey at Grand & 2 & 131 & 133 & $0.02 \%$ & $1.11 \%$ \\
\hline Government Center & 0 & 603 & 603 & $0.00 \%$ & $5.12 \%$ \\
\hline ECR at Santa Cruz (no longer served) & 0 & 15 & 15 & $0.00 \%$ & $0.13 \%$ \\
\hline Spring at 4th & 0 & 10 & 10 & $0.00 \%$ & $0.08 \%$ \\
\hline \multirow[t]{2}{*}{ Spring at 6th (no longer served) } & 0 & 3 & 3 & $0.00 \%$ & $0.02 \%$ \\
\hline & 1983 & 2011.5 & 3995 & $17 \%$ & $17 \%$ \\
\hline
\end{tabular}




\section{RTA Route 9 Weekdays Northbound}

\begin{tabular}{|c|c|c|c|c|c|}
\hline \multirow{2}{*}{$\begin{array}{l}9 \text { Weekday Northbound } \\
\text { WEEKDAY TOTALS } \\
\text { (After June 1st, 2014) }\end{array}$} & \multicolumn{2}{|c|}{ TOTAL } & \multirow{2}{*}{$\begin{array}{l}\text { Total } \\
\text { Stop } \\
\text { Activity }\end{array}$} & \multirow{2}{*}{$\begin{array}{l}\text { PCT of } \\
\text { System } \\
\text { ONS }\end{array}$} & \multirow{2}{*}{$\begin{array}{r}\text { PCT of } \\
\text { System } \\
\text { OFFS }\end{array}$} \\
\hline & ON & OFF & & & \\
\hline Government Center & 780 & 0 & 780 & $6.59 \%$ & $0.00 \%$ \\
\hline Cal Poly Library (NB) & 239 & 30 & 269 & $2.02 \%$ & $0.25 \%$ \\
\hline Pine at 8th & 168 & 500 & 668 & $1.42 \%$ & $4.25 \%$ \\
\hline Cal Poly Pac (NB) & 106 & 12 & 118 & $0.90 \%$ & $0.10 \%$ \\
\hline Cuesta College North & 95 & 0 & 95 & $0.80 \%$ & $0.00 \%$ \\
\hline Atascadero Transit Center & 68 & 381 & 449 & $0.57 \%$ & $3.23 \%$ \\
\hline Viejo Camino at Bocina (Bordeaux Apts) & 63 & 109 & 172 & $0.53 \%$ & $0.93 \%$ \\
\hline Monterey at Peach Tree Inn & 56 & 5 & 61 & $0.47 \%$ & $0.04 \%$ \\
\hline ECR at Encina & 50 & 69 & 119 & $0.42 \%$ & $0.59 \%$ \\
\hline Foothill at Casa (NB) (Santa Roas at Mstng / Stnr Glen) & 39 & 6 & 45 & $0.33 \%$ & $0.05 \%$ \\
\hline Theatre at Theatre & 35 & 20 & 55 & $0.30 \%$ & $0.17 \%$ \\
\hline ECR at Palomar & 32 & 61 & 93 & $0.27 \%$ & $0.51 \%$ \\
\hline ECR at Vons & 29 & 153 & 182 & $0.24 \%$ & $1.30 \%$ \\
\hline ECR at Avenida Maria & 29 & 95 & 124 & $0.24 \%$ & $0.81 \%$ \\
\hline ECR at Traffic Way & 25 & 45 & 70 & $0.21 \%$ & $0.38 \%$ \\
\hline ECR at Musselman & 20 & 51 & 71 & $0.17 \%$ & $0.43 \%$ \\
\hline ECR at Del Rio (Mission Oaks) & 20 & 8 & 28 & $0.17 \%$ & $0.06 \%$ \\
\hline ECR at Atalaya & 20 & 3 & 23 & $0.17 \%$ & $0.02 \%$ \\
\hline Las Tablas at Posada (no longer served) & 18 & 15 & 33 & $0.15 \%$ & $0.13 \%$ \\
\hline ECR at San Anselmo (Kmart) & 18 & 13 & 30 & $0.15 \%$ & $0.11 \%$ \\
\hline Las Tablas Park and Ride & 17 & 182 & 199 & $0.14 \%$ & $1.54 \%$ \\
\hline ECR at El Bordo (Post Office) & 15 & 54 & 69 & $0.13 \%$ & $0.45 \%$ \\
\hline Spring at 2nd & 15 & 0 & 15 & $0.13 \%$ & $0.00 \%$ \\
\hline ECR at Solano & 14 & 29 & 43 & $0.12 \%$ & $0.25 \%$ \\
\hline ECR at Santa Rosa & 13 & 12 & 25 & $0.11 \%$ & $0.10 \%$ \\
\hline Main at 1 st (no longer served) & 13 & 15 & 28 & $0.11 \%$ & $0.13 \%$ \\
\hline Main at 6th (no longer served) & 13 & 8 & 20 & $0.11 \%$ & $0.06 \%$ \\
\hline ECR at San Benito & 10 & 8 & 18 & $0.08 \%$ & $0.06 \%$ \\
\hline ECR at Pueblo & 10 & 32 & 42 & $0.08 \%$ & $0.27 \%$ \\
\hline ECR at Santa Margarita (County Care) & 8 & 8 & 16 & $0.07 \%$ & $0.07 \%$ \\
\hline Twin Cities Hospital & 8 & 23 & 30 & $0.06 \%$ & $0.19 \%$ \\
\hline ECR at San Jacinto & 8 & 15 & 23 & $0.06 \%$ & $0.13 \%$ \\
\hline ECR at Maya (Kennedy Club) & 8 & 8 & 15 & $0.06 \%$ & $0.06 \%$ \\
\hline ECR at Santa Cruz & 8 & 3 & 10 & $0.06 \%$ & $0.02 \%$ \\
\hline Spring at 5th & 8 & 0 & 8 & $0.06 \%$ & $0.00 \%$ \\
\hline ECR at Maria & 7 & 12 & 19 & $0.06 \%$ & $0.10 \%$ \\
\hline ECR at Pine (Garden Farms) & 6 & 6 & 12 & $0.05 \%$ & $0.05 \%$ \\
\hline Viejo Camino at Santa Barbara & 2 & 11 & 13 & $0.02 \%$ & $0.09 \%$ \\
\hline ECR at Viejo Camino (no longer served) & 1 & 8 & 9 & $0.01 \%$ & $0.07 \%$ \\
\hline Paloma Park (no longer served) & 0 & 50 & 50 & $0.00 \%$ & $0.42 \%$ \\
\hline Mission at 14th Street & 0 & 25 & 25 & $0.00 \%$ & $0.21 \%$ \\
\hline ECR at Carmel & 0 & 6 & 6 & $0.00 \%$ & $0.05 \%$ \\
\hline ECR at Rosario & 0 & 5 & 5 & $0.00 \%$ & $0.04 \%$ \\
\hline South Vine at 1st (Gateway Center) & 0 & 0 & 0 & $0.00 \%$ & $0.00 \%$ \\
\hline & 2089 & 2089 & 4178 & $18 \%$ & $18 \%$ \\
\hline
\end{tabular}




\section{RTA Route 9 Bus Stop Prerequisite Inventory Summary}

A table in APPENDIX B provides a summary of bus stops served by RTA Route 9 that lack ADA accessible mobility device landing pads and/or safe and accessible pathways. Corresponding proportions of RTA system boardings and alightings are also presented for each of these bus stops. The table in APPENDIX B identifies improvement opportunities associated with these bus stops and provides staff recommendations for next steps to create a bus stop improvement plan.

\section{RTA Route 9 High Priority Recommendation:}

Remove landing pad obstructions: Mobility device landing pads at three relatively safe and accessible bus stops (Cal Poly Kennedy Library NB, Cal Poly Performing Arts SB, and ECR at Encina NB) exist but are obstructed by bus stop amenities.

RTA staff recommends removing obstructions to create ADA compliant landing pads all three of these stops.

\section{RTA Route 9 Bus Stop Prerequisites: Mobility Device Landing Pads with Safe and Accessible Pathway Connections}

Of the 80 RTA Route 9 bus stops, 17 lack ADA accessible landing pads, so they are not ADA compliant. 16 RTA Route 9 bus stops lack connected sidewalks. Six bus stops without landing pads are under San Luis Obispo County's jurisdiction, and all are found along El Camino Real and Santa Barbara Road from Maria Avenue in Santa Margarita to Bordeaux Apartments in South Atascadero. Four bus stops without landing pads are under Atascadero jurisdiction, and they are all in north Atascadero. Two bus stops without landing pads are under San Luis Obispo City jurisdiction. There are five RTA 9 bus stops without landing pads under Paso Robles Jurisdiction.

Six RTA Route 9 ADA compliant stops under San Luis Obispo County jurisdiction found in Santa Margarita and South Atascadero have landing pads, but no connecting sidewalks. 


\section{RTA Route 9 Pedestrian Crossings}

At all six of the ADA non-compliant bus stops under San Luis Obispo County jurisdiction in Santa Margarita and South Atascadero, the speed limit of the adjacent street is 45 miles per hour or higher, and at five of the six stops, the speed limit of the adjacent street is 55 miles per hour. Roadway widths are two to three lanes. None of these six bus stops have a protected pedestrian crossing within sight. Of these six bus stops, two are near an at-grade railroad crossing. Given the rural nature of these stops, installing pedestrian protection features like those typically found in urban settings is not feasible nor advisable at this time. If development patterns change, or if local officials become aware of undue hazards, RTA should work with local officials to potentially relocate these bus stops.

All four of the ADA non-compliant bus stops under Atascadero jurisdiction have 45 miles per hour speed limits. One of the ADA non-compliant stops is adjacent to a roadway with five lanes, and three of these stops do not have a protected pedestrian crossing within sight.

At three of the five ADA non-compliant bus stops under Paso Robles jurisdiction, the speed limit is 45 miles per hour. One of the ADA non-compliant stops is adjacent to a roadway with five lanes, and one of these stops does not have a protected pedestrian crossing within sight.

\section{RTA Route 9 Pull-Out Space, Traffic Impact, and Sight Distance}

Each of the six ADA non-compliant bus stops in Santa Margarita and South Atascadero under San Luis Obispo County jurisdiction is on a road shoulder. A parked bus at each stop temporarily obstructs sight distance for traffic entering the roadway. None have an adequate "No Parking" zone. At two of these stops, a stopped bus obstructs traffic (Viejo Camino at Santa Barbara SB and ECR at Pine SB). At one of these stops, a stopped bus blocks a business driveway (ECR at Pine SB). Based on the rural nature and relatively low traffic volumes in this area, it is not recommended at this time that the bus stops be relocated or altered.

Three of the four ADA non-compliant bus stops in Atascadero are on a road shoulder. Buses stopped at three of the four stops obstruct traffic. None of the non-compliant Atascadero bus stops have an adequate "No Parking" zone.

One of the five ADA non-compliant bus stops in Paso Robles is on a road shoulder. Buses stopped at four of the five stops obstruct traffic, and a parked bus at one of these stops also obstructs a 
business driveway and a crosswalk. Four of the five non-compliant Paso Robles stops do not have an adequate "No Parking" zone.

\section{RTA Route 9 Existing Amenities at High-Use Bus Stops}

The following list provides a summary of existing passenger amenities at high-use RTA Route 9 bus stops. Corresponding proportions of RTA system boardings and alightings are also presented for each of these bus stops. The table of existing amenities at high-use stops is included in APPENDIX A.

- All five high-use bus stops have ADA compliant mobility device landing pads and safe and accessible sidewalks and/or pathways connecting the bus stop to nearby transit trip generators.

- As can be seen in the table in APPENDIX A, of the five high use bus stops served by RTA Route 9 exclusively, three high-use bus stops lack a bus stop sign (Atascadero City Hall, Cal Poly Performing Arts Center \& SB, Cal Poly Kennedy Library NB \& SB, and Monterey@ Grand). Cal Poly Performing Arts Center NB does not have a bus stop sign, either.

- All five of the bus stops with a high proportion of passenger boardings have both shelters and benches for waiting passengers.

- Both high-use bi-directional bus stops have bike racks..

- Two high-usel bus stops lack designated bicycle lanes connecting to the bus stop (Las Tablas Park and Ride and ECR at Hwy 1 (Car Wash)).

- All five high-use bus stops have sufficient ambient lighting.

- One bus stop with a high proportion of passenger alightings lacks an RTA information kiosk (Monterey@Grand).

- Three high use bus stops lack Braille pads. 
- All five high-use bus stops have trash receptacles. 


\section{Assessment of RTA Route 10}

RTA Route 10 Bus Stop Usage: Proportion of Boardings and Alightings

RTA Route 10 Weekdays Northbound

\begin{tabular}{|c|c|c|c|c|c|}
\hline \multirow{2}{*}{$\begin{array}{l}10 \text { Daily Northbound } \\
\text { WEEKDAY TOTALS }\end{array}$} & \multicolumn{2}{|c|}{ TOTAL } & \multirow{2}{*}{$\begin{array}{c}\text { Total } \\
\text { Stop } \\
\text { Activity }\end{array}$} & \multirow{2}{*}{$\begin{array}{c}\text { PCT of } \\
\text { System } \\
\text { ONS }\end{array}$} & \multirow{2}{*}{$\begin{array}{c}\text { PCT of } \\
\text { System } \\
\text { OFFS }\end{array}$} \\
\hline & ON & OFF & & & \\
\hline Town Center Mall (Santa Maria Transit Center) & 342 & 0 & 342 & $2.89 \%$ & $0.00 \%$ \\
\hline Prime Outlets & 339 & 77 & 416 & $2.86 \%$ & $0.65 \%$ \\
\hline Allan Hancock & 171 & 2 & 173 & $1.44 \%$ & $0.02 \%$ \\
\hline Tefft St. @ Carillo St. (NB) & 163 & 79 & 242 & $1.38 \%$ & $0.67 \%$ \\
\hline Halcyon Park and Ride & 142 & 118 & 260 & $1.20 \%$ & $1.00 \%$ \\
\hline E. Grand @ El Camino Real & 100 & 115 & 215 & $0.84 \%$ & $0.98 \%$ \\
\hline Thompson Ave @ Branch St. & 62 & 31 & 93 & $0.52 \%$ & $0.26 \%$ \\
\hline Greyhound (no longer served) & 53 & 0 & 53 & $0.45 \%$ & $0.00 \%$ \\
\hline Marian Hospital & 46 & 2 & 48 & $0.39 \%$ & $0.02 \%$ \\
\hline Nicholson St. @ Cypress St & 38 & 0 & 38 & $0.32 \%$ & $0.00 \%$ \\
\hline Thompson Ave @ Nipomo HS & 37 & 22 & 59 & $0.31 \%$ & $0.19 \%$ \\
\hline E. Main St. @ College Dr. & 37 & 1 & 38 & $0.31 \%$ & $0.01 \%$ \\
\hline S Higuera St. @ Suburban Rd. & 27 & 65 & 92 & $0.23 \%$ & $0.55 \%$ \\
\hline Thompson Ave @ Los Berros & 16 & 18 & 34 & $0.14 \%$ & $0.15 \%$ \\
\hline S. Higuera @ Prado (no longer served) & 13 & 39 & 52 & $0.11 \%$ & $0.33 \%$ \\
\hline South St. @ Beebee St (Higuera at South) & 11 & 34 & 45 & $0.09 \%$ & $0.29 \%$ \\
\hline S. Higuera St. @ Margarita Ave & 11 & 27 & 38 & $0.09 \%$ & $0.23 \%$ \\
\hline S. Higuera @ Hind (no longer served) & 9 & 16 & 25 & $0.08 \%$ & $0.14 \%$ \\
\hline South St. @ High (no longer served) & 6 & 12 & 18 & $0.05 \%$ & $0.10 \%$ \\
\hline S. Higuera @ Elks Lane (no longer served) & 6 & 11 & 17 & $0.05 \%$ & $0.09 \%$ \\
\hline S. Higuera @ Chumash (no longer served) & 6 & 10 & 16 & $0.05 \%$ & $0.08 \%$ \\
\hline South St. @ Meadow St. (no longer served) & 4 & 28 & 32 & $0.03 \%$ & $0.24 \%$ \\
\hline South Street @ King (no longer served) & 3 & 4 & 7 & $0.03 \%$ & $0.03 \%$ \\
\hline Santa Barbara @ Church (no longer served) & 1 & 17 & 18 & $0.01 \%$ & $0.14 \%$ \\
\hline Government Center & 0 & 740 & 740 & $0.00 \%$ & $6.29 \%$ \\
\hline Cal Poly @ Kennedy Library (NB) & 0 & 63 & 63 & $0.00 \%$ & $0.54 \%$ \\
\hline Santa Rosa @ Higuera (no longer served) & 0 & 46 & 46 & $0.00 \%$ & $0.39 \%$ \\
\hline Cal Poly @ Performing Arts & 0 & 32 & 32 & $0.00 \%$ & $0.27 \%$ \\
\hline Marsh St @ Broad St. & 0 & 25 & 25 & $0.00 \%$ & $0.21 \%$ \\
\hline South St. @ Exposition (no longer served) & 0 & 9 & 9 & $0.00 \%$ & $0.08 \%$ \\
\hline & 1643 & 1643 & 3286 & $13.87 \%$ & $13.96 \%$ \\
\hline
\end{tabular}




\section{RTA Route 10 Weekdays Southbound}

\begin{tabular}{|c|c|c|c|c|c|}
\hline \multirow{2}{*}{$\begin{array}{l}10 \text { Daily Southbound } \\
\text { WEEKDAY TOTALS }\end{array}$} & \multicolumn{2}{|c|}{ TOTAL } & \multirow{2}{*}{$\begin{array}{c}\text { Total } \\
\text { Stop } \\
\text { Activity }\end{array}$} & \multirow{2}{*}{$\begin{array}{l}\text { PCT of } \\
\text { System } \\
\text { ONS }\end{array}$} & \multirow{2}{*}{$\begin{array}{c}\text { PCT of } \\
\text { System } \\
\text { OFFS }\end{array}$} \\
\hline & ON & OFF & & & \\
\hline Government Center & 708 & 0 & 708 & $5.98 \%$ & $0.00 \%$ \\
\hline Halcyon Park \& Ride & 126 & 82 & 208 & $1.06 \%$ & $0.70 \%$ \\
\hline Prime Outlets & 104 & 299 & 403 & $0.88 \%$ & $2.54 \%$ \\
\hline Tefft St. @ Carillo St. (SB) & 90 & 111 & 201 & $0.76 \%$ & $0.94 \%$ \\
\hline E. Grand @ El Camino Real & 80 & 138 & 218 & $0.68 \%$ & $1.17 \%$ \\
\hline South Higuera St. @ Suburban & 59 & 22 & 81 & $0.50 \%$ & $0.19 \%$ \\
\hline Cal Poly @ Mott Gym & 49 & 0 & 49 & $0.41 \%$ & $0.00 \%$ \\
\hline South St. @ Beebee St. (Higuera at South) & 41 & 7 & 48 & $0.35 \%$ & $0.06 \%$ \\
\hline S.Higuera St. @ Margarita & 38 & 30 & 68 & $0.32 \%$ & $0.25 \%$ \\
\hline Thompson Ave @ Branch & 35 & 47 & 82 & $0.30 \%$ & $0.40 \%$ \\
\hline South St. @ Broad St (no longer served) & 24 & 7 & 31 & $0.20 \%$ & $0.06 \%$ \\
\hline Santa Barbara @ Church (no longer served) & 24 & 1 & 25 & $0.20 \%$ & $0.01 \%$ \\
\hline S. Higuera @ Bridge St. (no longer served) & 9 & 6 & 15 & $0.08 \%$ & $0.05 \%$ \\
\hline South Street @ Exposition (no longer served) & 8 & 0 & 8 & $0.07 \%$ & $0.00 \%$ \\
\hline Thompson Ave @ HS & 7 & 46 & 53 & $0.06 \%$ & $0.39 \%$ \\
\hline Marion Medical Center & 7 & 28 & 35 & $0.06 \%$ & $0.24 \%$ \\
\hline S. Higuera @ Prado (no longer served) & 7 & 11 & 18 & $0.06 \%$ & $0.09 \%$ \\
\hline Santa Barbara @ High (no longer served) & 6 & 1 & 7 & $0.05 \%$ & $0.01 \%$ \\
\hline Town Center Mall (Santa Maria Transit Center) & 5 & 301 & 306 & $0.04 \%$ & $2.56 \%$ \\
\hline Allan Hancock & 4 & 212 & 216 & $0.03 \%$ & $1.80 \%$ \\
\hline S. Higuera @ Silver City Mobile (no longer served) & 3 & 5 & 8 & $0.03 \%$ & $0.04 \%$ \\
\hline S. Higuera @ Granada (no longer served) & 3 & 1 & 4 & $0.03 \%$ & $0.01 \%$ \\
\hline Nipomo St. @ Higuera St & 2 & 0 & 2 & $0.02 \%$ & $0.00 \%$ \\
\hline South Street @ King St. (no longer served) & 1 & 0 & 1 & $0.01 \%$ & $0.00 \%$ \\
\hline Greyhound (no longer served) & 0 & 37 & 37 & $0.00 \%$ & $0.31 \%$ \\
\hline Thompson Ave @ Los Berros & 0 & 11 & 11 & $0.00 \%$ & $0.09 \%$ \\
\hline \multirow[t]{2}{*}{ Nicholson St. @ Cypress } & 0 & 7 & 7 & $0.00 \%$ & $0.06 \%$ \\
\hline & 1440 & 1410 & 2850 & $12.16 \%$ & $11.98 \%$ \\
\hline
\end{tabular}




\section{RTA Route 10 Bus Stop Prerequisite Inventory Summary}

A table in APPENDIX B provides a summary of bus stops served by RTA Route 10 that lack ADA accessible mobility device landing pads and/or safe and accessible connecting pathways. Corresponding proportions of RTA system boardings and alightings are also presented for each of these bus stops. The table also identifies improvement opportunities associated with these bus stops and provides staff recommendations for next steps to create a bus stop improvement plan.

\section{RTA Route 10 High Priority Recommendation:}

Remove landing pad and sidewalk obstructions: A mobility device landing pad at one relatively safe and accessible bus stop (S. Higuera at Suburban NB) exists but is obstructed by bus stop amenities. An ADA compliant sidewalk at one relatively safe and accessible bus stop (Higuera at South SB) exists but is obstructed by bus stop amenities.

RTA staff recommends removing obstructions to create ADA compliant landing pads and sidewalks at both of these stops.

\section{RTA Route 10 Bus Stop Prerequisites: Mobility Device Landing Pads with Safe and Accessible Pathway Connections}

Of the 24 RTA Route 10 bus stops, six lack ADA accessible landing pads. Four of these bus stops are under San Luis Obispo County jurisdiction (Nipomo High School, Thompson at Branch, $\mathbf{N}$. Thompson at Hwy 101 NB, and N. Thompson at Hwy 101 SB). One of these bus stops is under Santa Maria jurisdiction (Nicholson at E. Cypress). The last of these six bus stops that lacks an ADA compliant landing pad is under San Luis Obispo City jurisdiction-it meets the five-foot width requirement but is technically one-inch shy of the eight-foot depth requirement (Higuera at South SB).

Of the five RTA Route 10 fixed-route bus stops that lack ADA compliant landing pads, five also lack connected sidewalks - four of these bus stops are under San Luis Obispo County's jurisdiction (Nipomo High School NB, Thompson at Branch SB, N. Thompson at Hwy 101 NB, and N. Thompson at Hwy 101 SB) and one is under Santa Maria's jurisdiction (Nicholson at E. Cypress). 
Two bus stops meet ADA requirements but have noteworthy operational deficiencies. At the Alan Hancock College bus stop (S. Bradley at Jones) under Santa Maria jurisdiction, a bus can access an ADA compliant landing pad only if it stops awkwardly between the bus stop pole and the bus bay. At a bus stop under Pismo Beach jurisdiction, multiple buses stop simultaneously at the Pismo Beach Premium Outlets bus stop, but only one ADA compliant landing pad is present.

\section{RTA Route 10 Pedestrian Crossings}

At three ADA non-compliant bus stops, the speed limit of the adjacent street is at least 45 miles per hour (Nipomo High School NB, N. Thompson at Hwy 101 NB, and N. Thompson at Hwy 101 SB). At two non-ADA compliant stops, roadway widths are greater than four lanes, (Nipomo High School NB and Higuera at South SB). Four of the ADA non-compliant bus stops do not have a protected pedestrian crossing opportunity within sight (Nipomo High School NB, Nicholson at E. Cypress, N. Thompson at Hwy 101 NB, and N. Thompson at Hwy 101 SB).

\section{RTA Route 10 Pull-Out Space, Traffic Impact, and Sight Distance}

Four of the six ADA non-compliant bus stops are on the road shoulder; all of which are in Nipomo under San Luis Obispo County jurisdiction (Nipomo High School NB, Thompson at Branch SB, N. Thompson at Hwy 101 NB, and N. Thompson at Hwy 101 SB). A parked bus in each of the six ADA non-compliant bus stops obstruct traffic. A parked bus in four ADA non-compliant bus stops obstruct sight distance for traffic entering the roadway. None have an adequate "No Parking" zone.

\section{RTA Route 10 Existing Amenities at High-Use Bus Stops}

The following list provides a summary of existing amenities at high-use RTA Route 10 bus stops. Corresponding proportions of RTA system boardings and alightings are also presented for each of these bus stops. The table of existing amenities at high-use stops is included in APPENDIX A. 
- Two high-use bus stops lack safe and accessible sidewalks and/or routes connecting the bus stop to nearby transit trip generators (Pismo Prime Outlets and Teft st. @ Carillo St. NB).

- Of the six high-use bus stops served by RTA Route 10 exclusively, three lack RTA bus stop signs (Santa Maria Transit Center, Halcyon Park and Ride, and Alan Hancock College). * Notes: Santa Maria does not allow RTA bus stop signs at SMAT bus stops. Halcyon Park and Ride has a large highly-visible RTA logo in the 4'x6' shelter display.

- One bus stop with a high proportion of passenger boardings lacks an RTA information kiosk (Santa Maria Transit Center).

- Four bus stops lack Braille pads.

- All six of the high-use bus stops have both shelters and benches for waiting passengers.

- At two of the high-use bus stops, passengers could be hidden from view of an approaching bus (Halycyon Park and Ride and Pismo Prime Outlets).

- All six high-use bus stops have sufficient ambient lighting.

- Except for the Alan Hancock College bus stop, all five bi-directional high-use bus stops have bike racks.

- Four high-use bi-directional bus stops lack designated bicycle lanes connecting to the bus stop.

- All six high-use bus stops have trash receptacles. 


\section{Assessment of RTA Route 12/14}

\section{RTA Route 12/14 Bus Stop Usage: Proportion of Boardings and Alightings}

\section{RTA Route 12/14 Weekdays}

\begin{tabular}{|c|c|c|c|c|c|}
\hline \multirow{2}{*}{$\begin{array}{c}\text { 12A Daily } \\
\text { WEEKDAY TOTALS }\end{array}$} & \multicolumn{2}{|c|}{ TOTAL } & \multirow{2}{*}{$\begin{array}{c}\text { Total } \\
\text { Stop } \\
\text { Activity }\end{array}$} & \multirow{2}{*}{$\begin{array}{c}\text { PCT of } \\
\text { System } \\
\text { ONS }\end{array}$} & \multirow{2}{*}{$\begin{array}{l}\text { PCT of } \\
\text { System } \\
\text { OFFS }\end{array}$} \\
\hline & ON & OFF & & & \\
\hline Government Center & 831 & 0 & 831 & $7.02 \%$ & $0.00 \%$ \\
\hline Cuesta Parking Lot 3 (SB) & 421 & 175 & 596 & $3.55 \%$ & $1.49 \%$ \\
\hline Morro Bay Park (SB) & 334 & 91 & 425 & $2.82 \%$ & $0.77 \%$ \\
\hline Kennedy Library (NB) & 216 & 20 & 236 & $1.82 \%$ & $0.17 \%$ \\
\hline Foothill @ Casa (NB) (Santa Roas at Mstng / Stnr Glen) & 205 & 9 & 214 & $1.73 \%$ & $0.08 \%$ \\
\hline Morro Bay Park (NB) & 122 & 288 & 410 & $1.03 \%$ & $2.45 \%$ \\
\hline Cuesta Parking Lot 3 (NB) & 116 & 676 & 792 & $0.98 \%$ & $5.75 \%$ \\
\hline 10th @ LOVR & 87 & 95 & 182 & $0.73 \%$ & $0.81 \%$ \\
\hline 10th @ Santa Ynez & 77 & 90 & 167 & $0.65 \%$ & $0.76 \%$ \\
\hline Cuesta Building 1400 (no longer served) & 67 & 47 & 114 & $0.57 \%$ & $0.40 \%$ \\
\hline Pine @ LOVR & 63 & 46 & 109 & $0.53 \%$ & $0.39 \%$ \\
\hline Cuesta West Side (no longer served) & 58 & 12 & 70 & $0.49 \%$ & $0.10 \%$ \\
\hline Ramona @ 7th & 46 & 27 & 73 & $0.39 \%$ & $0.23 \%$ \\
\hline Cuesta Building 1400 (no longer served) & 44 & 42 & 86 & $0.37 \%$ & $0.36 \%$ \\
\hline Cuesta West Side (no longer served) & 43 & 14 & 57 & $0.36 \%$ & $0.12 \%$ \\
\hline Pine @ Loma & 42 & 29 & 71 & $0.35 \%$ & $0.25 \%$ \\
\hline Santa Ysabel @ 15th & 32 & 3 & 35 & $0.27 \%$ & $0.03 \%$ \\
\hline Santa Ysabel @ 7th & 29 & 9 & 38 & $0.24 \%$ & $0.08 \%$ \\
\hline 11th @ Ramona & 28 & 48 & 76 & $0.24 \%$ & $0.41 \%$ \\
\hline 11th @ El Morro & 27 & 51 & 78 & $0.23 \%$ & $0.43 \%$ \\
\hline LOVR @ Palisades & 25 & 20 & 45 & $0.21 \%$ & $0.17 \%$ \\
\hline 7th @ El Morro & 23 & 16 & 39 & $0.19 \%$ & $0.14 \%$ \\
\hline 2nd @ Santa Maria & 21 & 17 & 38 & $0.18 \%$ & $0.14 \%$ \\
\hline South Bay Boulevard @ Quintana & 18 & 12 & 30 & $0.15 \%$ & $0.10 \%$ \\
\hline Kansas Avenue & 16 & 8 & 24 & $0.14 \%$ & $0.07 \%$ \\
\hline Santa Ysabel @ 15th & 14 & 39 & 53 & $0.12 \%$ & $0.33 \%$ \\
\hline Kansas Avenue & 13 & 6 & 19 & $0.11 \%$ & $0.05 \%$ \\
\hline Kennedy Library (SB) & 6 & 187 & 193 & $0.05 \%$ & $1.59 \%$ \\
\hline Highland @ HWY 1 & 6 & 56 & 62 & $0.05 \%$ & $0.48 \%$ \\
\hline Patricia @ Foothill (no longer served) & 6 & 0 & 6 & $0.05 \%$ & $0.00 \%$ \\
\hline Foothill @ Casa (SB) (Santa Rosa at Foothill) & 5 & 102 & 107 & $0.04 \%$ & $0.87 \%$ \\
\hline South Bay Boulevard @ Quintana & 5 & 10 & 15 & $0.04 \%$ & $0.08 \%$ \\
\hline Achievement House & 3 & 4 & 7 & $0.03 \%$ & $0.03 \%$ \\
\hline LOVR @ Buckskin (no longer served) & 2 & 0 & 2 & $0.02 \%$ & $0.00 \%$ \\
\hline Men's Colony & 1 & 7 & 8 & $0.01 \%$ & $0.06 \%$ \\
\hline Government Center & 0 & 709 & 709 & $0.00 \%$ & $6.03 \%$ \\
\hline LOVR @ Buckskin (no longer served) & 0 & 6 & 6 & $0.00 \%$ & $0.05 \%$ \\
\hline Patricia @ Foothill (no longer served) & 0 & 5 & 5 & $0.00 \%$ & $0.04 \%$ \\
\hline Men's Colony & 0 & 1 & 1 & $0.00 \%$ & $0.01 \%$ \\
\hline & 3052 & 2977 & 6029 & $25.77 \%$ & $25.30 \%$ \\
\hline
\end{tabular}




\section{RTA Route 12/14 Bus Stop Prerequisite Inventory Summary}

A table in APPENDIX B provides a summary of bus stops served by RTA Route 12/14 that lack ADA accessible mobility device landing pads and/or safe and accessible connecting pathways. Corresponding proportions of RTA system boardings and alightings are also presented for each of these stops. The table also identifies improvement opportunities associated with these bus stops and provides staff recommendations for next steps to create a bus stop improvement plan.

\section{RTA Route 12/14 High Priority Recommendation:}

The lowest use RTA Route 12/14 bus stops that lack mobility device landing pads (Kansas at Highway 1 and California Men's Colony) are currently served as call stops. RTA staff recommends no immediate actions to stops served by RTA Route 12/14.

\section{RTA Route 12/14 Bus Stop Prerequisites: Mobility Device Landing Pads with Safe and Accessible Pathway Connections}

Of the 22 RTA Route 12/14 bus stops, thirteen lack ADA accessible landing pads: all are under San Luis Obispo County jurisdiction. Ten of these ADA non-compliant bus stops lack connecting pathways. Nine of the ten bus stops that lack landing pads are in Los Osos, except for Kansas at Highway 1, which is already a call stop and technically not considered part of fixed-route service.

Two bus stops under Morro Bay jurisdiction have landing pads but no connecting pathways (South Bay at Quintana SB and South Bay at Quintana NB).

\section{RTA Route 12/14 Pedestrian Crossings}

None of the non-ADA compliant bus stops have speed limits on adjacent streets that exceed 40 miles per hour or roadway widths greater than two lanes, except for Santa Rosa at Murray NB, which adjacent to a five lane street. Seven of the thirteen ADA non-compliant bus stops lack a 
protected pedestrian crossing opportunity within sight, and they are all under San Luis Obispo County jurisdiction (two are on the Highway 1 corridor and the other five are in Los Osos).

\section{RTA Route 12/14 Pull-Out Space, Traffic Impact, and Sight Distance}

Eleven of the thirteen ADA non-compliant bus stops are on the road shoulder; ten of these bus stops are in Los Osos, and one is Kansas at Highway 1; all are under San Luis Obispo County jurisdiction. A bus temporarily parked in twelve of the thirteen ADA non-compliant bus stops obstructs traffic.Furthermore, buses at six stops obstruct sight distance for traffic entering the roadway, buses at three stops obstruct residential driveways, and buses at one stop obstructs sightlines for parked vehicles. None ADA non-compliant stopshave an adequate "No Parking" zone.

\section{RTA Route 12/14 Existing Amenities at High-Use Bus Stops}

The table in APPENDIX A provides a summary of existing amenities at high-use RTA Route 12/14 bus stops. Corresponding proportions of RTA system boardings and alightings are also presented for each of these bus stops.

Cuesta College is the only high-use bus stop served by RTA Route 12/14 exclusively; it has an ADA compliant landing pad, and it has a sidewalk with a safe and accessible pathway to the campus core. The Cuesta College bus stop has an RTA bus stop sign, an RTA information kiosk, and a Braille pad. It also has passenger shelters, benches, ambient lighting, and trash and recycle receptacles. There are no bike racks, and no bike lane is directly connected to the stop. 


\section{Assessment of RTA Route 15}

\section{RTA Route 15 Bus Stop Usage: Proportion of Boardings and Alightings}

\section{RTA 15 Weekdays Southbound}

\begin{tabular}{|c|c|c|c|c|c|}
\hline \multirow{2}{*}{$\begin{array}{c}15 \text { Weekday Southbound } \\
\text { WEEKDAY TOTALS }\end{array}$} & \multicolumn{2}{|c|}{ TOTAL } & \multirow{2}{*}{$\begin{array}{c}\text { Total } \\
\text { Stop } \\
\text { Activity }\end{array}$} & \multirow{2}{*}{$\begin{array}{c}\text { PCT of } \\
\text { System } \\
\text { ONS }\end{array}$} & \multirow{2}{*}{$\begin{array}{c}\text { PCT of } \\
\text { System } \\
\text { OFFS } \\
\end{array}$} \\
\hline & ON & OFF & & & \\
\hline Burton @ Ardath & 16 & 0 & 16 & $0.14 \%$ & $0.00 \%$ \\
\hline Burton @ Main & 13 & 0 & 13 & $0.11 \%$ & $0.00 \%$ \\
\hline Ocean@ Cayucos Dr. & 11 & 7 & 18 & $0.09 \%$ & $0.06 \%$ \\
\hline Ocean @ 9th & 11 & 1 & 12 & $0.09 \%$ & $0.01 \%$ \\
\hline Hearst Castle & 10 & 0 & 10 & $0.08 \%$ & $0.00 \%$ \\
\hline Highway $1 @$ San Jacinto & 9 & 6 & 15 & $0.08 \%$ & $0.05 \%$ \\
\hline Ocean @ 3rd & 9 & 3 & 12 & $0.08 \%$ & $0.03 \%$ \\
\hline Ardath @ Green (Ardath @ Hwy 1) & 8 & 0 & 8 & $0.07 \%$ & $0.00 \%$ \\
\hline Main @ Arlington & 7 & 0 & 7 & $0.06 \%$ & $0.00 \%$ \\
\hline Moonstone@ @indsor & 6 & 0 & 6 & $0.05 \%$ & $0.00 \%$ \\
\hline Burton @ Cambria Pines Lodge & 6 & 0 & 6 & $0.05 \%$ & $0.00 \%$ \\
\hline Main @ Tamson & 5 & 0 & 5 & $0.04 \%$ & $0.00 \%$ \\
\hline Main @ Errol (no longer served) & 4 & 9 & 13 & $0.03 \%$ & $0.08 \%$ \\
\hline Ocean @ Old Creek Rd. & 4 & 5 & 9 & $0.03 \%$ & $0.04 \%$ \\
\hline Main @ Bluebird & 3 & 1 & 4 & $0.03 \%$ & $0.01 \%$ \\
\hline Main @ Veterans Hall & 3 & 0 & 3 & $0.03 \%$ & $0.00 \%$ \\
\hline Morro Bay Park & 0 & 76 & 76 & $0.00 \%$ & $0.65 \%$ \\
\hline Moonstone @ San Simeon Pines & 0 & 7 & 7 & $0.00 \%$ & $0.06 \%$ \\
\hline Hearst Drive @ San Simeon & 0 & 0 & 0 & $0.00 \%$ & $0.00 \%$ \\
\hline Moonstone @ Castle Inn & 0 & 0 & 0 & 0 & 0 \\
\hline \multirow[t]{2}{*}{ Moonstone @ Mariner's Inn (SB) } & 0 & 0 & 0 & 0 & 0 \\
\hline & 125 & 115 & 240 & $1.06 \%$ & $0.98 \%$ \\
\hline
\end{tabular}




\section{RTA Route 15 Weekdays Northbound}

\begin{tabular}{|c|c|c|c|c|c|}
\hline \multirow{2}{*}{$\begin{array}{c}15 \text { Weekday Northbound } \\
\text { WEEKDAY TOTALS }\end{array}$} & \multicolumn{2}{|c|}{ TOTAL } & \multirow{3}{*}{$\begin{array}{c}\text { Total } \\
\text { Stop } \\
\text { Activity }\end{array}$} & \multirow{3}{*}{$\begin{array}{l}\text { PCT of } \\
\text { System } \\
\text { ONS }\end{array}$} & \multirow{3}{*}{$\begin{array}{c}\text { PCT of } \\
\text { System } \\
\text { OFFS } \\
\end{array}$} \\
\hline & \multirow{2}{*}{ ON } & \multirow{2}{*}{ OFF } & & & \\
\hline MORRO BAY & & & & & \\
\hline Morro Bay Park & 75 & 0 & 75 & $0.63 \%$ & $0.00 \%$ \\
\hline Ocean @ Cayucos Dr. (Cayucos @ Ocean) & 8 & 3 & 11 & $0.07 \%$ & $0.03 \%$ \\
\hline Main @ Errol (no longer served) & 7 & 0 & 7 & $0.06 \%$ & $0.00 \%$ \\
\hline Main @ Elena (no longer served) & 4 & 3 & 7 & $0.03 \%$ & $0.03 \%$ \\
\hline Main @ Veterans Hall (Main @ Skate Park) & 3 & 7 & 10 & $0.03 \%$ & $0.06 \%$ \\
\hline Main @ San Joaquin & 3 & 4 & 7 & $0.03 \%$ & $0.03 \%$ \\
\hline Burton @ Yorkshire & 2 & 5 & 7 & $0.02 \%$ & $0.04 \%$ \\
\hline Main @ Bonita (no longer served) & 2 & 2 & 4 & $0.02 \%$ & $0.02 \%$ \\
\hline Moonstone @ Windsor & 1 & 9 & 10 & $0.01 \%$ & $0.08 \%$ \\
\hline Ardath @ Green (Ardath @ Hwy 1) & 1 & 4 & 5 & $0.01 \%$ & $0.03 \%$ \\
\hline Burton @ Ardath & 0 & 17 & 17 & $0.00 \%$ & $0.14 \%$ \\
\hline Burton @ Main & 0 & 15 & 15 & $0.00 \%$ & $0.13 \%$ \\
\hline Hearst Castle & 0 & 9 & 9 & $0.00 \%$ & $0.08 \%$ \\
\hline Ocean @ 8th St & 0 & 7 & 7 & $0.00 \%$ & $0.06 \%$ \\
\hline Ocean @ 4th (Ocean @ 3rd (NB)) & 0 & 6 & 6 & $0.00 \%$ & $0.05 \%$ \\
\hline Main @ Tamson & 0 & 4 & 4 & $0.00 \%$ & $0.03 \%$ \\
\hline Castillo @ Otter & 0 & 3 & 3 & $0.00 \%$ & $0.03 \%$ \\
\hline Ocean @ Old Creek Rd & 0 & 2 & 2 & $0.00 \%$ & $0.02 \%$ \\
\hline Moonstone @ San Simeon Pines & 0 & 2 & 2 & $0.00 \%$ & $0.02 \%$ \\
\hline Cornwall @ Arlington (Main @ Cornwall) & 0 & 1 & 1 & $0.00 \%$ & $0.01 \%$ \\
\hline Main @ Jamaica (no longer served) & 0 & 0 & 0 & 0 & 0 \\
\hline Main @ Bluebird Inn & 0 & 0 & 0 & 0 & 0 \\
\hline Moonstone @ Mariner's Inn (NB) & 0 & 0 & 0 & 0 & 0 \\
\hline Moonstone @ Firesiede Inn & 0 & 0 & 0 & 0 & 0 \\
\hline & 106 & 103 & 209 & $0.90 \%$ & $0.88 \%$ \\
\hline
\end{tabular}




\section{RTA Route 15 Existing Amenities at High-Use Bus Stops}

Since it lacks a single bus stop with greater than $1 \%$ of the total RTA system boardings and alightings, RTA Route 15 alone serves no high-use bus stops.

Morro Bay Park is a high-use stop, and it is discussed in the high-use multi-route passenger facility section above. Morro Bay Park is served by RTA Route 12, RTA Route 15, and Morro Bay Transit services.

\section{RTA Route 15 Bus Stop Prerequisite Inventory Summary}

A table in APPENDIX B provides a summary of bus stops served by RTA Route 15 that lack ADA accessible mobility device landing pads and/or safe and accessible connecting pathways. Corresponding proportions of RTA system boardings and alightings are also presented for each of these bus stops. The table also identifies improvement opportunities associated with these stops and provides staff recommendations for next steps to create a bus stop improvement plan.

\section{RTA Route 15 High Priority Recommendation:}

Remove landing pad and sidewalk obstructions: A mobility device landing pad at one relatively safe and accessible stop (MAIN at CORNWALL in Cambria) exists but is obstructed by a bench connected to the "Old Station Store."

RTA staff recommends working with the "Old Station Store" property owner to remove obstructions to create an ADA compliant landing pad.

\section{RTA Route 15 Bus Stop Prerequisites: Mobility Device Landing Pads with Safe and Accessible Pathway Connections}

Of the 37 RTA Route 15 bus stops, 31 lack ADA accessible landing pads. One of these ADA noncompliant bus stops (Highway 1 at SAN JACINTO) is under Morro Bay jurisdiction. The rest of the 30 bus stops are under San Luis Obispo County jurisdiction. 
Of the 31 RTA Route 15 stops without landing pads, 23 also lack connecting pathways; all of these bus stops are under San Luis Obispo County jurisdiction.

Two stops under Morro Bay jurisdiction have ADA compliant landing pads but lack connecting pathways (South Bay at Quintana SB and South Bay at Quintana NB).

\section{RTA Route 15 Pedestrian Crossings}

At one ADA non-compliant bus stop, the speed limit of the adjacent street exceeds 45 miles per hour and the roadway is five lanes wide (Highway 1 @ SAN JACINTO).

A total of 20 of the ADA non-compliant bus stops along the north coast lack a protected pedestrian crossing opportunity.

\section{RTA Route 15 Pull-Out Space, Traffic Impact, and Sight Distance}

A total of 18 of the 31 ADA non-compliant bus stops are on the road shoulder; all of which are under San Luis Obispo County jurisdiction. A bus temporarily parked in 24 of the 31 ADA noncompliant bus stops obstructs traffic; all 24 obstruct sight distance for traffic entering the roadway, 5 obstruct business driveways, and 2 obstruct parked vehicles. A total of 29 lack a "No Parking" zone. 


\section{Assessment of Paso Express}

Paso Express Bus Stop Usage: Proportion of Boardings and Alighting 


\begin{tabular}{|c|c|c|c|c|c|}
\hline \multirow{2}{*}{$\begin{array}{c}\text { Paso Express Route A } \\
\text { WEEKDAY TOTALS }\end{array}$} & \multicolumn{2}{|c|}{ TOTAL } & \multirow{2}{*}{$\begin{array}{c}\text { Total } \\
\text { Stop } \\
\text { Activity }\end{array}$} & \multirow{2}{*}{$\begin{array}{c}\text { PCT of } \\
\text { System } \\
\text { ONS }\end{array}$} & \multirow{2}{*}{$\begin{array}{l}\text { PCT of } \\
\text { System } \\
\text { OFFS }\end{array}$} \\
\hline & ON & OFF & & & \\
\hline Niblick at South River & 60 & 48 & 108 & $0.51 \%$ & $0.39 \%$ \\
\hline Niblick at Bearcat & 55 & 38 & 93 & $0.46 \%$ & $0.31 \%$ \\
\hline 8th at Pine & 53 & 75 & 128 & $0.44 \%$ & $0.62 \%$ \\
\hline Spring at 32nd (NB) (no longer served) & 35 & 0 & 35 & $0.30 \%$ & $0.00 \%$ \\
\hline Spring at 28th (NB) & 33 & 8 & 40 & $0.27 \%$ & $0.06 \%$ \\
\hline Stoney Creek at Creston & 30 & 73 & 103 & $0.25 \%$ & $0.60 \%$ \\
\hline Spring at 24th (NB) & 28 & 0 & 28 & $0.23 \%$ & $0.00 \%$ \\
\hline Spring at 34th (SB) & 25 & 48 & 73 & $0.21 \%$ & $0.39 \%$ \\
\hline Spring at 34th (NB) (no longer served) & 23 & 0 & 23 & $0.19 \%$ & $0.00 \%$ \\
\hline Spring at 5th & 20 & 30 & 50 & $0.17 \%$ & $0.25 \%$ \\
\hline Spring at 14th & 18 & 23 & 40 & $0.15 \%$ & $0.19 \%$ \\
\hline Sherwood at Creston & 18 & 13 & 30 & $0.15 \%$ & $0.10 \%$ \\
\hline Creston at Melody & 18 & 10 & 28 & $0.15 \%$ & $0.08 \%$ \\
\hline Creston at Scott & 15 & 30 & 45 & $0.13 \%$ & $0.25 \%$ \\
\hline Creston at Bolen & 15 & 25 & 40 & $0.13 \%$ & $0.21 \%$ \\
\hline Scott at Via Ramona & 15 & 13 & 28 & $0.13 \%$ & $0.10 \%$ \\
\hline Spring at 21st & 15 & 3 & 18 & $0.13 \%$ & $0.02 \%$ \\
\hline Spring at 17 th & 15 & 0 & 15 & $0.13 \%$ & $0.00 \%$ \\
\hline Spring at 2nd & 15 & 0 & 15 & $0.13 \%$ & $0.00 \%$ \\
\hline Spring at 10th & 13 & 23 & 35 & $0.11 \%$ & $0.19 \%$ \\
\hline Scott at Westfield & 13 & 5 & 18 & $0.11 \%$ & $0.04 \%$ \\
\hline Riverside at Ysabel & 13 & 3 & 15 & $0.11 \%$ & $0.02 \%$ \\
\hline Spring at 28th & 13 & 0 & 13 & $0.11 \%$ & $0.00 \%$ \\
\hline Oak at 36th (no longer served) & 13 & 0 & 13 & $0.11 \%$ & $0.00 \%$ \\
\hline Fontana at Linne & 10 & 10 & 20 & $0.08 \%$ & $0.08 \%$ \\
\hline Creston at Capital Hill & 10 & 5 & 15 & $0.08 \%$ & $0.04 \%$ \\
\hline Airport at Scott & 8 & 15 & 23 & $0.06 \%$ & $0.12 \%$ \\
\hline Scott at Larkellen (no longer served) & 8 & 8 & 15 & $0.06 \%$ & $0.06 \%$ \\
\hline Ysabel & 8 & 3 & 10 & $0.06 \%$ & $0.02 \%$ \\
\hline Spring at 26th & 5 & 23 & 28 & $0.04 \%$ & $0.19 \%$ \\
\hline Sherwood at Commerce & 5 & 0 & 5 & $0.04 \%$ & $0.00 \%$ \\
\hline Creston at Lana & 3 & 13 & 15 & $0.02 \%$ & $0.10 \%$ \\
\hline Spring at 32nd (SB) & 3 & 8 & 10 & $0.02 \%$ & $0.06 \%$ \\
\hline Riverside at 20th & 3 & 3 & 5 & $0.02 \%$ & $0.02 \%$ \\
\hline Spring at 19th & 3 & 0 & 3 & $0.02 \%$ & $0.00 \%$ \\
\hline Creston at Nickerson & 0 & 28 & 28 & $0.00 \%$ & $0.23 \%$ \\
\hline Spring at 28th (SB) & 0 & 15 & 15 & $0.00 \%$ & $0.12 \%$ \\
\hline Spring at 30th (SB) & 0 & 10 & 10 & $0.00 \%$ & $0.08 \%$ \\
\hline Riverside at 24th & 0 & 5 & 5 & $0.00 \%$ & $0.04 \%$ \\
\hline Riverside at 14th & 0 & 3 & 3 & $0.00 \%$ & $0.02 \%$ \\
\hline Rambouillet at Torrey Pines & 0 & 3 & 3 & $0.00 \%$ & $0.02 \%$ \\
\hline Rambouillet at Nicklaus & 0 & 0 & 0 & $0.00 \%$ & $0.00 \%$ \\
\hline \multirow[t]{2}{*}{ Rambouillet at Wade } & 0 & 0 & 0 & $0.00 \%$ & $0.00 \%$ \\
\hline & 628 & 610 & 1238 & $5 \%$ & $5 \%$ \\
\hline
\end{tabular}




\section{Paso Express Route B}

\begin{tabular}{|c|c|c|c|c|c|}
\hline \multirow{2}{*}{$\begin{array}{l}\text { Paso Express Route } B \\
\text { WEEKDAY TOTALS }\end{array}$} & \multicolumn{2}{|c|}{ TOTAL } & \multirow{2}{*}{$\begin{array}{c}\text { Total } \\
\text { Stop } \\
\text { Activity }\end{array}$} & \multirow{2}{*}{$\begin{array}{c}\text { PCT of } \\
\text { System } \\
\text { ONS }\end{array}$} & \multirow{2}{*}{$\begin{array}{c}\text { PCT of } \\
\text { System } \\
\text { OFFS }\end{array}$} \\
\hline & ON & OFF & & & \\
\hline 8th at Pine & 93 & 103 & 195 & $0.78 \%$ & $0.87 \%$ \\
\hline Niblick at South River & 85 & 55 & 140 & $0.72 \%$ & $0.47 \%$ \\
\hline Niblick at Bearcat & 63 & 53 & 115 & $0.53 \%$ & $0.45 \%$ \\
\hline Stoney Creek at Creston & 50 & 30 & 80 & $0.42 \%$ & $0.25 \%$ \\
\hline Spring at 13th & 45 & 0 & 45 & $0.38 \%$ & $0.00 \%$ \\
\hline Creston at Nickerson & 43 & 0 & 43 & $0.36 \%$ & $0.00 \%$ \\
\hline Spring at 8th & 35 & 3 & 38 & $0.30 \%$ & $0.02 \%$ \\
\hline Spring at 34th (NB) (no longer served) & 30 & 10 & 40 & $0.25 \%$ & $0.08 \%$ \\
\hline Spring at 30th (NB) & 28 & 5 & 33 & $0.23 \%$ & $0.04 \%$ \\
\hline Spring at 28th (NB) & 25 & 3 & 28 & $0.21 \%$ & $0.02 \%$ \\
\hline Creston at Stoney Creek & 23 & 40 & 63 & $0.19 \%$ & $0.34 \%$ \\
\hline Creston at Oak Meadows & 23 & 13 & 35 & $0.19 \%$ & $0.11 \%$ \\
\hline Spring at 4th & 20 & 23 & 43 & $0.17 \%$ & $0.19 \%$ \\
\hline Riverside at Ysabel & 20 & 5 & 25 & $0.17 \%$ & $0.04 \%$ \\
\hline Spring at 15th & 18 & 23 & 40 & $0.15 \%$ & $0.19 \%$ \\
\hline Creston at Walnut & 18 & 15 & 33 & $0.15 \%$ & $0.13 \%$ \\
\hline Spring at 19th & 18 & 15 & 33 & $0.15 \%$ & $0.13 \%$ \\
\hline Airport at Scott & 15 & 8 & 23 & $0.13 \%$ & $0.06 \%$ \\
\hline Spring at 32nd (NB) (no longer served) & 15 & 0 & 15 & $0.13 \%$ & $0.00 \%$ \\
\hline Spring at 21st & 13 & 25 & 38 & $0.11 \%$ & $0.21 \%$ \\
\hline Spring at 24th (NB) & 13 & 5 & 18 & $0.11 \%$ & $0.04 \%$ \\
\hline Spring at 10th & 10 & 33 & 43 & $0.08 \%$ & $0.28 \%$ \\
\hline Creston at Sherwood & 10 & 13 & 23 & $0.08 \%$ & $0.11 \%$ \\
\hline Oak at 2nd & 8 & 30 & 38 & $0.06 \%$ & $0.25 \%$ \\
\hline Scott at Larkellen (no longer served) & 8 & 5 & 13 & $0.06 \%$ & $0.04 \%$ \\
\hline Ysabel & 8 & 5 & 13 & $0.06 \%$ & $0.04 \%$ \\
\hline Spring at 34th (SB) & 5 & 125 & 130 & $0.04 \%$ & $1.06 \%$ \\
\hline Scott at Westfield & 5 & 13 & 18 & $0.04 \%$ & $0.11 \%$ \\
\hline Creston at Rolling Hills & 5 & 13 & 18 & $0.04 \%$ & $0.11 \%$ \\
\hline Niblick at Nicklaus & 5 & 3 & 8 & $0.04 \%$ & $0.02 \%$ \\
\hline Riverside at 19th & 5 & 3 & 8 & $0.04 \%$ & $0.02 \%$ \\
\hline Sherwood at Commerce & 5 & 0 & 5 & $0.04 \%$ & $0.00 \%$ \\
\hline Spring at 30th (SB) & 3 & 40 & 43 & $0.02 \%$ & $0.34 \%$ \\
\hline Spring at 32nd (SB) & 3 & 30 & 33 & $0.02 \%$ & $0.25 \%$ \\
\hline Spring at 24th (SB) & 3 & 18 & 20 & $0.02 \%$ & $0.15 \%$ \\
\hline Scott at Via Ramona & 3 & 13 & 15 & $0.02 \%$ & $0.11 \%$ \\
\hline Creston at Capitol Hill & 3 & 5 & 8 & $0.02 \%$ & $0.04 \%$ \\
\hline Rambouillet at Wade & 3 & 3 & 5 & $0.02 \%$ & $0.02 \%$ \\
\hline Creston at Shannon Hill & 3 & 3 & 5 & $0.02 \%$ & $0.02 \%$ \\
\hline Spring at 28th (SB) & 0 & 20 & 20 & $0.00 \%$ & $0.17 \%$ \\
\hline Rambouillet at Torrey Pines & 0 & 5 & 5 & $0.00 \%$ & $0.04 \%$ \\
\hline Riverside at 14 th & 0 & 3 & 3 & $0.00 \%$ & $0.02 \%$ \\
\hline \multirow[t]{2}{*}{ Riverside at 17th } & 0 & 0 & 0 & $0.00 \%$ & $0.00 \%$ \\
\hline & 778 & 808 & 1585 & $7 \%$ & $7 \%$ \\
\hline
\end{tabular}




\section{Paso Express Bus Stop Prerequisite Inventory Summary}

A table in APPENDIX B provides a summary of bus stops served by the Paso Express that lack ADA c mobility device landing pads and/or safe and accessible pathways. The table in APPENDIX B identifies improvement opportunities associated with these bus stops and provides staff recommendations for next steps to create a bus stop improvement plan.

\section{Paso Express High Priority Recommendation:}

Remove landing pad obstructions: Mobility device landing pads at three relatively safe and accessible bus stops (Creston at Walnut, Creston at Bolen, and Stoney Creek at Creston EB) exist but are obstructed by bus stop amenities.

RTA staff recommends removing obstructions to create ADA compliant landing pads all three of these stops.

\section{Paso Express Bus Stop Prerequisites: Mobility Device Landing Pads with Safe and} Accessible Pathway Connections

Of the 69 Paso Express bus stops (all are under Paso Robles jurisdiction), 27 lack ADA accessible landing pads, so they are not ADA compliant. Eight Paso Express bus stops lack connected sidewalks.

\section{Paso Express Pedestrian Crossings}

At two of the 27 ADA non-compliant bus stops, the speed limit of the adjacent street is 45 miles per hours. Five of these 27 stops are adjacent to four or five lane roadways. Seven of these 27 stops do not have a protected pedestrian crossing within sight. 


\section{Paso Express Pull-Out Space, Traffic Impact, and Sight Distance}

A stopped bus at 18 of the 27 ADA non-compliant stops temporarily obstructs traffic. A stopped bus at 25 of these 27 stops obstructs sight distance for pedestrians and/or traffic entering the roadway. 23 of these 27 stops do not have an adequate "No Parking" zone.

\section{Paso Express Existing Amenities at High-Use Bus Stops}

The Paso Express has one high-use bus stop (Spring at 34 ${ }^{\text {th }}$ SB). This stop has a shelter, a bench, a trash can, and ambient lighting. It does not have a braille pad, bike rack, labeled connected bike lane, or any type of vending. 


\section{References}

${ }^{1}$ Easer Seals Project Action (2006). Toolkit for the assessment of Bus Stop Accessibility and Safety, (pp. 6 and pp. 14-15). Washington, DC.

2 U.S. Department of Transportation, Federal Highway Administration (February 2008). Pedestrian Safety Guide for Transit Agencies, (pp. 37). Washington, DC.

${ }^{3}$ Darlene Bonanno v. Central Contra Costa Transit Authority, Supreme Court of California

${ }^{4}$ SLOCOG North County Transit Plan (May 2012).

\section{Bus Stop Photo Catalog}

A comprehensive bus stop photo catalog has been created for all stops surveyed. Please contact RTA for more information. 


\section{APPENDIX A: Amenities at High-Use Bus Stops}




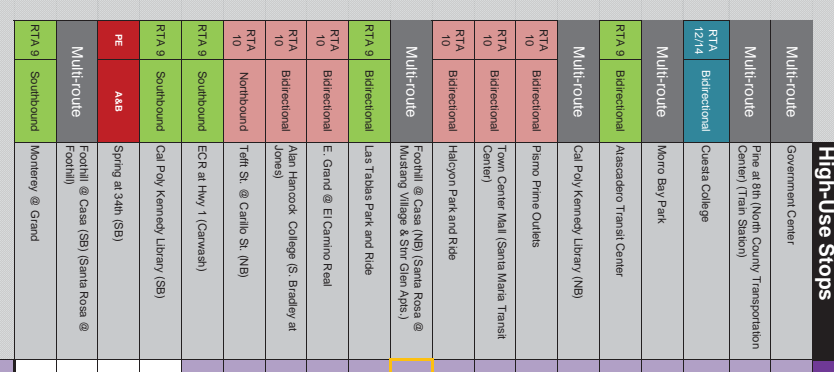

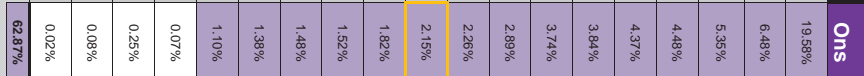

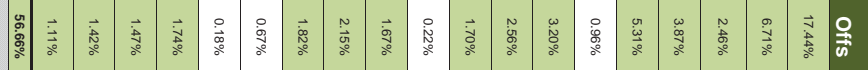

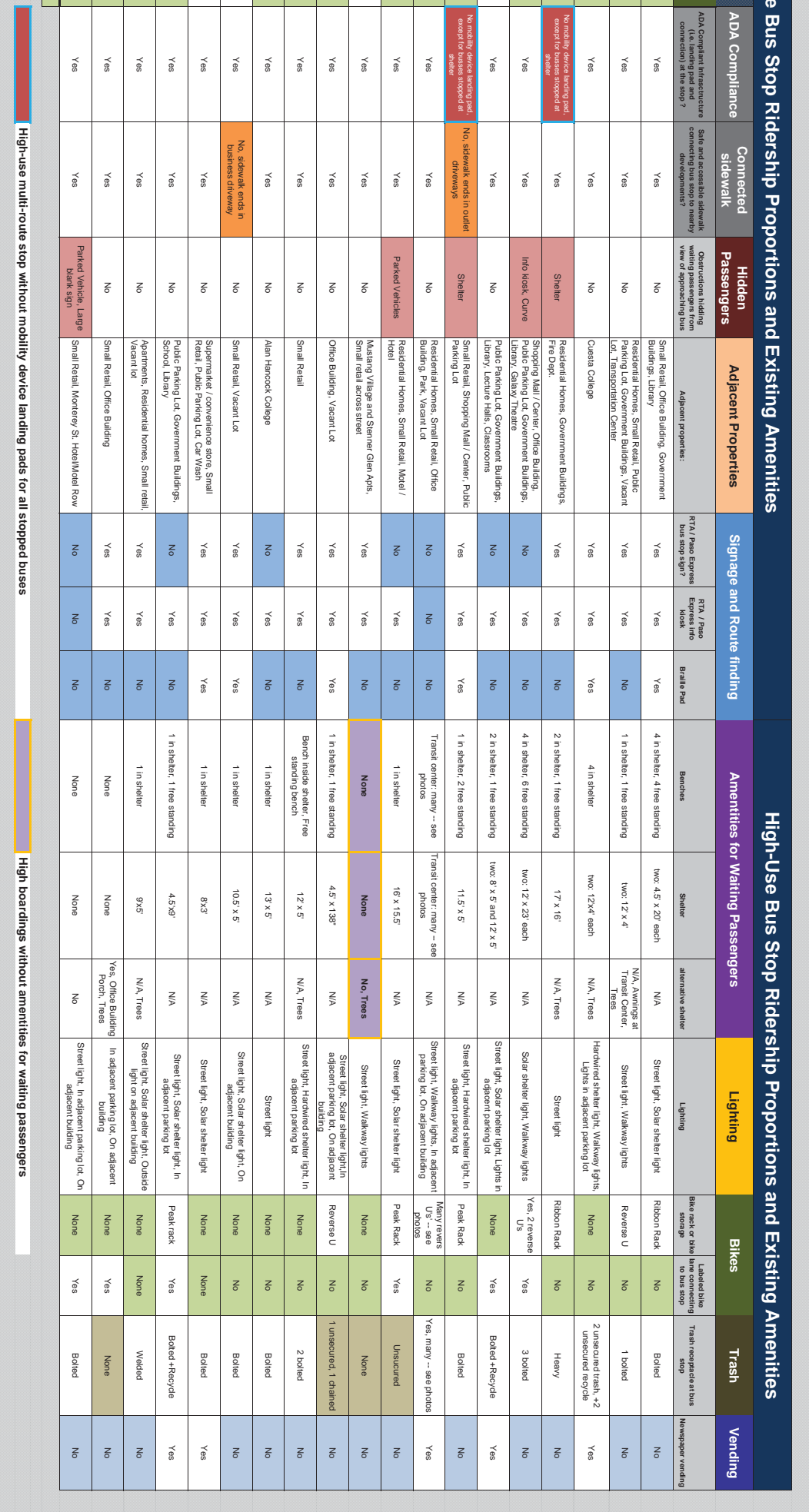


APPENDIX B: Non-ADA compliant Bus Stops 


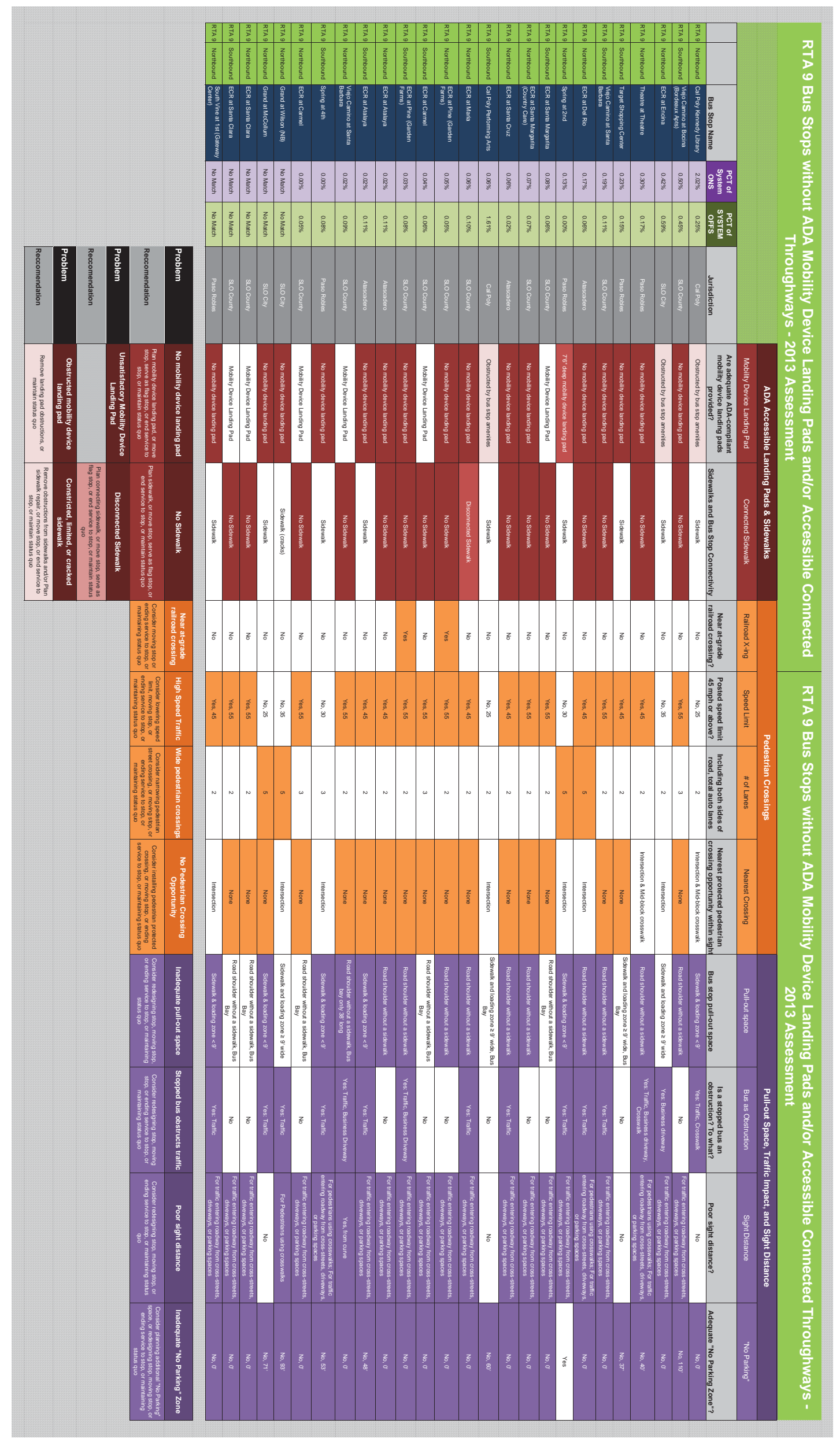




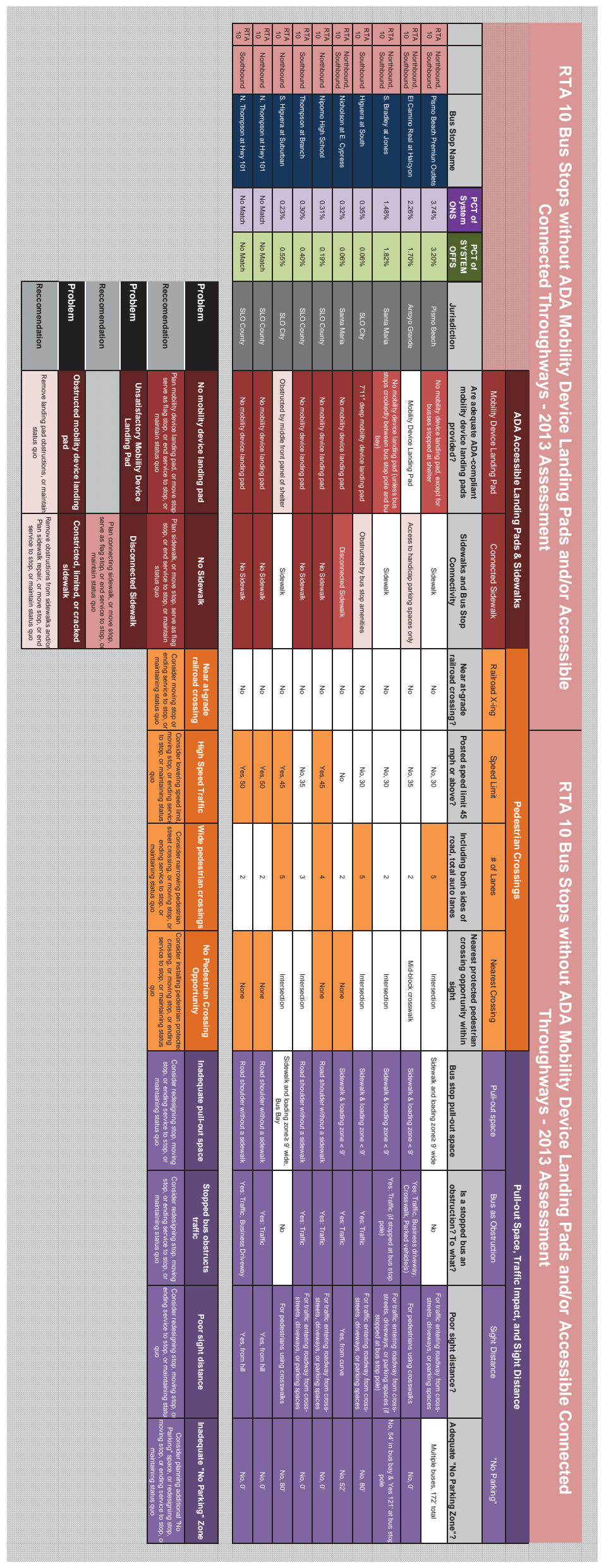




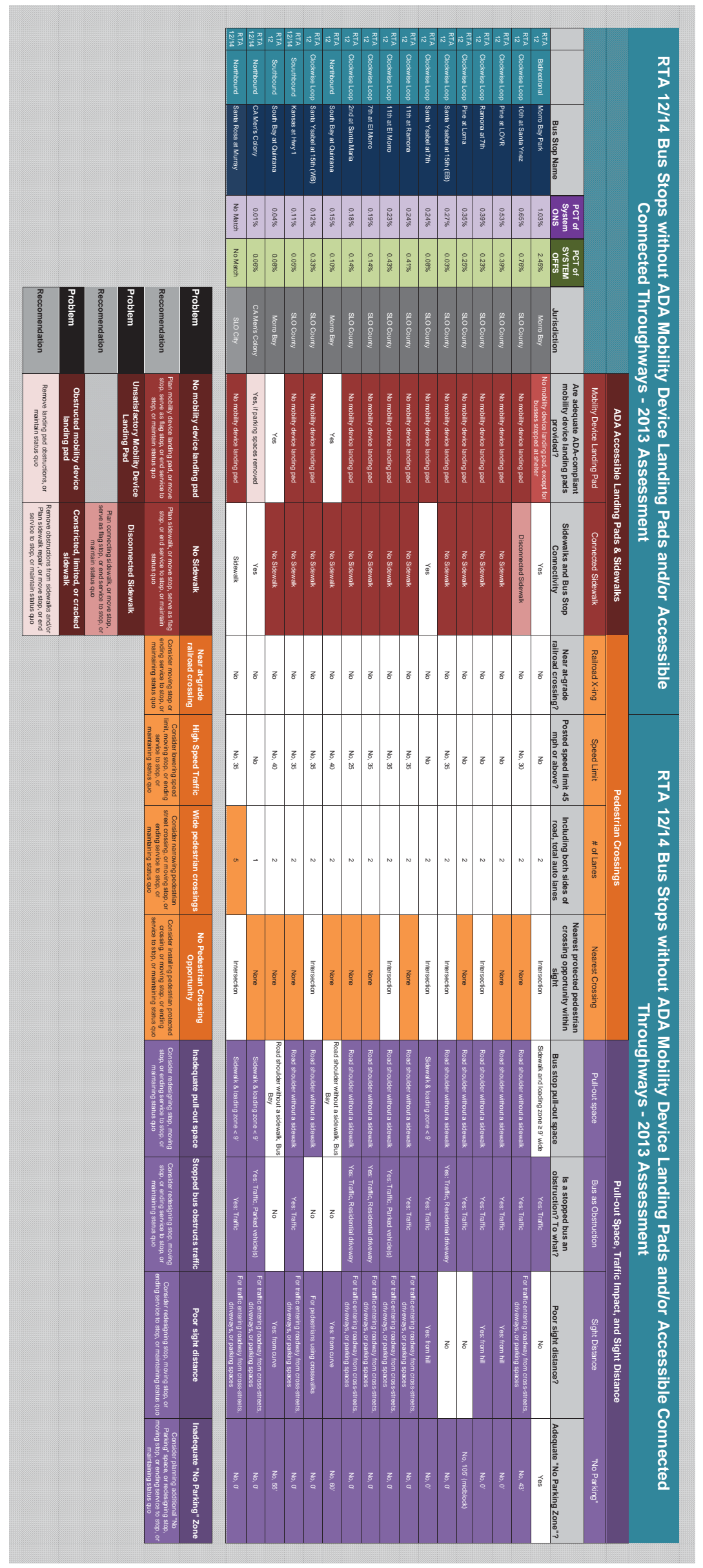




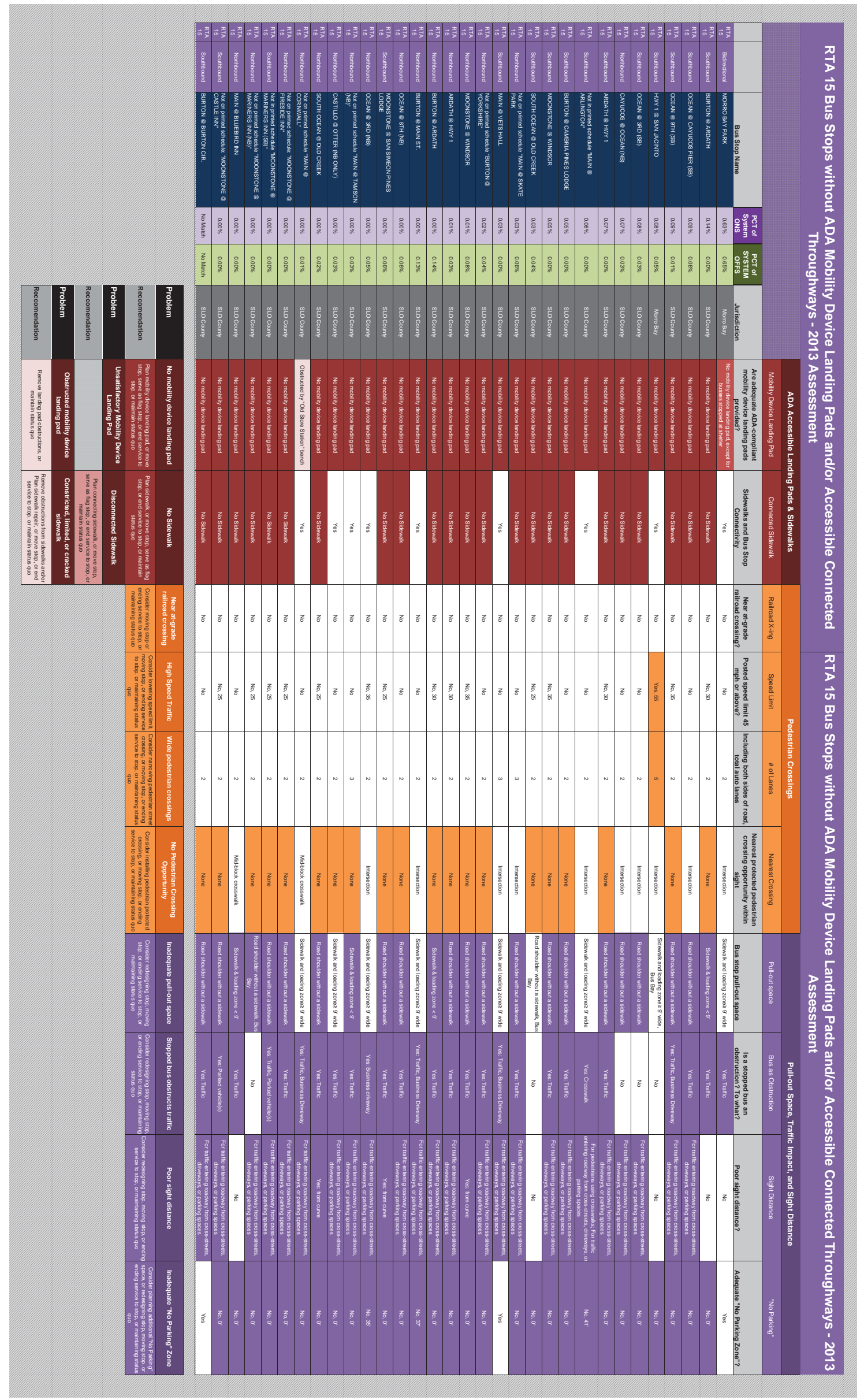




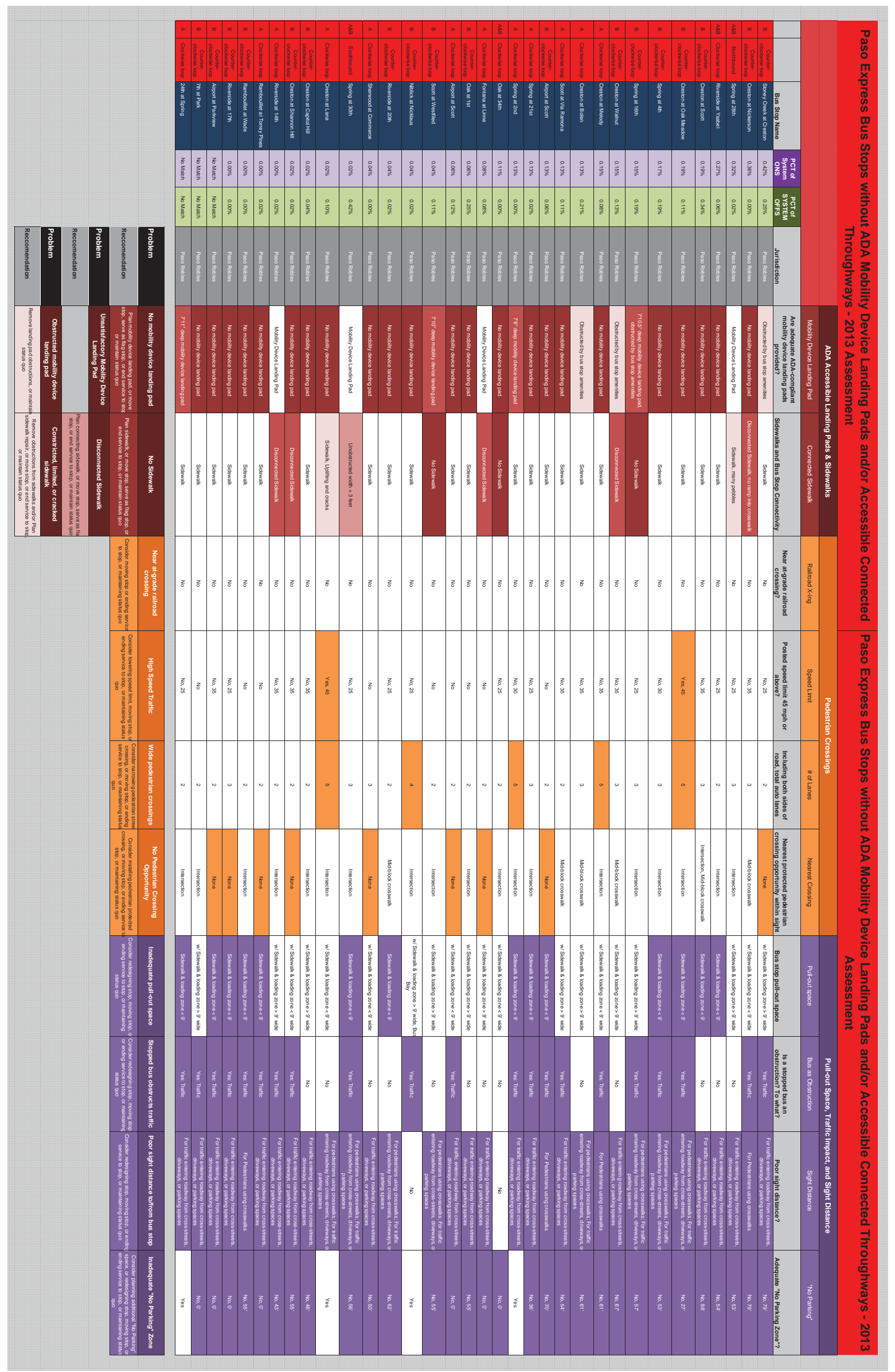


APPENDIX C: RTA Fixed-route Schedules (timetables, bus stop maps and diagrams) 


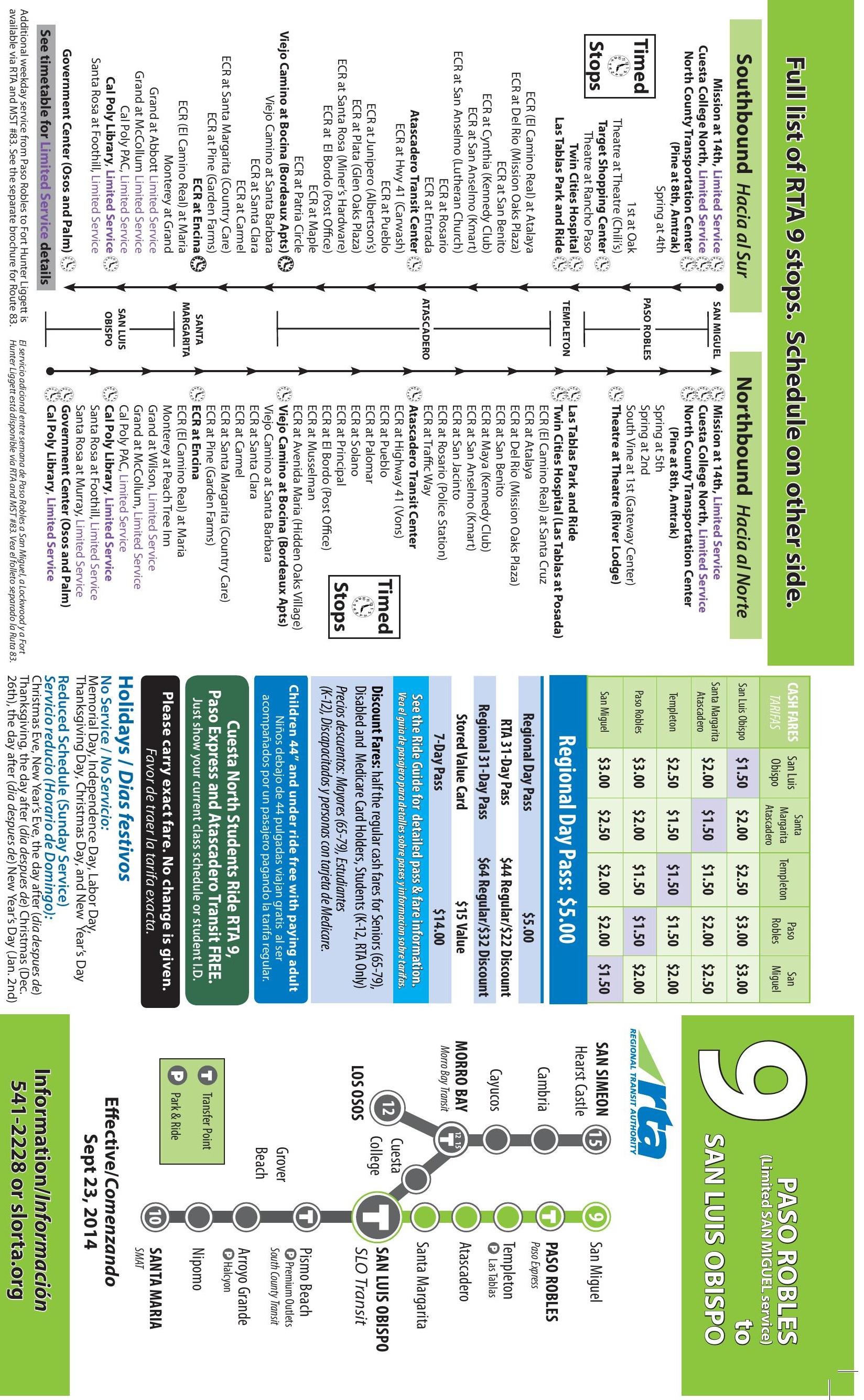




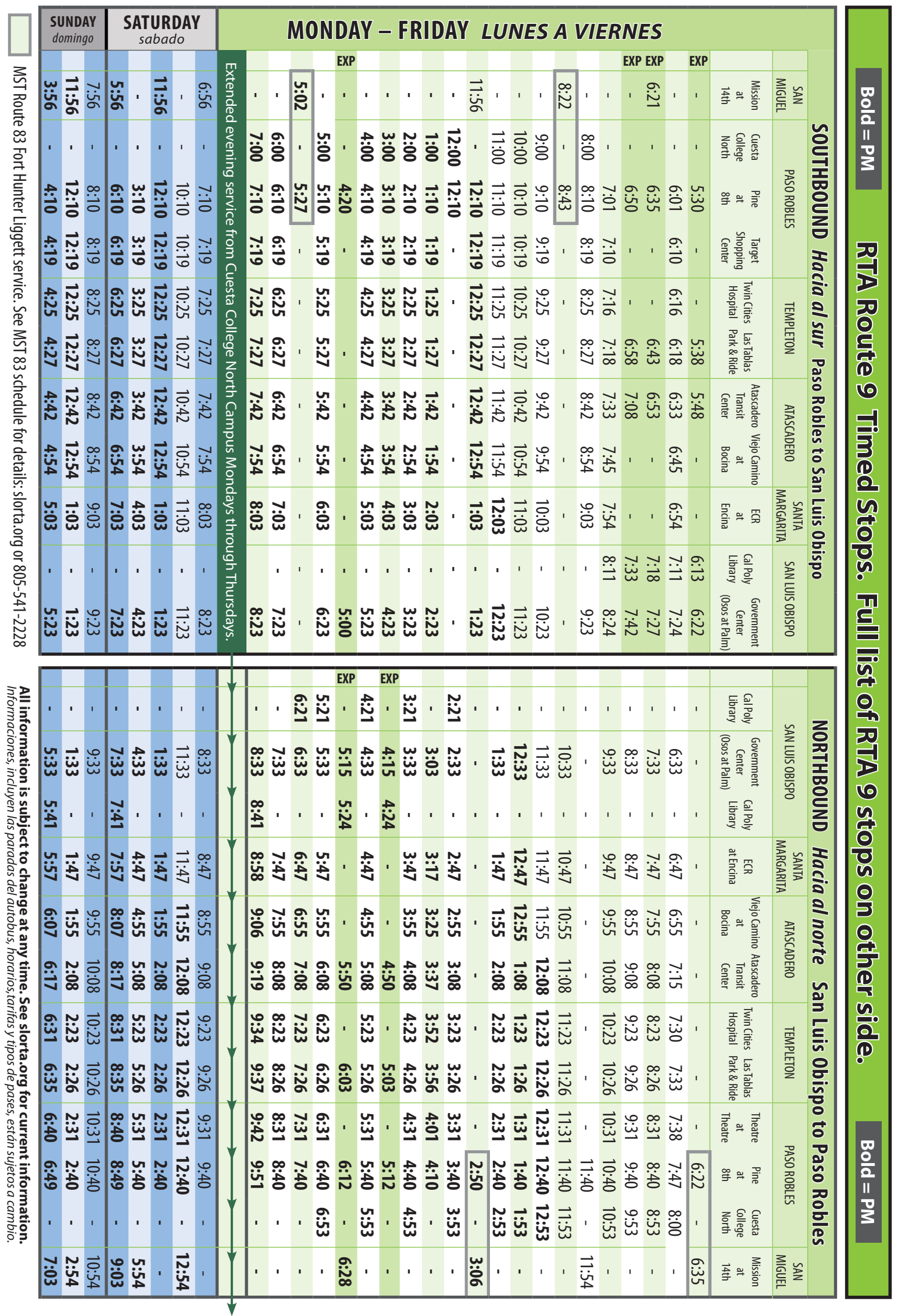

Call 805-541-2228 or visit slorta.org for Cuesta College North extended evening service details. 


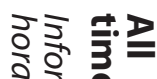

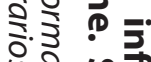

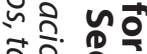

s.ำ

象贯

궁

०हें जे

จㅇำ

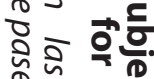

등

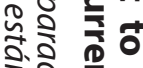

들

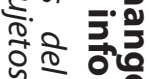

政

ใิ

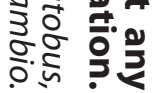

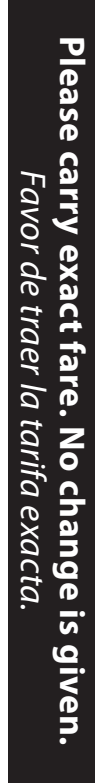

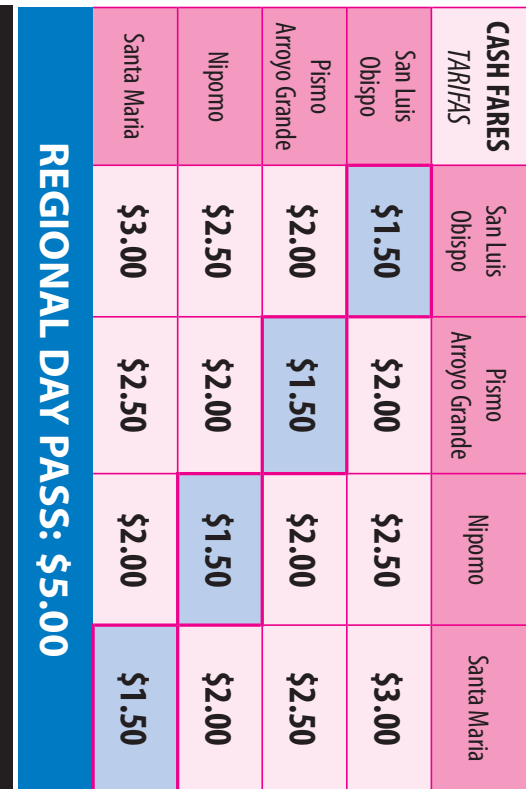

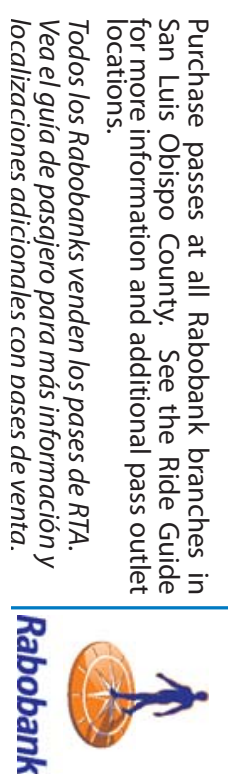

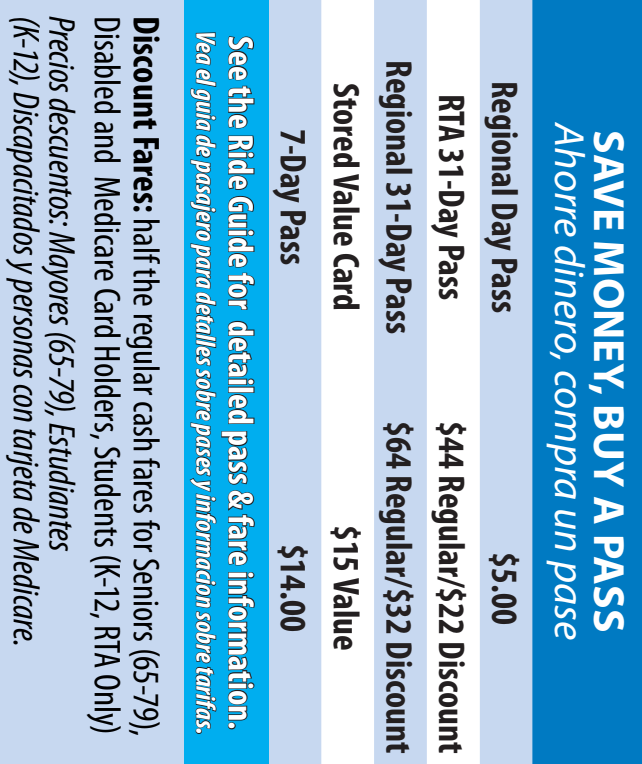
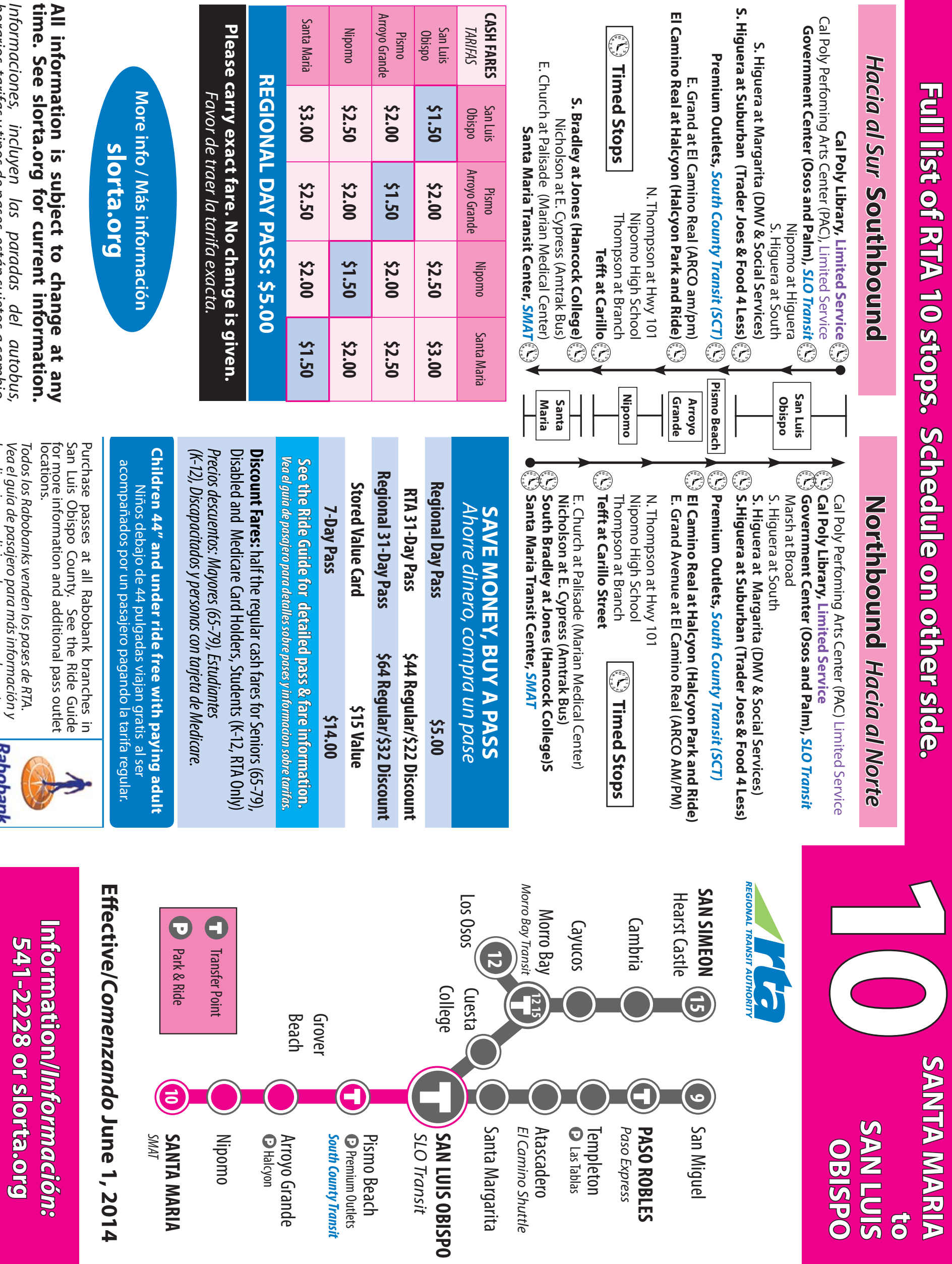


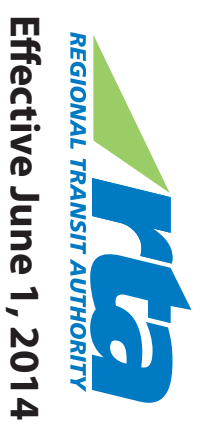

ㅇำ꾸은

ㄱ. 는 을 응 응

ริำ응

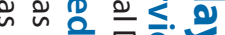

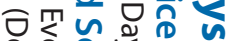

D

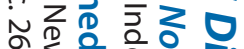

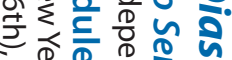

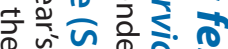

을 罗 ำ

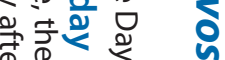

응 舟

능. 응

吕 D

든

בิ

กิ

乙仿

이

는

ำำ

可

ต 든. I

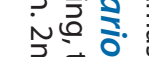

으눙ㅇำ

ริ ผำ ำ

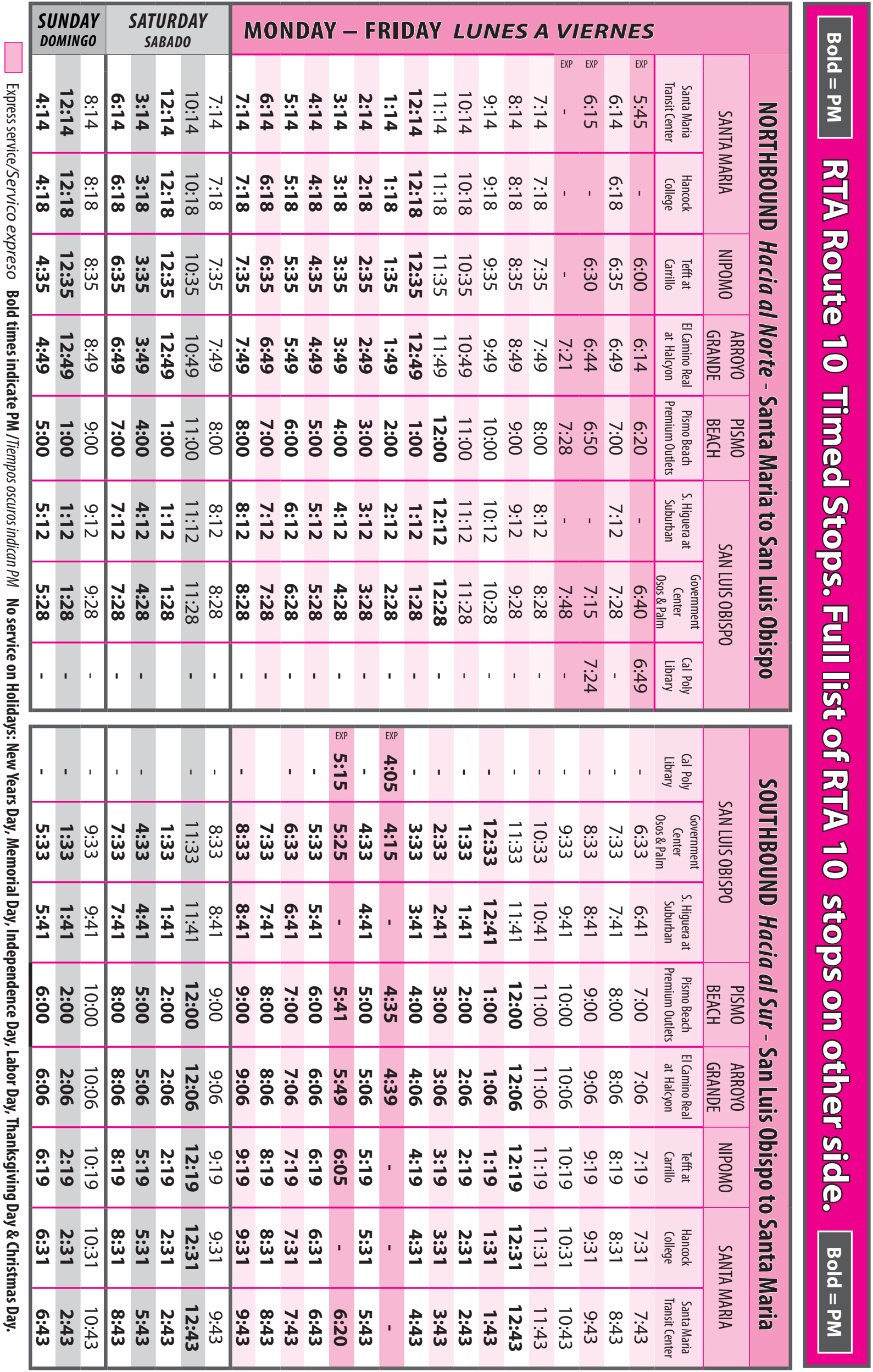




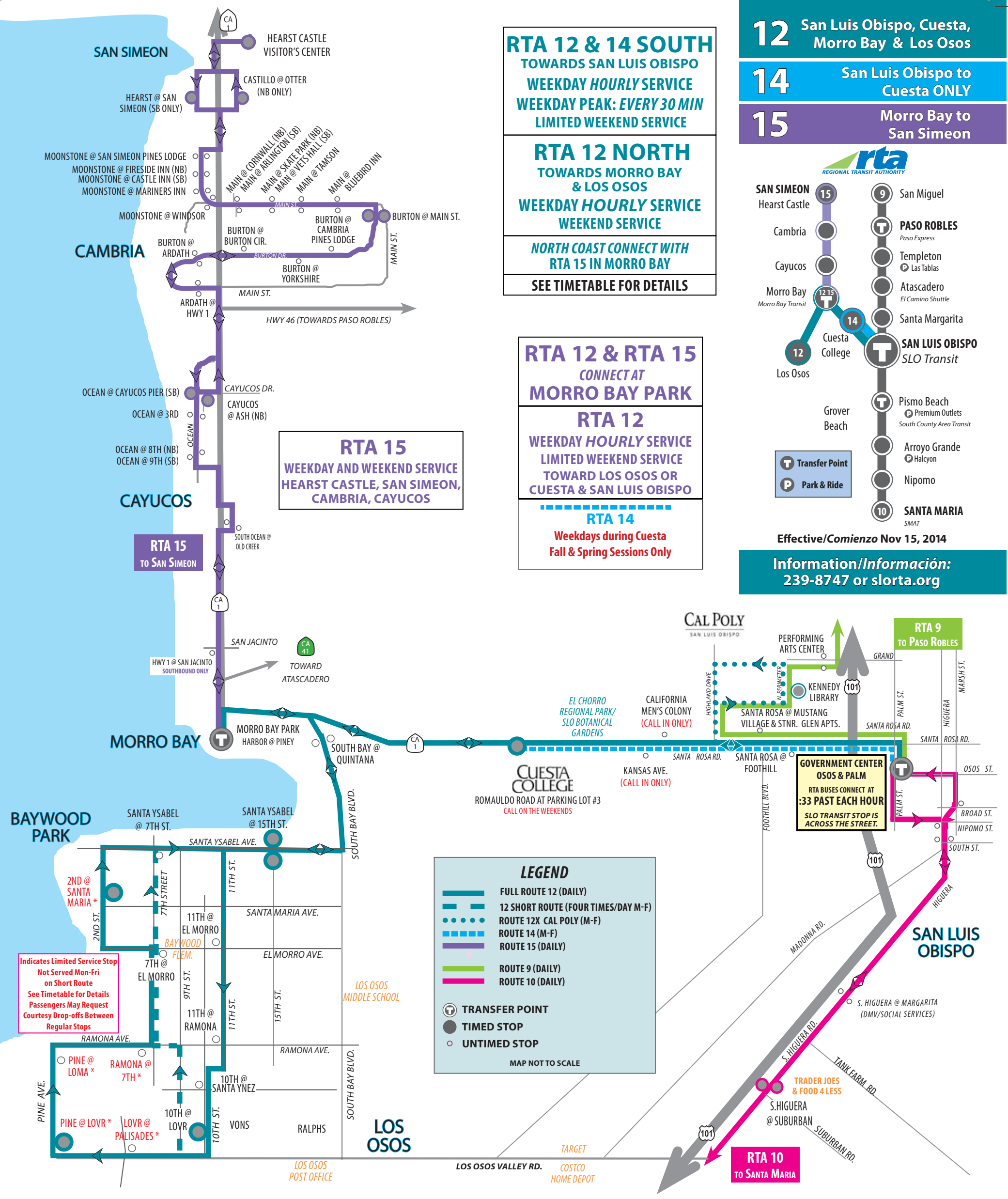




\begin{tabular}{|c|c|c|c|c|c|c|c|c|c|c|c|c|c|c|}
\hline \multirow{5}{*}{\begin{tabular}{|c|}
$\mathbf{z}$ \\
$\mathbf{2}$ \\
II \\
0 \\
0 \\
0 \\
0
\end{tabular}} & \multicolumn{14}{|c|}{ Route 12 Timed Stops: San Luis Obispo, Cuesta College, Los Osos, Morro Bay } \\
\hline & \multirow{4}{*}{\begin{tabular}{|l|} 
\\
$R$ \\
$O$ \\
$U$ \\
T \\
$E$ \\
\end{tabular}} & \multicolumn{4}{|c|}{ Northbound } & \multicolumn{5}{|c|}{ Los Osos Loop } & \multicolumn{4}{|c|}{ Southbound } \\
\hline & & \multicolumn{2}{|c|}{ San Luis Obispo } & \multirow{2}{*}{\multicolumn{2}{|c|}{$\begin{array}{l}\text { Morro Bay } \\
\text { Morro Bay Park }\end{array}$}} & \multicolumn{3}{|c|}{ Connect TO BTAA DS } & \multicolumn{2}{|c|}{ Connect FROM BiEA V5 } & \multirow{2}{*}{\multicolumn{2}{|c|}{$\frac{\text { Morro Bay }}{\text { Morro Bay Park }}$}} & \multicolumn{2}{|c|}{ San Luis Obispo } \\
\hline & & \multirow{2}{*}{$\begin{array}{l}\text { Gov't } \\
\text { Center }\end{array}$} & \multirow{2}{*}{\begin{tabular}{|l|} 
Cuesta \\
College \\
\end{tabular}} & & & \multirow{2}{*}{$\begin{array}{c}\text { Santa Ysabel } \\
\text { at 15th }\end{array}$} & \multirow{2}{*}{$\begin{array}{l}\text { 10th at } \\
\text { LOVR }\end{array}$} & \multirow{2}{*}{$\begin{array}{l}\text { Pine at } \\
\text { LOVR }\end{array}$} & \multirow{2}{*}{\begin{tabular}{|c|} 
2nd at \\
Santa Maria
\end{tabular}} & \multirow{2}{*}{$\begin{array}{c}\text { Santa Ysabel } \\
\text { at 15th }\end{array}$} & & & \multirow{2}{*}{\begin{tabular}{|l|} 
Cuesta \\
College
\end{tabular}} & \multirow{2}{*}{$\begin{array}{l}\text { Gov't } \\
\text { Center }\end{array}$} \\
\hline & & & & Arrive & Depart & & & & & & Arrive & Depart & & \\
\hline & & - & - & - & & $6: 23$ & $6: 29$ & $6: 32$ & $6: 40$ & $6: 43$ & $6: 55$ & $7: 00$ & $7: 11$ & $7: 25$ \\
\hline & $12 \mathrm{x}$ & $* * * 12 x$ & arrives at $C_{a}$ & Poly at & $0 \mathrm{am} * * *$ & 6:48 & 6:54 & 6:57 & 7:05 & 7:08 & 7:18 & 7:18 & $* * *$ & $7: 39$ \\
\hline & & 6:33 & $6: 46$ & $6: 55$ & $7: 15$ & 7:23 & $7: 29$ & $7: 32$ & 7:40 & $7: 43$ & $7: 55$ & $8: 00$ & 8:11 & $8: 25$ \\
\hline & & 7:33 & 7:46 & 7:55 & $8: 15$ & $8: 23$ & $8: 29$ & 8:32 & $8: 40$ & $8: 43$ & $8: 55$ & 9:00 & 9:11 & $9: 25$ \\
\hline$\underset{\Sigma}{\Sigma}$ & & $8: 33$ & 8:46 & $8: 55$ & 9:15 & 9:23 & 9:29 & 9:32 & 9:40 & 9:43 & 9:55 & 10:00 & 10:11 & 10:25 \\
\hline$\overline{\check{~}}$ & $12 \mathrm{~s}$ & 9:33 & 9:46 & 9:55 & $10: 25$ & 10:33 & 10:39 & & 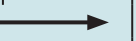 & 10:46 & 10:55 & $11: 00$ & 11:11 & $11: 25$ \\
\hline$\$$ & $12 \mathrm{~s}$ & 10:33 & 10:46 & 10:55 & $11: 25$ & $11: 33$ & 11:39 & & 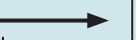 & $11: 46$ & $11: 55$ & $12: 00$ & 12:11 & $12: 25$ \\
\hline ह & & 11:33 & 11:46 & $11: 55$ & $12: 00$ & 12:08 & 12:14 & 12:17 & $12: 25$ & $12: 28$ & 12:38 & $1: 00$ & 1:11 & $1: 25$ \\
\hline 은 & & $12: 33$ & $12: 46$ & $12: 55$ & $1: 00$ & $1: 08$ & 1:14 & 1:17 & $1: 25$ & $1: 28$ & $1: 38$ & 2:00 & 2:11 & 2:25 \\
\hline 노 & & 1:33 & 1:46 & $1: 55$ & 2:00 & 2:08 & 2:14 & 2:17 & 2:25 & 2:28 & 2:38 & 3:00 & 3:11 & 3:25 \\
\hline 1 & & 2:33 & 2:46 & $2: 55$ & 3:00 & 3:08 & 3:14 & 3:17 & 3:25 & 3:28 & 3:38 & 4:00 & 4:11 & $4: 25$ \\
\hline ह & & 3:33 & 3:46 & 3:55 & 4:00 & 4:08 & $4: 14$ & 4:17 & 4:25 & 4:28 & 4:38 & $5: 00$ & 5:11 & $5: 25$ \\
\hline 을 & & 4:33 & 4:46 & 4:55 & $5: 00$ & 5:08 & $5: 14$ & 5:17 & $5: 25$ & $5: 28$ & 5:38 & $6: 00$ & $6: 11$ & $6: 25$ \\
\hline 으 & $12 \mathrm{x}$ & 5:10 & $* * *$ & $5: 38$ & $5: 38$ & 5:46 & 5:52 & $5: 55$ & 6:03 & 6:06 end & $* * * 12 x$ & departs $C$ & Poly at 5:2 & pm *** \\
\hline$\sum$ & $12 \mathrm{~s}$ & $5: 33$ & $5: 46$ & 5:55 & $6: 00$ & $6: 08$ & $6: 14$ & & $\longrightarrow$ & $6: 21$ & $6: 30$ & 7:00 & $7: 11$ & $7: 25$ \\
\hline & $12 \mathrm{~s}$ & $6: 33$ & $6: 46$ & $6: 55$ & 7:00 & 7:08 & 7:14 & & & 7:21 & 7:30 & $8: 00$ & 8:11 & $8: 25$ \\
\hline & & 7:33 & 7:46 & 7:55 & $8: 00$ & 8:08 & $8: 14$ & 8:17 & $8: 25$ & $8: 28$ & 8:38 & 8:38 & $8: 49$ & 9:03 \\
\hline & & $8: 33$ & $8: 46$ & $8: 55$ & 9:00 & 9:08 & 9:14 & 9:17 & 9:25 & 9:28 & 9:38 & 9:38 & 9:49 & 10:03 \\
\hline & & 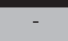 & & - & 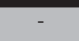 & $7: 23$ & $7: 29$ & $7: 32$ & $7: 40$ & $7: 43$ & $7: 53$ & $8: 00$ & CALL & $8: 25$ \\
\hline & & $8: 33$ & CALL & $8: 55$ & 9:00 & 9:08 & 9:14 & 9:17 & 9:25 & $9: 28$ & - & - & - & - \\
\hline E & & - & - & - & - & 10:23 & 10:29 & 10:32 & $10: 40$ & 10:43 & 10:53 & 11:00 & CALL & $11: 25$ \\
\hline$\Xi$ & & $11: 33$ & CALL & $11: 55$ & $12: 00$ & 12:08 & 12:14 & 12:17 & $12: 25$ & $12: 28$ & - & - & - & - \\
\hline$\vec{\sigma}$ & & - & - & - & - & $12: 23$ & $12: 29$ & $12: 32$ & $12: 40$ & $12: 43$ & $12: 53$ & 1:00 & CALL & 1:25 \\
\hline 은 & & 1:33 & CALL & 1:55 & 2:00 & 2:08 & 2:14 & $2: 17$ & $2: 25$ & $2: 28$ & - & - & - & - \\
\hline 룬 & & - & - & - & - & 3:23 & 3:29 & 3:32 & 3:40 & 3:43 & 3:53 & 4:00 & CALL & $4: 25$ \\
\hline$\pi$ & & 4:33 & CALL & 4:55 & 5:00 & 5:08 & $5: 14$ & 5:17 & $5: 25$ & $5: 28$ & - & - & - & - \\
\hline & & - & - & - & - & $6: 23$ & 6:29 & $6: 32$ & $6: 40$ & $6: 43$ & $6: 53$ & 7:00 & CALL & 7:25 \\
\hline & & 7:33 & CALL & 7:55 & $8: 00$ & 8:08 & $8: 14$ & $8: 17$ & $8: 25$ & $8: 28$ & - & - & - & - \\
\hline & & 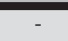 & & 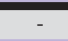 & & $8: 23$ & $8: 29$ & $8: 32$ & $8: 40$ & $8: 43$ & $8: 53$ & 9:00 & CALL & $9: 25$ \\
\hline$\cong$ & & 9:33 & CALL & 9:55 & 10:00 & 10:08 & 10:14 & 10:17 & 10:25 & $10: 28$ & 10:38 & 10:38 & CALL & $11: 00$ \\
\hline & & $11: 33$ & CALL & $11: 55$ & $12: 00$ & $12: 08$ & $12: 14$ & - & - & - & - & - & - & - \\
\hline & & - & - & - & - & $12: 23$ & $12: 29$ & $12: 32$ & $12: 40$ & 12:43 & $12: 53$ & 1:00 & CALL & 1:25 \\
\hline$\widetilde{\sigma}$ & & 1:33 & CALL & 1:55 & 2:00 & $2: 08$ & $2: 14$ & $2: 17$ & $2: 25$ & $2: 28$ & $2: 38$ & 2:38 & CALL & 3:00 \\
\hline 를 & & 3:33 & CALL & 3:55 & 4:00 & 4:08 & $4: 14$ & - & - & - & & - & - & - \\
\hline$\overline{\bar{n}}$ & & - & - & - & - & 4:23 & 4:29 & 4:32 & 4:40 & $4: 43$ & 5:00 & 5:00 & CALL & $5: 25$ \\
\hline & & $5: 33$ & CALL & 5:55 & 6:00 & 6:08 & 6:14 & 6:17 & $6: 25$ & $6: 28$ & - & - & - & - \\
\hline
\end{tabular}

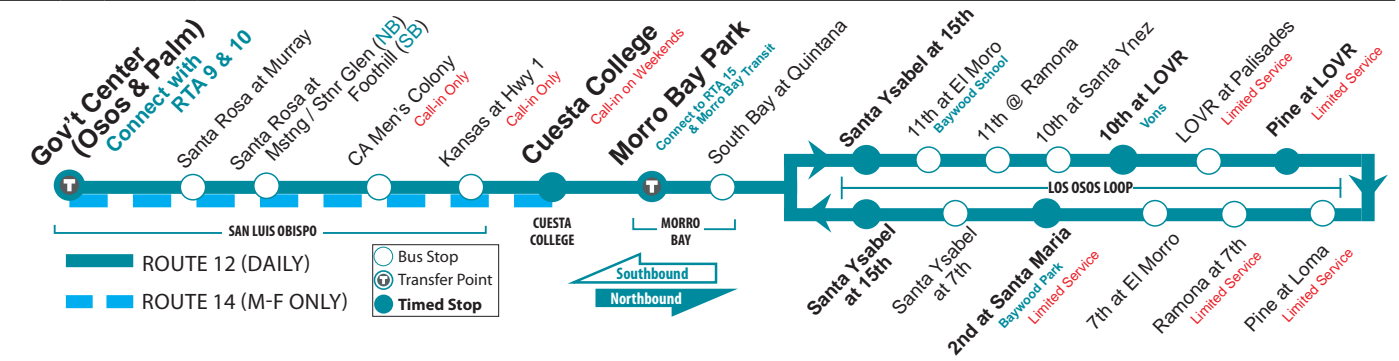

\begin{tabular}{|c|c|c|c|c|c|c|c|c|c|c|c|}
\hline \multirow{3}{*}{$\begin{array}{l}\sum \\
\text { II } \\
\text { II } \\
0 \\
0\end{array}$} & \multicolumn{5}{|c|}{$\begin{array}{l}\text { ROUTE } 15 \text { SOUTHBOUND } \\
\text { TIMED STOPS: HEARST CASTLE TOWARDS MORRO BAY }\end{array}$} & & \multicolumn{5}{|c|}{$\begin{array}{l}\text { ROUTE } 15 \text { NORTHBOUND } \\
\text { TIMED STOPS: MORRO BAY TOWARDS HEARST CASTLE }\end{array}$} \\
\hline & \multicolumn{2}{|c|}{ SAN SIMEON } & \multirow{2}{*}{$\begin{array}{l}\text { CAMBRIA } \\
\text { Burton @ } \\
\text { Main St. }\end{array}$} & \multirow{2}{*}{$\begin{array}{l}\text { CAYUCOS } \\
\text { Ocean @ } \\
\text { Cayucos }\end{array}$} & \multirow{2}{*}{$\begin{array}{l}\text { MORRO BAY } \\
\text { Morro Bay } \\
\text { Park-Arrive }\end{array}$} & & \multirow{2}{*}{$\begin{array}{l}\text { MORRO BAY } \\
\text { Morro Bay Park } \\
\text { - Depart }\end{array}$} & \multirow{2}{*}{$\begin{array}{l}\text { CAYUCOS } \\
\text { Cayucos Dr. } \\
@ \text { Ash }\end{array}$} & \multirow{2}{*}{$\begin{array}{l}\text { CAMBRIA } \\
\text { Burton @ } \\
\text { Main St. }\end{array}$} & \multicolumn{2}{|c|}{ SAN SIMEON } \\
\hline & $\begin{array}{l}\text { Hearst Castle } \\
\text { Visitors Center }\end{array}$ & $\begin{array}{l}\text { Hearst Dr.@ } \\
\text { San Simeon }\end{array}$ & & & & & & & & $\begin{array}{l}\text { Castillo@ } \\
\text { Otter Way }\end{array}$ & $\begin{array}{c}\text { Hearst Castle } \\
\text { Visitors Center }\end{array}$ \\
\hline \multirow{5}{*}{ 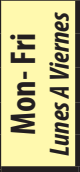 } & --- & 6:05 & 6:17 & 6:40 & 6:55 & \multirow{13}{*}{$\begin{array}{c}12 \\
83 \\
15 \\
\text { conned? } \\
\text { ats } \\
\text { Morro } \\
\text { Bay } \\
\text { Park }\end{array}$} & 7:02 & $7: 14$ & $7: 34$ & $7: 47$ & $7: 54$ \\
\hline & 8:00 & 8:05 & 8:17 & 8:40 & 8:55 & & 10:02 & 10:14 & 10:34 & 10:47 & 10:54 \\
\hline & 11:00 & 11:05 & 11:17 & 11:40 & $11: 55$ & & 12:02 & 12:14 & $12: 34$ & $12: 47$ & $12: 54$ \\
\hline & 2:00 & 2:05 & 2:17 & $2: 40$ & 2:55 & & 3:02 & 3:14 & 3:34 & 3:47 & $3: 54$ \\
\hline & 5:00 & 5:05 & 5:17 & $5: 40$ & 5:55 & & $6: 02$ & 6:14 & $6: 34$ & 6:47 & - \\
\hline \multirow{5}{*}{ 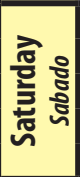 } & & 55 & $7: 17$ & $7: 40$ & $7: 55$ & & 9:02 & $9: 14$ & $9: 34$ & $9: 47$ & $9: 54$ \\
\hline & 10:00 & 10:05 & 10:17 & 10:40 & $10: 55$ & & 12:02 & $12: 14$ & $12: 34$ & $12: 47$ & $12: 54$ \\
\hline & $12: 00$ & 12:05 & 12:17 & 12:40 & 12:55 & & $2: 02$ & $2: 14$ & $2: 34$ & $2: 47$ & $2: 54$ \\
\hline & $3: 00$ & 3:05 & $3: 17$ & $3: 40$ & $3: 55$ & & 5:02 & 5:14 & $5: 34$ & $5: 47$ & $5: 54^{*}$ \\
\hline & $6: 00^{*}$ & 6:05 & $6: 17$ & $6: 40$ & $6: 55$ & & 8:02 & 8:14 & 8:34 & 8:47 & \\
\hline \multirow{3}{*}{ 총 } & - & $8: 05$ & $8: 17$ & $8: 40$ & $8: 55$ & & 10:02 & 10:14 & 10:34 & 10:47 & 10:54 \\
\hline & $12: 00$ & 12:05 & $12: 17$ & $12: 40$ & 12:55 & & 2:02 & 2:14 & $2: 34$ & 2:47 & 2:54 \\
\hline & 4:00 & 4:05 & 4:17 & 4:40 & $4: 55$ & & $6: 02$ & 6:14 & $6: 34$ & 6:47 & ---- \\
\hline
\end{tabular}

ROUTE 15 NORTHBOUND

TIMED STOPS: MORRO BAY TOWARDS HEARST CASTLE

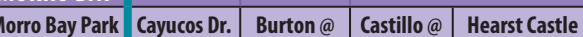

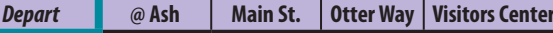

* Peak Summer season only: when Castle gates are open

\begin{tabular}{|c|c|c|c|}
\hline \multicolumn{3}{|c|}{ Route 14 Timed Stops } \\
\hline \multicolumn{3}{|c|}{ Weekdays during Cuesta } \\
Fall \& Spring Sessions Only \\
\hline \multicolumn{3}{|c|}{ To Cuesta } & From Cuesta \\
\hline Gov't & Cuesta & Cuesta & Gov't \\
Center & College & College & Center \\
7:42 & $7: 57$ & - & - \\
8:03 & $8: 16$ & $8: 48$ & $9: 00$ \\
9:03 & $9: 16$ & $9: 48$ & $10: 00$ \\
$10: 03$ & $10: 16$ & $10: 48$ & $11: 00$ \\
$\mathbf{1 : 0 3}$ & $\mathbf{1 : 1 6}$ & $\mathbf{1 : 4 8}$ & $\mathbf{2 : 0 0}$ \\
$\mathbf{2 : 0 3}$ & $\mathbf{2 : 1 6}$ & $\mathbf{2 : 4 8}$ & $\mathbf{3 : 0 0}$ \\
$\mathbf{3 : 0 3}$ & $\mathbf{3 : 1 6}$ & $\mathbf{3 : 3 0}$ & $\mathbf{3 : 4 5}$ \\
\hline
\end{tabular}

Holidays / Dias festivos

No Service / No Servicio:

Memorial Day, Independence Day, Labor Day,

Thanksgiving Day, Christmas Day, and New Year's Day

Reduced Schedule (Sunday Service)

Servicio reducio (Horario de Domingo):

Christmas Eve, New Year's Eve, the day after

(dia despues de) Thanksgiving, the day after

(dia despues de) Christmas (Dec. 26th),

the day after (dia despues de) New Year's Day (Jan. 2nd)

\subsection{1 .2228 slorta.org}

\begin{tabular}{|c|c|c|c|c|}
\hline $\begin{array}{c}\text { CASH FARES } \\
\text { TARIFAS }\end{array}$ & $\begin{array}{c}\text { San Luis } \\
\text { Obispo }\end{array}$ & $\begin{array}{c}\text { Cuesta } \\
\text { Kansas } \\
\text { CMC }\end{array}$ & $\begin{array}{l}\text { Morro Bay } \\
\text { Los Osos }\end{array}$ & $\begin{array}{c}\text { Cayucos } \\
\text { Cambria } \\
\text { San Simeon }\end{array}$ \\
\hline San Luis Obispo & $\mathbf{\$ 1 . 5 0}$ & $\mathbf{\$ 2 . 0 0}$ & $\mathbf{\$ 2 . 5 0}$ & $\mathbf{\$ 3 . 0 0}$ \\
\hline $\begin{array}{c}\text { Cuesta College } \\
\text { Kansas / CMC }\end{array}$ & $\mathbf{\$ 2 . 0 0}$ & $\mathbf{\$ 1 . 5 0}$ & $\mathbf{\$ 1 . 5 0}$ & $\mathbf{\$ 2 . 0 0}$ \\
\hline $\begin{array}{c}\text { Morro Bay } \\
\text { Los Osos }\end{array}$ & $\mathbf{\$ 2 . 5 0}$ & $\mathbf{\$ 1 . 5 0}$ & $\mathbf{\$ 1 . 5 0}$ & $\mathbf{\$ 1 . 5 0}$ \\
\hline $\begin{array}{c}\text { Cayucos, Cambria } \\
\text { San Simeon }\end{array}$ & $\mathbf{\$ 3 . 0 0}$ & $\mathbf{\$ 2 . 0 0}$ & $\mathbf{\$ 1 . 5 0}$ & $\mathbf{\$ 1 . 5 0}$ \\
\hline
\end{tabular}

Regional Day Pass: $\$ 5.00$

\section{SAVE MONEY, BUY A PASS}

Regional Day Pass $\$ 5.00$

$\begin{array}{cc}\text { Regional Day Pass } & \$ 5.00 \\ \text { RTA 31-Day Pass } & \$ 44 \text { Regular/ } \$ 22 \text { Discount }\end{array}$

Regional 31-Day Pass $\quad \$ 64$ Regular/\$32 Discount

Stored Value Card \$15 Value

7-Day Pass $\$ 14.00$

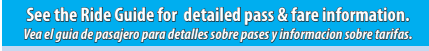

Discount Fares: half the regular cash fares for Seniors (65-79), Disabled and Medicare Card Holders, Students (K-12, RTA Only) Precios descuentos: Mayores (65-79), Estudiantes

$(K-12)$, Discapacitados y personas con tarjeta de Medicare.

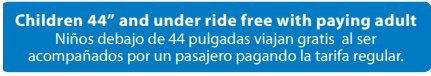

Purchase passes at all Rabobank branches in
San Luis Obispo County See the Ride Guide
for more information and additional pass outlet

Todos los Rabobanks venden los pases de RTA.

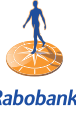

Please carry exact fare. No change is given.

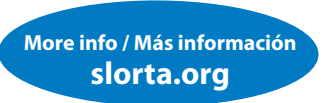


APPENDIX D: Timetables used to Populate Google with RTA Route and Schedule Information 


\begin{tabular}{|c|c|c|c|c|c|c|c|}
\hline & & & Start & End & $\begin{array}{l}\text { SPAN OF } \\
\text { SERVICE }\end{array}$ & & $\begin{array}{c}\text { \# of Bus } \\
\text { Trips per } \\
\text { Day }\end{array}$ \\
\hline & RTA 9 & Atascadero Transit Center & $5: 48$ & $21: 19$ & $15: 31$ & 0.516667 & 34 \\
\hline & & Cuesta College North & $8: 00$ & 19:00 & 11:00 & & 23 \\
\hline & & Las Tablas Park \& Ride & $5: 38$ & 21:37 & $15: 59$ & 0.983333 & 34 \\
\hline & & Twin Cities Hospital & $6: 16$ & $21: 34$ & $15: 18$ & 0.3 & 29 \\
\hline & & & & & $0: 00$ & & \\
\hline & RTA 10 & Pismo Beach Premiun Outlets & $6: 20$ & 21:00 & $14: 40$ & 0.666667 & 33 \\
\hline & & El Camino Real at Halcyon & $6: 15$ & $21: 06$ & $14: 51$ & 0.85 & 33 \\
\hline & & E. Grand at El Camino Real & $6: 14$ & $21: 05$ & $14: 51$ & 0.85 & 32 \\
\hline & & S. Bradley at Jones & $6: 18$ & $21: 31$ & $15: 13$ & 0.216667 & 28 \\
\hline & & Nicholson at E. Cypress & $6: 24$ & $21: 38$ & $15: 14$ & 0.233333 & 29 \\
\hline & & E. Church at Palisade & $6: 24$ & $21: 38$ & $15: 14$ & 0.233333 & 29 \\
\hline & & Santa Maria Transit Center & $5: 45$ & $21: 43$ & $15: 58$ & 0.966667 & 31 \\
\hline & & & & & & & \\
\hline & RTA 12/14 & Cuesta College & $6: 46$ & $21: 49$ & 15:03 & 0.05 & 44 \\
\hline & & & & & & & \\
\hline & RTA 15 & HEARST CASTLE VISITOR'S CENTER & 7:54 & $17: 00$ & 9:06 & 0.1 & 8 \\
\hline & & & & & & & \\
\hline & Paso Express & Spring at 24th NB & $7: 49$ & $18: 50$ & 11:01 & 0.016667 & 24 \\
\hline & & Spring at 28th NB & $7: 51$ & 18:52 & 11:01 & 0.016667 & 24 \\
\hline & & Spring at 30th NB & $7: 53$ & 18:54 & 11:01 & 0.016667 & 24 \\
\hline & & Oak at 34th & $7: 55$ & $18: 56$ & 11:01 & 0.016667 & 24 \\
\hline & & Spring at 34th SB & $6: 48$ & $17: 58$ & $11: 10$ & 0.166667 & 24 \\
\hline & & Spring at 32nd SB & $6: 48$ & $17: 58$ & 11:10 & 0.166667 & 24 \\
\hline & & Spring at 30th SB & $6: 49$ & $17: 59$ & $11: 10$ & 0.166667 & 24 \\
\hline & & Spring at 28th SB & $6: 49$ & 18:00 & 11:11 & 0.183333 & 24 \\
\hline & & Spring at 26th SB & $6: 50$ & 18:01 & $11: 11$ & 0.183333 & 24 \\
\hline & & Riverside at Ysabel & $7: 03$ & 18:47 & $11: 44$ & 0.733333 & 24 \\
\hline & & Ysabel & $7: 03$ & $18: 47$ & $11: 44$ & 0.733333 & 24 \\
\hline & & & & & & & \\
\hline $\begin{array}{c}\text { RTA 9, } \\
10,12 / 14 \\
\end{array}$ & $\begin{array}{l}\text { Northbound, } \\
\text { Southbound }\end{array}$ & Government Center (Osos \& Palm) & $6: 22$ & 22:03 & $15: 41$ & 0.683333 & 116 \\
\hline $\begin{array}{c}\text { RTA 9; PE } \\
\text { A\&B }\end{array}$ & $\begin{array}{l}\text { Northbound, } \\
\text { Southbound, } \\
\text { CW \& CCW } \\
\text { Loops }\end{array}$ & Paso Robles Transit Center (8th \& Pine) & $5: 30$ & 21:51 & $16: 21$ & 0.35 & 68 \\
\hline $\begin{array}{c}\text { RTA 12, } \\
15\end{array}$ & $\begin{array}{l}\text { Northbound, } \\
\text { Southbound, } \\
\text { Clockwise loop }\end{array}$ & MORRO BAY PARK & $6: 55$ & $21: 38$ & $14: 43$ & 0.716667 & 43 \\
\hline $\begin{array}{l}\text { RTA 9, } \\
10,12 \\
\end{array}$ & Northbound & Cal Poly Kennedy Library & $6: 49$ & $20: 41$ & 13:52 & 0.866667 & 12 \\
\hline RTA 9, 10 & Northbound & Cal Poly Performing Arts Cntr. & 6:50 & $20: 42$ & 13:52 & 0.866667 & 12 \\
\hline $\begin{array}{c}\text { RTA } 9, \\
10,12 / 14 \\
\end{array}$ & Northbound & Santa Rosa at Stenner Glen Apts (NB) & $6: 37$ & 20:38 & 14:01 & 0.016667 & 27 \\
\hline $\begin{array}{c}\text { RTA 9, } \\
12 / 14\end{array}$ & Southbound & Santa Rosa at Foothill & $6: 14$ & 21:59 & $15: 45$ & 0.916667 & 27 \\
\hline $\begin{array}{c}\text { RTA 9, } \\
10,12\end{array}$ & Northbound & Santa Rosa at Murray & $6: 36$ & $20: 37$ & 14:01 & 0.016667 & 27 \\
\hline $\begin{array}{c}\text { RTA 9, PE } \\
\text { A }\end{array}$ & $\begin{array}{l}\text { Northbound, } \\
\text { CW Loop }\end{array}$ & Spring at 2nd & $7: 32$ & 21:48 & $14: 16$ & 0.266667 & 27 \\
\hline $\begin{array}{c}\text { RTA 9; PE } \\
\text { A } \\
\end{array}$ & $\begin{array}{l}\text { Northbound, } \\
\text { CW Loop }\end{array}$ & Spring at 5th & $7: 33$ & 21:49 & $14: 16$ & 0.266667 & 27 \\
\hline $\begin{array}{c}\text { RTA 9, PE } \\
\text { B }\end{array}$ & $\begin{array}{l}\text { Southbound, } \\
\text { CCW Loop }\end{array}$ & Spring at 4 th & $6: 03$ & $19: 12$ & $13: 09$ & 0.15 & 26 \\
\hline
\end{tabular}



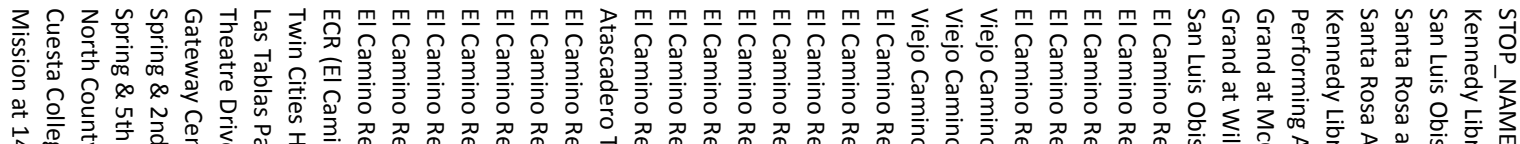

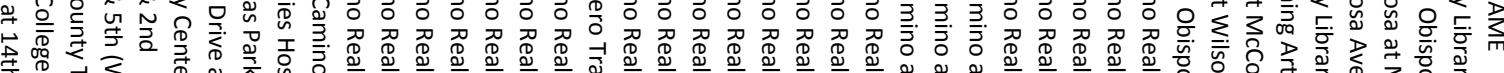

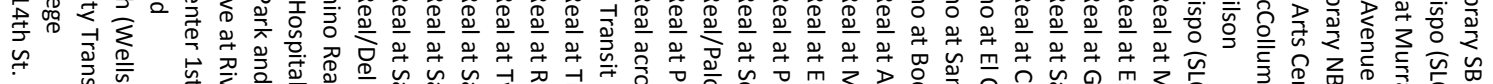

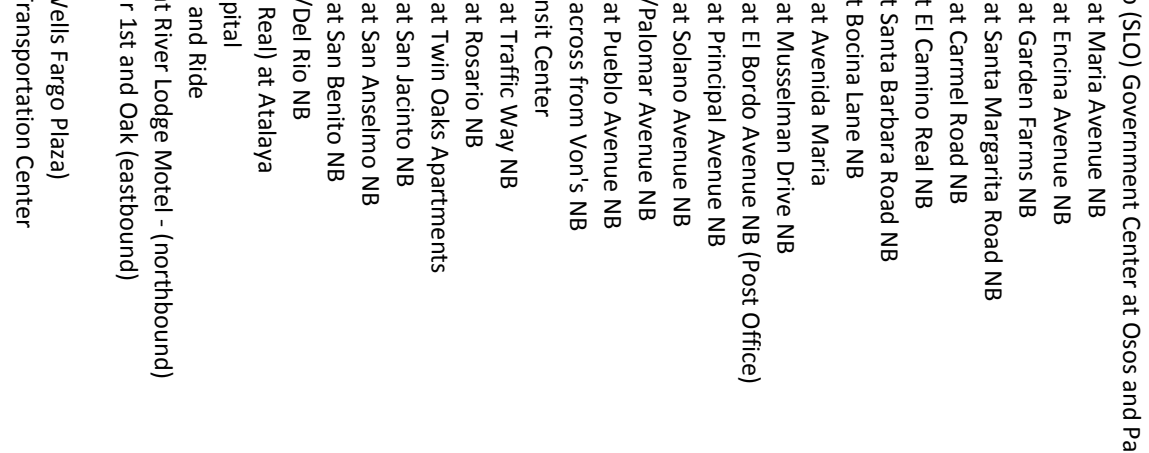

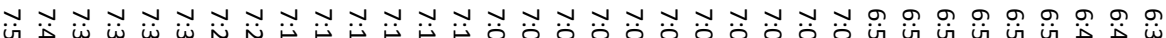

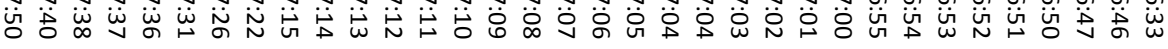

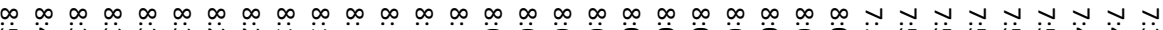

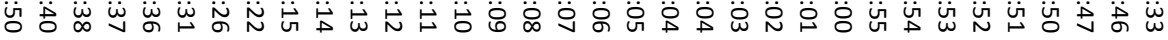

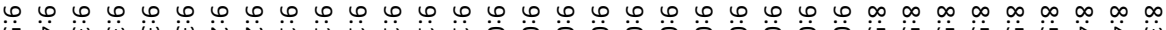

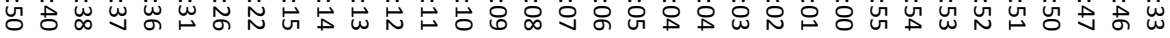

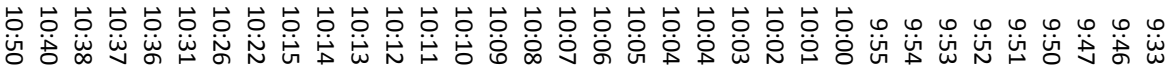

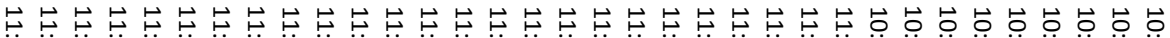

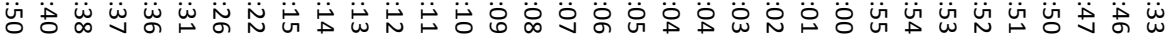
突

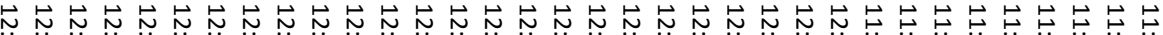

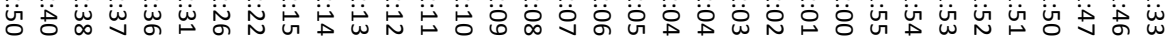

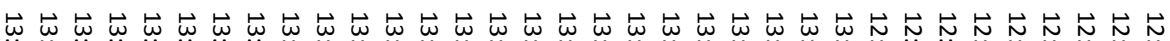

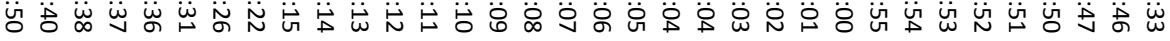

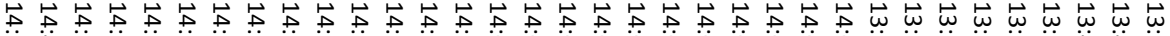

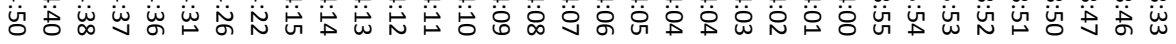

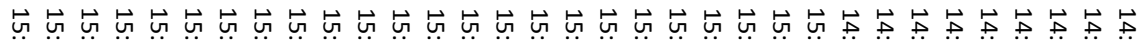
ठ

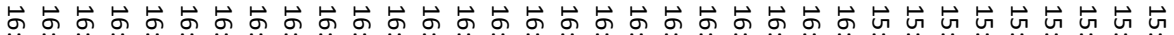

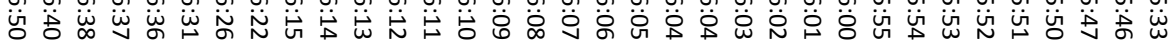

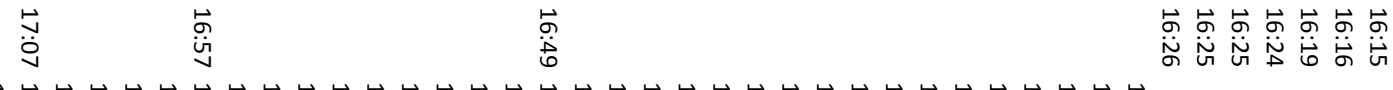

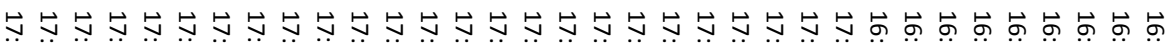

ن⿺辶寸子

崫

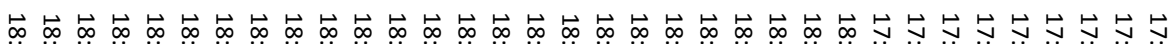

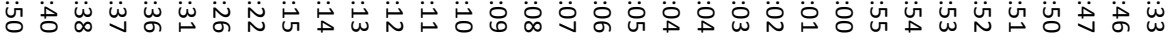

它

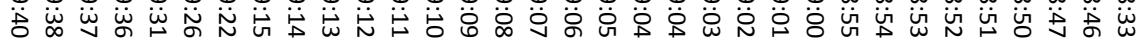

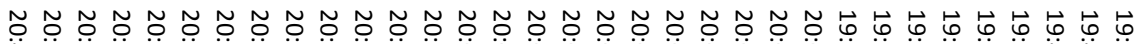

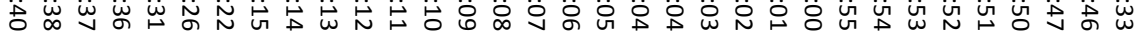

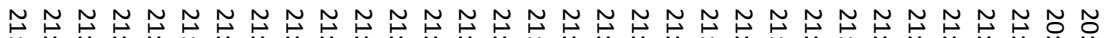

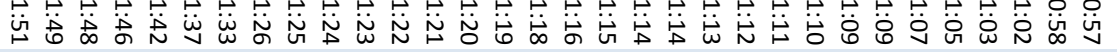

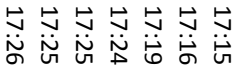

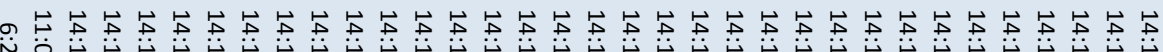

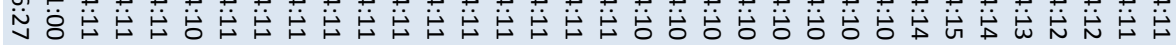

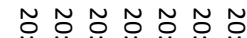

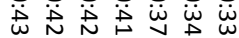



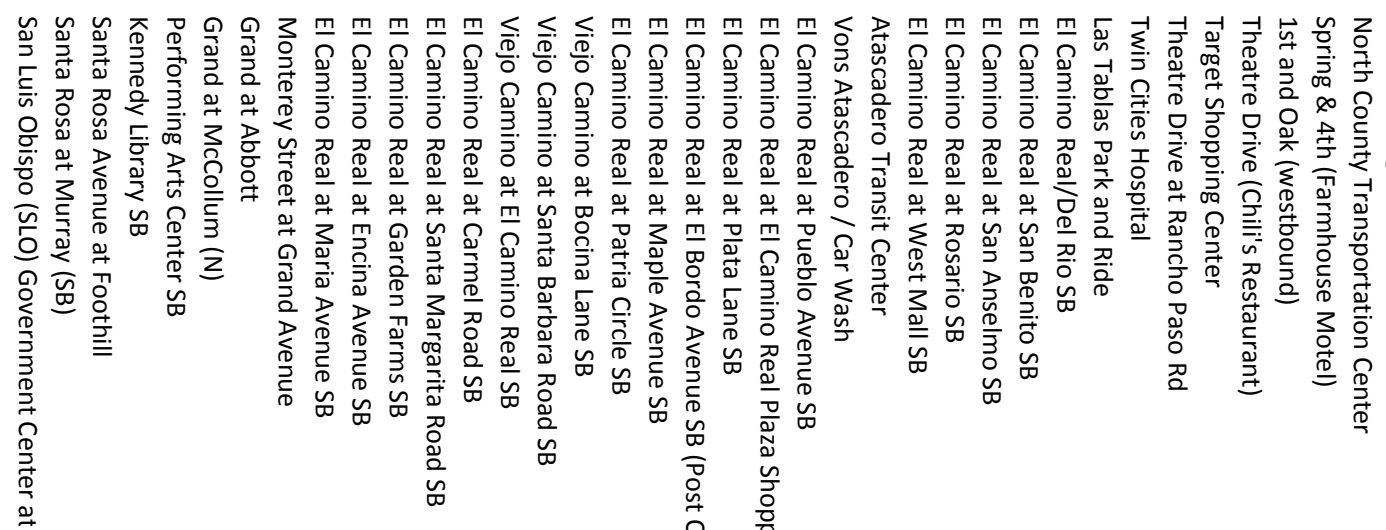

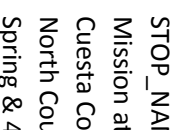

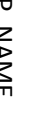

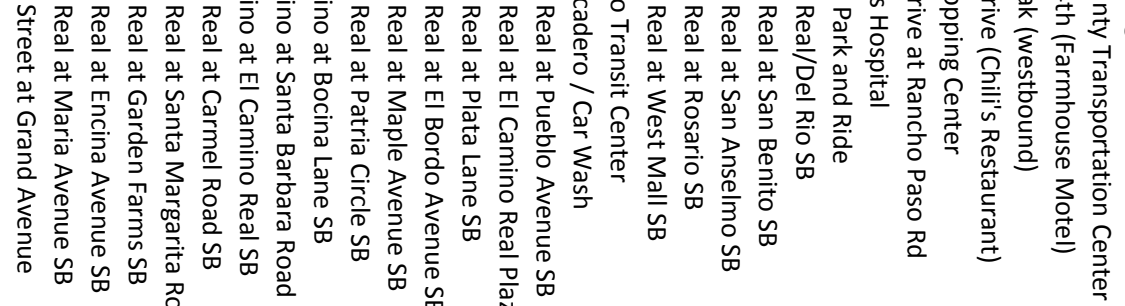

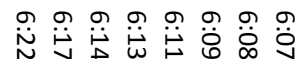

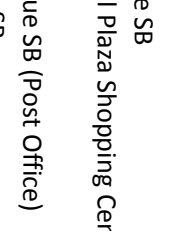

$\stackrel{ب}{\ddot{\infty}}$

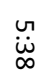

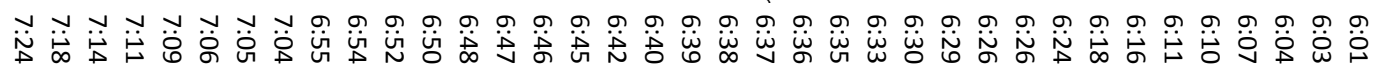

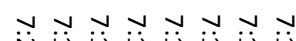

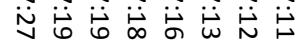

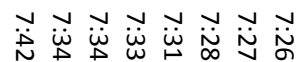

宊

a

$\ddot{\circ}$

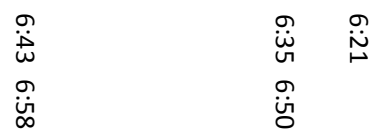

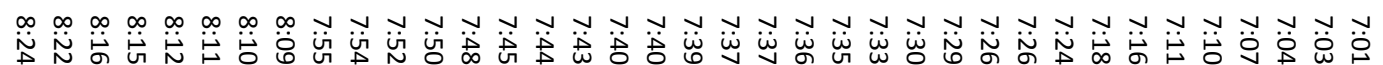

i.

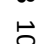

i்

$\stackrel{\vec{\sim}}{\vec{\sim}}$

w

$\stackrel{\stackrel{\sim}{\sim}}{\underset{\omega}{\omega}}$

$\overleftrightarrow{\ddot{w}}$

i்

$\stackrel{+}{+}$

岕

节

i்

官

i்

$\stackrel{\sim}{\sim}$

w

$\ddot{\ddot{8}}$

$\vec{\infty}$

i்

$\vec{b}$

ن்

$\tilde{\sim}$

نं

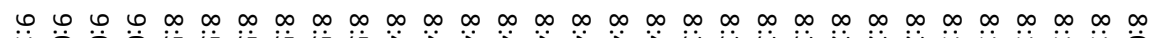

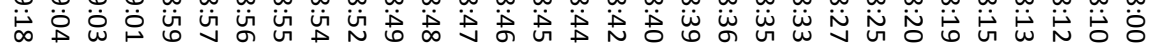
占

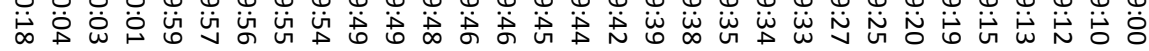

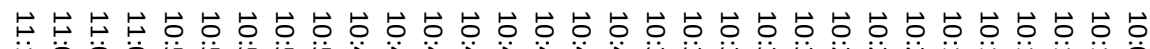

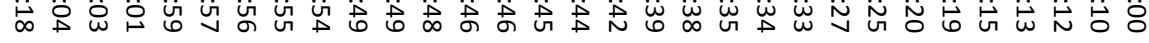

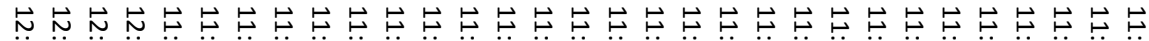

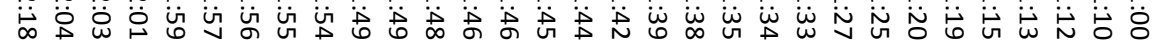

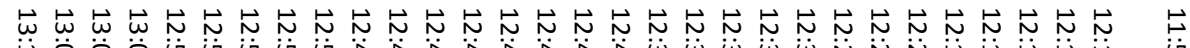

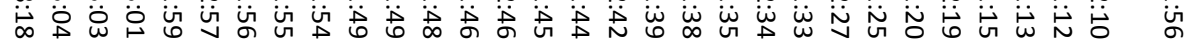

芦

$\ddot{\dot{\sigma}} \ddot{8}$

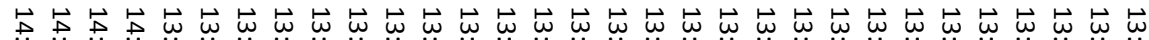

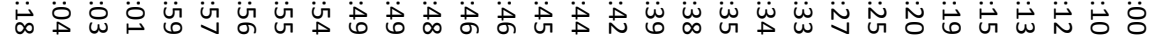

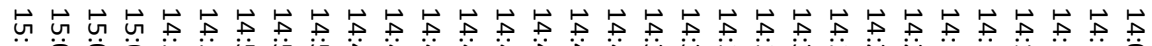

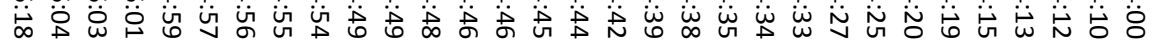

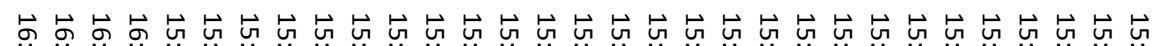

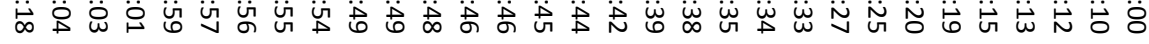
穴

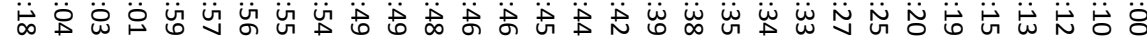

官

क

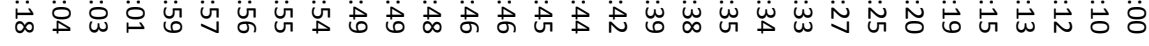

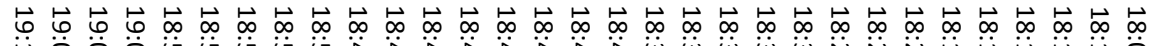

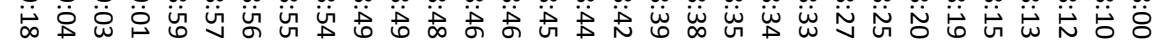

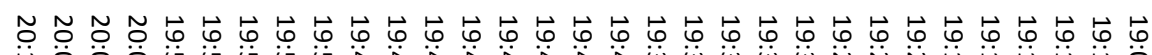

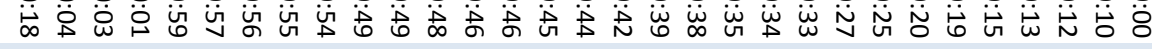

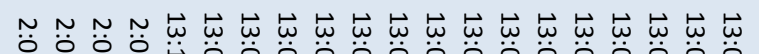

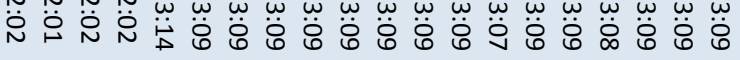

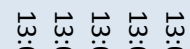

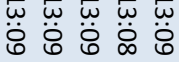

嵌

ठ்

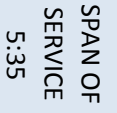

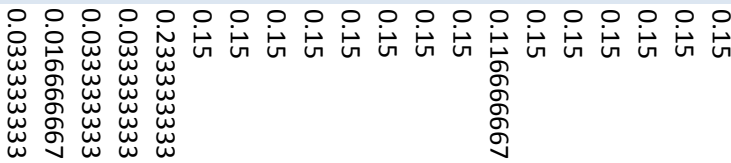

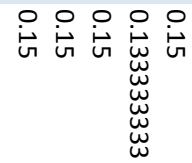

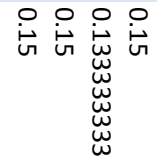

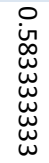

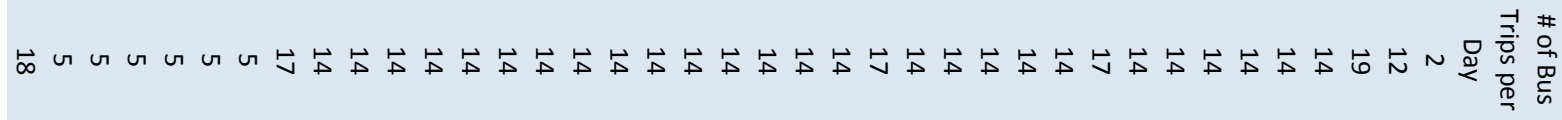




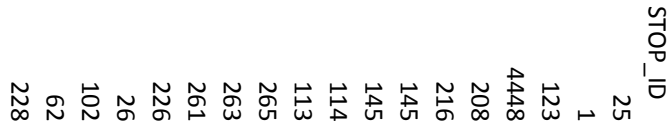
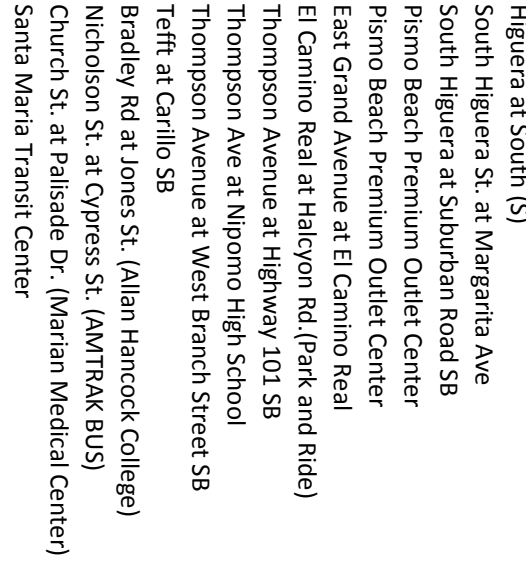

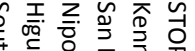

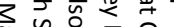

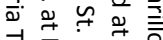

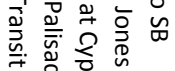

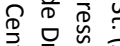

高变

烈

只

离空

$\stackrel{\text { D }}{=}$

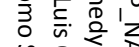

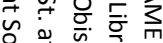

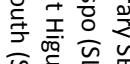

$\frac{1}{2}$ 은

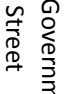

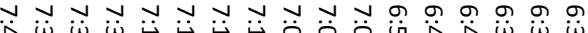

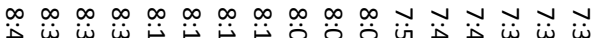

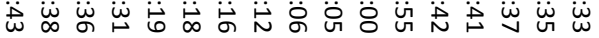

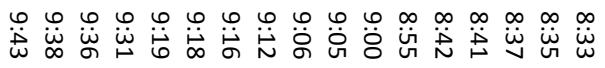

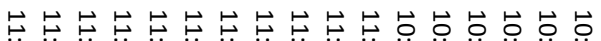

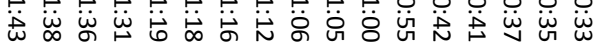

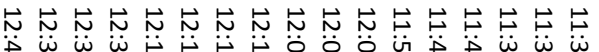

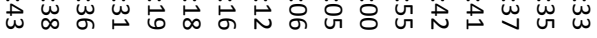

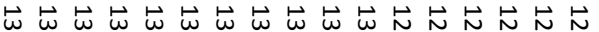

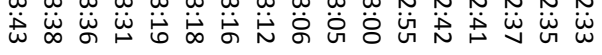

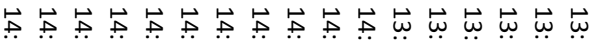

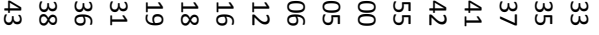

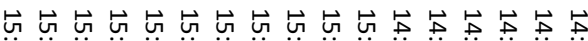

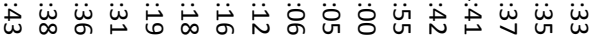
के

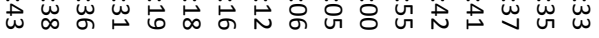

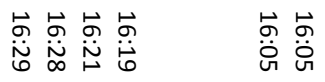

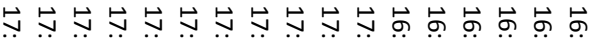

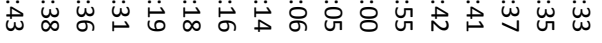
क्ष

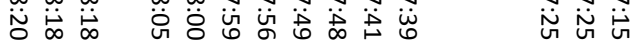

穴

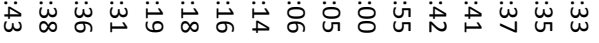

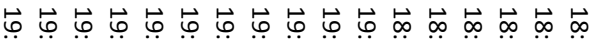

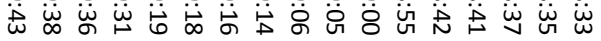

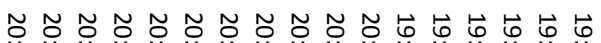

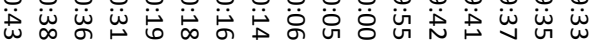

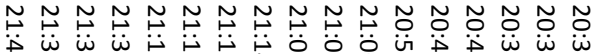

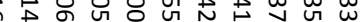

\section{点占点官} ठ் $\ddot{8} \dot{8} \dot{0}$

安吕台官 $\ddot{8} \ddot{8} \ddot{8} \ddot{8}$

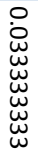

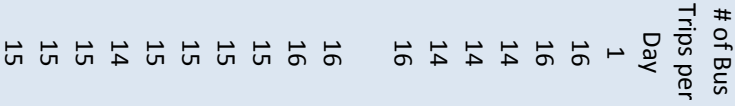




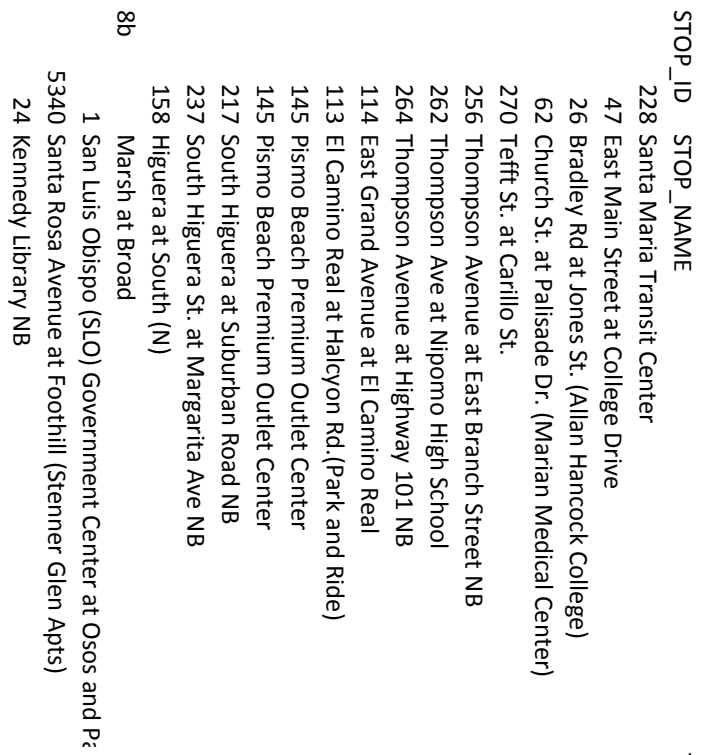

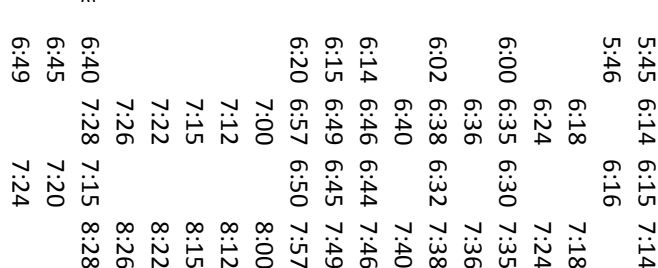

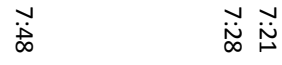

ب.

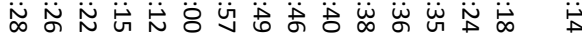

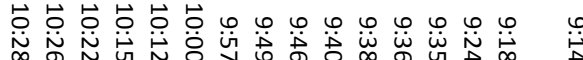

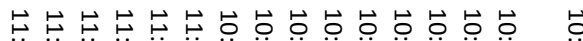

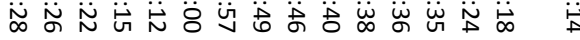

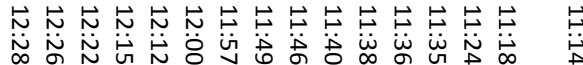

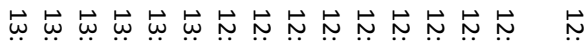

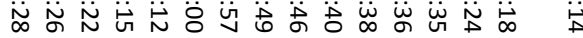

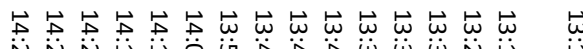

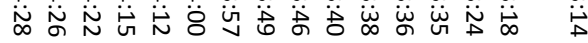

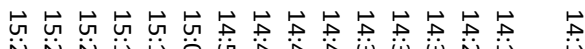

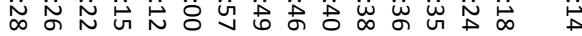

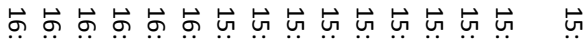

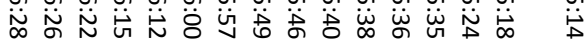

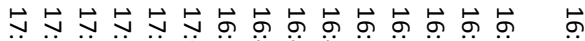

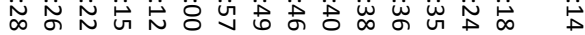

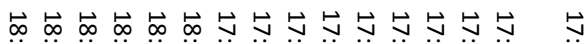

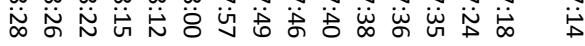

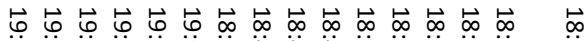

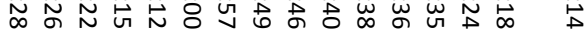

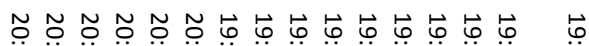

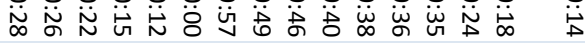

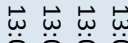

$\ddot{8} \ddot{\circ} \ddot{\circ} \ddot{\circ}$

$\vec{\omega} \vec{\omega} \vec{\omega} \vec{\omega}$

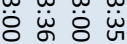

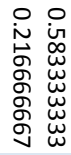

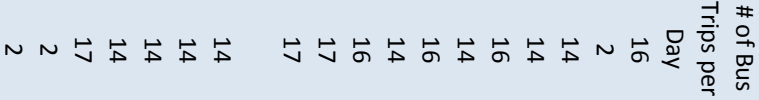




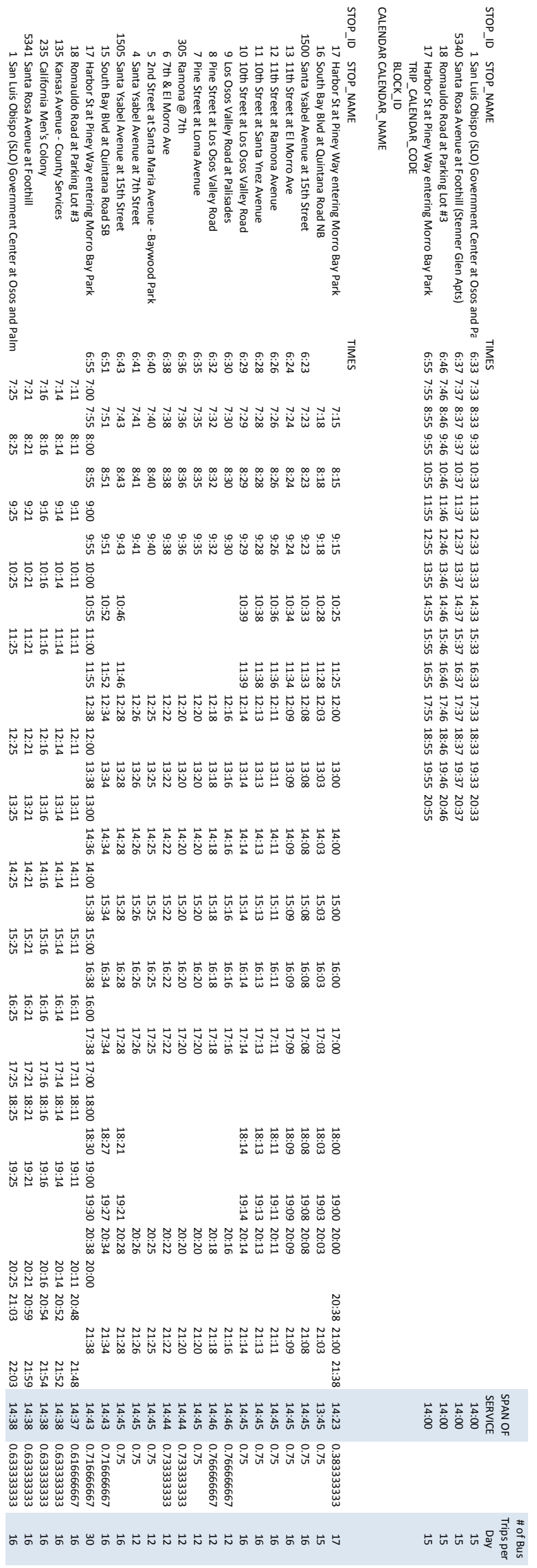




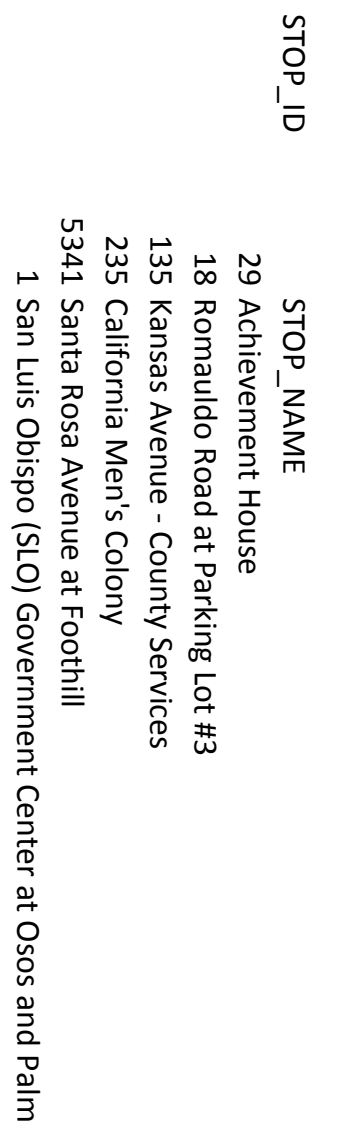

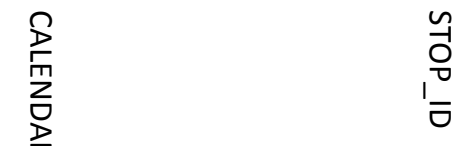

吕

$\sim \sim \widetilde{w}$

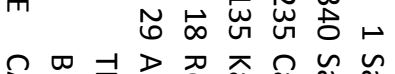

员

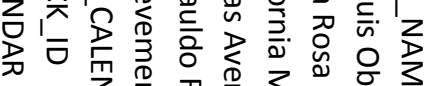

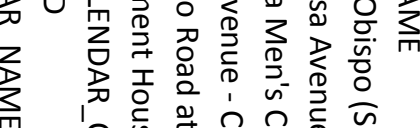

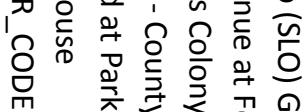

产. 主之

品

贲

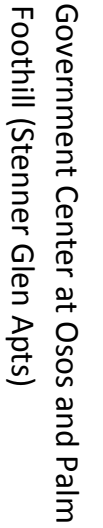

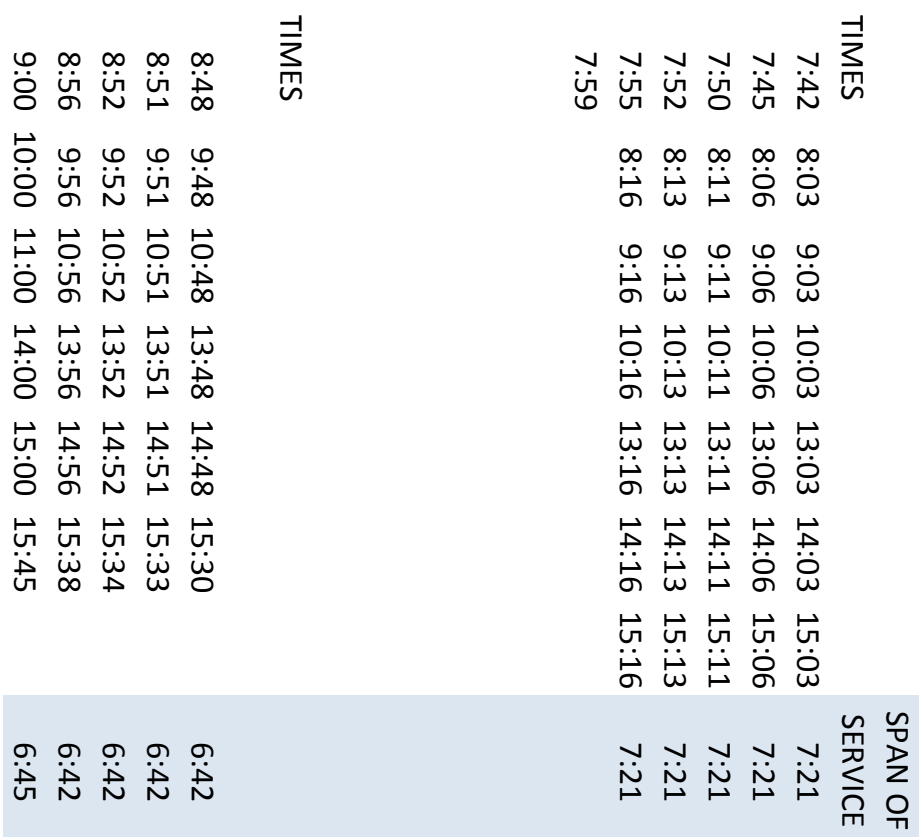

a $\sigma \sigma \sigma$

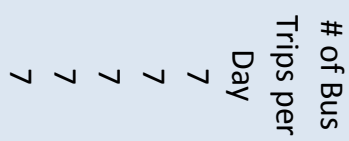




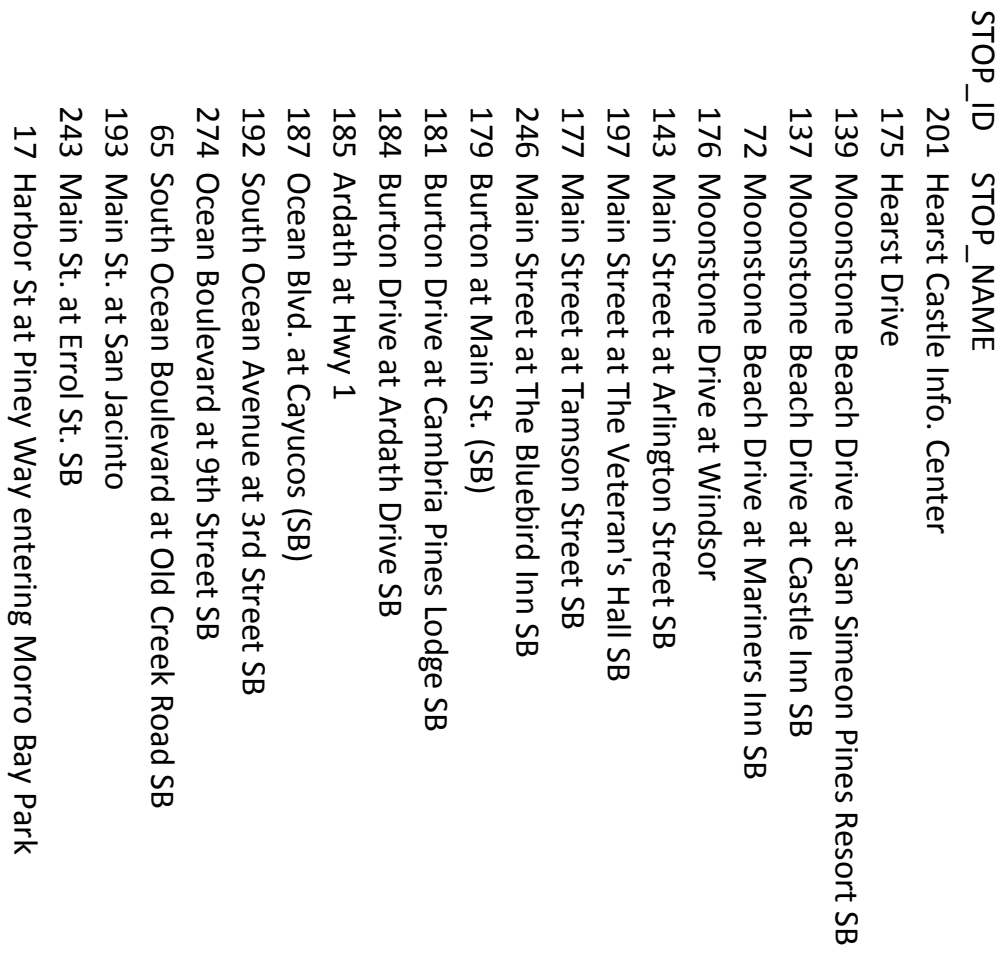

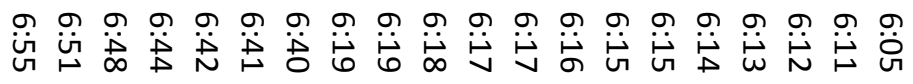

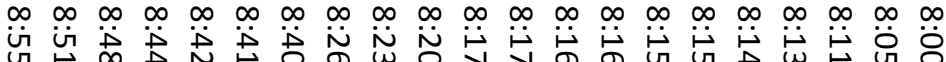

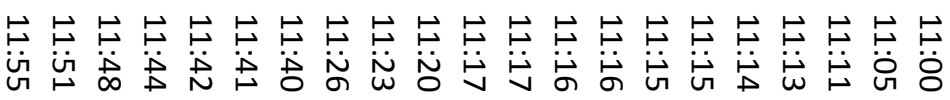

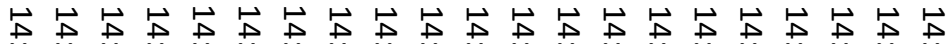
ن

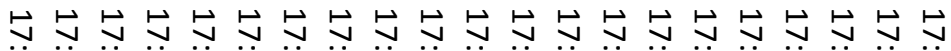

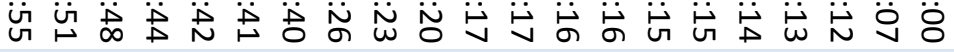

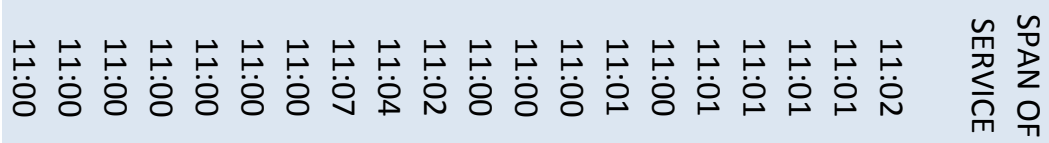

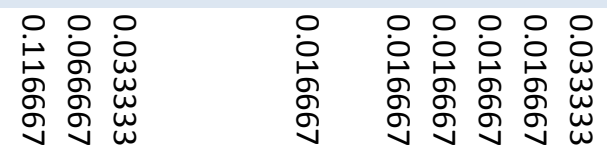

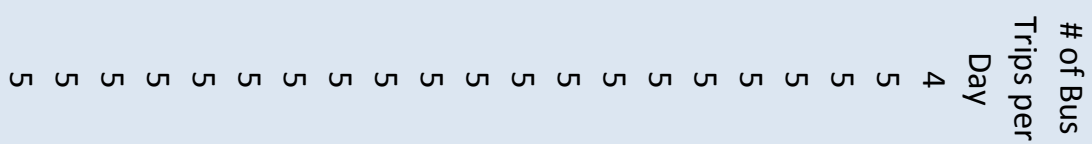


ヘ

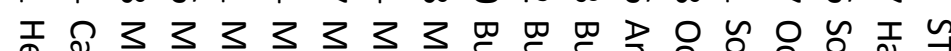

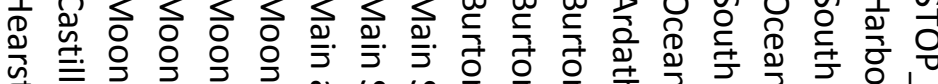

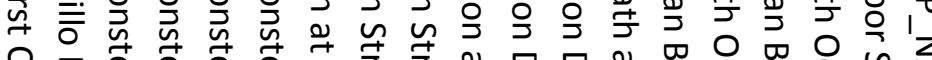

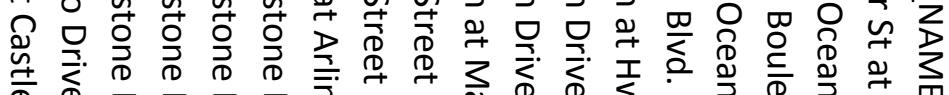

万人

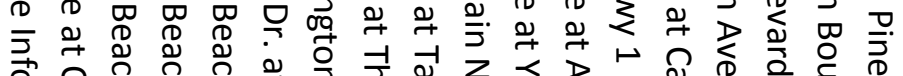

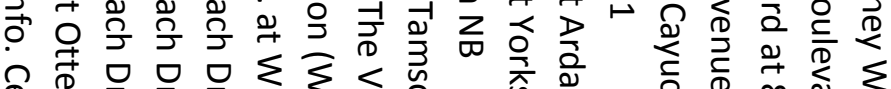

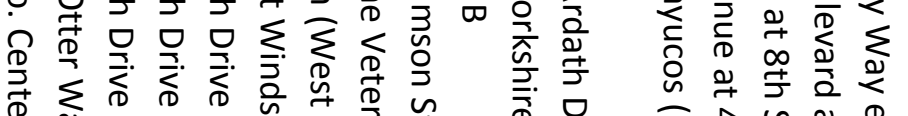

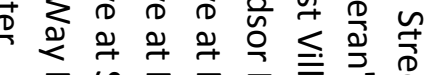

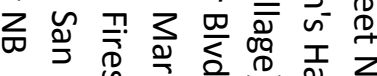

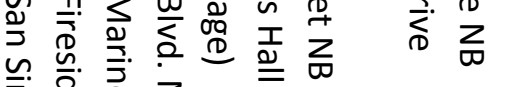

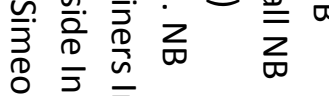

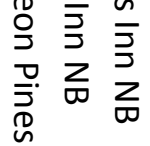

뀸

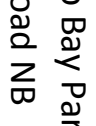

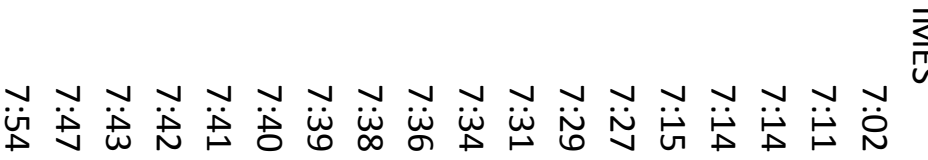

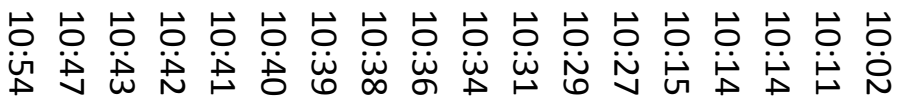

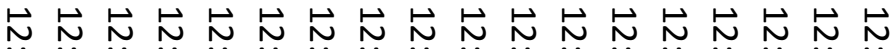

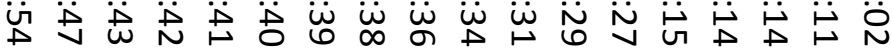

ज柁 ن⿺辶寸

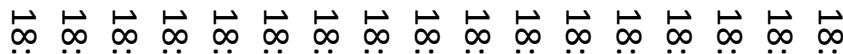

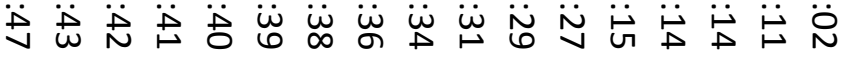

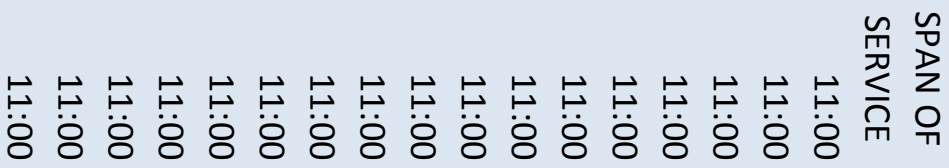

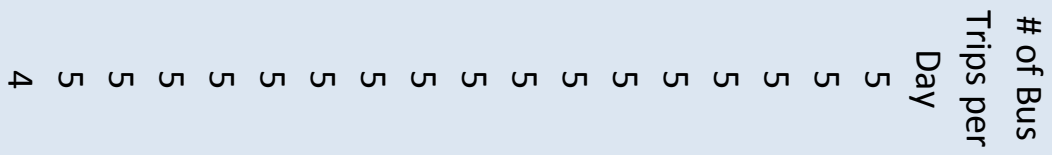


APPENDIX E: Final Dataset Spreadsheet (Basis of Analysis) 


\begin{tabular}{|c|c|c|c|c|c|c|c|}
\hline \multirow[b]{3}{*}{$\begin{array}{l}\text { Bus } \\
\text { Stop \# }\end{array}$} & \multicolumn{4}{|c|}{ General Bus Stop Info } & \multicolumn{3}{|c|}{ RTA Ridership (Ot } \\
\hline & & & & & \multicolumn{3}{|c|}{ Boardings } \\
\hline & $\begin{array}{l}\text { Fixed } \\
\text { Route } \\
\text { Name }\end{array}$ & Route Direction & Bus Stop Name & City & $\begin{array}{c}\text { PCT of } \\
\text { System ONS }\end{array}$ & Observed Ons & Model Ons \\
\hline 1 & $\begin{array}{l}\text { RTA 9, } \\
10,12 / 14\end{array}$ & $\begin{array}{l}\text { Northbound, } \\
\text { Southbound }\end{array}$ & $\begin{array}{l}\text { Government Center (Osos } \\
\text { \& Palm) }\end{array}$ & SLO & $22.72 \%$ & 2339 & 7264 \\
\hline 2 & $\begin{array}{l}\text { RTA 12, } \\
\quad 15\end{array}$ & $\begin{array}{l}\text { Northbound, } \\
\text { Southbound, } \\
\text { Clockwise loop }\end{array}$ & MORRO BAY PARK & Morro Bay & $5.20 \%$ & 536 & 236 \\
\hline 3 & $\begin{array}{l}\text { RTA 9, } \\
10,12\end{array}$ & Northbound & Cal Poly Kennedy Library & SLO & $4.46 \%$ & 459 & 111 \\
\hline 4 & $\begin{array}{l}\text { RTA 9, } \\
10\end{array}$ & Northbound & $\begin{array}{l}\text { Cal Poly Performing Arts } \\
\text { Cntr. }\end{array}$ & SLO & $1.52 \%$ & 156 & 144 \\
\hline 5 & $\begin{array}{l}\text { RTA 9, } \\
10,12 / 14\end{array}$ & Northbound & $\begin{array}{l}\text { Santa Rosa at Stenner } \\
\text { Glen Apts (NB) }\end{array}$ & SLO & $2.50 \%$ & 257 & 77 \\
\hline 6 & $\begin{array}{l}\text { RTA 9, } \\
12 / 14\end{array}$ & Southbound & Santa Rosa at Foothill & SLO & $0.16 \%$ & 16 & 44 \\
\hline 7 & RTA 9 & $\begin{array}{l}\text { Northbound, } \\
\text { Southbound }\end{array}$ & Atascadero Transit Center & Atascadero & $5.08 \%$ & 522 & 332 \\
\hline 8 & RTA 9 & $\begin{array}{l}\text { Northbound, } \\
\text { Southbound }\end{array}$ & Las Tablas Park \& Ride & Templeton & $2.11 \%$ & 217 & 188 \\
\hline 9 & RTA 9 & $\begin{array}{l}\text { Northbound, } \\
\text { Southbound }\end{array}$ & Twin Cities Hospital & Templeton & $0.42 \%$ & 43 & 121 \\
\hline 10 & RTA 9 & $\begin{array}{l}\text { Northbound, } \\
\text { Southbound }\end{array}$ & $\begin{array}{c}\text { Paso Robles Transit Center } \\
\text { (8th \& Pine) }\end{array}$ & Paso Robles & $6.10 \%$ & 628 & 218 \\
\hline 11 & RTA 9 & $\begin{array}{l}\text { Northbound, } \\
\text { Southbound }\end{array}$ & Cuesta College North & Paso Robles & $0.98 \%$ & 101 & 60 \\
\hline 12 & RTA 9 & Northbound & $\begin{array}{l}\text { Monterey at Peach Tree Inn } \\
\text { (NB) }\end{array}$ & SLO & $0.55 \%$ & 56 & 9 \\
\hline 13 & RTA 9 & Northbound & ECR at Maria & Santa Margarita & $0.07 \%$ & 7 & 11 \\
\hline 14 & RTA 9 & Northbound & ECR at Encina & Santa Margarita & $0.49 \%$ & 50 & 37 \\
\hline 15 & RTA 9 & Northbound & $\begin{array}{c}\text { ECR at Pine (Garden } \\
\text { Farms) }\end{array}$ & Atascadero & $0.06 \%$ & 6 & 11 \\
\hline 16 & RTA 9 & Northbound & $\begin{array}{l}\text { ECR at Santa Margarita } \\
\text { (Country Care) }\end{array}$ & Atascadero & $0.08 \%$ & 8 & 11 \\
\hline
\end{tabular}




\begin{tabular}{|c|c|c|c|c|c|c|c|}
\hline 17 & RTA 9 & Northbound & ECR at Carmel & Atascadero & $0.00 \%$ & 0 & 18 \\
\hline 18 & RTA 9 & Northbound & ECR at Santa Clara & Atascadero & $0.01 \%$ & 1 & 37 \\
\hline 19 & RTA 9 & Northbound & $\begin{array}{c}\text { Viejo Camino at Santa } \\
\text { Barbara }\end{array}$ & Atascadero & $0.02 \%$ & 2 & 11 \\
\hline 20 & RTA 9 & Northbound & $\begin{array}{l}\text { Viejo Camino at Bocina Ln } \\
\text { (Bordeaux Apts) }\end{array}$ & Atascadero & $0.61 \%$ & 63 & 25 \\
\hline 21 & RTA 9 & Northbound & ECR at Avenida Maria (NB) & Atascadero & $0.28 \%$ & 29 & 52 \\
\hline 22 & RTA 9 & Northbound & ECR at Musselman (NB) & Atascadero & $0.20 \%$ & 20 & 25 \\
\hline 23 & RTA 9 & Northbound & $\begin{array}{c}\text { ECR at El Bordo (Post } \\
\text { Office) }\end{array}$ & Atascadero & $0.15 \%$ & 15 & 25 \\
\hline 24 & RTA 9 & Northbound & ECR at Principal (NB) & Atascadero & $0.13 \%$ & 13 & 25 \\
\hline 25 & RTA 9 & Northbound & ECR at Solano (NB) & Atascadero & $0.14 \%$ & 14 & 52 \\
\hline 26 & RTA 9 & Northbound & ECR at Palomar (NB) & Atascadero & $0.31 \%$ & 32 & 52 \\
\hline 27 & RTA 9 & Northbound & ECR at Pueblo & Atascadero & $0.09 \%$ & 10 & 20 \\
\hline 28 & RTA 9 & Northbound & ECR at Vons (NB) & Atascadero & $0.28 \%$ & 29 & 41 \\
\hline 29 & RTA 9 & Northbound & ECR at Traffic Way & Atascadero & $0.24 \%$ & 25 & 41 \\
\hline 30 & RTA 9 & Northbound & $\begin{array}{c}\text { ECR at Rosario (Police } \\
\text { Station) }\end{array}$ & Atascadero & $0.00 \%$ & 0 & 41 \\
\hline 31 & RTA 9 & Northbound & ECR at San Jacinto & Atascadero & $0.07 \%$ & 8 & 20 \\
\hline 32 & RTA 9 & Northbound & $\begin{array}{l}\text { ECR at San Anselmo } \\
\text { (Kmart) }\end{array}$ & Atascadero & $0.17 \%$ & 18 & 41 \\
\hline 33 & RTA 9 & Northbound & $\begin{array}{l}\text { ECR at Maya (Kennedy } \\
\text { Club) }\end{array}$ & Atascadero & $0.07 \%$ & 8 & 20 \\
\hline 34 & RTA 9 & Northbound & ECR at San Benito & Atascadero & $0.10 \%$ & 10 & 13 \\
\hline 35 & RTA 9 & Northbound & ECR at Del Rio & Atascadero & $0.20 \%$ & 20 & 20 \\
\hline 36 & RTA 9 & Northbound & ECR at Atalaya & Atascadero & $0.20 \%$ & 20 & 20 \\
\hline
\end{tabular}




\begin{tabular}{|c|c|c|c|c|c|c|c|}
\hline 37 & RTA 9 & Northbound & ECR at Santa Cruz & Atascadero & $0.07 \%$ & 8 & 20 \\
\hline 38 & RTA 9 & Northbound & Theatre at Theatre & Paso Robles & $0.34 \%$ & 35 & 16 \\
\hline 39 & RTA 9 & Northbound & $\begin{array}{c}\text { South Vine at 1st (Gateway } \\
\text { Center) }\end{array}$ & Paso Robles & $0.00 \%$ & 0 & 4 \\
\hline 40 & RTA 9 & Northbound & Spring at $2 \mathrm{nd}$ & Paso Robles & $0.29 \%$ & 30 & 8 \\
\hline 41 & RTA 9 & Northbound & Spring at 5th & Paso Robles & $0.27 \%$ & 28 & 27 \\
\hline 42 & RTA 9 & Northbound & Mission at 14th & San Miguel & $0.00 \%$ & 0 & 5 \\
\hline 43 & RTA 9 & Southbound & Mission at 14th & San Miguel & $0.43 \%$ & 44 & 4 \\
\hline 44 & RTA 9 & Southbound & Spring at 4 th & Paso Robles & $0.20 \%$ & 20 & 26 \\
\hline 45 & RTA 9 & Southbound & Target Shopping Center & Paso Robles & $0.27 \%$ & 28 & 47 \\
\hline 46 & RTA 9 & Southbound & ECR at Atalaya & Atascadero & $0.02 \%$ & 3 & 23 \\
\hline 47 & RTA 9 & Southbound & $\begin{array}{c}\text { ECR at Del Rio (Mission } \\
\text { Oaks Plaza) }\end{array}$ & Atascadero & $0.22 \%$ & 23 & 47 \\
\hline 48 & RTA 9 & Southbound & ECR at San Benito & Atascadero & $0.07 \%$ & 8 & 23 \\
\hline 49 & RTA 9 & Southbound & $\begin{array}{c}\text { ECR at Cynthia (Kennedy } \\
\text { Club) }\end{array}$ & Atascadero & $0.15 \%$ & 15 & 23 \\
\hline 50 & RTA 9 & Southbound & $\begin{array}{l}\text { ECR at San Anselmo } \\
\text { (Kmart) }\end{array}$ & Atascadero & $0.12 \%$ & 13 & 47 \\
\hline 51 & RTA 9 & Southbound & $\begin{array}{l}\text { ECR at San Anselmo } \\
\text { (Lutheran Church) }\end{array}$ & Atascadero & $0.02 \%$ & 3 & 23 \\
\hline 52 & RTA 9 & Southbound & ECR at Rosario & Atascadero & $0.07 \%$ & 8 & 47 \\
\hline 53 & RTA 9 & Southbound & ECR at Entrada & Atascadero & $0.24 \%$ & 25 & 23 \\
\hline 54 & RTA 9 & Southbound & ECR at Hwy 41 (SB) & Atascadero & $1.28 \%$ & 132 & 47 \\
\hline 55 & RTA 9 & Southbound & ECR at Pueblo & Atascadero & $0.16 \%$ & 17 & 23 \\
\hline 56 & RTA 9 & Southbound & ECR at Albertson's (SB) & Atascadero & $0.07 \%$ & 8 & 47 \\
\hline
\end{tabular}




\begin{tabular}{|c|c|c|c|c|c|c|c|}
\hline 57 & RTA 9 & Southbound & $\begin{array}{c}\text { ECR @ Plata (DK Donuts) } \\
\text { (SB) }\end{array}$ & Atascadero & $0.40 \%$ & 41 & 23 \\
\hline 58 & RTA 9 & Southbound & $\begin{array}{c}\text { ECR at Santa Rosa (Motel } \\
\text { 6) (SB) }\end{array}$ & Atascadero & $0.10 \%$ & 10 & 23 \\
\hline 59 & RTA 9 & Southbound & $\begin{array}{c}\text { ECR at El Bordo (Post } \\
\text { Office) }\end{array}$ & Atascadero & $0.71 \%$ & 73 & 47 \\
\hline 60 & RTA 9 & Southbound & ECR at Maple (SB) & Atascadero & $0.47 \%$ & 48 & 23 \\
\hline 61 & RTA 9 & Southbound & $\begin{array}{l}\text { Viejo Camino at Bocina } \\
\text { (Bordeaux Apts) }\end{array}$ & Atascadero & $0.63 \%$ & 65 & 15 \\
\hline 62 & RTA 9 & Southbound & $\begin{array}{c}\text { Viejo Camino at Santa } \\
\text { Barbara }\end{array}$ & Atascadero & $0.23 \%$ & 23 & 15 \\
\hline 63 & RTA 9 & Southbound & ECR at Santa Clara & Atascadero & $0.03 \%$ & 3 & 16 \\
\hline 64 & RTA 9 & Southbound & ECR at Carmel & Atascadero & $0.05 \%$ & 5 & 16 \\
\hline 65 & RTA 9 & Southbound & ECR @ Santa Margarita & Atascadero & $0.09 \%$ & 9 & 11 \\
\hline 66 & RTA 9 & Southbound & ECR at Patria Circle (SB) & Atascadero & $0.28 \%$ & 29 & 34 \\
\hline 67 & RTA 9 & Southbound & $\begin{array}{c}\text { ECR @ Pine (Garden } \\
\text { Farms) }\end{array}$ & Atascadero & $0.03 \%$ & 3 & 11 \\
\hline 68 & RTA 9 & Southbound & ECR at Encina & Santa Margarita & $0.84 \%$ & 87 & 48 \\
\hline 69 & RTA 9 & Southbound & ECR at Maria & Santa Margarita & $0.06 \%$ & 6 & 16 \\
\hline 70 & RTA 9 & Southbound & Monterey at Grand (SB) & SLO & $0.02 \%$ & 2 & 35 \\
\hline 71 & RTA 9 & Southbound & Cal Poly Performing Arts & SLO & $0.07 \%$ & 7 & 55 \\
\hline 72 & RTA 9 & Southbound & Cal Poly Kennedy Library & SLO & $0.14 \%$ & 14 & 55 \\
\hline 73 & RTA 10 & $\begin{array}{l}\text { Northbound, } \\
\text { Southbound }\end{array}$ & $\begin{array}{l}\text { Pismo Beach Premiun } \\
\text { Outlets }\end{array}$ & Pismo Beach & $4.34 \%$ & 447 & 183 \\
\hline 74 & RTA 10 & $\begin{array}{l}\text { Northbound, } \\
\text { Southbound }\end{array}$ & El Camino Real at Halcyon & Arroyo Grande & $2.63 \%$ & 270 & 302 \\
\hline 75 & RTA 10 & $\begin{array}{l}\text { Northbound, } \\
\text { Southbound }\end{array}$ & $\begin{array}{c}\text { E. Grand at El Camino } \\
\text { Real }\end{array}$ & Arroyo Grande & $1.76 \%$ & 182 & 363 \\
\hline 76 & RTA 10 & $\begin{array}{l}\text { Northbound, } \\
\text { Southbound }\end{array}$ & S. Bradley at Jones & Santa Maria & $1.71 \%$ & 177 & 139 \\
\hline
\end{tabular}




\begin{tabular}{|c|c|c|c|c|c|c|c|}
\hline 77 & RTA 10 & $\begin{array}{l}\text { Northbound, } \\
\text { Southbound }\end{array}$ & Nicholson at E. Cypress & Santa Maria & $0.37 \%$ & 38 & 102 \\
\hline 78 & RTA 10 & $\begin{array}{l}\text { Northbound, } \\
\text { Southbound }\end{array}$ & E. Church at Palisade & Santa Maria & $0.52 \%$ & 53 & 142 \\
\hline 79 & RTA 10 & $\begin{array}{l}\text { Northbound, } \\
\text { Southbound }\end{array}$ & Santa Maria Transit Center & Santa Maria & $3.35 \%$ & 345 & 684 \\
\hline 80 & RTA 10 & Northbound & Tefft at Carrillo & Nipomo & $1.60 \%$ & 164 & 57 \\
\hline 81 & RTA 10 & Northbound & Thompson at Branch & Nipomo & $0.61 \%$ & 63 & 50 \\
\hline 82 & RTA 10 & Northbound & Nipomo High School & Nipomo & $0.36 \%$ & 37 & 57 \\
\hline 83 & RTA 10 & Northbound & N. Thompson at Hwy 101 & Nipomo & $0.16 \%$ & 16 & 11 \\
\hline 84 & RTA 10 & Northbound & S. Higuera at Suburban & SLO & $0.35 \%$ & 36 & 64 \\
\hline 85 & RTA 10 & Northbound & S. Higuera at Margarita & SLO & $0.29 \%$ & 30 & 26 \\
\hline 86 & RTA 10 & Northbound & Higuera at South & SLO & $0.29 \%$ & 30 & 27 \\
\hline 87 & RTA 10 & Northbound & Marsh at Broad (NB) & SLO & $0.00 \%$ & 0 & 340 \\
\hline 88 & RTA 10 & Southbound & Nipomo at Higuera (SB) & SLO & $0.02 \%$ & 2 & 31 \\
\hline 89 & RTA 10 & Southbound & Higuera at South & SLO & $0.81 \%$ & 84 & 57 \\
\hline 90 & RTA 10 & Southbound & S. Higuera at Margarita & SLO & $0.47 \%$ & 48 & 26 \\
\hline 91 & RTA 10 & Southbound & S. Higuera at Suburban & SLO & $0.61 \%$ & 63 & 197 \\
\hline 92 & RTA 10 & Southbound & N. Thompson at Hwy 101 & Nipomo & $0.00 \%$ & 0 & 12 \\
\hline 93 & RTA 10 & Southbound & Nipomo High School & Nipomo & $0.07 \%$ & 7 & 53 \\
\hline 94 & RTA 10 & Southbound & Thompson at Branch & Nipomo & $0.34 \%$ & 35 & 53 \\
\hline 95 & RTA 10 & Southbound & Tefft at Carrilo & Nipomo & $0.88 \%$ & 91 & 53 \\
\hline 96 & $\begin{array}{l}\text { RTA } \\
12 / 14\end{array}$ & $\begin{array}{l}\text { Northbound, } \\
\text { Southbound }\end{array}$ & Cuesta College & SLO & $7.34 \%$ & 755 & 337 \\
\hline
\end{tabular}




\begin{tabular}{|c|c|c|c|c|c|c|c|}
\hline 97 & $\begin{array}{l}\text { RTA } \\
12 / 14\end{array}$ & Northbound & CA Men's Colony & SLO & $0.01 \%$ & 1 & 192 \\
\hline 98 & RTA 12 & Northbound & South Bay at Quintana & Morro Bay & $0.05 \%$ & 5 & 27 \\
\hline 99 & RTA 12 & Clockwise loop & Santa Ysabel at 15th (WB) & Los Osos & $0.14 \%$ & 14 & 36 \\
\hline 100 & RTA 12 & Clockwise loop & 11th at El Morro & Los Osos & $0.26 \%$ & 27 & 57 \\
\hline 101 & RTA 12 & Clockwise loop & 11th @ Ramona & Los Osos & $0.27 \%$ & 28 & 33 \\
\hline 102 & RTA 12 & Clockwise loop & 10th at Santa Ynez & Los Osos & $0.75 \%$ & 78 & 69 \\
\hline 103 & RTA 12 & Clockwise loop & 10th at LOVR & Los Osos & $0.85 \%$ & 88 & 69 \\
\hline 104 & RTA 12 & Clockwise loop & LOVR at Palisades & Los Osos & $0.24 \%$ & 25 & 21 \\
\hline 105 & RTA 12 & Clockwise loop & Pine at LOVR & Los Osos & $0.62 \%$ & 64 & 21 \\
\hline 106 & RTA 12 & Clockwise loop & Pine at Loma & Los Osos & $0.41 \%$ & 42 & 44 \\
\hline 107 & RTA 12 & Clockwise loop & Ramona at 7 th & Los Osos & $0.45 \%$ & 46 & 87 \\
\hline 108 & RTA 12 & Clockwise loop & 7th at El Morro & Los Osos & $0.23 \%$ & 23 & 27 \\
\hline 109 & RTA 12 & Clockwise loop & 2nd at Santa Maria & Los Osos & $0.21 \%$ & 21 & 42 \\
\hline 110 & RTA 12 & Clockwise loop & Santa Ysabel @ 7th & Los Osos & $0.28 \%$ & 29 & 42 \\
\hline 111 & RTA 12 & Clockwise loop & Santa Ysabel at 15th (EB) & Los Osos & $0.31 \%$ & 32 & 57 \\
\hline 112 & RTA 12 & Southbound & South Bay at Quintana & Morro Bay & $0.18 \%$ & 18 & 29 \\
\hline 113 & $\begin{array}{l}\text { RTA } \\
12 / 14\end{array}$ & Southbound & Kansas at Hwy 1 & SLO & $0.28 \%$ & 29 & 105 \\
\hline 114 & RTA 15 & $\begin{array}{l}\text { Northbound, } \\
\text { Southbound }\end{array}$ & $\begin{array}{l}\text { HEARST CASTLE } \\
\text { VISITOR'S CENTER }\end{array}$ & San Simeon & $0.10 \%$ & 10 & 23 \\
\hline 115 & RTA 15 & Northbound & $\begin{array}{c}\text { SOUTH OCEAN @ OLD } \\
\text { CREEK }\end{array}$ & Cayucos & $0.00 \%$ & 0 & 6 \\
\hline 116 & RTA 15 & Northbound & OCEAN @ 8TH (NB) & Cayucos & $0.00 \%$ & 0 & 4 \\
\hline
\end{tabular}




\begin{tabular}{|c|c|c|c|c|c|c|c|}
\hline 117 & RTA 15 & Northbound & OCEAN @ 3RD (NB) & Cayucos & $0.00 \%$ & 0 & 4 \\
\hline 118 & RTA 15 & Northbound & CAYUCOS@ASH (NB) & Cayucos & $0.08 \%$ & 8 & 4 \\
\hline 119 & RTA 15 & Northbound & ARDATH @ HWY 1 & Cambria & $0.01 \%$ & 1 & 6 \\
\hline 120 & RTA 15 & Northbound & BURTON @ ARDATH & Cambria & $0.00 \%$ & 0 & 6 \\
\hline 121 & RTA 15 & Northbound & $\begin{array}{c}\text { Not on printed } \\
\text { schedule"BURTON @ } \\
\text { YORKSHIRE" }\end{array}$ & Cambria & $0.02 \%$ & 2 & 9 \\
\hline 122 & RTA 15 & Northbound & BURTON@ @MAIN ST. & Cambria & $0.00 \%$ & 0 & 3 \\
\hline 123 & RTA 15 & Northbound & MAIN@ @BLUEBIRD INN & Cambria & $0.00 \%$ & 0 & 2 \\
\hline 124 & RTA 15 & Northbound & $\begin{array}{l}\text { Not on printed schedule } \\
\text { "MAIN @ TAMSON (NB)" }\end{array}$ & Cambria & $0.00 \%$ & 0 & 2 \\
\hline 125 & RTA 15 & Northbound & $\begin{array}{l}\text { Not on printed schedule } \\
\text { "MAIN @ SKATE PARK }\end{array}$ & Cambria & $0.03 \%$ & 3 & 3 \\
\hline 126 & RTA 15 & Northbound & $\begin{array}{l}\text { No on printed schedule } \\
\text { "MAIN @ CORNWALL" }\end{array}$ & Cambria & $0.00 \%$ & 0 & 4 \\
\hline 127 & RTA 15 & Northbound & $\begin{array}{c}\text { MOONSTONE @ } \\
\text { WINDSOR }\end{array}$ & Cambria & $0.01 \%$ & 1 & 2 \\
\hline 128 & RTA 15 & Northbound & $\begin{array}{l}\text { Not on printed schedule } \\
\text { "MOONSTONE @ } \\
\text { MARINERS INN (NB)" }\end{array}$ & Cambria & $0.00 \%$ & 0 & 3 \\
\hline 129 & RTA 15 & Northbound & $\begin{array}{l}\text { Not on printed schedule: } \\
\text { "MOONSTONE @ } \\
\text { FIRESIDE INN" }\end{array}$ & Cambria & $0.00 \%$ & 0 & 3 \\
\hline 130 & RTA 15 & Northbound & $\begin{array}{l}\text { MOONSTONE @ SAN } \\
\text { SIMEON PINES LODGE }\end{array}$ & Cambria & $0.00 \%$ & 0 & 2 \\
\hline 131 & RTA 15 & Northbound & $\begin{array}{c}\text { CASTILLO @ OTTER (NB } \\
\text { ONLY) }\end{array}$ & San Simeon & $0.00 \%$ & 0 & 6 \\
\hline 132 & RTA 15 & Southbound & $\begin{array}{c}\text { HEARST @ SAN SIMEON } \\
\text { (SB ONLY) }\end{array}$ & San Simeon & $0.00 \%$ & 0 & 6 \\
\hline 133 & RTA 15 & Southbound & $\begin{array}{l}\text { MOONSTONE @ SAN } \\
\text { SIMEON PINES LODGE }\end{array}$ & Cambria & $0.00 \%$ & 0 & 2 \\
\hline 134 & RTA 15 & Southbound & $\begin{array}{l}\text { Not on printed schedule: } \\
\text { "MOONSTONE @ } \\
\text { CASTLE INN" }\end{array}$ & Cambria & $0.00 \%$ & 0 & 3 \\
\hline 135 & RTA 15 & Southbound & $\begin{array}{l}\text { Not in printed schedule } \\
\text { "MOONSTONE @ } \\
\text { MARINERS INN (SB)" }\end{array}$ & Cambria & $0.00 \%$ & 0 & 3 \\
\hline 136 & RTA 15 & Southbound & $\begin{array}{l}\text { MOONSTONE @ } \\
\text { WINDSOR }\end{array}$ & Cambria & $0.06 \%$ & 6 & 3 \\
\hline
\end{tabular}




\begin{tabular}{|c|c|c|c|c|c|c|c|}
\hline 137 & RTA 15 & Southbound & $\begin{array}{l}\text { Not in printed schedule } \\
\text { "MAIN @ ARLINGTON" }\end{array}$ & Cambria & $0.07 \%$ & 7 & 2 \\
\hline 138 & RTA 15 & Southbound & MAIN @ VETS HALL & Cambria & $0.03 \%$ & 3 & 3 \\
\hline 139 & RTA 15 & Southbound & $\begin{array}{l}\text { Not on printed schedule } \\
\text { "Main @ Tamson (SB)" }\end{array}$ & Cambria & $0.05 \%$ & 5 & 3 \\
\hline 140 & RTA 15 & Southbound & $\begin{array}{l}\text { MAIN STREET @ } \\
\text { BLUEBIRD INN }\end{array}$ & Cambria & $0.03 \%$ & 3 & 3 \\
\hline 141 & RTA 15 & Southbound & BURTON@ MAIN & Cambria & $0.13 \%$ & 13 & 10 \\
\hline 142 & RTA 15 & Southbound & $\begin{array}{l}\text { BURTON@ CAMBRIA } \\
\text { PINES LODGE }\end{array}$ & Cambria & $0.06 \%$ & 6 & 9 \\
\hline 143 & RTA 15 & Southbound & BURTON@ARDATH & Cambria & $0.16 \%$ & 16 & 9 \\
\hline 144 & RTA 15 & Southbound & ARDATH @ HWY 1 & Cambria & $0.08 \%$ & 8 & 9 \\
\hline 145 & RTA 15 & Southbound & $\begin{array}{c}\text { OCEAN @ CAYUCOS } \\
\text { PIER (SB) }\end{array}$ & Cayucos & $0.11 \%$ & 11 & 6 \\
\hline 146 & RTA 15 & Southbound & OCEAN @ 3RD (SB) & Cayucos & $0.09 \%$ & 9 & 6 \\
\hline 147 & RTA 15 & Southbound & OCEAN@ @ 9TH (SB) & Cayucos & $0.11 \%$ & 11 & 6 \\
\hline 148 & RTA 15 & Southbound & $\begin{array}{c}\text { SOUTH OCEAN @ OLD } \\
\text { CREEK }\end{array}$ & Cayucos & $0.04 \%$ & 4 & 4 \\
\hline 149 & RTA 15 & Southbound & HWY 1 @ SAN JACINTO & Morro Bay & $0.09 \%$ & 9 & 10 \\
\hline
\end{tabular}




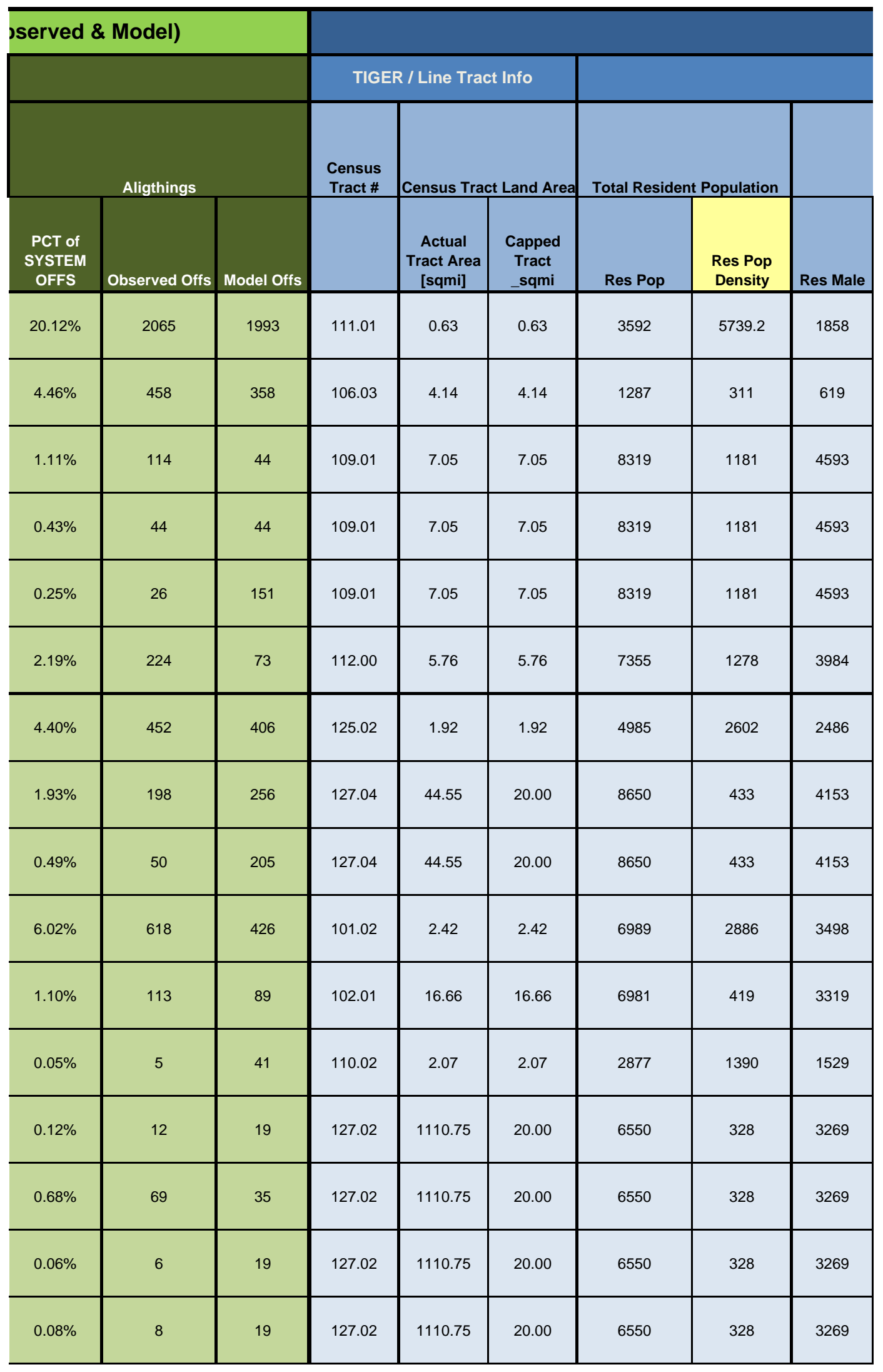




\begin{tabular}{|c|c|c|c|c|c|c|c|c|}
\hline $0.06 \%$ & 6 & 19 & 127.02 & 1110.75 & 20.00 & 6550 & 328 & 3269 \\
\hline $0.08 \%$ & 8 & 19 & 127.02 & 1110.75 & 20.00 & 6550 & 328 & 3269 \\
\hline $0.11 \%$ & 11 & 19 & 127.02 & 1110.75 & 20.00 & 6550 & 328 & 3269 \\
\hline $1.56 \%$ & 160 & 40 & 125.03 & 1.76 & 1.76 & 5240 & 2975 & 2449 \\
\hline $0.93 \%$ & 96 & 40 & 125.03 & 1.76 & 1.76 & 5240 & 2975 & 2449 \\
\hline $0.50 \%$ & 51 & 40 & 125.03 & 1.76 & 1.76 & 5240 & 2975 & 2449 \\
\hline $0.52 \%$ & 54 & 40 & 125.03 & 1.76 & 1.76 & 5240 & 2975 & 2449 \\
\hline $0.12 \%$ & 12 & 40 & 125.03 & 1.76 & 1.76 & 5240 & 2978 & 2449 \\
\hline $0.28 \%$ & 29 & 40 & 125.03 & 1.76 & 1.76 & 5240 & 2978 & 2449 \\
\hline $0.59 \%$ & 61 & 40 & 125.03 & 1.76 & 1.76 & 5240 & 2978 & 2449 \\
\hline $0.31 \%$ & 32 & 30 & 125.02 & 1.92 & 1.92 & 4985 & 2602 & 2486 \\
\hline $1.50 \%$ & 153 & 30 & 125.02 & 1.92 & 1.92 & 4985 & 2602 & 2486 \\
\hline $0.44 \%$ & 45 & 16 & 125.05 & 3.25 & 3.25 & 4891 & 1504 & 2440 \\
\hline $0.05 \%$ & 5 & 16 & 125.05 & 3.25 & 3.25 & 4891 & 1504 & 2440 \\
\hline $0.15 \%$ & 15 & 16 & 125.05 & 3.25 & 3.25 & 4891 & 1504 & 2440 \\
\hline $0.12 \%$ & 13 & 16 & 125.05 & 3.25 & 3.25 & 4891 & 1504 & 2440 \\
\hline $0.07 \%$ & 8 & 16 & 125.05 & 3.25 & 3.25 & 4891 & 1504 & 2440 \\
\hline $0.07 \%$ & 8 & 16 & 125.05 & 3.25 & 3.25 & 4891 & 1504 & 2440 \\
\hline $0.07 \%$ & 8 & 16 & 125.05 & 3.25 & 3.25 & 4891 & 1504 & 2440 \\
\hline $0.02 \%$ & 3 & 16 & 125.05 & 3.25 & 3.25 & 4891 & 1504 & 2440 \\
\hline
\end{tabular}




\begin{tabular}{|c|c|c|c|c|c|c|c|c|}
\hline $0.02 \%$ & 3 & 16 & 125.05 & 3.25 & 3.25 & 4891 & 1504 & 2440 \\
\hline $0.20 \%$ & 20 & 20 & 127.04 & 44.55 & 20.00 & 8650 & 433 & 4153 \\
\hline $0.00 \%$ & 0 & 7 & 101.02 & 2.42 & 2.42 & 6989 & 2886 & 3498 \\
\hline $0.00 \%$ & 0 & 18 & 101.02 & 2.42 & 2.42 & 6989 & 2886 & 3498 \\
\hline $0.29 \%$ & 30 & 18 & 101.02 & 2.42 & 2.42 & 6989 & 2886 & 3498 \\
\hline $0.25 \%$ & 25 & 3 & 103.00 & 650.09 & 20.00 & 10043 & 502 & 5024 \\
\hline $0.00 \%$ & 0 & 2 & 103.00 & 650.09 & 20.00 & 10043 & 502 & 5024 \\
\hline $0.34 \%$ & 35 & 19 & 101.02 & 2.42 & 2.42 & 6989 & 2886 & 3498 \\
\hline $0.17 \%$ & 18 & 20 & 127.04 & 44.55 & 20.00 & 8650 & 433 & 4153 \\
\hline $0.27 \%$ & 28 & 14 & 126.00 & 5.22 & 5.22 & 7793 & 1494 & 3834 \\
\hline $0.10 \%$ & 10 & 14 & 126.00 & 5.22 & 5.22 & 7793 & 1494 & 3834 \\
\hline $0.00 \%$ & 0 & 14 & 126.00 & 5.22 & 5.22 & 7793 & 1494 & 3834 \\
\hline $0.12 \%$ & 13 & 14 & 126.00 & 5.22 & 5.22 & 7793 & 1494 & 3834 \\
\hline $0.02 \%$ & 3 & 14 & 126.00 & 5.22 & 5.22 & 7793 & 1494 & 3834 \\
\hline $0.05 \%$ & 5 & 14 & 126.00 & 5.22 & 5.22 & 7793 & 1494 & 3834 \\
\hline $0.05 \%$ & 5 & 14 & 126.00 & 5.22 & 5.22 & 7793 & 1494 & 3834 \\
\hline $0.02 \%$ & 3 & 14 & 126.00 & 5.22 & 5.22 & 7793 & 1494 & 3834 \\
\hline $0.21 \%$ & 21 & 14 & 126.00 & 5.22 & 5.22 & 7793 & 1494 & 3834 \\
\hline $0.18 \%$ & 18 & 14 & 126.00 & 5.22 & 5.22 & 7793 & 1494 & 3834 \\
\hline $0.05 \%$ & 5 & 14 & 126.00 & 5.22 & 5.22 & 7793 & 1494 & 3834 \\
\hline
\end{tabular}




\begin{tabular}{|c|c|c|c|c|c|c|c|c|}
\hline $0.14 \%$ & 15 & 14 & 126.00 & 5.22 & 5.22 & 7793 & 1494 & 3834 \\
\hline $0.02 \%$ & 3 & 14 & 126.00 & 5.22 & 5.22 & 7793 & 1494 & 3834 \\
\hline $0.30 \%$ & 31 & 14 & 126.00 & 5.22 & 5.22 & 7793 & 1494 & 3834 \\
\hline $0.23 \%$ & 23 & 14 & 126.00 & 5.22 & 5.22 & 7793 & 1494 & 3834 \\
\hline $0.51 \%$ & 53 & 41 & 125.03 & 1.76 & 1.76 & 5240 & 2978 & 2449 \\
\hline $0.13 \%$ & 13 & 41 & 125.03 & 1.76 & 1.76 & 5240 & 2978 & 2449 \\
\hline $0.08 \%$ & 8 & 19 & 127.02 & 1110.75 & 20.00 & 6550 & 328 & 3269 \\
\hline $0.07 \%$ & 7 & 19 & 127.02 & 1110.75 & 20.00 & 6550 & 328 & 3269 \\
\hline $0.07 \%$ & 7 & 19 & 127.02 & 1110.75 & 20.00 & 6550 & 328 & 3269 \\
\hline $0.15 \%$ & 15 & 19 & 127.02 & 1110.75 & 20.00 & 6550 & 328 & 3269 \\
\hline $0.10 \%$ & 10 & 19 & 127.02 & 1110.75 & 20.00 & 6550 & 328 & 3269 \\
\hline $0.61 \%$ & 62 & 36 & 127.02 & 1110.75 & 20.00 & 6550 & 328 & 3269 \\
\hline $0.11 \%$ & 11 & 19 & 127.02 & 1110.75 & 20.00 & 6550 & 328 & 3269 \\
\hline $1.28 \%$ & 132 & 90 & 110.02 & 2.07 & 2.07 & 2877 & 1388 & 1529 \\
\hline $1.85 \%$ & 190 & 249 & 109.01 & 7.05 & 7.05 & 8319 & 1181 & 4593 \\
\hline $3.84 \%$ & 394 & 462 & 109.01 & 7.05 & 7.05 & 8319 & 1181 & 4593 \\
\hline $3.69 \%$ & 378 & 213 & 117.01 & 8.52 & 8.52 & 4301 & 505 & 2032 \\
\hline $1.96 \%$ & 201 & 190 & 119.01 & 2.27 & 2.27 & 2987 & 1318 & 1428 \\
\hline $2.48 \%$ & 255 & 190 & 119.01 & 2.27 & 2.27 & 2987 & 1318 & 1428 \\
\hline $2.10 \%$ & 215 & 116 & 21.02 & 0.52 & 0.52 & 2084 & 3991 & 1036 \\
\hline
\end{tabular}




\begin{tabular}{|c|c|c|c|c|c|c|c|c|}
\hline $0.07 \%$ & 7 & 25 & 22.11 & 3.45 & 3.45 & 5366 & 1555 & 2501 \\
\hline $0.29 \%$ & 30 & 25 & 22.11 & 3.45 & 3.45 & 5366 & 1555 & 2501 \\
\hline $2.95 \%$ & 303 & 143 & 21.01 & 0.53 & 0.53 & 3873 & 7249 & 1960 \\
\hline $0.77 \%$ & 80 & 41 & 124.01 & 4.68 & 4.68 & 6621 & 1415 & 3291 \\
\hline $0.30 \%$ & 31 & 35 & 124.01 & 4.68 & 4.68 & 6621 & 1415 & 3291 \\
\hline $0.22 \%$ & 22 & 41 & 124.01 & 4.68 & 4.68 & 6621 & 1415 & 3291 \\
\hline $0.18 \%$ & 18 & 13 & 123.02 & 365.38 & 20.00 & 5137 & 257 & 2587 \\
\hline $0.79 \%$ & 82 & 13 & 115.03 & 10.34 & 10.34 & 3624 & 350 & 1765 \\
\hline $0.75 \%$ & 76 & 109 & 111.03 & 1.92 & 1.92 & 2737 & 1426 & 1368 \\
\hline $0.96 \%$ & 99 & 5 & 111.01 & 0.63 & 0.63 & 3592 & 5739 & 1858 \\
\hline $0.70 \%$ & 71 & 441 & 111.02 & 0.89 & 0.89 & 5127 & 5771 & 2640 \\
\hline $0.00 \%$ & 0 & 6 & 111.01 & 0.63 & 0.63 & 3592 & 5739 & 1858 \\
\hline $0.20 \%$ & 20 & 5 & 111.01 & 0.63 & 0.63 & 3592 & 5739 & 1858 \\
\hline $0.41 \%$ & 42 & 98 & 111.03 & 1.92 & 1.92 & 2737 & 1426 & 1368 \\
\hline $0.26 \%$ & 27 & 93 & 115.01 & 0.54 & 0.54 & 1783 & 3301 & 853 \\
\hline $0.11 \%$ & 11 & 13 & 123.02 & 365.38 & 20.00 & 5137 & 257 & 2587 \\
\hline $0.45 \%$ & 46 & 36 & 124.01 & 4.68 & 4.68 & 6621 & 1415 & 3291 \\
\hline $0.46 \%$ & 47 & 36 & 124.01 & 4.68 & 4.68 & 6621 & 1415 & 3291 \\
\hline $1.09 \%$ & 112 & 36 & 124.01 & 4.68 & 4.68 & 6621 & 1415 & 3291 \\
\hline $9.47 \%$ & 972 & 360 & 115.04 & 110.15 & 20.00 & 1362 & 68 & 944 \\
\hline
\end{tabular}




\begin{tabular}{|c|c|c|c|c|c|c|c|c|}
\hline $0.08 \%$ & 8 & 10 & 114.00 & 0.52 & 0.52 & 6446 & 34.7 & 6445 \\
\hline $0.10 \%$ & 10 & 14 & 106.02 & 2.02 & 2.02 & 3836 & 1901 & 1851 \\
\hline $0.38 \%$ & 39 & 26 & 107.01 & 0.93 & 0.93 & 4650 & 5017 & 2281 \\
\hline $0.50 \%$ & 51 & 26 & 107.01 & 0.93 & 0.93 & 4650 & 5017 & 2281 \\
\hline $0.47 \%$ & 48 & 60 & 107.03 & 1.55 & 1.55 & 3487 & 2253 & 1759 \\
\hline $0.88 \%$ & 91 & 60 & 107.03 & 1.55 & 1.55 & 3487 & 2253 & 1759 \\
\hline $0.93 \%$ & 96 & 60 & 107.03 & 1.55 & 1.55 & 3487 & 2253 & 1759 \\
\hline $0.20 \%$ & 20 & 17 & 107.07 & 9.65 & 9.65 & 5751 & 596 & 2734 \\
\hline $0.45 \%$ & 46 & 17 & 107.07 & 9.65 & 9.65 & 5751 & 596 & 2734 \\
\hline $0.28 \%$ & 29 & 17 & 107.07 & 9.65 & 9.65 & 5751 & 596 & 2734 \\
\hline $0.26 \%$ & 27 & 18 & 107.01 & 0.93 & 0.93 & 4650 & 5017 & 2281 \\
\hline $0.16 \%$ & 16 & 18 & 107.01 & 0.93 & 0.93 & 4650 & 5017 & 2281 \\
\hline $0.17 \%$ & 17 & 18 & 107.01 & 0.93 & 0.93 & 4650 & 5017 & 2281 \\
\hline $0.09 \%$ & 9 & 18 & 107.01 & 0.93 & 0.93 & 4650 & 5017 & 2281 \\
\hline $0.03 \%$ & 3 & 26 & 107.01 & 0.93 & 0.93 & 4650 & 5017 & 2281 \\
\hline $0.12 \%$ & 12 & 14 & 106.02 & 2.02 & 2.02 & 3836 & 1901 & 1851 \\
\hline $0.14 \%$ & 14 & 75 & 115.04 & 110.15 & 20.00 & 1362 & 68 & 944 \\
\hline $0.09 \%$ & 9 & 23 & 130.00 & 364.66 & 20.00 & 2539 & 127 & 1296 \\
\hline $0.02 \%$ & 2 & 6 & 105.04 & 4.03 & 4.03 & 2592 & 643 & 1241 \\
\hline $0.07 \%$ & 7 & 6 & 105.04 & 4.03 & 4.03 & 2592 & 643 & 1241 \\
\hline
\end{tabular}




\begin{tabular}{|c|c|c|c|c|c|c|c|c|}
\hline $0.06 \%$ & 6 & 6 & 105.04 & 4.03 & 4.03 & 2592 & 643 & 1241 \\
\hline $0.03 \%$ & 3 & 6 & 105.04 & 4.03 & 4.03 & 2592 & 643 & 1241 \\
\hline $0.04 \%$ & 4 & 5 & 104.03 & 6.65 & 6.65 & 3788 & 570 & 1816 \\
\hline $0.17 \%$ & 17 & 5 & 104.03 & 6.65 & 6.65 & 3788 & 570 & 1816 \\
\hline $0.05 \%$ & 5 & 5 & 104.03 & 6.65 & 6.65 & 3788 & 570 & 1816 \\
\hline $0.15 \%$ & 15 & 3 & 104.04 & 5.21 & 5.21 & 2249 & 432 & 1054 \\
\hline $0.00 \%$ & 0 & 3 & 104.04 & 5.21 & 5.21 & 2249 & 432 & 1054 \\
\hline $0.04 \%$ & 4 & 3 & 104.04 & 5.21 & 5.21 & 2249 & 432 & 1054 \\
\hline $0.07 \%$ & 7 & 3 & 104.04 & 5.21 & 5.21 & 2249 & 432 & 1054 \\
\hline $0.01 \%$ & 1 & 3 & 104.04 & 5.21 & 5.21 & 2249 & 432 & 1054 \\
\hline $0.09 \%$ & 9 & 3 & 104.04 & 5.21 & 5.21 & 2249 & 432 & 1054 \\
\hline $0.00 \%$ & 0 & 3 & 104.04 & 5.21 & 5.21 & 2249 & 432 & 1054 \\
\hline $0.00 \%$ & 0 & 3 & 104.04 & 5.21 & 5.21 & 2249 & 432 & 1054 \\
\hline $0.02 \%$ & 2 & 3 & 104.04 & 5.21 & 5.21 & 2249 & 432 & 1054 \\
\hline $0.03 \%$ & 3 & 5 & 130.00 & 364.66 & 20.00 & 2539 & 127 & 1296 \\
\hline $0.00 \%$ & 0 & 5 & 130.00 & 364.66 & 20.00 & 2539 & 127 & 1296 \\
\hline $0.07 \%$ & 7 & 3 & 104.04 & 5.21 & 5.21 & 2249 & 432 & 1054 \\
\hline $0.00 \%$ & 0 & 3 & 104.04 & 5.21 & 5.21 & 2249 & 432 & 1054 \\
\hline $0.00 \%$ & 0 & 3 & 104.04 & 5.21 & 5.21 & 2249 & 432 & 1054 \\
\hline $0.00 \%$ & 0 & 3 & 104.04 & 5.21 & 5.21 & 2249 & 432 & 1054 \\
\hline
\end{tabular}




\begin{tabular}{|c|c|c|c|c|c|c|c|c|}
\hline $0.00 \%$ & 0 & 3 & 104.04 & 5.21 & 5.21 & 2249 & 432 & 1054 \\
\hline $0.00 \%$ & 0 & 3 & 104.04 & 5.21 & 5.21 & 2249 & 432 & 1054 \\
\hline $0.00 \%$ & 0 & 3 & 104.04 & 5.21 & 5.21 & 2249 & 432 & 1054 \\
\hline $0.01 \%$ & 1 & 3 & 104.04 & 5.21 & 5.21 & 2249 & 432 & 1054 \\
\hline $0.00 \%$ & 0 & 5 & 104.04 & 5.21 & 5.21 & 2249 & 432 & 1054 \\
\hline $0.00 \%$ & 0 & 5 & 104.03 & 6.65 & 6.65 & 3788 & 570 & 1816 \\
\hline $0.00 \%$ & 0 & 5 & 104.03 & 6.65 & 6.65 & 3788 & 570 & 1816 \\
\hline $0.00 \%$ & 0 & 5 & 104.03 & 6.65 & 6.65 & 3788 & 570 & 1816 \\
\hline $0.07 \%$ & 7 & 6 & 105.04 & 4.03 & 4.03 & 2592 & 643 & 1241 \\
\hline $0.03 \%$ & 3 & 6 & 105.04 & 4.03 & 4.03 & 2592 & 643 & 1241 \\
\hline $0.01 \%$ & 1 & 6 & 105.04 & 4.03 & 4.03 & 2592 & 643 & 1241 \\
\hline $0.05 \%$ & 5 & 6 & 105.04 & 4.03 & 4.03 & 2592 & 643 & 1241 \\
\hline $0.06 \%$ & 6 & 9 & 105.03 & 3.17 & 3.17 & 5339 & 1682 & 2639 \\
\hline
\end{tabular}




\begin{tabular}{|c|c|c|c|c|c|c|c|c|c|c|c|}
\hline Gen & & & & & & & & \multicolumn{4}{|c|}{ Resident Age } \\
\hline $\begin{array}{c}\text { Res Male } \\
\text { Density }\end{array}$ & $\begin{array}{c}\text { Res } \\
\text { Female }\end{array}$ & $\begin{array}{c}\text { Res } \\
\text { Female } \\
\text { Density }\end{array}$ & Res $<18$ & $\begin{array}{l}\text { Res }<18 \\
\text { Density }\end{array}$ & Res $>18$ & $\begin{array}{l}\text { Res }>18 \\
\text { Density }\end{array}$ & $\begin{array}{c}\text { Res } 20 \\
\text { to } 24\end{array}$ & $\begin{array}{l}\text { Res } 20 \text { to } \\
24 \text { Density }\end{array}$ & $\begin{array}{c}\text { Res } 25 \\
\text { to } 34\end{array}$ & $\begin{array}{l}\text { Res } 25 \text { to } \\
\text { 34 Density }\end{array}$ & $\begin{array}{c}\text { Res } 35 \\
\text { to } 49\end{array}$ \\
\hline 2968.7 & 1734 & 2770.5 & 265 & 423.4 & 3327 & 5315.8 & 1213 & 1938.1 & 809 & 1292.6 & 488 \\
\hline 149.6 & 668 & 161.5 & 167 & 40.4 & 1120 & 270.7 & 59 & 14.3 & 177 & 42.8 & 189 \\
\hline 651.9 & 3726 & 528.9 & 58 & 8.2 & 8261 & 1172.6 & 2700 & 383.2 & 134 & 19.0 & 55 \\
\hline 651.9 & 3726 & 528.9 & 58 & 8.2 & 8261 & 1172.6 & 2700 & 383.2 & 134 & 19.0 & 55 \\
\hline 651.9 & 3726 & 528.9 & 58 & 8.2 & 8261 & 1172.6 & 2700 & 383.2 & 134 & 19.0 & 55 \\
\hline 692.2 & 3371 & 585.7 & 6642 & 1154.0 & 2862 & 497.2 & 2862 & 497.2 & 696 & 120.9 & 769 \\
\hline 1297.6 & 2499 & 1304.4 & 1232 & 643.1 & 3753 & 1959.0 & 367 & 191.6 & 851 & 444.2 & 1019 \\
\hline 207.7 & 4497 & 224.9 & 1802 & 90.1 & 6848 & 342.4 & 344 & 17.2 & 589 & 29.5 & 1560 \\
\hline 207.7 & 4497 & 224.9 & 1802 & 90.1 & 6848 & 342.4 & 344 & 17.2 & 589 & 29.5 & 1560 \\
\hline 1444.5 & 3491 & 1441.6 & 1950 & 805.3 & 5039 & 2080.9 & 678 & 280.0 & 1299 & 536.4 & 1266 \\
\hline 199.2 & 3662 & 219.8 & 1712 & 102.8 & 5269 & 316.2 & 269 & 16.1 & 716 & 43.0 & 1387 \\
\hline 738.5 & 1348 & 651.0 & 287 & 138.6 & 2590 & 1250.9 & 975 & 470.9 & 359 & 173.4 & 342 \\
\hline 163.5 & 3281 & 164.1 & 1340 & 67.0 & 5210 & 260.5 & 347 & 17.4 & 625 & 31.3 & 1279 \\
\hline 163.5 & 3281 & 164.1 & 1340 & 67.0 & 5210 & 260.5 & 347 & 17.4 & 625 & 31.3 & 1279 \\
\hline 163.5 & 3281 & 164.1 & 1340 & 67.0 & 5210 & 260.5 & 347 & 17.4 & 625 & 31.3 & 1279 \\
\hline 163.5 & 3281 & 164.1 & 1340 & 67.0 & 5210 & 260.5 & 347 & 17.4 & 625 & 31.3 & 1279 \\
\hline
\end{tabular}




\begin{tabular}{|c|c|c|c|c|c|c|c|c|c|c|c|}
\hline 163.5 & 3281 & 164.1 & 1340 & 67.0 & 5210 & 260.5 & 347 & 17.4 & 625 & 31.3 & 1279 \\
\hline 163.5 & 3281 & 164.1 & 1340 & 67.0 & 5210 & 260.5 & 347 & 17.4 & 625 & 31.3 & 1279 \\
\hline 163.5 & 3281 & 164.1 & 1340 & 67.0 & 5210 & 260.5 & 347 & 17.4 & 625 & 31.3 & 1279 \\
\hline 1390.5 & 2791 & 1584.7 & 1236 & 701.8 & 4004 & 2273.4 & 398 & 226.0 & 877 & 498.0 & 980 \\
\hline 1390.5 & 2791 & 1584.7 & 1236 & 701.8 & 4004 & 2273.4 & 398 & 226.0 & 877 & 498.0 & 980 \\
\hline 1390.5 & 2791 & 1584.7 & 1236 & 701.8 & 4004 & 2273.4 & 398 & 226.0 & 877 & 498.0 & 980 \\
\hline 1390.5 & 2791 & 1584.7 & 1236 & 701.8 & 4004 & 2273.4 & 398 & 226.0 & 877 & 498.0 & 980 \\
\hline 1391.9 & 2791 & 1586.2 & 1236 & 702.5 & 4004 & 2275.6 & 398 & 226.2 & 877 & 498.4 & 980 \\
\hline 1391.9 & 2791 & 1586.2 & 1236 & 702.5 & 4004 & 2275.6 & 398 & 226.2 & 877 & 498.4 & 980 \\
\hline 1391.9 & 2791 & 1586.2 & 1236 & 702.5 & 4004 & 2275.6 & 398 & 226.2 & 877 & 498.4 & 980 \\
\hline 1297.6 & 2499 & 1304.4 & 1232 & 643.1 & 3753 & 1959.0 & 367 & 191.6 & 851 & 444.2 & 1019 \\
\hline 1297.6 & 2499 & 1304.4 & 1232 & 643.1 & 3753 & 1959.0 & 367 & 191.6 & 851 & 444.2 & 1019 \\
\hline 750.2 & 2451 & 753.6 & 1145 & 352.0 & 3746 & 1151.7 & 284 & 87.3 & 587 & 180.5 & 1032 \\
\hline 750.2 & 2451 & 753.6 & 1145 & 352.0 & 3746 & 1151.7 & 284 & 87.3 & 587 & 180.5 & 1032 \\
\hline 750.2 & 2451 & 753.6 & 1145 & 352.0 & 3746 & 1151.7 & 284 & 87.3 & 587 & 180.5 & 1032 \\
\hline 750.2 & 2451 & 753.6 & 1145 & 352.0 & 3746 & 1151.7 & 284 & 87.3 & 587 & 180.5 & 1032 \\
\hline 750.2 & 2451 & 753.6 & 1145 & 352.0 & 3746 & 1151.7 & 284 & 87.3 & 587 & 180.5 & 1032 \\
\hline 750.2 & 2451 & 753.6 & 1145 & 352.0 & 3746 & 1151.7 & 284 & 87.3 & 587 & 180.5 & 1032 \\
\hline 750.2 & 2451 & 753.6 & 1145 & 352.0 & 3746 & 1151.7 & 284 & 87.3 & 587 & 180.5 & 1032 \\
\hline 750.2 & 2451 & 753.6 & 1145 & 352.0 & 3746 & 1151.7 & 284 & 87.3 & 587 & 180.5 & 1032 \\
\hline
\end{tabular}




\begin{tabular}{|c|c|c|c|c|c|c|c|c|c|c|c|}
\hline 750.2 & 2451 & 753.6 & 1145 & 352.0 & 3746 & 1151.7 & 284 & 87.3 & 587 & 180.5 & 1032 \\
\hline 207.7 & 4497 & 224.9 & 1802 & 90.1 & 6848 & 342.4 & 344 & 17.2 & 589 & 29.5 & 1560 \\
\hline 1444.5 & 3491 & 1441.6 & 1950 & 805.3 & 5039 & 2080.9 & 678 & 280.0 & 1299 & 536.4 & 1266 \\
\hline 1444.5 & 3491 & 1441.6 & 1950 & 805.3 & 5039 & 2080.9 & 678 & 280.0 & 1299 & 536.4 & 1266 \\
\hline 1444.5 & 3491 & 1441.6 & 1950 & 805.3 & 5039 & 2080.9 & 678 & 280.0 & 1299 & 536.4 & 1266 \\
\hline 251.2 & 5019 & 251.0 & 2344 & 117.2 & 7699 & 385.0 & 492 & 24.6 & 1008 & 50.4 & 2013 \\
\hline 251.2 & 5019 & 251.0 & 2344 & 117.2 & 7699 & 385.0 & 492 & 24.6 & 1008 & 50.4 & 2013 \\
\hline 1444.5 & 3491 & 1441.6 & 1950 & 805.3 & 5039 & 2080.9 & 678 & 280.0 & 1299 & 536.4 & 1266 \\
\hline 207.7 & 4497 & 224.9 & 1802 & 90.1 & 6848 & 342.4 & 344 & 17.2 & 589 & 29.5 & 1560 \\
\hline 734.9 & 3959 & 758.9 & 1718 & 329.3 & 6075 & 1164.5 & 399 & 76.5 & 937 & 179.6 & 1477 \\
\hline 734.9 & 3959 & 758.9 & 1718 & 329.3 & 6075 & 1164.5 & 399 & 76.5 & 937 & 179.6 & 1477 \\
\hline 734.9 & 3959 & 758.9 & 1718 & 329.3 & 6075 & 1164.5 & 399 & 76.5 & 937 & 179.6 & 1477 \\
\hline 734.9 & 3959 & 758.9 & 1718 & 329.3 & 6075 & 1164.5 & 399 & 76.5 & 937 & 179.6 & 1477 \\
\hline 734.9 & 3959 & 758.9 & 1718 & 329.3 & 6075 & 1164.5 & 399 & 76.5 & 937 & 179.6 & 1477 \\
\hline 734.9 & 3959 & 758.9 & 1718 & 329.3 & 6075 & 1164.5 & 399 & 76.5 & 937 & 179.6 & 1477 \\
\hline 734.9 & 3959 & 758.9 & 1718 & 329.3 & 6075 & 1164.5 & 399 & 76.5 & 937 & 179.6 & 1477 \\
\hline 734.9 & 3959 & 758.9 & 1718 & 329.3 & 6075 & 1164.5 & 399 & 76.5 & 937 & 179.6 & 1477 \\
\hline 734.9 & 3959 & 758.9 & 1718 & 329.3 & 6075 & 1164.5 & 399 & 76.5 & 937 & 179.6 & 1477 \\
\hline 734.9 & 3959 & 758.9 & 1718 & 329.3 & 6075 & 1164.5 & 399 & 76.5 & 937 & 179.6 & 1477 \\
\hline 734.9 & 3959 & 758.9 & 1718 & 329.3 & 6075 & 1164.5 & 399 & 76.5 & 937 & 179.6 & 1477 \\
\hline
\end{tabular}




\begin{tabular}{|c|c|c|c|c|c|c|c|c|c|c|c|}
\hline 734.9 & 3959 & 758.9 & 1718 & 329.3 & 6075 & 1164.5 & 399 & 76.5 & 937 & 179.6 & 1477 \\
\hline 734.9 & 3959 & 758.9 & 1718 & 329.3 & 6075 & 1164.5 & 399 & 76.5 & 937 & 179.6 & 1477 \\
\hline 734.9 & 3959 & 758.9 & 1718 & 329.3 & 6075 & 1164.5 & 399 & 76.5 & 937 & 179.6 & 1477 \\
\hline 734.9 & 3959 & 758.9 & 1718 & 329.3 & 6075 & 1164.5 & 399 & 76.5 & 937 & 179.6 & 1477 \\
\hline 1391.9 & 2791 & 1586.2 & 1236 & 702.5 & 4004 & 2275.6 & 398 & 226.2 & 877 & 498.4 & 980 \\
\hline 1391.9 & 2791 & 1586.2 & 1236 & 702.5 & 4004 & 2275.6 & 398 & 226.2 & 877 & 498.4 & 980 \\
\hline 163.5 & 3281 & 164.1 & 1340 & 67.0 & 5210 & 260.5 & 347 & 17.4 & 625 & 31.3 & 1279 \\
\hline 163.5 & 3281 & 164.1 & 1340 & 67.0 & 5210 & 260.5 & 347 & 17.4 & 625 & 31.3 & 1279 \\
\hline 163.5 & 3281 & 164.1 & 1340 & 67.0 & 5210 & 260.5 & 347 & 17.4 & 625 & 31.3 & 1279 \\
\hline 163.5 & 3281 & 164.1 & 1340 & 67.0 & 5210 & 260.5 & 347 & 17.4 & 625 & 31.3 & 1279 \\
\hline 163.5 & 3281 & 164.1 & 1340 & 67.0 & 5210 & 260.5 & 347 & 17.4 & 625 & 31.3 & 1279 \\
\hline 163.5 & 3281 & 164.1 & 1340 & 67.0 & 5210 & 260.5 & 347 & 17.4 & 625 & 31.3 & 1279 \\
\hline 163.5 & 3281 & 164.1 & 1340 & 67.0 & 5210 & 260.5 & 347 & 17.4 & 625 & 31.3 & 1279 \\
\hline 737.9 & 1348 & 650.6 & 287 & 138.5 & 2590 & 1250.0 & 975 & 470.6 & 359 & 173.3 & 342 \\
\hline 651.9 & 3726 & 528.9 & 58 & 8.2 & 8261 & 1172.6 & 2700 & 383.2 & 134 & 19.0 & 55 \\
\hline 651.9 & 3726 & 528.9 & 58 & 8.2 & 8261 & 1172.6 & 2700 & 383.2 & 134 & 19.0 & 55 \\
\hline 238.4 & 2269 & 266.3 & 601 & 70.5 & 3700 & 434.2 & 140 & 16.4 & 313 & 36.7 & 685 \\
\hline 630.1 & 1559 & 687.9 & 535 & 236.1 & 2452 & 1082.0 & 159 & 70.2 & 259 & 114.3 & 485 \\
\hline 630.1 & 1559 & 687.9 & 535 & 236.1 & 2452 & 1082.0 & 159 & 70.2 & 259 & 114.3 & 485 \\
\hline 1984.1 & 1048 & 2007.1 & 524 & 1003.5 & 1560 & 2987.7 & 160 & 306.4 & 270 & 517.1 & 405 \\
\hline
\end{tabular}




\begin{tabular}{|c|c|c|c|c|c|c|c|c|c|c|c|}
\hline 724.6 & 2865 & 830.1 & 1116 & 323.4 & 4250 & 1231.4 & 320 & 92.7 & 553 & 160.2 & 852 \\
\hline 724.6 & 2865 & 830.1 & 1116 & 323.4 & 4250 & 1231.4 & 320 & 92.7 & 553 & 160.2 & 852 \\
\hline 3668.3 & 1913 & 3580.3 & 1156 & 2163.5 & 2717 & 5085.0 & 364 & 681.2 & 727 & 1360.6 & 697 \\
\hline 703.3 & 3330 & 711.7 & 1944 & 415.5 & 4677 & 999.5 & 450 & 96.2 & 954 & 203.9 & 1309 \\
\hline 703.3 & 3330 & 711.7 & 1944 & 415.5 & 4677 & 999.5 & 450 & 96.2 & 954 & 203.9 & 1309 \\
\hline 703.3 & 3330 & 711.7 & 1944 & 415.5 & 4677 & 999.5 & 450 & 96.2 & 954 & 203.9 & 1309 \\
\hline 129.4 & 2550 & 127.5 & 1098 & 54.9 & 4039 & 202.0 & 205 & 10.3 & 413 & 20.7 & 906 \\
\hline 170.6 & 1859 & 179.7 & 917 & 88.6 & 2707 & 261.7 & 257 & 24.8 & 322 & 31.1 & 741 \\
\hline 712.9 & 1369 & 713.4 & 332 & 173.0 & 2405 & 1253.2 & 356 & 185.5 & 424 & 220.9 & 442 \\
\hline 2968.7 & 1734 & 2770.5 & 265 & 423.4 & 3327 & 5315.8 & 1213 & 1938.1 & 809 & 1292.6 & 488 \\
\hline 2971.4 & 2487 & 2799.2 & 629 & 708.0 & 4498 & 5062.6 & 1196 & 1346.1 & 1137 & 1279.7 & 806 \\
\hline 2968.7 & 1734 & 2770.5 & 265 & 423.4 & 3327 & 5315.8 & 1213 & 1938.1 & 809 & 1292.6 & 488 \\
\hline 2968.7 & 1734 & 2770.5 & 265 & 423.4 & 3327 & 5315.8 & 1213 & 1938.1 & 809 & 1292.6 & 488 \\
\hline 712.9 & 1369 & 713.4 & 332 & 173.0 & 2405 & 1253.2 & 356 & 185.5 & 424 & 220.9 & 442 \\
\hline 1579.4 & 930 & 1721.9 & 264 & 488.8 & 1519 & 2812.5 & 220 & 407.3 & 209 & 387.0 & 311 \\
\hline 129.4 & 2550 & 127.5 & 1098 & 54.9 & 4039 & 202.0 & 205 & 10.3 & 413 & 20.7 & 906 \\
\hline 703.3 & 3330 & 711.7 & 1944 & 415.5 & 4677 & 999.5 & 450 & 96.2 & 954 & 203.9 & 1309 \\
\hline 703.3 & 3330 & 711.7 & 1944 & 415.5 & 4677 & 999.5 & 450 & 96.2 & 954 & 203.9 & 1309 \\
\hline 703.3 & 3330 & 711.7 & 1944 & 415.5 & 4677 & 999.5 & 450 & 96.2 & 954 & 203.9 & 1309 \\
\hline 47.2 & 418 & 20.9 & 264 & 13.2 & 1098 & 54.9 & 196 & 9.8 & 217 & 10.9 & 220 \\
\hline
\end{tabular}




\begin{tabular}{|c|c|c|c|c|c|c|c|c|c|c|c|}
\hline 34.7 & 1 & 1.9 & 0 & 0.0 & 6446 & 34.7 & 526 & 34.7 & 1512 & 34.7 & 2780 \\
\hline 917.3 & 1985 & 983.7 & 507 & 251.2 & 3329 & 1649.7 & 216 & 107.0 & 397 & 196.7 & 631 \\
\hline 2461.0 & 2369 & 2556.0 & 939 & 1013.1 & 3711 & 4003.9 & 279 & 301.0 & 580 & 625.8 & 892 \\
\hline 2461.0 & 2369 & 2556.0 & 939 & 1013.1 & 3711 & 4003.9 & 279 & 301.0 & 580 & 625.8 & 892 \\
\hline 1136.6 & 1728 & 1116.6 & 689 & 445.2 & 2798 & 1807.9 & 282 & 182.2 & 434 & 280.4 & 645 \\
\hline 1136.6 & 1728 & 1116.6 & 689 & 445.2 & 2798 & 1807.9 & 282 & 182.2 & 434 & 280.4 & 645 \\
\hline 1136.6 & 1728 & 1116.6 & 689 & 445.2 & 2798 & 1807.9 & 282 & 182.2 & 434 & 280.4 & 645 \\
\hline 283.2 & 3017 & 312.6 & 857 & 88.8 & 4894 & 507.0 & 235 & 24.3 & 470 & 48.7 & 870 \\
\hline 283.2 & 3017 & 312.6 & 857 & 88.8 & 4894 & 507.0 & 235 & 24.3 & 470 & 48.7 & 870 \\
\hline 283.2 & 3017 & 312.6 & 857 & 88.8 & 4894 & 507.0 & 235 & 24.3 & 470 & 48.7 & 870 \\
\hline 2461.0 & 2369 & 2556.0 & 939 & 1013.1 & 3711 & 4003.9 & 279 & 301.0 & 580 & 625.8 & 892 \\
\hline 2461.0 & 2369 & 2556.0 & 939 & 1013.1 & 3711 & 4003.9 & 279 & 301.0 & 580 & 625.8 & 892 \\
\hline 2461.0 & 2369 & 2556.0 & 939 & 1013.1 & 3711 & 4003.9 & 279 & 301.0 & 580 & 625.8 & 892 \\
\hline 2461.0 & 2369 & 2556.0 & 939 & 1013.1 & 3711 & 4003.9 & 279 & 301.0 & 580 & 625.8 & 892 \\
\hline 2461.0 & 2369 & 2556.0 & 939 & 1013.1 & 3711 & 4003.9 & 279 & 301.0 & 580 & 625.8 & 892 \\
\hline 917.3 & 1985 & 983.7 & 507 & 251.2 & 3329 & 1649.7 & 216 & 107.0 & 397 & 196.7 & 631 \\
\hline 47.2 & 418 & 20.9 & 264 & 13.2 & 1098 & 54.9 & 196 & 9.8 & 217 & 10.9 & 220 \\
\hline 64.8 & 1243 & 62.2 & 450 & 22.5 & 2089 & 104.5 & 125 & 6.3 & 255 & 12.8 & 480 \\
\hline 307.6 & 1351 & 334.9 & 337 & 83.5 & 2255 & 559.0 & 125 & 31.0 & 235 & 58.3 & 430 \\
\hline 307.6 & 1351 & 334.9 & 337 & 83.5 & 2255 & 559.0 & 125 & 31.0 & 235 & 58.3 & 430 \\
\hline
\end{tabular}




\begin{tabular}{|c|c|c|c|c|c|c|c|c|c|c|c|}
\hline 307.6 & 1351 & 334.9 & 337 & 83.5 & 2255 & 559.0 & 125 & 31.0 & 235 & 58.3 & 430 \\
\hline 307.6 & 1351 & 334.9 & 337 & 83.5 & 2255 & 559.0 & 125 & 31.0 & 235 & 58.3 & 430 \\
\hline 273.1 & 1972 & 296.5 & 476 & 71.6 & 3312 & 498.0 & 120 & 18.0 & 224 & 33.7 & 471 \\
\hline 273.1 & 1972 & 296.5 & 476 & 71.6 & 3312 & 498.0 & 120 & 18.0 & 224 & 33.7 & 471 \\
\hline 273.1 & 1972 & 296.5 & 476 & 71.6 & 3312 & 498.0 & 120 & 18.0 & 224 & 33.7 & 471 \\
\hline 202.3 & 1195 & 229.3 & 383 & 73.5 & 1866 & 358.1 & 76 & 14.6 & 193 & 37.0 & 275 \\
\hline 202.3 & 1195 & 229.3 & 383 & 73.5 & 1866 & 358.1 & 76 & 14.6 & 193 & 37.0 & 275 \\
\hline 202.3 & 1195 & 229.3 & 383 & 73.5 & 1866 & 358.1 & 76 & 14.6 & 193 & 37.0 & 275 \\
\hline 202.3 & 1195 & 229.3 & 383 & 73.5 & 1866 & 358.1 & 76 & 14.6 & 193 & 37.0 & 275 \\
\hline 202.3 & 1195 & 229.3 & 383 & 73.5 & 1866 & 358.1 & 76 & 14.6 & 193 & 37.0 & 275 \\
\hline 202.3 & 1195 & 229.3 & 383 & 73.5 & 1866 & 358.1 & 76 & 14.6 & 193 & 37.0 & 275 \\
\hline 202.3 & 1195 & 229.3 & 383 & 73.5 & 1866 & 358.1 & 76 & 14.6 & 193 & 37.0 & 275 \\
\hline 202.3 & 1195 & 229.3 & 383 & 73.5 & 1866 & 358.1 & 76 & 14.6 & 193 & 37.0 & 275 \\
\hline 202.3 & 1195 & 229.3 & 383 & 73.5 & 1866 & 358.1 & 76 & 14.6 & 193 & 37.0 & 275 \\
\hline 64.8 & 1243 & 62.2 & 450 & 22.5 & 2089 & 104.5 & 125 & 6.3 & 255 & 12.8 & 480 \\
\hline 64.8 & 1243 & 62.2 & 450 & 22.5 & 2089 & 104.5 & 125 & 6.3 & 255 & 12.8 & 480 \\
\hline 202.3 & 1195 & 229.3 & 383 & 73.5 & 1866 & 358.1 & 76 & 14.6 & 193 & 37.0 & 275 \\
\hline 202.3 & 1195 & 229.3 & 383 & 73.5 & 1866 & 358.1 & 76 & 14.6 & 193 & 37.0 & 275 \\
\hline 202.3 & 1195 & 229.3 & 383 & 73.5 & 1866 & 358.1 & 76 & 14.6 & 193 & 37.0 & 275 \\
\hline 202.3 & 1195 & 229.3 & 383 & 73.5 & 1866 & 358.1 & 76 & 14.6 & 193 & 37.0 & 275 \\
\hline
\end{tabular}




\begin{tabular}{|c|c|c|c|c|c|c|c|c|c|c|c|}
\hline 202.3 & 1195 & 229.3 & 383 & 73.5 & 1866 & 358.1 & 76 & 14.6 & 193 & 37.0 & 275 \\
\hline 202.3 & 1195 & 229.3 & 383 & 73.5 & 1866 & 358.1 & 76 & 14.6 & 193 & 37.0 & 275 \\
\hline 202.3 & 1195 & 229.3 & 383 & 73.5 & 1866 & 358.1 & 76 & 14.6 & 193 & 37.0 & 275 \\
\hline 202.3 & 1195 & 229.3 & 383 & 73.5 & 1866 & 358.1 & 76 & 14.6 & 193 & 37.0 & 275 \\
\hline 202.3 & 1195 & 229.3 & 383 & 73.5 & 1866 & 358.1 & 76 & 14.6 & 193 & 37.0 & 275 \\
\hline 273.1 & 1972 & 296.5 & 476 & 71.6 & 3312 & 498.0 & 120 & 18.0 & 224 & 33.7 & 471 \\
\hline 273.1 & 1972 & 296.5 & 476 & 71.6 & 3312 & 498.0 & 120 & 18.0 & 224 & 33.7 & 471 \\
\hline 273.1 & 1972 & 296.5 & 476 & 71.6 & 3312 & 498.0 & 120 & 18.0 & 224 & 33.7 & 471 \\
\hline 307.6 & 1351 & 334.9 & 337 & 83.5 & 2255 & 559.0 & 125 & 31.0 & 235 & 58.3 & 430 \\
\hline 307.6 & 1351 & 334.9 & 337 & 83.5 & 2255 & 559.0 & 125 & 31.0 & 235 & 58.3 & 430 \\
\hline 307.6 & 1351 & 334.9 & 337 & 83.5 & 2255 & 559.0 & 125 & 31.0 & 235 & 58.3 & 430 \\
\hline 307.6 & 1351 & 334.9 & 337 & 83.5 & 2255 & 559.0 & 125 & 31.0 & 235 & 58.3 & 430 \\
\hline 831.6 & 2700 & 850.8 & 883 & 278.3 & 4456 & 1404.2 & 329 & 103.7 & 642 & 202.3 & 948 \\
\hline
\end{tabular}




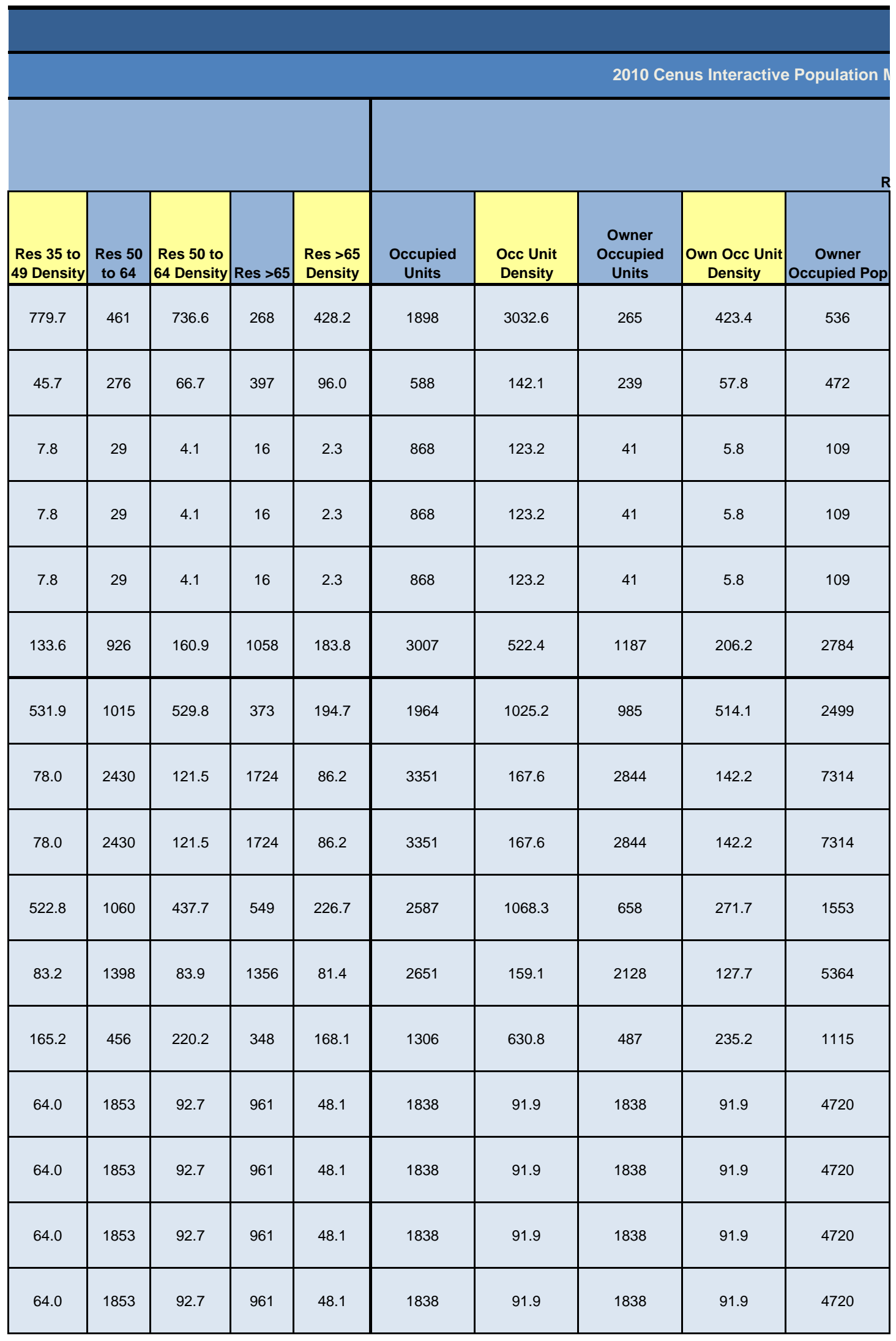




\begin{tabular}{|c|c|c|c|c|c|c|c|c|c|}
\hline 64.0 & 1853 & 92.7 & 961 & 48.1 & 1838 & 91.9 & 1838 & 91.9 & 4720 \\
\hline 64.0 & 1853 & 92.7 & 961 & 48.1 & 1838 & 91.9 & 1838 & 91.9 & 4720 \\
\hline 556.4 & 951 & 540.0 & 673 & 382.1 & 2195 & 1246.3 & 1007 & 571.8 & 2378 \\
\hline 556.4 & 951 & 540.0 & 673 & 382.1 & 2195 & 1246.3 & 1007 & 571.8 & 2378 \\
\hline 556.4 & 951 & 540.0 & 673 & 382.1 & 2195 & 1246.3 & 1007 & 571.8 & 2378 \\
\hline 556.4 & 951 & 540.0 & 673 & 382.1 & 2195 & 1246.3 & 1007 & 571.8 & 2378 \\
\hline 557.0 & 951 & 540.5 & 673 & 382.5 & 2195 & 1247.5 & 1007 & 572.3 & 2378 \\
\hline 557.0 & 951 & 540.5 & 673 & 382.5 & 2195 & 1247.5 & 1007 & 572.3 & 2378 \\
\hline 557.0 & 951 & 540.5 & 673 & 382.5 & 2195 & 1247.5 & 1007 & 572.3 & 2378 \\
\hline 531.9 & 1015 & 529.8 & 373 & 194.7 & 1964 & 1025.2 & 985 & 514.1 & 2499 \\
\hline 531.9 & 1015 & 529.8 & 373 & 194.7 & 1964 & 1025.2 & 985 & 514.1 & 2499 \\
\hline 317.3 & 1185 & 364.3 & 543 & 166.9 & 1839 & 565.4 & 1318 & 405.2 & 3467 \\
\hline 317.3 & 1185 & 364.3 & 543 & 166.9 & 1839 & 565.4 & 1318 & 405.2 & 3467 \\
\hline 317.3 & 1185 & 364.3 & 543 & 166.9 & 1839 & 565.4 & 1318 & 405.2 & 3467 \\
\hline 317.3 & 1185 & 364.3 & 543 & 166.9 & 1839 & 565.4 & 1318 & 405.2 & 3467 \\
\hline 317.3 & 1185 & 364.3 & 543 & 166.9 & 1839 & 565.4 & 1318 & 405.2 & 3467 \\
\hline 317.3 & 1185 & 364.3 & 543 & 166.9 & 1839 & 565.4 & 1318 & 405.2 & 3467 \\
\hline 317.3 & 1185 & 364.3 & 543 & 166.9 & 1839 & 565.4 & 1318 & 405.2 & 3467 \\
\hline 317.3 & 1185 & 364.3 & 543 & 166.9 & 1839 & 565.4 & 1318 & 405.2 & 3467 \\
\hline
\end{tabular}




\begin{tabular}{|c|c|c|c|c|c|c|c|c|c|}
\hline 317.3 & 1185 & 364.3 & 543 & 166.9 & 1839 & 565.4 & 1318 & 405.2 & 3467 \\
\hline 78.0 & 2430 & 121.5 & 1724 & 86.2 & 3351 & 167.6 & 2844 & 142.2 & 7314 \\
\hline 522.8 & 1060 & 437.7 & 549 & 226.7 & 2587 & 1068.3 & 658 & 271.7 & 1553 \\
\hline 522.8 & 1060 & 437.7 & 549 & 226.7 & 2587 & 1068.3 & 658 & 271.7 & 1553 \\
\hline 100.7 & 2579 & 129.0 & 1334 & 66.7 & 3585 & 179.3 & 2671 & 133.6 & 7338 \\
\hline 100.7 & 2579 & 129.0 & 1334 & 66.7 & 3585 & 179.3 & 2671 & 133.6 & 7338 \\
\hline 522.8 & 1060 & 437.7 & 549 & 226.7 & 2587 & 1068.3 & 658 & 271.7 & 1553 \\
\hline 78.0 & 2430 & 121.5 & 1724 & 86.2 & 3351 & 167.6 & 2844 & 142.2 & 7314 \\
\hline 283.1 & 1950 & 373.8 & 1148 & 220.1 & 2967 & 568.7 & 1979 & 379.4 & 5265 \\
\hline 283.1 & 1950 & 373.8 & 1148 & 220.1 & 2967 & 568.7 & 1979 & 379.4 & 5265 \\
\hline 283.1 & 1950 & 373.8 & 1148 & 220.1 & 2967 & 568.7 & 1979 & 379.4 & 5265 \\
\hline 283.1 & 1950 & 373.8 & 1148 & 220.1 & 2967 & 568.7 & 1979 & 379.4 & 5265 \\
\hline 283.1 & 1950 & 373.8 & 1148 & 220.1 & 2967 & 568.7 & 1979 & 379.4 & 5265 \\
\hline 283.1 & 1950 & 373.8 & 1148 & 220.1 & 2967 & 568.7 & 1979 & 379.4 & 5265 \\
\hline 283.1 & 1950 & 373.8 & 1148 & 220.1 & 2967 & 568.7 & 1979 & 379.4 & 5265 \\
\hline 283.1 & 1950 & 373.8 & 1148 & 220.1 & 2967 & 568.7 & 1979 & 379.4 & 5265 \\
\hline 283.1 & 1950 & 373.8 & 1148 & 220.1 & 2967 & 568.7 & 1979 & 379.4 & 5265 \\
\hline 283.1 & 1950 & 373.8 & 1148 & 220.1 & 2967 & 568.7 & 1979 & 379.4 & 5265 \\
\hline 283.1 & 1950 & 373.8 & 1148 & 220.1 & 2967 & 568.7 & 1979 & 379.4 & 5265 \\
\hline
\end{tabular}




\begin{tabular}{|c|c|c|c|c|c|c|c|c|c|}
\hline 283.1 & 1950 & 373.8 & 1148 & 220.1 & 2967 & 568.7 & 1979 & 379.4 & 5265 \\
\hline 283.1 & 1950 & 373.8 & 1148 & 220.1 & 2967 & 568.7 & 1979 & 379.4 & 5265 \\
\hline 283.1 & 1950 & 373.8 & 1148 & 220.1 & 2967 & 568.7 & 1979 & 379.4 & 5265 \\
\hline 283.1 & 1950 & 373.8 & 1148 & 220.1 & 2967 & 568.7 & 1979 & 379.4 & 5265 \\
\hline 557.0 & 951 & 540.5 & 673 & 382.5 & 2195 & 1247.5 & 1007 & 572.3 & 2378 \\
\hline 557.0 & 951 & 540.5 & 673 & 382.5 & 2195 & 1247.5 & 1007 & 572.3 & 2378 \\
\hline 64.0 & 1853 & 92.7 & 961 & 48.1 & 1838 & 91.9 & 1838 & 91.9 & 4720 \\
\hline 64.0 & 1853 & 92.7 & 961 & 48.1 & 1838 & 91.9 & 1838 & 91.9 & 4720 \\
\hline 64.0 & 1853 & 92.7 & 961 & 48.1 & 1838 & 91.9 & 1838 & 91.9 & 4720 \\
\hline 64.0 & 1853 & 92.7 & 961 & 48.1 & 1838 & 91.9 & 1838 & 91.9 & 4720 \\
\hline 64.0 & 1853 & 92.7 & 961 & 48.1 & 1838 & 91.9 & 1838 & 91.9 & 4720 \\
\hline 64.0 & 1853 & 92.7 & 961 & 48.1 & 1838 & 91.9 & 1838 & 91.9 & 4720 \\
\hline 64.0 & 1853 & 92.7 & 961 & 48.1 & 1838 & 91.9 & 1838 & 91.9 & 4720 \\
\hline 165.1 & 456 & 220.1 & 348 & 168.0 & 1306 & 630.3 & 487 & 235.0 & 1115 \\
\hline 7.8 & 29 & 4.1 & 16 & 2.3 & 868 & 123.2 & 41 & 5.8 & 109 \\
\hline 7.8 & 29 & 4.1 & 16 & 2.3 & 868 & 123.2 & 41 & 5.8 & 109 \\
\hline 80.4 & 1153 & 135.3 & 1344 & 157.7 & 2060 & 241.7 & 1546 & 181.4 & 3110 \\
\hline 214.0 & 663 & 292.6 & 829 & 365.8 & 1302 & 574.5 & 966 & 426.3 & 2157 \\
\hline 214.0 & 663 & 292.6 & 829 & 365.8 & 1302 & 574.5 & 966 & 426.3 & 2157 \\
\hline 775.6 & 384 & 735.4 & 275 & 526.7 & 739 & 1415.3 & 433 & 829.3 & 1179 \\
\hline
\end{tabular}




\begin{tabular}{|c|c|c|c|c|c|c|c|c|c|}
\hline 246.9 & 1055 & 305.7 & 1345 & 389.7 & 2033 & 589.0 & 1434 & 415.5 & 3721 \\
\hline 246.9 & 1055 & 305.7 & 1345 & 389.7 & 2033 & 589.0 & 1434 & 415.5 & 3721 \\
\hline 1304.5 & 497 & 930.2 & 304 & 569.0 & 1211 & 2266.5 & 403 & 754.2 & 1045 \\
\hline 279.8 & 1173 & 250.7 & 582 & 124.4 & 1959 & 418.7 & 1354 & 289.4 & 4513 \\
\hline 279.8 & 1173 & 250.7 & 582 & 124.4 & 1959 & 418.7 & 1354 & 289.4 & 4513 \\
\hline 279.8 & 1173 & 250.7 & 582 & 124.4 & 1959 & 418.7 & 1354 & 289.4 & 4513 \\
\hline 45.3 & 1493 & 74.7 & 911 & 45.6 & 1967 & 98.4 & 1382 & 69.1 & 3725 \\
\hline 71.6 & 896 & 86.6 & 382 & 36.9 & 1384 & 133.8 & 1012 & 97.8 & 2653 \\
\hline 230.3 & 548 & 285.6 & 580 & 302.2 & 1329 & 692.5 & 648 & 337.7 & 1179 \\
\hline 779.7 & 461 & 736.6 & 268 & 428.2 & 1898 & 3032.6 & 265 & 423.4 & 536 \\
\hline 907.2 & 779 & 876.8 & 473 & 532.4 & 2439 & 2745.2 & 688 & 774.4 & 1472 \\
\hline 779.7 & 461 & 736.6 & 268 & 428.2 & 1898 & 3032.6 & 265 & 423.4 & 536 \\
\hline 779.7 & 461 & 736.6 & 268 & 428.2 & 1898 & 3032.6 & 265 & 423.4 & 536 \\
\hline 230.3 & 548 & 285.6 & 580 & 302.2 & 1329 & 692.5 & 648 & 337.7 & 1179 \\
\hline 575.8 & 455 & 842.4 & 276 & 511.0 & 781 & 1446.0 & 551 & 1020.2 & 1151 \\
\hline 45.3 & 1493 & 74.7 & 911 & 45.6 & 1967 & 98.4 & 1382 & 69.1 & 3725 \\
\hline 279.8 & 1173 & 250.7 & 582 & 124.4 & 1959 & 418.7 & 1354 & 289.4 & 4513 \\
\hline 279.8 & 1173 & 250.7 & 582 & 124.4 & 1959 & 418.7 & 1354 & 289.4 & 4513 \\
\hline 279.8 & 1173 & 250.7 & 582 & 124.4 & 1959 & 418.7 & 1354 & 289.4 & 4513 \\
\hline 11.0 & 243 & 12.2 & 111 & 5.6 & 235 & 11.8 & 155 & 7.8 & 382 \\
\hline
\end{tabular}




\begin{tabular}{|c|c|c|c|c|c|c|c|c|c|}
\hline 34.7 & 1391 & 34.7 & 188 & 34.7 & 6 & 11.6 & 0 & 0.0 & 0 \\
\hline 312.7 & 1036 & 513.4 & 969 & 480.2 & 1898 & 940.5 & 1005 & 498.0 & 1995 \\
\hline 962.4 & 1205 & 1300.1 & 633 & 683.0 & 1864 & 2011.1 & 1175 & 1267.7 & 2854 \\
\hline 962.4 & 1205 & 1300.1 & 633 & 683.0 & 1864 & 2011.1 & 1175 & 1267.7 & 2854 \\
\hline 416.8 & 876 & 566.0 & 455 & 294.0 & 1348 & 871.0 & 721 & 465.9 & 1923 \\
\hline 416.8 & 876 & 566.0 & 455 & 294.0 & 1348 & 871.0 & 721 & 465.9 & 1923 \\
\hline 416.8 & 876 & 566.0 & 455 & 294.0 & 1348 & 871.0 & 721 & 465.9 & 1923 \\
\hline 90.1 & 1684 & 174.5 & 1538 & 159.3 & 2610 & 270.4 & 2050 & 212.4 & 4334 \\
\hline 90.1 & 1684 & 174.5 & 1538 & 159.3 & 2610 & 270.4 & 2050 & 212.4 & 4334 \\
\hline 90.1 & 1684 & 174.5 & 1538 & 159.3 & 2610 & 270.4 & 2050 & 212.4 & 4334 \\
\hline 962.4 & 1205 & 1300.1 & 633 & 683.0 & 1864 & 2011.1 & 1175 & 1267.7 & 2854 \\
\hline 962.4 & 1205 & 1300.1 & 633 & 683.0 & 1864 & 2011.1 & 1175 & 1267.7 & 2854 \\
\hline 962.4 & 1205 & 1300.1 & 633 & 683.0 & 1864 & 2011.1 & 1175 & 1267.7 & 2854 \\
\hline 962.4 & 1205 & 1300.1 & 633 & 683.0 & 1864 & 2011.1 & 1175 & 1267.7 & 2854 \\
\hline 962.4 & 1205 & 1300.1 & 633 & 683.0 & 1864 & 2011.1 & 1175 & 1267.7 & 2854 \\
\hline 312.7 & 1036 & 513.4 & 969 & 480.2 & 1898 & 940.5 & 1005 & 498.0 & 1995 \\
\hline 11.0 & 243 & 12.2 & 111 & 5.6 & 235 & 11.8 & 155 & 7.8 & 382 \\
\hline 24.0 & 737 & 36.9 & 442 & 22.1 & 1042 & 52.1 & 579 & 29.0 & 1330 \\
\hline 106.6 & 769 & 190.6 & 562 & 139.3 & 1314 & 325.7 & 781 & 193.6 & 1555 \\
\hline 106.6 & 769 & 190.6 & 562 & 139.3 & 1314 & 325.7 & 781 & 193.6 & 1555 \\
\hline
\end{tabular}




\begin{tabular}{|c|c|c|c|c|c|c|c|c|c|}
\hline 106.6 & 769 & 190.6 & 562 & 139.3 & 1314 & 325.7 & 781 & 193.6 & 1555 \\
\hline 106.6 & 769 & 190.6 & 562 & 139.3 & 1314 & 325.7 & 781 & 193.6 & 1555 \\
\hline 70.8 & 1192 & 179.2 & 1258 & 189.2 & 1784 & 268.3 & 1306 & 196.4 & 2625 \\
\hline 70.8 & 1192 & 179.2 & 1258 & 189.2 & 1784 & 268.3 & 1306 & 196.4 & 2625 \\
\hline 52.8 & 626 & 120.1 & 656 & 125.9 & 980 & 188.1 & 681 & 130.7 & 1410 \\
\hline 52.8 & 626 & 120.1 & 656 & 125.9 & 980 & 188.1 & 681 & 130.7 & 1410 \\
\hline 52.8 & 626 & 120.1 & 656 & 125.9 & 980 & 188.1 & 681 & 130.7 & 1410 \\
\hline 52.8 & 626 & 120.1 & 656 & 125.9 & 980 & 188.1 & 681 & 130.7 & 1410 \\
\hline 52.8 & 626 & 120.1 & 656 & 125.9 & 980 & 188.1 & 681 & 130.7 & 1410 \\
\hline 52.8 & 626 & 120.1 & 656 & 125.9 & 980 & 188.1 & 681 & 130.7 & 1410 \\
\hline 52.8 & 626 & 120.1 & 656 & 125.9 & 980 & 188.1 & 681 & 130.7 & 1410 \\
\hline 52.8 & 626 & 120.1 & 656 & 125.9 & 980 & 188.1 & 681 & 130.7 & 1410 \\
\hline 52.8 & 626 & 120.1 & 656 & 125.9 & 980 & 188.1 & 681 & 130.7 & 1410 \\
\hline 24.0 & 737 & 36.9 & 442 & 22.1 & 1042 & 52.1 & 579 & 29.0 & 1330 \\
\hline 24.0 & 737 & 36.9 & 442 & 22.1 & 1042 & 52.1 & 579 & 29.0 & 1330 \\
\hline 52.8 & 626 & 120.1 & 656 & 125.9 & 980 & 188.1 & 681 & 130.7 & 1410 \\
\hline 52.8 & 626 & 120.1 & 656 & 125.9 & 980 & 188.1 & 681 & 130.7 & 1410 \\
\hline 52.8 & 626 & 120.1 & 656 & 125.9 & 980 & 188.1 & 681 & 130.7 & 1410 \\
\hline 52.8 & 626 & 120.1 & 656 & 125.9 & 980 & 188.1 & 681 & 130.7 & 1410 \\
\hline
\end{tabular}




\begin{tabular}{|c|c|c|c|c|c|c|c|c|c|}
\hline 52.8 & 626 & 120.1 & 656 & 125.9 & 980 & 188.1 & 681 & 130.7 & 1410 \\
\hline 52.8 & 626 & 120.1 & 656 & 125.9 & 980 & 188.1 & 681 & 130.7 & 1410 \\
\hline 52.8 & 626 & 120.1 & 656 & 125.9 & 980 & 188.1 & 681 & 130.7 & 1410 \\
\hline 52.8 & 626 & 120.1 & 656 & 125.9 & 980 & 188.1 & 681 & 130.7 & 1410 \\
\hline 52.8 & 626 & 120.1 & 656 & 125.9 & 980 & 188.1 & 681 & 130.7 & 1410 \\
\hline 70.8 & 1192 & 179.2 & 1258 & 189.2 & 1784 & 268.3 & 1306 & 196.4 & 2625 \\
\hline 70.8 & 1192 & 179.2 & 1258 & 189.2 & 1784 & 268.3 & 1306 & 196.4 & 2625 \\
\hline 70.8 & 1192 & 179.2 & 1258 & 189.2 & 1784 & 268.3 & 1306 & 196.4 & 2625 \\
\hline 106.6 & 769 & 190.6 & 562 & 139.3 & 1314 & 325.7 & 781 & 193.6 & 1555 \\
\hline 106.6 & 769 & 190.6 & 562 & 139.3 & 1314 & 325.7 & 781 & 193.6 & 1555 \\
\hline 106.6 & 769 & 190.6 & 562 & 139.3 & 1314 & 325.7 & 781 & 193.6 & 1555 \\
\hline 106.6 & 769 & 190.6 & 562 & 139.3 & 1314 & 325.7 & 781 & 193.6 & 1555 \\
\hline 298.7 & 1275 & 401.8 & 1137 & 358.3 & 2466 & 777.1 & 1419 & 447.2 & 2920 \\
\hline
\end{tabular}




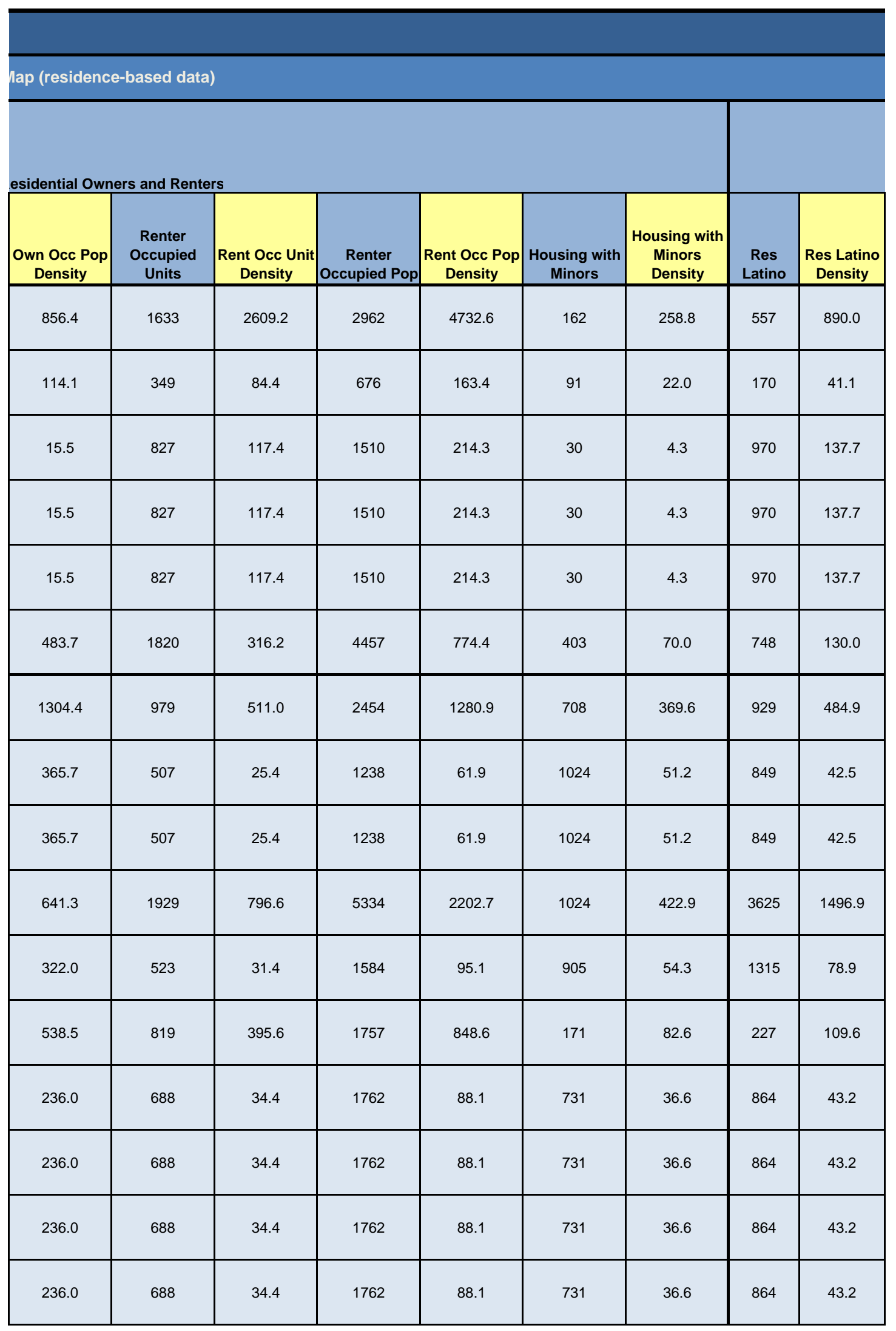




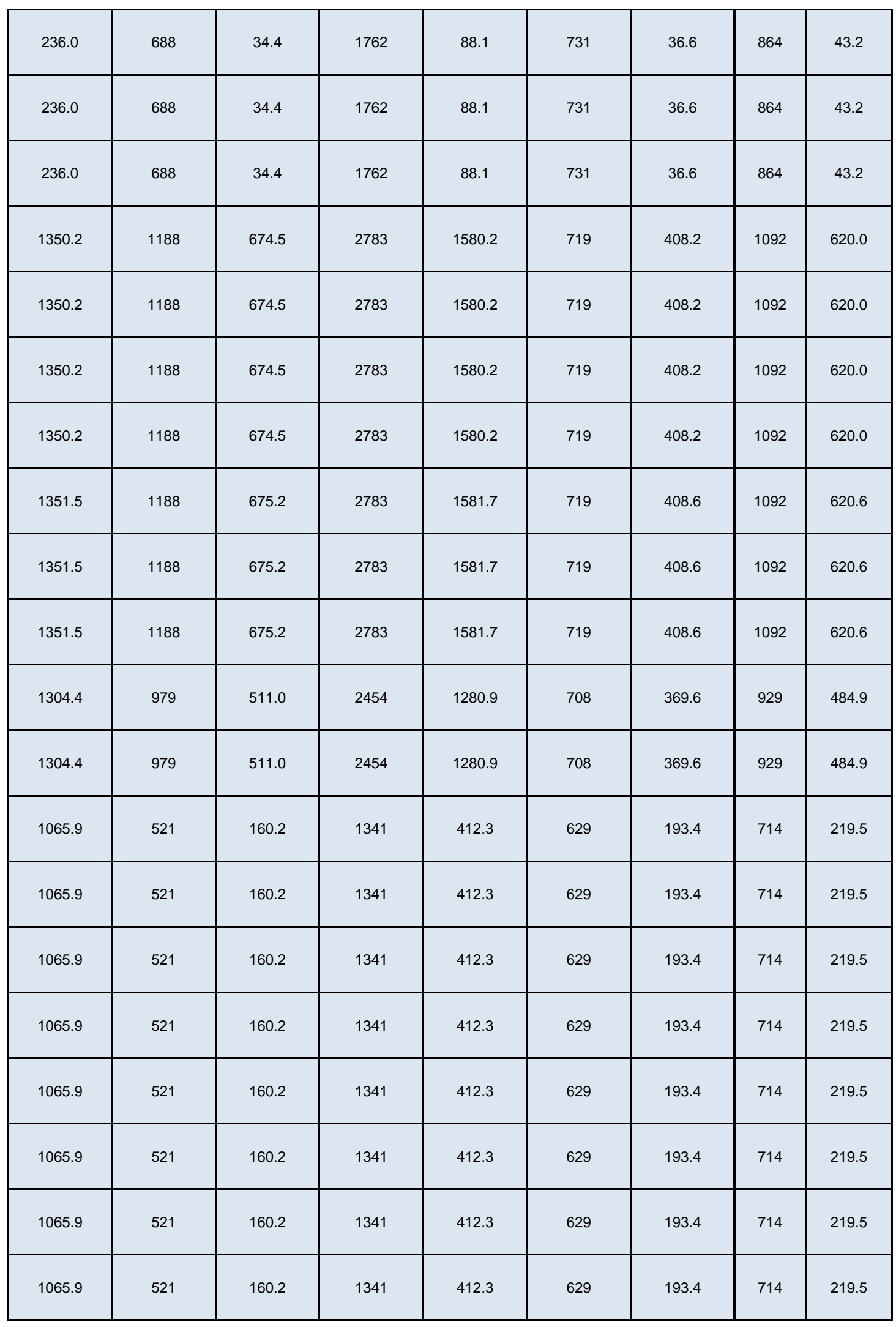




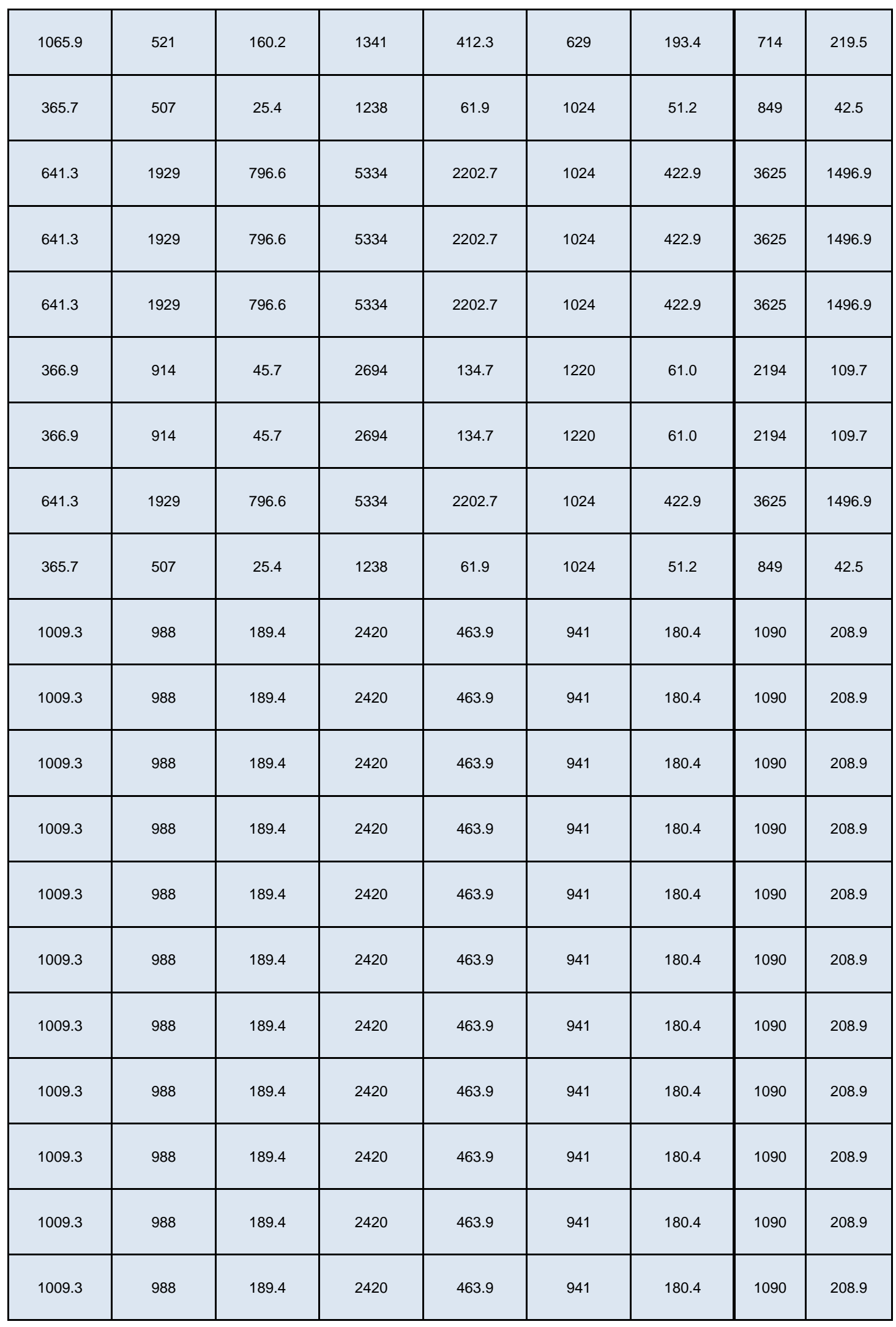




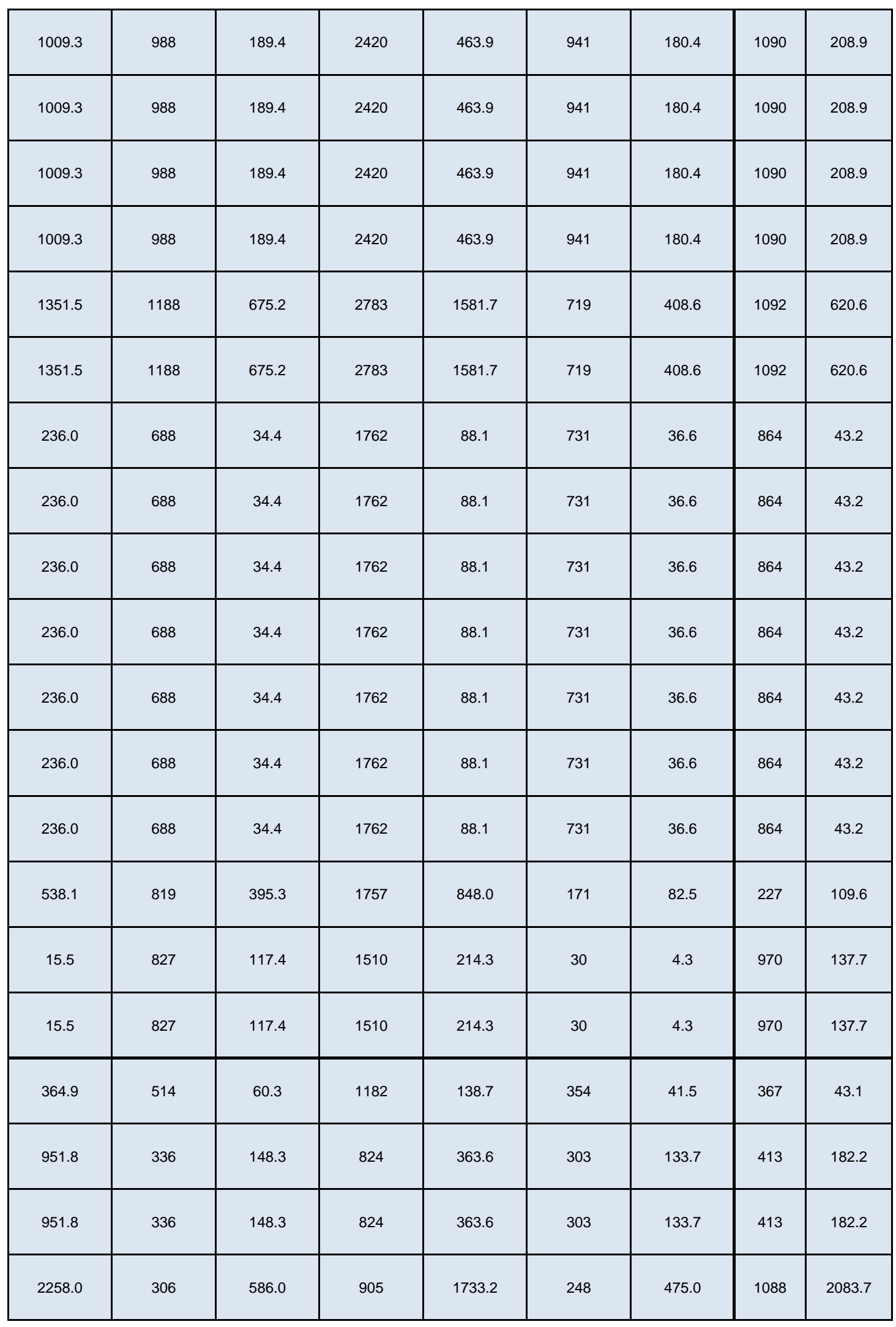




\begin{tabular}{|c|c|c|c|c|c|c|c|c|}
\hline 1078.1 & 599 & 173.6 & 1550 & 449.1 & 546 & 158.2 & 2343 & 678.9 \\
\hline 1078.1 & 599 & 173.6 & 1550 & 449.1 & 546 & 158.2 & 2343 & 678.9 \\
\hline 1955.8 & 808 & 1512.2 & 2725 & 5100.0 & 510 & 954.5 & 2417 & 4523.6 \\
\hline 964.5 & 605 & 129.3 & 2105 & 449.9 & 944 & 201.7 & 3356 & 717.2 \\
\hline 964.5 & 605 & 129.3 & 2105 & 449.9 & 944 & 201.7 & 3356 & 717.2 \\
\hline 964.5 & 605 & 129.3 & 2105 & 449.9 & 944 & 201.7 & 3356 & 717.2 \\
\hline 186.3 & 585 & 29.3 & 1412 & 70.6 & 564 & 28.2 & 570 & 28.5 \\
\hline 256.5 & 372 & 36.0 & 964 & 93.2 & 508 & 49.1 & 323 & 31.2 \\
\hline 614.4 & 681 & 354.9 & 1548 & 806.7 & 203 & 105.8 & 682 & 355.4 \\
\hline 856.4 & 1633 & 2609.2 & 2962 & 4732.6 & 162 & 258.8 & 557 & 890.0 \\
\hline 1656.8 & 1751 & 1970.8 & 3523 & 3965.2 & 363 & 408.6 & 806 & 907.2 \\
\hline 856.4 & 1633 & 2609.2 & 2962 & 4732.6 & 162 & 258.8 & 557 & 890.0 \\
\hline 856.4 & 1633 & 2609.2 & 2962 & 4732.6 & 162 & 258.8 & 557 & 890.0 \\
\hline 614.4 & 681 & 354.9 & 1548 & 806.7 & 203 & 105.8 & 682 & 355.4 \\
\hline 2131.1 & 230 & 425.9 & 540 & 999.8 & 157 & 290.7 & 306 & 566.6 \\
\hline 186.3 & 585 & 29.3 & 1412 & 70.6 & 564 & 28.2 & 570 & 28.5 \\
\hline 964.5 & 605 & 129.3 & 2105 & 449.9 & 944 & 201.7 & 3356 & 717.2 \\
\hline 964.5 & 605 & 129.3 & 2105 & 449.9 & 944 & 201.7 & 3356 & 717.2 \\
\hline 964.5 & 605 & 129.3 & 2105 & 449.9 & 944 & 201.7 & 3356 & 717.2 \\
\hline 19.1 & 80 & 4.0 & 171 & 8.6 & 54 & 2.7 & 349 & 17.5 \\
\hline
\end{tabular}




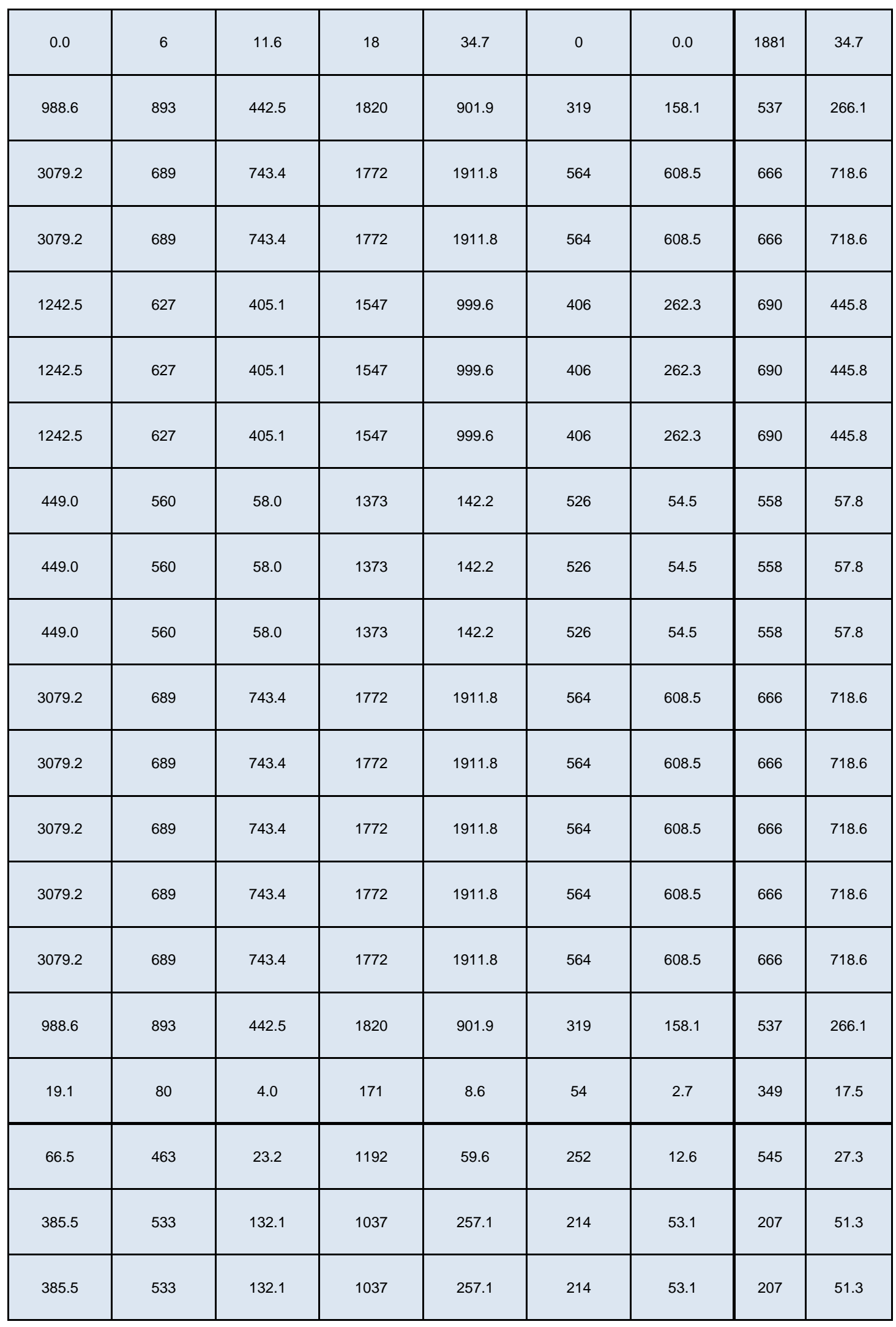




\begin{tabular}{|c|c|c|c|c|c|c|c|c|}
\hline 385.5 & 533 & 132.1 & 1037 & 257.1 & 214 & 53.1 & 207 & 51.3 \\
\hline 385.5 & 533 & 132.1 & 1037 & 257.1 & 214 & 53.1 & 207 & 51.3 \\
\hline 394.7 & 478 & 71.9 & 1163 & 174.9 & 255 & 38.3 & 552 & 83.0 \\
\hline 394.7 & 478 & 71.9 & 1163 & 174.9 & 255 & 38.3 & 552 & 83.0 \\
\hline 394.7 & 478 & 71.9 & 1163 & 174.9 & 255 & 38.3 & 552 & 83.0 \\
\hline 270.6 & 299 & 57.4 & 838 & 160.8 & 188 & 36.1 & 638 & 122.4 \\
\hline 270.6 & 299 & 57.4 & 838 & 160.8 & 188 & 36.1 & 638 & 122.4 \\
\hline 270.6 & 299 & 57.4 & 838 & 160.8 & 188 & 36.1 & 638 & 122.4 \\
\hline 270.6 & 299 & 57.4 & 838 & 160.8 & 188 & 36.1 & 638 & 122.4 \\
\hline 270.6 & 299 & 57.4 & 838 & 160.8 & 188 & 36.1 & 638 & 122.4 \\
\hline 270.6 & 299 & 57.4 & 838 & 160.8 & 188 & 36.1 & 638 & 122.4 \\
\hline 270.6 & 299 & 57.4 & 838 & 160.8 & 188 & 36.1 & 638 & 122.4 \\
\hline 270.6 & 299 & 57.4 & 838 & 160.8 & 188 & 36.1 & 638 & 122.4 \\
\hline 270.6 & 299 & 57.4 & 838 & 160.8 & 188 & 36.1 & 638 & 122.4 \\
\hline 66.5 & 463 & 23.2 & 1192 & 59.6 & 252 & 12.6 & 545 & 27.3 \\
\hline 66.5 & 463 & 23.2 & 1192 & 59.6 & 252 & 12.6 & 545 & 27.3 \\
\hline 270.6 & 299 & 57.4 & 838 & 160.8 & 188 & 36.1 & 638 & 122.4 \\
\hline 270.6 & 299 & 57.4 & 838 & 160.8 & 188 & 36.1 & 638 & 122.4 \\
\hline 270.6 & 299 & 57.4 & 838 & 160.8 & 188 & 36.1 & 638 & 122.4 \\
\hline 270.6 & 299 & 57.4 & 838 & 160.8 & 188 & 36.1 & 638 & 122.4 \\
\hline
\end{tabular}




\begin{tabular}{|c|c|c|c|c|c|c|c|c|}
\hline 270.6 & 299 & 57.4 & 838 & 160.8 & 188 & 36.1 & 638 & 122.4 \\
\hline 270.6 & 299 & 57.4 & 838 & 160.8 & 188 & 36.1 & 638 & 122.4 \\
\hline 270.6 & 299 & 57.4 & 838 & 160.8 & 188 & 36.1 & 638 & 122.4 \\
\hline 270.6 & 299 & 57.4 & 838 & 160.8 & 188 & 36.1 & 638 & 122.4 \\
\hline 270.6 & 299 & 57.4 & 838 & 160.8 & 188 & 36.1 & 638 & 122.4 \\
\hline 394.7 & 478 & 71.9 & 1163 & 174.9 & 255 & 38.3 & 552 & 83.0 \\
\hline 394.7 & 478 & 71.9 & 1163 & 174.9 & 255 & 38.3 & 552 & 83.0 \\
\hline 394.7 & 478 & 71.9 & 1163 & 174.9 & 255 & 38.3 & 552 & 83.0 \\
\hline 385.5 & 533 & 132.1 & 1037 & 257.1 & 214 & 53.1 & 207 & 51.3 \\
\hline 385.5 & 533 & 132.1 & 1037 & 257.1 & 214 & 53.1 & 207 & 51.3 \\
\hline 385.5 & 533 & 132.1 & 1037 & 257.1 & 214 & 53.1 & 207 & 51.3 \\
\hline 385.5 & 533 & 132.1 & 1037 & 257.1 & 214 & 53.1 & 207 & 51.3 \\
\hline 920.2 & 1047 & 329.9 & 2418 & 762.0 & 525 & 165.4 & 837 & 263.8 \\
\hline
\end{tabular}


Resident Race/Ethnicity

\begin{tabular}{|c|c|c|c|c|c|c|c|c|c|c|}
\hline $\begin{array}{c}\text { Res } \\
\text { White }\end{array}$ & $\begin{array}{c}\text { Res White } \\
\text { Density }\end{array}$ & $\begin{array}{c}\text { Res } \\
\text { Black }\end{array}$ & $\begin{array}{c}\text { Res Black } \\
\text { Density }\end{array}$ & $\begin{array}{c}\text { Res } \\
\text { Asian }\end{array}$ & $\begin{array}{c}\text { Res Asian } \\
\text { Density }\end{array}$ & $\begin{array}{l}\text { Res } \\
\text { AIAN }\end{array}$ & $\begin{array}{c}\text { Res AIAN } \\
\text { Density }\end{array}$ & $\begin{array}{c}\text { Res } \\
\text { NHPI }\end{array}$ & $\begin{array}{l}\text { Res NHPI } \\
\text { Density }\end{array}$ & $\begin{array}{l}\text { Res } \\
\text { Other } \\
\text { Race }\end{array}$ \\
\hline 3067 & 4900.4 & 59 & 94.3 & 130 & 207.7 & 26 & 41.5 & 6 & 9.6 & 150 \\
\hline 1122 & 271.2 & 5 & 1.2 & 50 & 12.1 & 18 & 4.4 & 2 & 0.5 & 58 \\
\hline 6487 & 920.8 & 86 & 12.2 & 967 & 137.3 & 23 & 3.3 & 11 & 1.6 & 234 \\
\hline 6487 & 920.8 & 86 & 12.2 & 967 & 137.3 & 23 & 3.3 & 11 & 1.6 & 234 \\
\hline 6487 & 920.8 & 86 & 12.2 & 967 & 137.3 & 23 & 3.3 & 11 & 1.6 & 234 \\
\hline 6393 & 1110.7 & 60 & 10.4 & 362 & 62.9 & 39 & 6.8 & 15 & 2.6 & 191 \\
\hline 4233 & 2209.5 & 52 & 27.1 & 101 & 52.7 & 68 & 35.5 & 4 & 2.1 & 297 \\
\hline 8028 & 401.4 & 45 & 2.3 & 123 & 6.2 & 73 & 3.7 & 7 & 0.4 & 159 \\
\hline 8028 & 401.4 & 45 & 2.3 & 123 & 6.2 & 73 & 3.7 & 7 & 0.4 & 159 \\
\hline 5010 & 2068.9 & 209 & 86.3 & 93 & 38.4 & 100 & 41.3 & 19 & 7.8 & 1267 \\
\hline 6007 & 360.5 & 122 & 7.3 & 150 & 9.0 & 47 & 2.8 & 6 & 0.4 & 363 \\
\hline 2538 & 1225.8 & 18 & 8.7 & 133 & 64.2 & 7 & 3.4 & 1 & 0.5 & 82 \\
\hline 5754 & 287.7 & 36 & 1.8 & 112 & 5.6 & 83 & 4.2 & 5 & 0.3 & 326 \\
\hline 5754 & 287.7 & 36 & 1.8 & 112 & 5.6 & 83 & 4.2 & 5 & 0.3 & 326 \\
\hline 5754 & 287.7 & 36 & 1.8 & 112 & 5.6 & 83 & 4.2 & 5 & 0.3 & 326 \\
\hline 5754 & 287.7 & 36 & 1.8 & 112 & 5.6 & 83 & 4.2 & 5 & 0.3 & 326 \\
\hline
\end{tabular}




\begin{tabular}{|c|c|c|c|c|c|c|c|c|c|c|}
\hline 5754 & 287.7 & 36 & 1.8 & 112 & 5.6 & 83 & 4.2 & 5 & 0.3 & 326 \\
\hline 5754 & 287.7 & 36 & 1.8 & 112 & 5.6 & 83 & 4.2 & 5 & 0.3 & 326 \\
\hline 5754 & 287.7 & 36 & 1.8 & 112 & 5.6 & 83 & 4.2 & 5 & 0.3 & 326 \\
\hline 4283 & 2431.8 & 108 & 61.3 & 217 & 123.2 & 45 & 25.6 & 11 & 6.2 & 360 \\
\hline 4283 & 2431.8 & 108 & 61.3 & 217 & 123.2 & 45 & 25.6 & 11 & 6.2 & 360 \\
\hline 4283 & 2431.8 & 108 & 61.3 & 217 & 123.2 & 45 & 25.6 & 11 & 6.2 & 360 \\
\hline 4283 & 2431.8 & 108 & 61.3 & 217 & 123.2 & 45 & 25.6 & 11 & 6.2 & 360 \\
\hline 4283 & 2434.2 & 108 & 61.4 & 217 & 123.3 & 45 & 25.6 & 11 & 6.3 & 360 \\
\hline 4283 & 2434.2 & 108 & 61.4 & 217 & 123.3 & 45 & 25.6 & 11 & 6.3 & 360 \\
\hline 4283 & 2434.2 & 108 & 61.4 & 217 & 123.3 & 45 & 25.6 & 11 & 6.3 & 360 \\
\hline 4233 & 2209.5 & 52 & 27.1 & 101 & 52.7 & 68 & 35.5 & 4 & 2.1 & 297 \\
\hline 4233 & 2209.5 & 52 & 27.1 & 101 & 52.7 & 68 & 35.5 & 4 & 2.1 & 297 \\
\hline 4303 & 1323.0 & 39 & 12.0 & 108 & 33.2 & 54 & 16.6 & 6 & 1.8 & 173 \\
\hline 4303 & 1323.0 & 39 & 12.0 & 108 & 33.2 & 54 & 16.6 & 6 & 1.8 & 173 \\
\hline 4303 & 1323.0 & 39 & 12.0 & 108 & 33.2 & 54 & 16.6 & 6 & 1.8 & 173 \\
\hline 4303 & 1323.0 & 39 & 12.0 & 108 & 33.2 & 54 & 16.6 & 6 & 1.8 & 173 \\
\hline 4303 & 1323.0 & 39 & 12.0 & 108 & 33.2 & 54 & 16.6 & 6 & 1.8 & 173 \\
\hline 4303 & 1323.0 & 39 & 12.0 & 108 & 33.2 & 54 & 16.6 & 6 & 1.8 & 173 \\
\hline 4303 & 1323.0 & 39 & 12.0 & 108 & 33.2 & 54 & 16.6 & 6 & 1.8 & 173 \\
\hline 4303 & 1323.0 & 39 & 12.0 & 108 & 33.2 & 54 & 16.6 & 6 & 1.8 & 173 \\
\hline
\end{tabular}




\begin{tabular}{|c|c|c|c|c|c|c|c|c|c|c|}
\hline 4303 & 1323.0 & 39 & 12.0 & 108 & 33.2 & 54 & 16.6 & 6 & 1.8 & 173 \\
\hline 8028 & 401.4 & 45 & 2.3 & 123 & 6.2 & 73 & 3.7 & 7 & 0.4 & 159 \\
\hline 5010 & 2068.9 & 209 & 86.3 & 93 & 38.4 & 100 & 41.3 & 19 & 7.8 & 1267 \\
\hline 5010 & 2068.9 & 209 & 86.3 & 93 & 38.4 & 100 & 41.3 & 19 & 7.8 & 1267 \\
\hline 5010 & 2068.9 & 209 & 86.3 & 93 & 38.4 & 100 & 41.3 & 19 & 7.8 & 1267 \\
\hline 8489 & 424.5 & 94 & 4.7 & 79 & 4.0 & 101 & 5.1 & 7 & 0.4 & 923 \\
\hline 8489 & 424.5 & 94 & 4.7 & 79 & 4.0 & 101 & 5.1 & 7 & 0.4 & 923 \\
\hline 5010 & 2068.9 & 209 & 86.3 & 93 & 38.4 & 100 & 41.3 & 19 & 7.8 & 1267 \\
\hline 8028 & 401.4 & 45 & 2.3 & 123 & 6.2 & 73 & 3.7 & 7 & 0.4 & 159 \\
\hline 6924 & 1327.3 & 78 & 15.0 & 132 & 25.3 & 82 & 15.7 & 28 & 5.4 & 298 \\
\hline 6924 & 1327.3 & 78 & 15.0 & 132 & 25.3 & 82 & 15.7 & 28 & 5.4 & 298 \\
\hline 6924 & 1327.3 & 78 & 15.0 & 132 & 25.3 & 82 & 15.7 & 28 & 5.4 & 298 \\
\hline 6924 & 1327.3 & 78 & 15.0 & 132 & 25.3 & 82 & 15.7 & 28 & 5.4 & 298 \\
\hline 6924 & 1327.3 & 78 & 15.0 & 132 & 25.3 & 82 & 15.7 & 28 & 5.4 & 298 \\
\hline 6924 & 1327.3 & 78 & 15.0 & 132 & 25.3 & 82 & 15.7 & 28 & 5.4 & 298 \\
\hline 6924 & 1327.3 & 78 & 15.0 & 132 & 25.3 & 82 & 15.7 & 28 & 5.4 & 298 \\
\hline 6924 & 1327.3 & 78 & 15.0 & 132 & 25.3 & 82 & 15.7 & 28 & 5.4 & 298 \\
\hline 6924 & 1327.3 & 78 & 15.0 & 132 & 25.3 & 82 & 15.7 & 28 & 5.4 & 298 \\
\hline 6924 & 1327.3 & 78 & 15.0 & 132 & 25.3 & 82 & 15.7 & 28 & 5.4 & 298 \\
\hline 6924 & 1327.3 & 78 & 15.0 & 132 & 25.3 & 82 & 15.7 & 28 & 5.4 & 298 \\
\hline
\end{tabular}




\begin{tabular}{|c|c|c|c|c|c|c|c|c|c|c|}
\hline 6924 & 1327.3 & 78 & 15.0 & 132 & 25.3 & 82 & 15.7 & 28 & 5.4 & 298 \\
\hline 6924 & 1327.3 & 78 & 15.0 & 132 & 25.3 & 82 & 15.7 & 28 & 5.4 & 298 \\
\hline 6924 & 1327.3 & 78 & 15.0 & 132 & 25.3 & 82 & 15.7 & 28 & 5.4 & 298 \\
\hline 6924 & 1327.3 & 78 & 15.0 & 132 & 25.3 & 82 & 15.7 & 28 & 5.4 & 298 \\
\hline 4283 & 2434.2 & 108 & 61.4 & 217 & 123.3 & 45 & 25.6 & 11 & 6.3 & 360 \\
\hline 4283 & 2434.2 & 108 & 61.4 & 217 & 123.3 & 45 & 25.6 & 11 & 6.3 & 360 \\
\hline 5754 & 287.7 & 36 & 1.8 & 112 & 5.6 & 83 & 4.2 & 5 & 0.3 & 326 \\
\hline 5754 & 287.7 & 36 & 1.8 & 112 & 5.6 & 83 & 4.2 & 5 & 0.3 & 326 \\
\hline 5754 & 287.7 & 36 & 1.8 & 112 & 5.6 & 83 & 4.2 & 5 & 0.3 & 326 \\
\hline 5754 & 287.7 & 36 & 1.8 & 112 & 5.6 & 83 & 4.2 & 5 & 0.3 & 326 \\
\hline 5754 & 287.7 & 36 & 1.8 & 112 & 5.6 & 83 & 4.2 & 5 & 0.3 & 326 \\
\hline 5754 & 287.7 & 36 & 1.8 & 112 & 5.6 & 83 & 4.2 & 5 & 0.3 & 326 \\
\hline 5754 & 287.7 & 36 & 1.8 & 112 & 5.6 & 83 & 4.2 & 5 & 0.3 & 326 \\
\hline 2538 & 1224.9 & 18 & 8.7 & 133 & 64.2 & 7 & 3.4 & 1 & 0.5 & 82 \\
\hline 6487 & 920.8 & 86 & 12.2 & 967 & 137.3 & 23 & 3.3 & 11 & 1.6 & 234 \\
\hline 6487 & 920.8 & 86 & 12.2 & 967 & 137.3 & 23 & 3.3 & 11 & 1.6 & 234 \\
\hline 3907 & 458.5 & 20 & 2.3 & 151 & 17.7 & 23 & 2.7 & 7 & 0.8 & 81 \\
\hline 2626 & 1158.7 & 28 & 12.4 & 112 & 49.4 & 20 & 8.8 & 2 & 0.9 & 49 \\
\hline 2626 & 1158.7 & 28 & 12.4 & 112 & 49.4 & 20 & 8.8 & 2 & 0.9 & 49 \\
\hline 1369 & 2621.9 & 19 & 36.4 & 80 & 153.2 & 21 & 40.2 & 2 & 3.8 & 487 \\
\hline
\end{tabular}




\begin{tabular}{|c|c|c|c|c|c|c|c|c|c|c|}
\hline 3667 & 1062.5 & 60 & 17.4 & 321 & 93.0 & 63 & 18.3 & 17 & 4.9 & 1009 \\
\hline 3667 & 1062.5 & 60 & 17.4 & 321 & 93.0 & 63 & 18.3 & 17 & 4.9 & 1009 \\
\hline 2558 & 4787.4 & 106 & 198.4 & 65 & 121.7 & 75 & 140.4 & 8 & 15.0 & 805 \\
\hline 4297 & 918.3 & 86 & 18.4 & 206 & 44.0 & 95 & 20.3 & 10 & 2.1 & 1618 \\
\hline 4297 & 918.3 & 86 & 18.4 & 206 & 44.0 & 95 & 20.3 & 10 & 2.1 & 1618 \\
\hline 4297 & 918.3 & 86 & 18.4 & 206 & 44.0 & 95 & 20.3 & 10 & 2.1 & 1618 \\
\hline 4651 & 232.6 & 16 & 0.8 & 90 & 4.5 & 53 & 2.7 & 3 & 0.2 & 153 \\
\hline 3245 & 313.7 & 32 & 3.1 & 150 & 14.5 & 5 & 0.5 & 7 & 0.7 & 72 \\
\hline 2224 & 1158.9 & 51 & 26.6 & 93 & 48.5 & 14 & 7.3 & 1 & 0.5 & 258 \\
\hline 3067 & 4900.4 & 59 & 94.3 & 130 & 207.7 & 26 & 41.5 & 6 & 9.6 & 150 \\
\hline 4431 & 4987.2 & 58 & 65.3 & 169 & 190.2 & 52 & 58.5 & 5 & 5.6 & 179 \\
\hline 3067 & 4900.4 & 59 & 94.3 & 130 & 207.7 & 26 & 41.5 & 6 & 9.6 & 150 \\
\hline 3067 & 4900.4 & 59 & 94.3 & 130 & 207.7 & 26 & 41.5 & 6 & 9.6 & 150 \\
\hline 2224 & 1158.9 & 51 & 26.6 & 93 & 48.5 & 14 & 7.3 & 1 & 0.5 & 258 \\
\hline 1481 & 2742.1 & 28 & 51.8 & 83 & 153.7 & 30 & 55.5 & 3 & 5.6 & 101 \\
\hline 4651 & 232.6 & 16 & 0.8 & 90 & 4.5 & 53 & 2.7 & 3 & 0.2 & 153 \\
\hline 4297 & 918.3 & 86 & 18.4 & 206 & 44.0 & 95 & 20.3 & 10 & 2.1 & 1618 \\
\hline 4297 & 918.3 & 86 & 18.4 & 206 & 44.0 & 95 & 20.3 & 10 & 2.1 & 1618 \\
\hline 4297 & 918.3 & 86 & 18.4 & 206 & 44.0 & 95 & 20.3 & 10 & 2.1 & 1618 \\
\hline 1137 & 56.9 & 46 & 2.3 & 14 & 0.7 & 20 & 1.0 & 1 & 0.1 & 106 \\
\hline
\end{tabular}




\begin{tabular}{|c|c|c|c|c|c|c|c|c|c|c|}
\hline 3391 & 34.7 & 2557 & 34.7 & 20 & 34.7 & 61 & 34.7 & 1 & 1.9 & 406 \\
\hline 3372 & 1671.0 & 18 & 8.9 & 98 & 48.6 & 44 & 21.8 & 5 & 2.5 & 200 \\
\hline 3968 & 4281.1 & 27 & 29.1 & 243 & 262.2 & 46 & 49.6 & 10 & 10.8 & 171 \\
\hline 3968 & 4281.1 & 27 & 29.1 & 243 & 262.2 & 46 & 49.6 & 10 & 10.8 & 171 \\
\hline 2820 & 1822.1 & 27 & 17.4 & 314 & 202.9 & 27 & 17.4 & 3 & 1.9 & 199 \\
\hline 2820 & 1822.1 & 27 & 17.4 & 314 & 202.9 & 27 & 17.4 & 3 & 1.9 & 199 \\
\hline 2820 & 1822.1 & 27 & 17.4 & 314 & 202.9 & 27 & 17.4 & 3 & 1.9 & 199 \\
\hline 5280 & 547.0 & 24 & 2.5 & 164 & 17.0 & 24 & 2.5 & 5 & 0.5 & 140 \\
\hline 5280 & 547.0 & 24 & 2.5 & 164 & 17.0 & 24 & 2.5 & 5 & 0.5 & 140 \\
\hline 5280 & 547.0 & 24 & 2.5 & 164 & 17.0 & 24 & 2.5 & 5 & 0.5 & 140 \\
\hline 3968 & 4281.1 & 27 & 29.1 & 243 & 262.2 & 46 & 49.6 & 10 & 10.8 & 171 \\
\hline 3968 & 4281.1 & 27 & 29.1 & 243 & 262.2 & 46 & 49.6 & 10 & 10.8 & 171 \\
\hline 3968 & 4281.1 & 27 & 29.1 & 243 & 262.2 & 46 & 49.6 & 10 & 10.8 & 171 \\
\hline 3968 & 4281.1 & 27 & 29.1 & 243 & 262.2 & 46 & 49.6 & 10 & 10.8 & 171 \\
\hline 3968 & 4281.1 & 27 & 29.1 & 243 & 262.2 & 46 & 49.6 & 10 & 10.8 & 171 \\
\hline 3372 & 1671.0 & 18 & 8.9 & 98 & 48.6 & 44 & 21.8 & 5 & 2.5 & 200 \\
\hline 1137 & 56.9 & 46 & 2.3 & 14 & 0.7 & 20 & 1.0 & 1 & 0.1 & 106 \\
\hline 2096 & 104.8 & 10 & 0.5 & 87 & 4.4 & 22 & 1.1 & 6 & 0.3 & 276 \\
\hline 2366 & 586.5 & 6 & 1.5 & 54 & 13.4 & 12 & 3.0 & 8 & 2.0 & 57 \\
\hline 2366 & 586.5 & 6 & 1.5 & 54 & 13.4 & 12 & 3.0 & 8 & 2.0 & 57 \\
\hline
\end{tabular}




\begin{tabular}{|c|c|c|c|c|c|c|c|c|c|c|}
\hline 2366 & 586.5 & 6 & 1.5 & 54 & 13.4 & 12 & 3.0 & 8 & 2.0 & 57 \\
\hline 2366 & 586.5 & 6 & 1.5 & 54 & 13.4 & 12 & 3.0 & 8 & 2.0 & 57 \\
\hline 3389 & 509.6 & 8 & 1.2 & 57 & 8.6 & 26 & 3.9 & 8 & 1.2 & 221 \\
\hline 3389 & 509.6 & 8 & 1.2 & 57 & 8.6 & 26 & 3.9 & 8 & 1.2 & 221 \\
\hline 3389 & 509.6 & 8 & 1.2 & 57 & 8.6 & 26 & 3.9 & 8 & 1.2 & 221 \\
\hline 1779 & 341.4 & 10 & 1.9 & 21 & 4.0 & 21 & 4.0 & 6 & 1.2 & 336 \\
\hline 1779 & 341.4 & 10 & 1.9 & 21 & 4.0 & 21 & 4.0 & 6 & 1.2 & 336 \\
\hline 1779 & 341.4 & 10 & 1.9 & 21 & 4.0 & 21 & 4.0 & 6 & 1.2 & 336 \\
\hline 1779 & 341.4 & 10 & 1.9 & 21 & 4.0 & 21 & 4.0 & 6 & 1.2 & 336 \\
\hline 1779 & 341.4 & 10 & 1.9 & 21 & 4.0 & 21 & 4.0 & 6 & 1.2 & 336 \\
\hline 1779 & 341.4 & 10 & 1.9 & 21 & 4.0 & 21 & 4.0 & 6 & 1.2 & 336 \\
\hline 1779 & 341.4 & 10 & 1.9 & 21 & 4.0 & 21 & 4.0 & 6 & 1.2 & 336 \\
\hline 1779 & 341.4 & 10 & 1.9 & 21 & 4.0 & 21 & 4.0 & 6 & 1.2 & 336 \\
\hline 1779 & 341.4 & 10 & 1.9 & 21 & 4.0 & 21 & 4.0 & 6 & 1.2 & 336 \\
\hline 2096 & 104.8 & 10 & 0.5 & 87 & 4.4 & 22 & 1.1 & 6 & 0.3 & 276 \\
\hline 2096 & 104.8 & 10 & 0.5 & 87 & 4.4 & 22 & 1.1 & 6 & 0.3 & 276 \\
\hline 1779 & 341.4 & 10 & 1.9 & 21 & 4.0 & 21 & 4.0 & 6 & 1.2 & 336 \\
\hline 1779 & 341.4 & 10 & 1.9 & 21 & 4.0 & 21 & 4.0 & 6 & 1.2 & 336 \\
\hline 1779 & 341.4 & 10 & 1.9 & 21 & 4.0 & 21 & 4.0 & 6 & 1.2 & 336 \\
\hline 1779 & 341.4 & 10 & 1.9 & 21 & 4.0 & 21 & 4.0 & 6 & 1.2 & 336 \\
\hline
\end{tabular}




\begin{tabular}{|c|c|c|c|c|c|c|c|c|c|c|}
\hline 1779 & 341.4 & 10 & 1.9 & 21 & 4.0 & 21 & 4.0 & 6 & 1.2 & 336 \\
\hline 1779 & 341.4 & 10 & 1.9 & 21 & 4.0 & 21 & 4.0 & 6 & 1.2 & 336 \\
\hline 1779 & 341.4 & 10 & 1.9 & 21 & 4.0 & 21 & 4.0 & 6 & 1.2 & 336 \\
\hline 1779 & 341.4 & 10 & 1.9 & 21 & 4.0 & 21 & 4.0 & 6 & 1.2 & 336 \\
\hline 1779 & 341.4 & 10 & 1.9 & 21 & 4.0 & 21 & 4.0 & 6 & 1.2 & 336 \\
\hline 3389 & 509.6 & 8 & 1.2 & 57 & 8.6 & 26 & 3.9 & 8 & 1.2 & 221 \\
\hline 3389 & 509.6 & 8 & 1.2 & 57 & 8.6 & 26 & 3.9 & 8 & 1.2 & 221 \\
\hline 3389 & 509.6 & 8 & 1.2 & 57 & 8.6 & 26 & 3.9 & 8 & 1.2 & 221 \\
\hline 2366 & 586.5 & 6 & 1.5 & 54 & 13.4 & 12 & 3.0 & 8 & 2.0 & 57 \\
\hline 2366 & 586.5 & 6 & 1.5 & 54 & 13.4 & 12 & 3.0 & 8 & 2.0 & 57 \\
\hline 2366 & 586.5 & 6 & 1.5 & 54 & 13.4 & 12 & 3.0 & 8 & 2.0 & 57 \\
\hline 2366 & 586.5 & 6 & 1.5 & 54 & 13.4 & 12 & 3.0 & 8 & 2.0 & 57 \\
\hline 4613 & 1453.7 & 23 & 7.2 & 119 & 37.5 & 39 & 12.3 & 2 & 0.6 & 358 \\
\hline
\end{tabular}




\begin{tabular}{|c|c|c|c|c|c|c|c|c|}
\hline & & & \multicolumn{5}{|c|}{ Census Explorer (resident-based data) } & \\
\hline & & & $>16$ years & & $\begin{array}{c}\text { Workers who } \\
\text { own car, } \\
\text { truck, or van }\end{array}$ & $\begin{array}{l}\text { Workers } \\
\text { without } \\
\text { personal } \\
\text { vehicles } \\
\end{array}$ & & Tot: \\
\hline $\begin{array}{l}\text { Res Other } \\
\text { Race } \\
\text { Density }\end{array}$ & $\begin{array}{c}\text { Res Two } \\
\text { or More } \\
\text { Races }\end{array}$ & $\begin{array}{c}\text { Res Two or } \\
\text { More Races } \\
\text { Density }\end{array}$ & Res Workers & $\begin{array}{c}\text { Res Worker } \\
\text { Density }\end{array}$ & & $\begin{array}{c}\text { Res Workers } \\
\text { NoAuto }\end{array}$ & $\begin{array}{c}\text { Res Worker } \\
\text { NoAuto } \\
\text { Density }\end{array}$ & All Jobs \\
\hline 239.7 & 154 & 246.1 & 2517 & 4022 & 1716 & 801 & 1279.8 & 8977 \\
\hline 14.0 & 32 & 7.7 & 490 & 118 & 380 & 110 & 26.6 & 1847 \\
\hline 33.2 & 511 & 72.5 & 1967 & 279 & 951 & 1016 & 144.2 & 2180 \\
\hline 33.2 & 511 & 72.5 & 1967 & 279 & 951 & 1016 & 144.2 & 2180 \\
\hline 33.2 & 511 & 72.5 & 1967 & 279 & 951 & 1016 & 144.2 & 2180 \\
\hline 33.2 & 295 & 51.3 & 2524 & 439 & 1848 & 676 & 117.4 & 4947 \\
\hline 155.0 & 230 & 120.1 & 2574 & 1344 & 2369 & 205 & 107.0 & 1791 \\
\hline 8.0 & 215 & 10.8 & 3665 & 183 & 3181 & 484 & 24.2 & 2538 \\
\hline 8.0 & 215 & 10.8 & 3665 & 183 & 3181 & 484 & 24.2 & 2538 \\
\hline 523.2 & 291 & 120.2 & 2831 & 1169 & 2508 & 323 & 133.4 & 5606 \\
\hline 21.8 & 286 & 17.2 & 3513 & 211 & 3218 & 295 & 17.7 & 2344 \\
\hline 39.6 & 98 & 47.3 & 1725 & 833 & 1253 & 472 & 228.0 & 2995 \\
\hline 16.3 & 234 & 11.7 & 2953 & 148 & 2576 & 377 & 18.9 & 851 \\
\hline 16.3 & 234 & 11.7 & 2953 & 148 & 2576 & 377 & 18.9 & 851 \\
\hline 16.3 & 234 & 11.7 & 2953 & 148 & 2576 & 377 & 18.9 & 851 \\
\hline 16.3 & 234 & 11.7 & 2953 & 148 & 2576 & 377 & 18.9 & 851 \\
\hline
\end{tabular}




\begin{tabular}{|c|c|c|c|c|c|c|c|c|}
\hline 16.3 & 234 & 11.7 & 2953 & 148 & 2576 & 377 & 18.9 & 851 \\
\hline 16.3 & 234 & 11.7 & 2953 & 148 & 2576 & 377 & 18.9 & 851 \\
\hline 16.3 & 234 & 11.7 & 2953 & 148 & 2576 & 377 & 18.9 & 851 \\
\hline 204.4 & 216 & 122.6 & 2459 & 1396 & 2178 & 281 & 159.5 & 1366 \\
\hline 204.4 & 216 & 122.6 & 2459 & 1396 & 2178 & 281 & 159.5 & 1366 \\
\hline 204.4 & 216 & 122.6 & 2459 & 1396 & 2178 & 281 & 159.5 & 1366 \\
\hline 204.4 & 216 & 122.6 & 2459 & 1396 & 2178 & 281 & 159.5 & 1366 \\
\hline 204.6 & 216 & 122.8 & 2459 & 1398 & 2178 & 281 & 159.7 & 1366 \\
\hline 204.6 & 216 & 122.8 & 2459 & 1398 & 2178 & 281 & 159.7 & 1366 \\
\hline 204.6 & 216 & 122.8 & 2459 & 1398 & 2178 & 281 & 159.7 & 1366 \\
\hline 155.0 & 230 & 120.1 & 2574 & 1344 & 2369 & 205 & 107.0 & 1791 \\
\hline 155.0 & 230 & 120.1 & 2574 & 1344 & 2369 & 205 & 107.0 & 1791 \\
\hline 53.2 & 208 & 64.0 & 2413 & 742 & 2095 & 318 & 97.8 & 1131 \\
\hline 53.2 & 208 & 64.0 & 2413 & 742 & 2095 & 318 & 97.8 & 1131 \\
\hline 53.2 & 208 & 64.0 & 2413 & 742 & 2095 & 318 & 97.8 & 1131 \\
\hline 53.2 & 208 & 64.0 & 2413 & 742 & 2095 & 318 & 97.8 & 1131 \\
\hline 53.2 & 208 & 64.0 & 2413 & 742 & 2095 & 318 & 97.8 & 1131 \\
\hline 53.2 & 208 & 64.0 & 2413 & 742 & 2095 & 318 & 97.8 & 1131 \\
\hline 53.2 & 208 & 64.0 & 2413 & 742 & 2095 & 318 & 97.8 & 1131 \\
\hline 53.2 & 208 & 64.0 & 2413 & 742 & 2095 & 318 & 97.8 & 1131 \\
\hline
\end{tabular}




\begin{tabular}{|c|c|c|c|c|c|c|c|c|}
\hline 53.2 & 208 & 64.0 & 2413 & 742 & 2095 & 318 & 97.8 & 1131 \\
\hline 8.0 & 215 & 10.8 & 3665 & 183 & 3181 & 484 & 24.2 & 2538 \\
\hline 523.2 & 291 & 120.2 & 2831 & 1169 & 2508 & 323 & 133.4 & 5606 \\
\hline 523.2 & 291 & 120.2 & 2831 & 1169 & 2508 & 323 & 133.4 & 5606 \\
\hline 523.2 & 291 & 120.2 & 2831 & 1169 & 2508 & 323 & 133.4 & 5606 \\
\hline 46.2 & 350 & 17.5 & 4717 & 236 & 3909 & 808 & 40.4 & 3008 \\
\hline 46.2 & 350 & 17.5 & 4717 & 236 & 3909 & 808 & 40.4 & 3008 \\
\hline 523.2 & 291 & 120.2 & 2831 & 1169 & 2508 & 323 & 133.4 & 5606 \\
\hline 8.0 & 215 & 10.8 & 3665 & 183 & 3181 & 484 & 24.2 & 2538 \\
\hline 57.1 & 251 & 48.1 & 3695 & 708 & 3387 & 308 & 59.0 & 1348 \\
\hline 57.1 & 251 & 48.1 & 3695 & 708 & 3387 & 308 & 59.0 & 1348 \\
\hline 57.1 & 251 & 48.1 & 3695 & 708 & 3387 & 308 & 59.0 & 1348 \\
\hline 57.1 & 251 & 48.1 & 3695 & 708 & 3387 & 308 & 59.0 & 1348 \\
\hline 57.1 & 251 & 48.1 & 3695 & 708 & 3387 & 308 & 59.0 & 1348 \\
\hline 57.1 & 251 & 48.1 & 3695 & 708 & 3387 & 308 & 59.0 & 1348 \\
\hline 57.1 & 251 & 48.1 & 3695 & 708 & 3387 & 308 & 59.0 & 1348 \\
\hline 57.1 & 251 & 48.1 & 3695 & 708 & 3387 & 308 & 59.0 & 1348 \\
\hline 57.1 & 251 & 48.1 & 3695 & 708 & 3387 & 308 & 59.0 & 1348 \\
\hline 57.1 & 251 & 48.1 & 3695 & 708 & 3387 & 308 & 59.0 & 1348 \\
\hline 57.1 & 251 & 48.1 & 3695 & 708 & 3387 & 308 & 59.0 & 1348 \\
\hline
\end{tabular}




\begin{tabular}{|c|c|c|c|c|c|c|c|c|}
\hline 57.1 & 251 & 48.1 & 3695 & 708 & 3387 & 308 & 59.0 & 1348 \\
\hline 57.1 & 251 & 48.1 & 3695 & 708 & 3387 & 308 & 59.0 & 1348 \\
\hline 57.1 & 251 & 48.1 & 3695 & 708 & 3387 & 308 & 59.0 & 1348 \\
\hline 57.1 & 251 & 48.1 & 3695 & 708 & 3387 & 308 & 59.0 & 1348 \\
\hline 204.6 & 216 & 122.8 & 2459 & 1398 & 2178 & 281 & 159.7 & 1366 \\
\hline 204.6 & 216 & 122.8 & 2459 & 1398 & 2178 & 281 & 159.7 & 1366 \\
\hline 16.3 & 234 & 11.7 & 2953 & 148 & 2576 & 377 & 18.9 & 851 \\
\hline 16.3 & 234 & 11.7 & 2953 & 148 & 2576 & 377 & 18.9 & 851 \\
\hline 16.3 & 234 & 11.7 & 2953 & 148 & 2576 & 377 & 18.9 & 851 \\
\hline 16.3 & 234 & 11.7 & 2953 & 148 & 2576 & 377 & 18.9 & 851 \\
\hline 16.3 & 234 & 11.7 & 2953 & 148 & 2576 & 377 & 18.9 & 851 \\
\hline 16.3 & 234 & 11.7 & 2953 & 148 & 2576 & 377 & 18.9 & 851 \\
\hline 16.3 & 234 & 11.7 & 2953 & 148 & 2576 & 377 & 18.9 & 851 \\
\hline 39.6 & 98 & 47.3 & 1725 & 833 & 1253 & 472 & 227.8 & 2995 \\
\hline 33.2 & 511 & 72.5 & 1967 & 279 & 951 & 1016 & 144.2 & 2180 \\
\hline 33.2 & 511 & 72.5 & 1967 & 279 & 951 & 1016 & 144.2 & 2180 \\
\hline 9.5 & 112 & 13.1 & 1846 & 217 & 1372 & 474 & 55.6 & 1794 \\
\hline 21.6 & 150 & 66.2 & 1493 & 659 & 1239 & 254 & 112.1 & 1476 \\
\hline 21.6 & 150 & 66.2 & 1493 & 659 & 1239 & 254 & 112.1 & 1476 \\
\hline 932.7 & 106 & 203.0 & 1168 & 2237 & 1022 & 146 & 279.6 & 2073 \\
\hline
\end{tabular}




\begin{tabular}{|c|c|c|c|c|c|c|c|c|}
\hline 292.3 & 229 & 66.4 & 2691 & 780 & 2579 & 112 & 32.5 & 3786 \\
\hline 292.3 & 229 & 66.4 & 2691 & 780 & 2579 & 112 & 32.5 & 3786 \\
\hline 1506.6 & 256 & 479.1 & 1392 & 2605 & 1291 & 101 & 189.0 & 1683 \\
\hline 345.8 & 309 & 66.0 & 3173 & 678 & 2861 & 312 & 66.7 & 860 \\
\hline 345.8 & 309 & 66.0 & 3173 & 678 & 2861 & 312 & 66.7 & 860 \\
\hline 345.8 & 309 & 66.0 & 2194 & 469 & 1912 & 282 & 60.3 & 860 \\
\hline 7.7 & 171 & 8.6 & 2194 & 110 & 1912 & 282 & 14.1 & 837 \\
\hline 7.0 & 113 & 10.9 & 1655 & 160 & 1339 & 316 & 30.5 & 4903 \\
\hline 134.4 & 96 & 50.0 & 1369 & 713 & 1174 & 195 & 101.6 & 4957 \\
\hline 239.7 & 154 & 246.1 & 2517 & 4022 & 1716 & 801 & 1279.8 & 8977 \\
\hline 201.5 & 233 & 262.2 & 3303 & 3718 & 2464 & 839 & 944.3 & 4475 \\
\hline 239.7 & 154 & 246.1 & 2517 & 4022 & 1716 & 801 & 1279.8 & 8977 \\
\hline 239.7 & 154 & 246.1 & 2517 & 4022 & 1716 & 801 & 1279.8 & 8977 \\
\hline 134.4 & 96 & 50.0 & 1369 & 713 & 1174 & 195 & 101.6 & 4957 \\
\hline 187.0 & 57 & 105.5 & 756 & 1400 & 642 & 114 & 211.1 & 480 \\
\hline 7.7 & 171 & 8.6 & 2194 & 110 & 1912 & 282 & 14.1 & 837 \\
\hline 345.8 & 309 & 66.0 & 3173 & 678 & 2861 & 312 & 66.7 & 860 \\
\hline 345.8 & 309 & 66.0 & 3173 & 678 & 2861 & 312 & 66.7 & 860 \\
\hline 345.8 & 309 & 66.0 & 3173 & 678 & 2861 & 312 & 66.7 & 860 \\
\hline 5.3 & 38 & 1.9 & 558 & 28 & 375 & 183 & 9.2 & 2011 \\
\hline
\end{tabular}




\begin{tabular}{|c|c|c|c|c|c|c|c|c|}
\hline 34.7 & 10 & 19.3 & 0 & 0 & 0 & 0 & 0.0 & 1819 \\
\hline 99.1 & 99 & 49.1 & 1776 & 880 & 1171 & 605 & 299.8 & 597 \\
\hline 184.5 & 185 & 199.6 & 2415 & 2606 & 2115 & 300 & 323.7 & 373 \\
\hline 184.5 & 185 & 199.6 & 2415 & 2606 & 2115 & 300 & 323.7 & 373 \\
\hline 128.6 & 97 & 62.7 & 1895 & 1224 & 1616 & 279 & 180.3 & 813 \\
\hline 128.6 & 97 & 62.7 & 1895 & 1224 & 1616 & 279 & 180.3 & 813 \\
\hline 128.6 & 97 & 62.7 & 1895 & 1224 & 1616 & 279 & 180.3 & 813 \\
\hline 14.5 & 186 & 19.3 & 2511 & 260 & 2321 & 190 & 19.7 & 454 \\
\hline 14.5 & 186 & 19.3 & 2511 & 260 & 2321 & 190 & 19.7 & 454 \\
\hline 14.5 & 186 & 19.3 & 2511 & 260 & 2321 & 190 & 19.7 & 454 \\
\hline 184.5 & 185 & 199.6 & 2415 & 2606 & 2115 & 300 & 323.7 & 373 \\
\hline 184.5 & 185 & 199.6 & 2415 & 2606 & 2115 & 300 & 323.7 & 373 \\
\hline 184.5 & 185 & 199.6 & 2415 & 2606 & 2115 & 300 & 323.7 & 373 \\
\hline 184.5 & 185 & 199.6 & 2415 & 2606 & 2115 & 300 & 323.7 & 373 \\
\hline 184.5 & 185 & 199.6 & 2415 & 2606 & 2115 & 300 & 323.7 & 373 \\
\hline 99.1 & 99 & 49.1 & 1776 & 880 & 1171 & 605 & 299.8 & 597 \\
\hline 5.3 & 38 & 1.9 & 558 & 28 & 375 & 183 & 9.2 & 2011 \\
\hline 13.8 & 42 & 2.1 & 1223 & 61 & 1029 & 194 & 9.7 & 928 \\
\hline 14.1 & 89 & 22.1 & 956 & 237 & 855 & 101 & 25.0 & 453 \\
\hline 14.1 & 89 & 22.1 & 956 & 237 & 855 & 101 & 25.0 & 453 \\
\hline
\end{tabular}




\begin{tabular}{|c|c|c|c|c|c|c|c|c|}
\hline 14.1 & 89 & 22.1 & 956 & 237 & 855 & 101 & 25.0 & 453 \\
\hline 14.1 & 89 & 22.1 & 956 & 237 & 855 & 101 & 25.0 & 453 \\
\hline 33.2 & 79 & 11.9 & 1281 & 193 & 960 & 321 & 48.3 & 121 \\
\hline 33.2 & 79 & 11.9 & 1281 & 193 & 960 & 321 & 48.3 & 121 \\
\hline 33.2 & 79 & 11.9 & 1281 & 193 & 960 & 321 & 48.3 & 121 \\
\hline 64.5 & 76 & 14.6 & 1003 & 192 & 841 & 162 & 31.1 & 1608 \\
\hline 64.5 & 76 & 14.6 & 1003 & 192 & 841 & 162 & 31.1 & 1608 \\
\hline 64.5 & 76 & 14.6 & 1003 & 192 & 841 & 162 & 31.1 & 1608 \\
\hline 64.5 & 76 & 14.6 & 1003 & 192 & 841 & 162 & 31.1 & 1608 \\
\hline 64.5 & 76 & 14.6 & 1003 & 192 & 841 & 162 & 31.1 & 1608 \\
\hline 64.5 & 76 & 14.6 & 1003 & 192 & 841 & 162 & 31.1 & 1608 \\
\hline 64.5 & 76 & 14.6 & 1003 & 192 & 841 & 162 & 31.1 & 1608 \\
\hline 64.5 & 76 & 14.6 & 1003 & 192 & 841 & 162 & 31.1 & 1608 \\
\hline 64.5 & 76 & 14.6 & 1003 & 192 & 841 & 162 & 31.1 & 1608 \\
\hline 13.8 & 42 & 2.1 & 1223 & 61 & 1029 & 194 & 9.7 & 928 \\
\hline 13.8 & 42 & 2.1 & 1223 & 61 & 1029 & 194 & 9.7 & 928 \\
\hline 64.5 & 76 & 14.6 & 1003 & 192 & 841 & 162 & 31.1 & 1608 \\
\hline 64.5 & 76 & 14.6 & 1003 & 192 & 841 & 162 & 31.1 & 1608 \\
\hline 64.5 & 76 & 14.6 & 1003 & 192 & 841 & 162 & 31.1 & 1608 \\
\hline 64.5 & 76 & 14.6 & 1003 & 192 & 841 & 162 & 31.1 & 1608 \\
\hline
\end{tabular}




\begin{tabular}{|c|c|c|c|c|c|c|c|c|}
\hline 64.5 & 76 & 14.6 & 1003 & 192 & 841 & 162 & 31.1 & 1608 \\
\hline 64.5 & 76 & 14.6 & 1003 & 192 & 841 & 162 & 31.1 & 1608 \\
\hline 64.5 & 76 & 14.6 & 1003 & 192 & 841 & 162 & 31.1 & 1608 \\
\hline 64.5 & 76 & 14.6 & 1003 & 192 & 841 & 162 & 31.1 & 1608 \\
\hline 64.5 & 76 & 14.6 & 1003 & 192 & 841 & 162 & 31.1 & 1608 \\
\hline 33.2 & 79 & 11.9 & 1281 & 193 & 960 & 321 & 48.3 & 121 \\
\hline 33.2 & 79 & 11.9 & 1281 & 193 & 960 & 321 & 48.3 & 121 \\
\hline 33.2 & 79 & 11.9 & 1281 & 193 & 960 & 321 & 48.3 & 121 \\
\hline 14.1 & 89 & 22.1 & 956 & 237 & 855 & 101 & 25.0 & 453 \\
\hline 14.1 & 89 & 22.1 & 956 & 237 & 855 & 101 & 25.0 & 453 \\
\hline 14.1 & 89 & 22.1 & 956 & 237 & 855 & 101 & 25.0 & 453 \\
\hline 14.1 & 89 & 22.1 & 956 & 237 & 855 & 101 & 25.0 & 453 \\
\hline 112.8 & 185 & 58.3 & 2996 & 944 & 2699 & 297 & 93.6 & 671 \\
\hline
\end{tabular}




\begin{tabular}{|c|c|c|c|c|c|c|c|c|c|c|}
\hline ll Jobs & & Work & S Sex & & & & Worl & ker Age & & \\
\hline $\begin{array}{l}\text { All Jobs } \\
\text { Density }\end{array}$ & $\begin{array}{l}\text { Work } \\
\text { Male } \\
\end{array}$ & $\begin{array}{c}\text { Work Male } \\
\text { Density }\end{array}$ & $\begin{array}{c}\text { Work } \\
\text { Female }\end{array}$ & $\begin{array}{l}\text { Female } \\
\text { Density }\end{array}$ & $\begin{array}{c}\text { Work } \\
<29 \\
\end{array}$ & $\begin{array}{c}\text { Work }<29 \\
\text { Density }\end{array}$ & \begin{tabular}{|c|} 
Work 30 \\
to 54
\end{tabular} & $\begin{array}{l}\text { Work } 30 \text { to } \\
54 \text { Density }\end{array}$ & $\begin{array}{c}\text { Work } \\
>55\end{array}$ & $\begin{array}{c}\text { Work }>55 \\
\text { Density }\end{array}$ \\
\hline 14343.2 & 4180 & 6678.7 & 4797 & 7664.5 & 2925 & 4673.5 & 4339 & 6932.8 & 1713 & 2737.0 \\
\hline 446.5 & 872 & 210.8 & 975 & 235.7 & 653 & 157.8 & 849 & 205.2 & 345 & 83.4 \\
\hline 309.4 & 1052 & 149.3 & 1128 & 160.1 & 1513 & 214.8 & 476 & 67.6 & 191 & 27.1 \\
\hline 309.4 & 1052 & 149.3 & 1128 & 160.1 & 1513 & 214.8 & 476 & 67.6 & 191 & 27.1 \\
\hline 309.4 & 1052 & 149.3 & 1128 & 160.1 & 1513 & 214.8 & 476 & 67.6 & 191 & 27.1 \\
\hline 859.5 & 2153 & 374.1 & 2794 & 485.4 & 1328 & 230.7 & 2402 & 417.3 & 1217 & 211.4 \\
\hline 934.9 & 882 & 460.4 & 909 & 474.5 & 506 & 264.1 & 913 & 476.6 & 372 & 194.2 \\
\hline 126.9 & 825 & 41.3 & 1713 & 85.7 & 619 & 31.0 & 1412 & 70.6 & 507 & 25.4 \\
\hline 126.9 & 825 & 41.3 & 1713 & 85.7 & 619 & 31.0 & 1412 & 70.6 & 507 & 25.4 \\
\hline 2315.0 & 2728 & 1126.5 & 2878 & 1188.5 & 1713 & 707.4 & 2783 & 1149.2 & 1110 & 458.4 \\
\hline 140.7 & 1396 & 83.8 & 948 & 56.9 & 609 & 36.6 & 1252 & 75.1 & 483 & 29.0 \\
\hline 1446.5 & 1175 & 567.5 & 1820 & 879.0 & 622 & 300.4 & 1658 & 800.8 & 715 & 345.3 \\
\hline 42.6 & 470 & 23.5 & 381 & 19.1 & 154 & 7.7 & 451 & 22.6 & 246 & 12.3 \\
\hline 42.6 & 470 & 23.5 & 381 & 19.1 & 154 & 7.7 & 451 & 22.6 & 246 & 12.3 \\
\hline 42.6 & 470 & 23.5 & 381 & 19.1 & 154 & 7.7 & 451 & 22.6 & 246 & 12.3 \\
\hline 42.6 & 470 & 23.5 & 381 & 19.1 & 154 & 7.7 & 451 & 22.6 & 246 & 12.3 \\
\hline
\end{tabular}




\begin{tabular}{|c|c|c|c|c|c|c|c|c|c|c|}
\hline 42.6 & 470 & 23.5 & 381 & 19.1 & 154 & 7.7 & 451 & 22.6 & 246 & 12.3 \\
\hline 42.6 & 470 & 23.5 & 381 & 19.1 & 154 & 7.7 & 451 & 22.6 & 246 & 12.3 \\
\hline 42.6 & 470 & 23.5 & 381 & 19.1 & 154 & 7.7 & 451 & 22.6 & 246 & 12.3 \\
\hline 775.6 & 698 & 396.3 & 668 & 379.3 & 453 & 257.2 & 672 & 381.6 & 241 & 136.8 \\
\hline 775.6 & 698 & 396.3 & 668 & 379.3 & 453 & 257.2 & 672 & 381.6 & 241 & 136.8 \\
\hline 775.6 & 698 & 396.3 & 668 & 379.3 & 453 & 257.2 & 672 & 381.6 & 241 & 136.8 \\
\hline 775.6 & 698 & 396.3 & 668 & 379.3 & 453 & 257.2 & 672 & 381.6 & 241 & 136.8 \\
\hline 776.4 & 698 & 396.7 & 668 & 379.7 & 453 & 257.5 & 672 & 381.9 & 241 & 137.0 \\
\hline 776.4 & 698 & 396.7 & 668 & 379.7 & 453 & 257.5 & 672 & 381.9 & 241 & 137.0 \\
\hline 776.4 & 698 & 396.7 & 668 & 379.7 & 453 & 257.5 & 672 & 381.9 & 241 & 137.0 \\
\hline 934.9 & 882 & 460.4 & 909 & 474.5 & 506 & 264.1 & 913 & 476.6 & 372 & 194.2 \\
\hline 934.9 & 882 & 460.4 & 909 & 474.5 & 506 & 264.1 & 913 & 476.6 & 372 & 194.2 \\
\hline 347.7 & 507 & 155.9 & 624 & 191.9 & 347 & 106.7 & 551 & 169.4 & 233 & 71.6 \\
\hline 347.7 & 507 & 155.9 & 624 & 191.9 & 347 & 106.7 & 551 & 169.4 & 233 & 71.6 \\
\hline 347.7 & 507 & 155.9 & 624 & 191.9 & 347 & 106.7 & 551 & 169.4 & 233 & 71.6 \\
\hline 347.7 & 507 & 155.9 & 624 & 191.9 & 347 & 106.7 & 551 & 169.4 & 233 & 71.6 \\
\hline 347.7 & 507 & 155.9 & 624 & 191.9 & 347 & 106.7 & 551 & 169.4 & 233 & 71.6 \\
\hline 347.7 & 507 & 155.9 & 624 & 191.9 & 347 & 106.7 & 551 & 169.4 & 233 & 71.6 \\
\hline 347.7 & 507 & 155.9 & 624 & 191.9 & 347 & 106.7 & 551 & 169.4 & 233 & 71.6 \\
\hline 347.7 & 507 & 155.9 & 624 & 191.9 & 347 & 106.7 & 551 & 169.4 & 233 & 71.6 \\
\hline
\end{tabular}




\begin{tabular}{|c|c|c|c|c|c|c|c|c|c|c|}
\hline 347.7 & 507 & 155.9 & 624 & 191.9 & 347 & 106.7 & 551 & 169.4 & 233 & 71.6 \\
\hline 126.9 & 825 & 41.3 & 1713 & 85.7 & 619 & 31.0 & 1412 & 70.6 & 507 & 25.4 \\
\hline 2315.0 & 2728 & 1126.5 & 2878 & 1188.5 & 1713 & 707.4 & 2783 & 1149.2 & 1110 & 458.4 \\
\hline 2315.0 & 2728 & 1126.5 & 2878 & 1188.5 & 1713 & 707.4 & 2783 & 1149.2 & 1110 & 458.4 \\
\hline 2315.0 & 2728 & 1126.5 & 2878 & 1188.5 & 1713 & 707.4 & 2783 & 1149.2 & 1110 & 458.4 \\
\hline 150.4 & 1739 & 87.0 & 1269 & 63.5 & 763 & 38.2 & 1597 & 79.9 & 648 & 32.4 \\
\hline 150.4 & 1739 & 87.0 & 1269 & 63.5 & 763 & 38.2 & 1597 & 79.9 & 648 & 32.4 \\
\hline 2315.0 & 2728 & 1126.5 & 2878 & 1188.5 & 1713 & 707.4 & 2783 & 1149.2 & 1110 & 458.4 \\
\hline 126.9 & 825 & 41.3 & 1713 & 85.7 & 619 & 31.0 & 1412 & 70.6 & 507 & 25.4 \\
\hline 258.4 & 513 & 98.3 & 835 & 160.1 & 299 & 57.3 & 733 & 140.5 & 316 & 60.6 \\
\hline 258.4 & 513 & 98.3 & 835 & 160.1 & 299 & 57.3 & 733 & 140.5 & 316 & 60.6 \\
\hline 258.4 & 513 & 98.3 & 835 & 160.1 & 299 & 57.3 & 733 & 140.5 & 316 & 60.6 \\
\hline 258.4 & 513 & 98.3 & 835 & 160.1 & 299 & 57.3 & 733 & 140.5 & 316 & 60.6 \\
\hline 258.4 & 513 & 98.3 & 835 & 160.1 & 299 & 57.3 & 733 & 140.5 & 316 & 60.6 \\
\hline 258.4 & 513 & 98.3 & 835 & 160.1 & 299 & 57.3 & 733 & 140.5 & 316 & 60.6 \\
\hline 258.4 & 513 & 98.3 & 835 & 160.1 & 299 & 57.3 & 733 & 140.5 & 316 & 60.6 \\
\hline 258.4 & 513 & 98.3 & 835 & 160.1 & 299 & 57.3 & 733 & 140.5 & 316 & 60.6 \\
\hline 258.4 & 513 & 98.3 & 835 & 160.1 & 299 & 57.3 & 733 & 140.5 & 316 & 60.6 \\
\hline 258.4 & 513 & 98.3 & 835 & 160.1 & 299 & 57.3 & 733 & 140.5 & 316 & 60.6 \\
\hline 258.4 & 513 & 98.3 & 835 & 160.1 & 299 & 57.3 & 733 & 140.5 & 316 & 60.6 \\
\hline
\end{tabular}




\begin{tabular}{|c|c|c|c|c|c|c|c|c|c|c|}
\hline 258.4 & 513 & 98.3 & 835 & 160.1 & 299 & 57.3 & 733 & 140.5 & 316 & 60.6 \\
\hline 258.4 & 513 & 98.3 & 835 & 160.1 & 299 & 57.3 & 733 & 140.5 & 316 & 60.6 \\
\hline 258.4 & 513 & 98.3 & 835 & 160.1 & 299 & 57.3 & 733 & 140.5 & 316 & 60.6 \\
\hline 258.4 & 513 & 98.3 & 835 & 160.1 & 299 & 57.3 & 733 & 140.5 & 316 & 60.6 \\
\hline 776.4 & 698 & 396.7 & 668 & 379.7 & 453 & 257.5 & 672 & 381.9 & 241 & 137.0 \\
\hline 776.4 & 698 & 396.7 & 668 & 379.7 & 453 & 257.5 & 672 & 381.9 & 241 & 137.0 \\
\hline 42.6 & 470 & 23.5 & 381 & 19.1 & 154 & 7.7 & 451 & 22.6 & 246 & 12.3 \\
\hline 42.6 & 470 & 23.5 & 381 & 19.1 & 154 & 7.7 & 451 & 22.6 & 246 & 12.3 \\
\hline 42.6 & 470 & 23.5 & 381 & 19.1 & 154 & 7.7 & 451 & 22.6 & 246 & 12.3 \\
\hline 42.6 & 470 & 23.5 & 381 & 19.1 & 154 & 7.7 & 451 & 22.6 & 246 & 12.3 \\
\hline 42.6 & 470 & 23.5 & 381 & 19.1 & 154 & 7.7 & 451 & 22.6 & 246 & 12.3 \\
\hline 42.6 & 470 & 23.5 & 381 & 19.1 & 154 & 7.7 & 451 & 22.6 & 246 & 12.3 \\
\hline 42.6 & 470 & 23.5 & 381 & 19.1 & 154 & 7.7 & 451 & 22.6 & 246 & 12.3 \\
\hline 1445.4 & 1175 & 567.1 & 1820 & 878.4 & 622 & 300.2 & 1658 & 800.2 & 715 & 345.1 \\
\hline 309.4 & 1052 & 149.3 & 1128 & 160.1 & 1513 & 214.8 & 476 & 67.6 & 191 & 27.1 \\
\hline 309.4 & 1052 & 149.3 & 1128 & 160.1 & 1513 & 214.8 & 476 & 67.6 & 191 & 27.1 \\
\hline 210.5 & 726 & 85.2 & 1068 & 125.3 & 677 & 79.4 & 799 & 93.8 & 318 & 37.3 \\
\hline 651.3 & 616 & 271.8 & 860 & 379.5 & 309 & 136.3 & 820 & 361.8 & 347 & 153.1 \\
\hline 651.3 & 616 & 271.8 & 860 & 379.5 & 309 & 136.3 & 820 & 361.8 & 347 & 153.1 \\
\hline 3970.1 & 930 & 1781.1 & 1143 & 2189.0 & 328 & 628.2 & 1123 & 2150.7 & 622 & 1191.2 \\
\hline
\end{tabular}




\begin{tabular}{|c|c|c|c|c|c|c|c|c|c|c|}
\hline 1097.0 & 1382 & 400.4 & 2404 & 696.5 & 832 & 241.1 & 2104 & 609.6 & 850 & 246.3 \\
\hline 1097.0 & 1382 & 400.4 & 2404 & 696.5 & 832 & 241.1 & 2104 & 609.6 & 850 & 246.3 \\
\hline 3149.8 & 832 & 1557.1 & 851 & 1592.7 & 574 & 1074.3 & 859 & 1607.7 & 250 & 467.9 \\
\hline 183.8 & 457 & 97.7 & 403 & 86.1 & 252 & 53.9 & 445 & 95.1 & 163 & 34.8 \\
\hline 183.8 & 457 & 97.7 & 403 & 86.1 & 252 & 53.9 & 445 & 95.1 & 163 & 34.8 \\
\hline 183.8 & 457 & 97.7 & 403 & 86.1 & 252 & 53.9 & 445 & 95.1 & 163 & 34.8 \\
\hline 41.9 & 524 & 26.2 & 313 & 15.7 & 183 & 9.2 & 461 & 23.1 & 193 & 9.7 \\
\hline 474.0 & 3025 & 292.4 & 1878 & 181.5 & 1385 & 133.9 & 2690 & 260.0 & 828 & 80.0 \\
\hline 2583.1 & 2722 & 1418.4 & 2235 & 1164.7 & 940 & 489.8 & 2820 & 1469.5 & 1197 & 623.8 \\
\hline 14343.2 & 4180 & 6678.7 & 4797 & 7664.5 & 2925 & 4673.5 & 4339 & 6932.8 & 1713 & 2737.0 \\
\hline 5036.7 & 2568 & 2890.4 & 1907 & 2146.4 & 1291 & 1453.1 & 2373 & 2670.9 & 811 & 912.8 \\
\hline 14343.2 & 4180 & 6678.7 & 4797 & 7664.5 & 2925 & 4673.5 & 4339 & 6932.8 & 1713 & 2737.0 \\
\hline 14343.2 & 4180 & 6678.7 & 4797 & 7664.5 & 2925 & 4673.5 & 4339 & 6932.8 & 1713 & 2737.0 \\
\hline 2583.1 & 2722 & 1418.4 & 2235 & 1164.7 & 940 & 489.8 & 2820 & 1469.5 & 1197 & 623.8 \\
\hline 888.7 & 261 & 483.2 & 219 & 405.5 & 103 & 190.7 & 272 & 503.6 & 105 & 194.4 \\
\hline 41.9 & 524 & 26.2 & 313 & 15.7 & 183 & 9.2 & 461 & 23.1 & 193 & 9.7 \\
\hline 183.8 & 457 & 97.7 & 403 & 86.1 & 252 & 53.9 & 445 & 95.1 & 163 & 34.8 \\
\hline 183.8 & 457 & 97.7 & 403 & 86.1 & 252 & 53.9 & 445 & 95.1 & 163 & 34.8 \\
\hline 183.8 & 457 & 97.7 & 403 & 86.1 & 252 & 53.9 & 445 & 95.1 & 163 & 34.8 \\
\hline 100.6 & 72 & 3.6 & 57 & 2.9 & 36 & 1.8 & 64 & 3.2 & 29 & 1.5 \\
\hline
\end{tabular}




\begin{tabular}{|c|c|c|c|c|c|c|c|c|c|c|}
\hline 3508.7 & 1145 & 2208.6 & 674 & 1300.1 & 133 & 256.5 & 1315 & 2536.5 & 371 & 715.6 \\
\hline 295.8 & 285 & 141.2 & 312 & 154.6 & 178 & 88.2 & 278 & 137.8 & 141 & 69.9 \\
\hline 402.4 & 152 & 164.0 & 221 & 238.4 & 89 & 96.0 & 181 & 195.3 & 103 & 111.1 \\
\hline 402.4 & 152 & 164.0 & 221 & 238.4 & 89 & 96.0 & 181 & 195.3 & 103 & 111.1 \\
\hline 525.3 & 396 & 255.9 & 417 & 269.4 & 221 & 142.8 & 402 & 259.8 & 190 & 122.8 \\
\hline 525.3 & 396 & 255.9 & 417 & 269.4 & 221 & 142.8 & 402 & 259.8 & 190 & 122.8 \\
\hline 525.3 & 396 & 255.9 & 417 & 269.4 & 221 & 142.8 & 402 & 259.8 & 190 & 122.8 \\
\hline 47.0 & 194 & 20.1 & 260 & 26.9 & 149 & 15.4 & 212 & 22.0 & 93 & 9.6 \\
\hline 47.0 & 194 & 20.1 & 260 & 26.9 & 149 & 15.4 & 212 & 22.0 & 93 & 9.6 \\
\hline 47.0 & 194 & 20.1 & 260 & 26.9 & 149 & 15.4 & 212 & 22.0 & 93 & 9.6 \\
\hline 402.4 & 152 & 164.0 & 221 & 238.4 & 89 & 96.0 & 181 & 195.3 & 103 & 111.1 \\
\hline 402.4 & 152 & 164.0 & 221 & 238.4 & 89 & 96.0 & 181 & 195.3 & 103 & 111.1 \\
\hline 402.4 & 152 & 164.0 & 221 & 238.4 & 89 & 96.0 & 181 & 195.3 & 103 & 111.1 \\
\hline 402.4 & 152 & 164.0 & 221 & 238.4 & 89 & 96.0 & 181 & 195.3 & 103 & 111.1 \\
\hline 402.4 & 152 & 164.0 & 221 & 238.4 & 89 & 96.0 & 181 & 195.3 & 103 & 111.1 \\
\hline 295.8 & 285 & 141.2 & 312 & 154.6 & 178 & 88.2 & 278 & 137.8 & 141 & 69.9 \\
\hline 100.6 & 72 & 3.6 & 57 & 2.9 & 36 & 1.8 & 64 & 3.2 & 29 & 1.5 \\
\hline 46.4 & 532 & 26.6 & 396 & 19.8 & 195 & 9.8 & 444 & 22.2 & 289 & 14.5 \\
\hline 112.3 & 224 & 55.5 & 229 & 56.8 & 160 & 39.7 & 185 & 45.9 & 108 & 26.8 \\
\hline 112.3 & 224 & 55.5 & 229 & 56.8 & 160 & 39.7 & 185 & 45.9 & 108 & 26.8 \\
\hline
\end{tabular}




\begin{tabular}{|c|c|c|c|c|c|c|c|c|c|c|}
\hline 112.3 & 224 & 55.5 & 229 & 56.8 & 160 & 39.7 & 185 & 45.9 & 108 & 26.8 \\
\hline 112.3 & 224 & 55.5 & 229 & 56.8 & 160 & 39.7 & 185 & 45.9 & 108 & 26.8 \\
\hline 18.2 & 68 & 10.2 & 53 & 8.0 & 27 & 4.1 & 61 & 9.2 & 33 & 5.0 \\
\hline 18.2 & 68 & 10.2 & 53 & 8.0 & 27 & 4.1 & 61 & 9.2 & 33 & 5.0 \\
\hline 18.2 & 68 & 10.2 & 53 & 8.0 & 27 & 4.1 & 61 & 9.2 & 33 & 5.0 \\
\hline 308.6 & 768 & 147.4 & 840 & 161.2 & 466 & 89.4 & 720 & 138.2 & 422 & 81.0 \\
\hline 308.6 & 768 & 147.4 & 840 & 161.2 & 466 & 89.4 & 720 & 138.2 & 422 & 81.0 \\
\hline 308.6 & 768 & 147.4 & 840 & 161.2 & 466 & 89.4 & 720 & 138.2 & 422 & 81.0 \\
\hline 308.6 & 768 & 147.4 & 840 & 161.2 & 466 & 89.4 & 720 & 138.2 & 422 & 81.0 \\
\hline 308.6 & 768 & 147.4 & 840 & 161.2 & 466 & 89.4 & 720 & 138.2 & 422 & 81.0 \\
\hline 308.6 & 768 & 147.4 & 840 & 161.2 & 466 & 89.4 & 720 & 138.2 & 422 & 81.0 \\
\hline 308.6 & 768 & 147.4 & 840 & 161.2 & 466 & 89.4 & 720 & 138.2 & 422 & 81.0 \\
\hline 308.6 & 768 & 147.4 & 840 & 161.2 & 466 & 89.4 & 720 & 138.2 & 422 & 81.0 \\
\hline 308.6 & 768 & 147.4 & 840 & 161.2 & 466 & 89.4 & 720 & 138.2 & 422 & 81.0 \\
\hline 46.4 & 532 & 26.6 & 396 & 19.8 & 195 & 9.8 & 444 & 22.2 & 289 & 14.5 \\
\hline 46.4 & 532 & 26.6 & 396 & 19.8 & 195 & 9.8 & 444 & 22.2 & 289 & 14.5 \\
\hline 308.6 & 768 & 147.4 & 840 & 161.2 & 466 & 89.4 & 720 & 138.2 & 422 & 81.0 \\
\hline 308.6 & 768 & 147.4 & 840 & 161.2 & 466 & 89.4 & 720 & 138.2 & 422 & 81.0 \\
\hline 308.6 & 768 & 147.4 & 840 & 161.2 & 466 & 89.4 & 720 & 138.2 & 422 & 81.0 \\
\hline 308.6 & 768 & 147.4 & 840 & 161.2 & 466 & 89.4 & 720 & 138.2 & 422 & 81.0 \\
\hline
\end{tabular}




\begin{tabular}{|c|c|c|c|c|c|c|c|c|c|c|}
\hline 308.6 & 768 & 147.4 & 840 & 161.2 & 466 & 89.4 & 720 & 138.2 & 422 & 81.0 \\
\hline 308.6 & 768 & 147.4 & 840 & 161.2 & 466 & 89.4 & 720 & 138.2 & 422 & 81.0 \\
\hline 308.6 & 768 & 147.4 & 840 & 161.2 & 466 & 89.4 & 720 & 138.2 & 422 & 81.0 \\
\hline 308.6 & 768 & 147.4 & 840 & 161.2 & 466 & 89.4 & 720 & 138.2 & 422 & 81.0 \\
\hline 308.6 & 768 & 147.4 & 840 & 161.2 & 466 & 89.4 & 720 & 138.2 & 422 & 81.0 \\
\hline 18.2 & 68 & 10.2 & 53 & 8.0 & 27 & 4.1 & 61 & 9.2 & 33 & 5.0 \\
\hline 18.2 & 68 & 10.2 & 53 & 8.0 & 27 & 4.1 & 61 & 9.2 & 33 & 5.0 \\
\hline 18.2 & 68 & 10.2 & 53 & 8.0 & 27 & 4.1 & 61 & 9.2 & 33 & 5.0 \\
\hline 112.3 & 224 & 55.5 & 229 & 56.8 & 160 & 39.7 & 185 & 45.9 & 108 & 26.8 \\
\hline 112.3 & 224 & 55.5 & 229 & 56.8 & 160 & 39.7 & 185 & 45.9 & 108 & 26.8 \\
\hline 112.3 & 224 & 55.5 & 229 & 56.8 & 160 & 39.7 & 185 & 45.9 & 108 & 26.8 \\
\hline 112.3 & 224 & 55.5 & 229 & 56.8 & 160 & 39.7 & 185 & 45.9 & 108 & 26.8 \\
\hline 211.4 & 326 & 102.7 & 345 & 108.7 & 187 & 58.9 & 334 & 105.3 & 150 & 47.3 \\
\hline
\end{tabular}




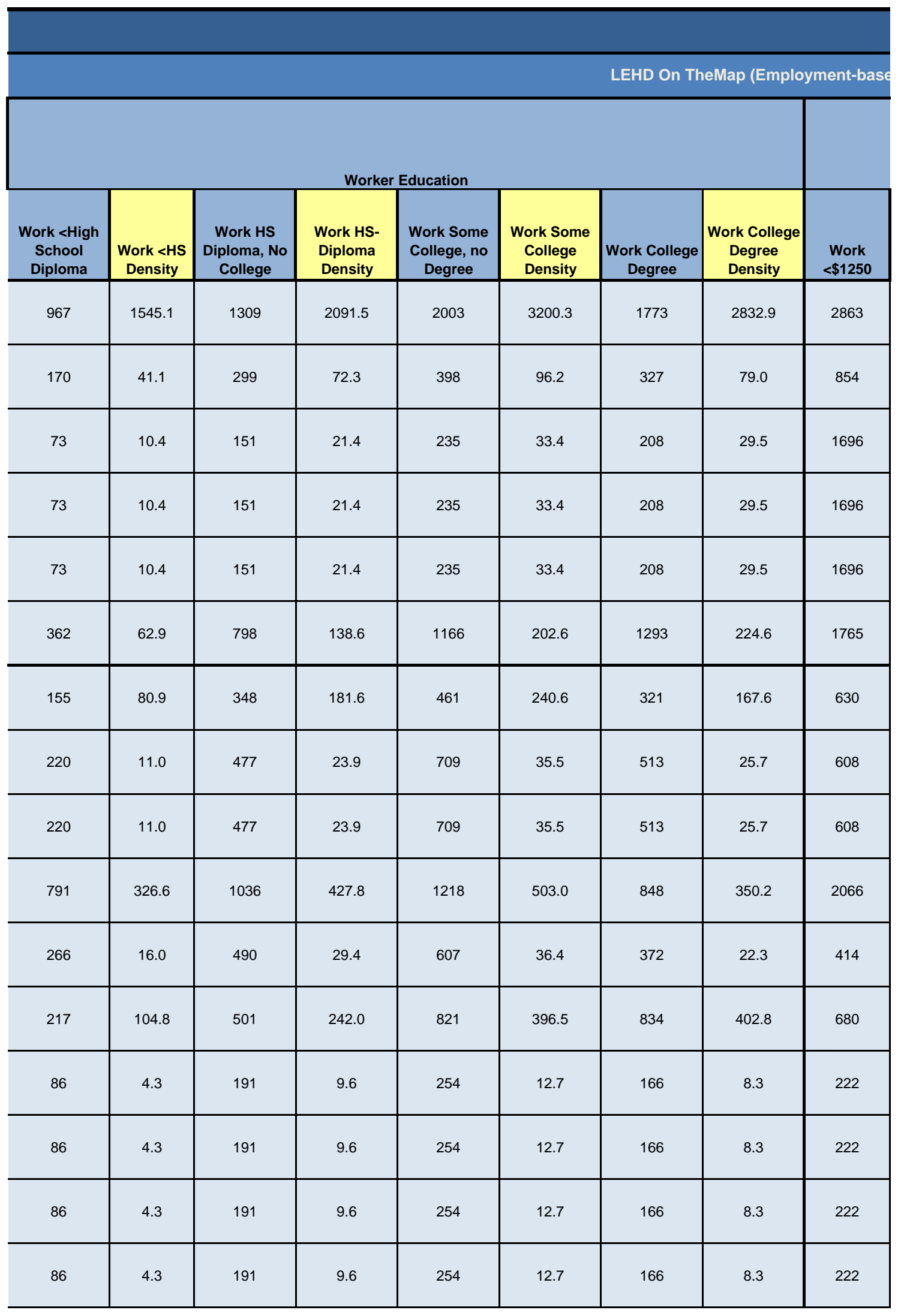




\begin{tabular}{|c|c|c|c|c|c|c|c|c|}
\hline 86 & 4.3 & 191 & 9.6 & 254 & 12.7 & 166 & 8.3 & 222 \\
\hline 86 & 4.3 & 191 & 9.6 & 254 & 12.7 & 166 & 8.3 & 222 \\
\hline 86 & 4.3 & 191 & 9.6 & 254 & 12.7 & 166 & 8.3 & 222 \\
\hline 125 & 71.0 & 291 & 165.2 & 309 & 175.4 & 188 & 106.7 & 456 \\
\hline 125 & 71.0 & 291 & 165.2 & 309 & 175.4 & 188 & 106.7 & 456 \\
\hline 125 & 71.0 & 291 & 165.2 & 309 & 175.4 & 188 & 106.7 & 456 \\
\hline 125 & 71.0 & 291 & 165.2 & 309 & 175.4 & 188 & 106.7 & 456 \\
\hline 125 & 71.0 & 291 & 165.4 & 309 & 175.6 & 188 & 106.8 & 456 \\
\hline 125 & 71.0 & 291 & 165.4 & 309 & 175.6 & 188 & 106.8 & 456 \\
\hline 125 & 71.0 & 291 & 165.4 & 309 & 175.6 & 188 & 106.8 & 456 \\
\hline 155 & 80.9 & 348 & 181.6 & 461 & 240.6 & 321 & 167.6 & 630 \\
\hline 155 & 80.9 & 348 & 181.6 & 461 & 240.6 & 321 & 167.6 & 630 \\
\hline 90 & 27.7 & 217 & 66.7 & 290 & 89.2 & 187 & 57.5 & 465 \\
\hline 90 & 27.7 & 217 & 66.7 & 290 & 89.2 & 187 & 57.5 & 465 \\
\hline 90 & 27.7 & 217 & 66.7 & 290 & 89.2 & 187 & 57.5 & 465 \\
\hline 90 & 27.7 & 217 & 66.7 & 290 & 89.2 & 187 & 57.5 & 465 \\
\hline 90 & 27.7 & 217 & 66.7 & 290 & 89.2 & 187 & 57.5 & 465 \\
\hline 90 & 27.7 & 217 & 66.7 & 290 & 89.2 & 187 & 57.5 & 465 \\
\hline 90 & 27.7 & 217 & 66.7 & 290 & 89.2 & 187 & 57.5 & 465 \\
\hline 90 & 27.7 & 217 & 66.7 & 290 & 89.2 & 187 & 57.5 & 465 \\
\hline
\end{tabular}




\begin{tabular}{|c|c|c|c|c|c|c|c|c|}
\hline 90 & 27.7 & 217 & 66.7 & 290 & 89.2 & 187 & 57.5 & 465 \\
\hline 220 & 11.0 & 477 & 23.9 & 709 & 35.5 & 513 & 25.7 & 608 \\
\hline 791 & 326.6 & 1036 & 427.8 & 1218 & 503.0 & 848 & 350.2 & 2066 \\
\hline 791 & 326.6 & 1036 & 427.8 & 1218 & 503.0 & 848 & 350.2 & 2066 \\
\hline 791 & 326.6 & 1036 & 427.8 & 1218 & 503.0 & 848 & 350.2 & 2066 \\
\hline 468 & 23.4 & 607 & 30.4 & 696 & 34.8 & 474 & 23.7 & 1071 \\
\hline 468 & 23.4 & 607 & 30.4 & 696 & 34.8 & 474 & 23.7 & 1071 \\
\hline 791 & 326.6 & 1036 & 427.8 & 1218 & 503.0 & 848 & 350.2 & 2066 \\
\hline 220 & 11.0 & 477 & 23.9 & 709 & 35.5 & 513 & 25.7 & 608 \\
\hline 137 & 26.3 & 291 & 55.8 & 341 & 65.4 & 280 & 53.7 & 412 \\
\hline 137 & 26.3 & 291 & 55.8 & 341 & 65.4 & 280 & 53.7 & 412 \\
\hline 137 & 26.3 & 291 & 55.8 & 341 & 65.4 & 280 & 53.7 & 412 \\
\hline 137 & 26.3 & 291 & 55.8 & 341 & 65.4 & 280 & 53.7 & 412 \\
\hline 137 & 26.3 & 291 & 55.8 & 341 & 65.4 & 280 & 53.7 & 412 \\
\hline 137 & 26.3 & 291 & 55.8 & 341 & 65.4 & 280 & 53.7 & 412 \\
\hline 137 & 26.3 & 291 & 55.8 & 341 & 65.4 & 280 & 53.7 & 412 \\
\hline 137 & 26.3 & 291 & 55.8 & 341 & 65.4 & 280 & 53.7 & 412 \\
\hline 137 & 26.3 & 291 & 55.8 & 341 & 65.4 & 280 & 53.7 & 412 \\
\hline 137 & 26.3 & 291 & 55.8 & 341 & 65.4 & 280 & 53.7 & 412 \\
\hline 137 & 26.3 & 291 & 55.8 & 341 & 65.4 & 280 & 53.7 & 412 \\
\hline
\end{tabular}




\begin{tabular}{|c|c|c|c|c|c|c|c|c|}
\hline 137 & 26.3 & 291 & 55.8 & 341 & 65.4 & 280 & 53.7 & 412 \\
\hline 137 & 26.3 & 291 & 55.8 & 341 & 65.4 & 280 & 53.7 & 412 \\
\hline 137 & 26.3 & 291 & 55.8 & 341 & 65.4 & 280 & 53.7 & 412 \\
\hline 137 & 26.3 & 291 & 55.8 & 341 & 65.4 & 280 & 53.7 & 412 \\
\hline 125 & 71.0 & 291 & 165.4 & 309 & 175.6 & 188 & 106.8 & 456 \\
\hline 125 & 71.0 & 291 & 165.4 & 309 & 175.6 & 188 & 106.8 & 456 \\
\hline 86 & 4.3 & 191 & 9.6 & 254 & 12.7 & 166 & 8.3 & 222 \\
\hline 86 & 4.3 & 191 & 9.6 & 254 & 12.7 & 166 & 8.3 & 222 \\
\hline 86 & 4.3 & 191 & 9.6 & 254 & 12.7 & 166 & 8.3 & 222 \\
\hline 86 & 4.3 & 191 & 9.6 & 254 & 12.7 & 166 & 8.3 & 222 \\
\hline 86 & 4.3 & 191 & 9.6 & 254 & 12.7 & 166 & 8.3 & 222 \\
\hline 86 & 4.3 & 191 & 9.6 & 254 & 12.7 & 166 & 8.3 & 222 \\
\hline 86 & 4.3 & 191 & 9.6 & 254 & 12.7 & 166 & 8.3 & 222 \\
\hline 217 & 104.7 & 501 & 241.8 & 821 & 396.2 & 834 & 402.5 & 680 \\
\hline 73 & 10.4 & 151 & 21.4 & 235 & 33.4 & 208 & 29.5 & 1696 \\
\hline 73 & 10.4 & 151 & 21.4 & 235 & 33.4 & 208 & 29.5 & 1696 \\
\hline 151 & 17.7 & 289 & 33.9 & 385 & 45.2 & 292 & 34.3 & 720 \\
\hline 127 & 56.0 & 248 & 109.4 & 274 & 120.9 & 418 & 184.4 & 422 \\
\hline 127 & 56.0 & 248 & 109.4 & 274 & 120.9 & 418 & 184.4 & 422 \\
\hline 216 & 413.7 & 300 & 574.5 & 596 & 1141.4 & 633 & 1212.3 & 832 \\
\hline
\end{tabular}




\begin{tabular}{|c|c|c|c|c|c|c|c|c|}
\hline 539 & 156.2 & 655 & 189.8 & 986 & 285.7 & 774 & 224.3 & 842 \\
\hline 539 & 156.2 & 655 & 189.8 & 986 & 285.7 & 774 & 224.3 & 842 \\
\hline 171 & 320.0 & 250 & 467.9 & 414 & 774.8 & 274 & 512.8 & 601 \\
\hline 118 & 25.2 & 136 & 29.1 & 224 & 47.9 & 130 & 27.8 & 263 \\
\hline 118 & 25.2 & 136 & 29.1 & 224 & 47.9 & 130 & 27.8 & 263 \\
\hline 118 & 25.2 & 136 & 29.1 & 224 & 47.9 & 130 & 27.8 & 263 \\
\hline 139 & 7.0 & 165 & 8.3 & 218 & 10.9 & 132 & 6.6 & 208 \\
\hline 529 & 51.1 & 800 & 77.3 & 1170 & 113.1 & 1019 & 98.5 & 938 \\
\hline 438 & 228.2 & 946 & 493.0 & 1471 & 766.5 & 1162 & 605.5 & 906 \\
\hline 967 & 1545.1 & 1309 & 2091.5 & 2003 & 3200.3 & 1773 & 2832.9 & 2863 \\
\hline 393 & 442.3 & 717 & 807.0 & 1105 & 1243.7 & 969 & 1090.6 & 1181 \\
\hline 967 & 1545.1 & 1309 & 2091.5 & 2003 & 3200.3 & 1773 & 2832.9 & 2863 \\
\hline 967 & 1545.1 & 1309 & 2091.5 & 2003 & 3200.3 & 1773 & 2832.9 & 2863 \\
\hline 438 & 228.2 & 946 & 493.0 & 1471 & 766.5 & 1162 & 605.5 & 906 \\
\hline 33 & 61.1 & 89 & 164.8 & 130 & 240.7 & 125 & 231.4 & 122 \\
\hline 139 & 7.0 & 165 & 8.3 & 218 & 10.9 & 132 & 6.6 & 208 \\
\hline 118 & 25.2 & 136 & 29.1 & 224 & 47.9 & 130 & 27.8 & 263 \\
\hline 118 & 25.2 & 136 & 29.1 & 224 & 47.9 & 130 & 27.8 & 263 \\
\hline 118 & 25.2 & 136 & 29.1 & 224 & 47.9 & 130 & 27.8 & 263 \\
\hline 13 & 0.7 & 25 & 1.3 & 31 & 1.6 & 24 & 1.2 & 47 \\
\hline
\end{tabular}




\begin{tabular}{|c|c|c|c|c|c|c|c|c|}
\hline 127 & 245.0 & 394 & 760.0 & 657 & 1267.3 & 508 & 979.9 & 38 \\
\hline 61 & 30.2 & 131 & 64.9 & 146 & 72.3 & 81 & 40.1 & 276 \\
\hline 39 & 42.1 & 67 & 72.3 & 104 & 112.2 & 74 & 79.8 & 163 \\
\hline 39 & 42.1 & 67 & 72.3 & 104 & 112.2 & 74 & 79.8 & 163 \\
\hline 68 & 43.9 & 177 & 114.4 & 203 & 131.2 & 144 & 93.0 & 268 \\
\hline 68 & 43.9 & 177 & 114.4 & 203 & 131.2 & 144 & 93.0 & 268 \\
\hline 68 & 43.9 & 177 & 114.4 & 203 & 131.2 & 144 & 93.0 & 268 \\
\hline 27 & 2.8 & 82 & 8.5 & 111 & 11.5 & 85 & 8.8 & 179 \\
\hline 27 & 2.8 & 82 & 8.5 & 111 & 11.5 & 85 & 8.8 & 179 \\
\hline 27 & 2.8 & 82 & 8.5 & 111 & 11.5 & 85 & 8.8 & 179 \\
\hline 39 & 42.1 & 67 & 72.3 & 104 & 112.2 & 74 & 79.8 & 163 \\
\hline 39 & 42.1 & 67 & 72.3 & 104 & 112.2 & 74 & 79.8 & 163 \\
\hline 39 & 42.1 & 67 & 72.3 & 104 & 112.2 & 74 & 79.8 & 163 \\
\hline 39 & 42.1 & 67 & 72.3 & 104 & 112.2 & 74 & 79.8 & 163 \\
\hline 39 & 42.1 & 67 & 72.3 & 104 & 112.2 & 74 & 79.8 & 163 \\
\hline 61 & 30.2 & 131 & 64.9 & 146 & 72.3 & 81 & 40.1 & 276 \\
\hline 13 & 0.7 & 25 & 1.3 & 31 & 1.6 & 24 & 1.2 & 47 \\
\hline 153 & 7.7 & 186 & 9.3 & 213 & 10.7 & 181 & 9.1 & 306 \\
\hline 37 & 9.2 & 73 & 18.1 & 116 & 28.8 & 67 & 16.6 & 204 \\
\hline 37 & 9.2 & 73 & 18.1 & 116 & 28.8 & 67 & 16.6 & 204 \\
\hline
\end{tabular}




\begin{tabular}{|c|c|c|c|c|c|c|c|c|}
\hline 37 & 9.2 & 73 & 18.1 & 116 & 28.8 & 67 & 16.6 & 204 \\
\hline 37 & 9.2 & 73 & 18.1 & 116 & 28.8 & 67 & 16.6 & 204 \\
\hline 25 & 3.8 & 20 & 3.0 & 26 & 3.9 & 23 & 3.5 & 46 \\
\hline 25 & 3.8 & 20 & 3.0 & 26 & 3.9 & 23 & 3.5 & 46 \\
\hline 25 & 3.8 & 20 & 3.0 & 26 & 3.9 & 23 & 3.5 & 46 \\
\hline 225 & 43.2 & 289 & 55.5 & 348 & 66.8 & 280 & 53.7 & 667 \\
\hline 225 & 43.2 & 289 & 55.5 & 348 & 66.8 & 280 & 53.7 & 667 \\
\hline 225 & 43.2 & 289 & 55.5 & 348 & 66.8 & 280 & 53.7 & 667 \\
\hline 225 & 43.2 & 289 & 55.5 & 348 & 66.8 & 280 & 53.7 & 667 \\
\hline 225 & 43.2 & 289 & 55.5 & 348 & 66.8 & 280 & 53.7 & 667 \\
\hline 225 & 43.2 & 289 & 55.5 & 348 & 66.8 & 280 & 53.7 & 667 \\
\hline 225 & 43.2 & 289 & 55.5 & 348 & 66.8 & 280 & 53.7 & 667 \\
\hline 225 & 43.2 & 289 & 55.5 & 348 & 66.8 & 280 & 53.7 & 667 \\
\hline 225 & 43.2 & 289 & 55.5 & 348 & 66.8 & 280 & 53.7 & 667 \\
\hline 153 & 7.7 & 186 & 9.3 & 213 & 10.7 & 181 & 9.1 & 306 \\
\hline 153 & 7.7 & 186 & 9.3 & 213 & 10.7 & 181 & 9.1 & 306 \\
\hline 225 & 43.2 & 289 & 55.5 & 348 & 66.8 & 280 & 53.7 & 667 \\
\hline 225 & 43.2 & 289 & 55.5 & 348 & 66.8 & 280 & 53.7 & 667 \\
\hline 225 & 43.2 & 289 & 55.5 & 348 & 66.8 & 280 & 53.7 & 667 \\
\hline 225 & 43.2 & 289 & 55.5 & 348 & 66.8 & 280 & 53.7 & 667 \\
\hline
\end{tabular}




\begin{tabular}{|c|c|c|c|c|c|c|c|c|}
\hline 225 & 43.2 & 289 & 55.5 & 348 & 66.8 & 280 & 53.7 & 667 \\
\hline 225 & 43.2 & 289 & 55.5 & 348 & 66.8 & 280 & 53.7 & 667 \\
\hline 225 & 43.2 & 289 & 55.5 & 348 & 66.8 & 280 & 53.7 & 667 \\
\hline 225 & 43.2 & 289 & 55.5 & 348 & 66.8 & 280 & 53.7 & 667 \\
\hline 225 & 43.2 & 289 & 55.5 & 348 & 66.8 & 280 & 53.7 & 667 \\
\hline 25 & 3.8 & 20 & 3.0 & 26 & 3.9 & 23 & 3.5 & 46 \\
\hline 25 & 3.8 & 20 & 3.0 & 26 & 3.9 & 23 & 3.5 & 46 \\
\hline 25 & 3.8 & 20 & 3.0 & 26 & 3.9 & 23 & 3.5 & 46 \\
\hline 37 & 9.2 & 73 & 18.1 & 116 & 28.8 & 67 & 16.6 & 204 \\
\hline 37 & 9.2 & 73 & 18.1 & 116 & 28.8 & 67 & 16.6 & 204 \\
\hline 37 & 9.2 & 73 & 18.1 & 116 & 28.8 & 67 & 16.6 & 204 \\
\hline 37 & 9.2 & 73 & 18.1 & 116 & 28.8 & 67 & 16.6 & 204 \\
\hline 56 & 17.6 & 134 & 42.2 & 169 & 53.3 & 125 & 39.4 & 245 \\
\hline
\end{tabular}




\begin{tabular}{|c|c|c|c|c|c|c|c|c|c|}
\hline \multirow{2}{*}{\multicolumn{10}{|c|}{ Worker Earnings }} \\
\hline & & & & & & & & & \\
\hline $\begin{array}{c}\text { Work } \\
<\$ 1250 \\
\text { Density }\end{array}$ & $\begin{array}{c}\text { Work } \$ 1251 \\
\text { to } \$ 3333\end{array}$ & $\begin{array}{c}\text { Work } \$ 1251 \\
\text { to } \$ 3333 \\
\text { Density }\end{array}$ & $\begin{array}{c}\text { Work } \\
>\$ 3333\end{array}$ & $\begin{array}{c}\text { Work } \\
>\$ 3333 \\
\text { Density }\end{array}$ & $\begin{array}{l}\text { Work } \\
\text { Latino }\end{array}$ & $\begin{array}{c}\text { Work } \\
\text { Latino } \\
\text { Density }\end{array}$ & $\begin{array}{l}\text { Work } \\
\text { White }\end{array}$ & $\begin{array}{l}\text { Work } \\
\text { White } \\
\text { Density }\end{array}$ & $\begin{array}{l}\text { Work } \\
\text { Black }\end{array}$ \\
\hline 4574.4 & 3432 & 5483.6 & 2682 & 4285.2 & 2377 & 3797.9 & 8022 & 12817.4 & 203 \\
\hline 206.4 & 629 & 152.0 & 364 & 88.0 & 364 & 88.0 & 1636 & 395.5 & 37 \\
\hline 240.7 & 290 & 41.2 & 194 & 27.5 & 294 & 41.7 & 1888 & 268.0 & 27 \\
\hline 240.7 & 290 & 41.2 & 194 & 27.5 & 294 & 41.7 & 1888 & 268.0 & 27 \\
\hline 240.7 & 290 & 41.2 & 194 & 27.5 & 294 & 41.7 & 1888 & 268.0 & 27 \\
\hline 306.7 & 1640 & 284.9 & 1542 & 267.9 & 901 & 156.5 & 4497 & 781.3 & 85 \\
\hline 328.8 & 620 & 323.6 & 541 & 282.4 & 271 & 141.5 & 1647 & 859.7 & 39 \\
\hline 30.4 & 970 & 48.5 & 960 & 48.0 & 477 & 23.9 & 2312 & 115.6 & 34 \\
\hline 30.4 & 970 & 48.5 & 960 & 48.0 & 477 & 23.9 & 2312 & 115.6 & 34 \\
\hline 853.2 & 2338 & 965.5 & 1202 & 496.4 & 1572 & 649.2 & 4922 & 2032.5 & 154 \\
\hline 24.8 & 1037 & 62.2 & 893 & 53.6 & 623 & 37.4 & 2141 & 128.5 & 46 \\
\hline 328.4 & 959 & 463.2 & 1356 & 654.9 & 549 & 265.2 & 2733 & 1320.0 & 38 \\
\hline 11.1 & 292 & 14.6 & 337 & 16.9 & 169 & 8.5 & 783 & 39.2 & 12 \\
\hline 11.1 & 292 & 14.6 & 337 & 16.9 & 169 & 8.5 & 783 & 39.2 & 12 \\
\hline 11.1 & 292 & 14.6 & 337 & 16.9 & 169 & 8.5 & 783 & 39.2 & 12 \\
\hline 11.1 & 292 & 14.6 & 337 & 16.9 & 169 & 8.5 & 783 & 39.2 & 12 \\
\hline
\end{tabular}




\begin{tabular}{|c|c|c|c|c|c|c|c|c|c|}
\hline 11.1 & 292 & 14.6 & 337 & 16.9 & 169 & 8.5 & 783 & 39.2 & 12 \\
\hline 11.1 & 292 & 14.6 & 337 & 16.9 & 169 & 8.5 & 783 & 39.2 & 12 \\
\hline 11.1 & 292 & 14.6 & 337 & 16.9 & 169 & 8.5 & 783 & 39.2 & 12 \\
\hline 258.9 & 589 & 334.4 & 321 & 182.3 & 287 & 163.0 & 1233 & 700.1 & 24 \\
\hline 258.9 & 589 & 334.4 & 321 & 182.3 & 287 & 163.0 & 1233 & 700.1 & 24 \\
\hline 258.9 & 589 & 334.4 & 321 & 182.3 & 287 & 163.0 & 1233 & 700.1 & 24 \\
\hline 258.9 & 589 & 334.4 & 321 & 182.3 & 287 & 163.0 & 1233 & 700.1 & 24 \\
\hline 259.2 & 589 & 334.8 & 321 & 182.4 & 287 & 163.1 & 1233 & 700.8 & 24 \\
\hline 259.2 & 589 & 334.8 & 321 & 182.4 & 287 & 163.1 & 1233 & 700.8 & 24 \\
\hline 259.2 & 589 & 334.8 & 321 & 182.4 & 287 & 163.1 & 1233 & 700.8 & 24 \\
\hline 328.8 & 620 & 323.6 & 541 & 282.4 & 271 & 141.5 & 1647 & 859.7 & 39 \\
\hline 328.8 & 620 & 323.6 & 541 & 282.4 & 271 & 141.5 & 1647 & 859.7 & 39 \\
\hline 143.0 & 412 & 126.7 & 254 & 78.1 & 218 & 67.0 & 1024 & 314.8 & 10 \\
\hline 143.0 & 412 & 126.7 & 254 & 78.1 & 218 & 67.0 & 1024 & 314.8 & 10 \\
\hline 143.0 & 412 & 126.7 & 254 & 78.1 & 218 & 67.0 & 1024 & 314.8 & 10 \\
\hline 143.0 & 412 & 126.7 & 254 & 78.1 & 218 & 67.0 & 1024 & 314.8 & 10 \\
\hline 143.0 & 412 & 126.7 & 254 & 78.1 & 218 & 67.0 & 1024 & 314.8 & 10 \\
\hline 143.0 & 412 & 126.7 & 254 & 78.1 & 218 & 67.0 & 1024 & 314.8 & 10 \\
\hline 143.0 & 412 & 126.7 & 254 & 78.1 & 218 & 67.0 & 1024 & 314.8 & 10 \\
\hline 143.0 & 412 & 126.7 & 254 & 78.1 & 218 & 67.0 & 1024 & 314.8 & 10 \\
\hline
\end{tabular}




\begin{tabular}{|c|c|c|c|c|c|c|c|c|c|}
\hline 143.0 & 412 & 126.7 & 254 & 78.1 & 218 & 67.0 & 1024 & 314.8 & 10 \\
\hline 30.4 & 970 & 48.5 & 960 & 48.0 & 477 & 23.9 & 2312 & 115.6 & 34 \\
\hline 853.2 & 2338 & 965.5 & 1202 & 496.4 & 1572 & 649.2 & 4922 & 2032.5 & 154 \\
\hline 853.2 & 2338 & 965.5 & 1202 & 496.4 & 1572 & 649.2 & 4922 & 2032.5 & 154 \\
\hline 853.2 & 2338 & 965.5 & 1202 & 496.4 & 1572 & 649.2 & 4922 & 2032.5 & 154 \\
\hline 53.6 & 1131 & 56.6 & 806 & 40.3 & 884 & 44.2 & 2711 & 135.6 & 74 \\
\hline 53.6 & 1131 & 56.6 & 806 & 40.3 & 884 & 44.2 & 2711 & 135.6 & 74 \\
\hline 853.2 & 2338 & 965.5 & 1202 & 496.4 & 1572 & 649.2 & 4922 & 2032.5 & 154 \\
\hline 30.4 & 970 & 48.5 & 960 & 48.0 & 477 & 23.9 & 2312 & 115.6 & 34 \\
\hline 79.0 & 561 & 107.5 & 375 & 71.9 & 251 & 48.1 & 1244 & 238.5 & 17 \\
\hline 79.0 & 561 & 107.5 & 375 & 71.9 & 251 & 48.1 & 1244 & 238.5 & 17 \\
\hline 79.0 & 561 & 107.5 & 375 & 71.9 & 251 & 48.1 & 1244 & 238.5 & 17 \\
\hline 79.0 & 561 & 107.5 & 375 & 71.9 & 251 & 48.1 & 1244 & 238.5 & 17 \\
\hline 79.0 & 561 & 107.5 & 375 & 71.9 & 251 & 48.1 & 1244 & 238.5 & 17 \\
\hline 79.0 & 561 & 107.5 & 375 & 71.9 & 251 & 48.1 & 1244 & 238.5 & 17 \\
\hline 79.0 & 561 & 107.5 & 375 & 71.9 & 251 & 48.1 & 1244 & 238.5 & 17 \\
\hline 79.0 & 561 & 107.5 & 375 & 71.9 & 251 & 48.1 & 1244 & 238.5 & 17 \\
\hline 79.0 & 561 & 107.5 & 375 & 71.9 & 251 & 48.1 & 1244 & 238.5 & 17 \\
\hline 79.0 & 561 & 107.5 & 375 & 71.9 & 251 & 48.1 & 1244 & 238.5 & 17 \\
\hline 79.0 & 561 & 107.5 & 375 & 71.9 & 251 & 48.1 & 1244 & 238.5 & 17 \\
\hline
\end{tabular}




\begin{tabular}{|c|c|c|c|c|c|c|c|c|c|}
\hline 79.0 & 561 & 107.5 & 375 & 71.9 & 251 & 48.1 & 1244 & 238.5 & 17 \\
\hline 79.0 & 561 & 107.5 & 375 & 71.9 & 251 & 48.1 & 1244 & 238.5 & 17 \\
\hline 79.0 & 561 & 107.5 & 375 & 71.9 & 251 & 48.1 & 1244 & 238.5 & 17 \\
\hline 79.0 & 561 & 107.5 & 375 & 71.9 & 251 & 48.1 & 1244 & 238.5 & 17 \\
\hline 259.2 & 589 & 334.8 & 321 & 182.4 & 287 & 163.1 & 1233 & 700.8 & 24 \\
\hline 259.2 & 589 & 334.8 & 321 & 182.4 & 287 & 163.1 & 1233 & 700.8 & 24 \\
\hline 11.1 & 292 & 14.6 & 337 & 16.9 & 169 & 8.5 & 783 & 39.2 & 12 \\
\hline 11.1 & 292 & 14.6 & 337 & 16.9 & 169 & 8.5 & 783 & 39.2 & 12 \\
\hline 11.1 & 292 & 14.6 & 337 & 16.9 & 169 & 8.5 & 783 & 39.2 & 12 \\
\hline 11.1 & 292 & 14.6 & 337 & 16.9 & 169 & 8.5 & 783 & 39.2 & 12 \\
\hline 11.1 & 292 & 14.6 & 337 & 16.9 & 169 & 8.5 & 783 & 39.2 & 12 \\
\hline 11.1 & 292 & 14.6 & 337 & 16.9 & 169 & 8.5 & 783 & 39.2 & 12 \\
\hline 11.1 & 292 & 14.6 & 337 & 16.9 & 169 & 8.5 & 783 & 39.2 & 12 \\
\hline 328.2 & 959 & 462.8 & 1356 & 654.4 & 549 & 265.0 & 2733 & 1319.0 & 38 \\
\hline 240.7 & 290 & 41.2 & 194 & 27.5 & 294 & 41.7 & 1888 & 268.0 & 27 \\
\hline 240.7 & 290 & 41.2 & 194 & 27.5 & 294 & 41.7 & 1888 & 268.0 & 27 \\
\hline 84.5 & 688 & 80.7 & 386 & 45.3 & 444 & 52.1 & 1591 & 186.7 & 31 \\
\hline 186.2 & 468 & 206.5 & 586 & 258.6 & 349 & 154.0 & 1300 & 573.6 & 36 \\
\hline 186.2 & 468 & 206.5 & 586 & 258.6 & 349 & 154.0 & 1300 & 573.6 & 36 \\
\hline 1593.4 & 629 & 1204.6 & 612 & 1172.1 & 626 & 1198.9 & 1092 & 2091.4 & 36 \\
\hline
\end{tabular}




\begin{tabular}{|c|c|c|c|c|c|c|c|c|c|}
\hline 244.0 & 1673 & 484.7 & 1271 & 368.3 & 1530 & 443.3 & 3020 & 875.0 & 138 \\
\hline 244.0 & 1673 & 484.7 & 1271 & 368.3 & 1530 & 443.3 & 3020 & 875.0 & 138 \\
\hline 1124.8 & 504 & 943.3 & 578 & 1081.8 & 729 & 1364.4 & 1426 & 2668.8 & 72 \\
\hline 56.2 & 372 & 79.5 & 225 & 48.1 & 316 & 67.5 & 794 & 169.7 & 13 \\
\hline 56.2 & 372 & 79.5 & 225 & 48.1 & 316 & 67.5 & 794 & 169.7 & 13 \\
\hline 56.2 & 372 & 79.5 & 225 & 48.1 & 316 & 67.5 & 794 & 169.7 & 13 \\
\hline 10.4 & 430 & 21.5 & 199 & 10.0 & 288 & 14.4 & 741 & 37.1 & 15 \\
\hline 90.7 & 1902 & 183.9 & 2063 & 199.4 & 1042 & 100.7 & 4381 & 423.5 & 71 \\
\hline 472.1 & 1638 & 853.6 & 2413 & 1257.4 & 874 & 455.4 & 4488 & 2338.7 & 104 \\
\hline 4574.4 & 3432 & 5483.6 & 2682 & 4285.2 & 2377 & 3797.9 & 8022 & 12817.4 & 203 \\
\hline 1329.2 & 1601 & 1802.0 & 1693 & 1905.5 & 850 & 956.7 & 4008 & 4511.1 & 82 \\
\hline 4574.4 & 3432 & 5483.6 & 2682 & 4285.2 & 2377 & 3797.9 & 8022 & 12817.4 & 203 \\
\hline 4574.4 & 3432 & 5483.6 & 2682 & 4285.2 & 2377 & 3797.9 & 8022 & 12817.4 & 203 \\
\hline 472.1 & 1638 & 853.6 & 2413 & 1257.4 & 874 & 455.4 & 4488 & 2338.7 & 104 \\
\hline 225.9 & 132 & 244.4 & 226 & 418.4 & 73 & 135.2 & 442 & 818.4 & 5 \\
\hline 10.4 & 430 & 21.5 & 199 & 10.0 & 288 & 14.4 & 741 & 37.1 & 15 \\
\hline 56.2 & 372 & 79.5 & 225 & 48.1 & 316 & 67.5 & 794 & 169.7 & 13 \\
\hline 56.2 & 372 & 79.5 & 225 & 48.1 & 316 & 67.5 & 794 & 169.7 & 13 \\
\hline 56.2 & 372 & 79.5 & 225 & 48.1 & 316 & 67.5 & 794 & 169.7 & 13 \\
\hline 2.4 & 52 & 2.6 & 30 & 1.5 & 27 & 1.4 & 120 & 6.0 & 2 \\
\hline
\end{tabular}




\begin{tabular}{|c|c|c|c|c|c|c|c|c|c|}
\hline 73.3 & 178 & 343.3 & 1603 & 3092.0 & 394 & 760.0 & 1553 & 2995.6 & 60 \\
\hline 136.8 & 221 & 109.5 & 100 & 49.6 & 103 & 51.0 & 529 & 262.1 & 10 \\
\hline 175.9 & 137 & 147.8 & 73 & 78.8 & 61 & 65.8 & 327 & 352.8 & 2 \\
\hline 175.9 & 137 & 147.8 & 73 & 78.8 & 61 & 65.8 & 327 & 352.8 & 2 \\
\hline 173.2 & 328 & 211.9 & 217 & 140.2 & 142 & 91.8 & 729 & 471.0 & 8 \\
\hline 173.2 & 328 & 211.9 & 217 & 140.2 & 142 & 91.8 & 729 & 471.0 & 8 \\
\hline 173.2 & 328 & 211.9 & 217 & 140.2 & 142 & 91.8 & 729 & 471.0 & 8 \\
\hline 18.5 & 172 & 17.8 & 103 & 10.7 & 69 & 7.1 & 423 & 43.8 & 4 \\
\hline 18.5 & 172 & 17.8 & 103 & 10.7 & 69 & 7.1 & 423 & 43.8 & 4 \\
\hline 18.5 & 172 & 17.8 & 103 & 10.7 & 69 & 7.1 & 423 & 43.8 & 4 \\
\hline 175.9 & 137 & 147.8 & 73 & 78.8 & 61 & 65.8 & 327 & 352.8 & 2 \\
\hline 175.9 & 137 & 147.8 & 73 & 78.8 & 61 & 65.8 & 327 & 352.8 & 2 \\
\hline 175.9 & 137 & 147.8 & 73 & 78.8 & 61 & 65.8 & 327 & 352.8 & 2 \\
\hline 175.9 & 137 & 147.8 & 73 & 78.8 & 61 & 65.8 & 327 & 352.8 & 2 \\
\hline 175.9 & 137 & 147.8 & 73 & 78.8 & 61 & 65.8 & 327 & 352.8 & 2 \\
\hline 136.8 & 221 & 109.5 & 100 & 49.6 & 103 & 51.0 & 529 & 262.1 & 10 \\
\hline 2.4 & 52 & 2.6 & 30 & 1.5 & 27 & 1.4 & 120 & 6.0 & 2 \\
\hline 15.3 & 422 & 21.1 & 200 & 10.0 & 254 & 12.7 & 816 & 40.8 & 25 \\
\hline 50.6 & 182 & 45.1 & 67 & 16.6 & 83 & 20.6 & 411 & 101.9 & 7 \\
\hline 50.6 & 182 & 45.1 & 67 & 16.6 & 83 & 20.6 & 411 & 101.9 & 7 \\
\hline
\end{tabular}




\begin{tabular}{|c|c|c|c|c|c|c|c|c|c|}
\hline 50.6 & 182 & 45.1 & 67 & 16.6 & 83 & 20.6 & 411 & 101.9 & 7 \\
\hline 50.6 & 182 & 45.1 & 67 & 16.6 & 83 & 20.6 & 411 & 101.9 & 7 \\
\hline 6.9 & 45 & 6.8 & 30 & 4.5 & 38 & 5.7 & 107 & 16.1 & 5 \\
\hline 6.9 & 45 & 6.8 & 30 & 4.5 & 38 & 5.7 & 107 & 16.1 & 5 \\
\hline 6.9 & 45 & 6.8 & 30 & 4.5 & 38 & 5.7 & 107 & 16.1 & 5 \\
\hline 128.0 & 660 & 126.7 & 281 & 53.9 & 369 & 70.8 & 1461 & 280.4 & 26 \\
\hline 128.0 & 660 & 126.7 & 281 & 53.9 & 369 & 70.8 & 1461 & 280.4 & 26 \\
\hline 128.0 & 660 & 126.7 & 281 & 53.9 & 369 & 70.8 & 1461 & 280.4 & 26 \\
\hline 128.0 & 660 & 126.7 & 281 & 53.9 & 369 & 70.8 & 1461 & 280.4 & 26 \\
\hline 128.0 & 660 & 126.7 & 281 & 53.9 & 369 & 70.8 & 1461 & 280.4 & 26 \\
\hline 128.0 & 660 & 126.7 & 281 & 53.9 & 369 & 70.8 & 1461 & 280.4 & 26 \\
\hline 128.0 & 660 & 126.7 & 281 & 53.9 & 369 & 70.8 & 1461 & 280.4 & 26 \\
\hline 128.0 & 660 & 126.7 & 281 & 53.9 & 369 & 70.8 & 1461 & 280.4 & 26 \\
\hline 128.0 & 660 & 126.7 & 281 & 53.9 & 369 & 70.8 & 1461 & 280.4 & 26 \\
\hline 15.3 & 422 & 21.1 & 200 & 10.0 & 254 & 12.7 & 816 & 40.8 & 25 \\
\hline 15.3 & 422 & 21.1 & 200 & 10.0 & 254 & 12.7 & 816 & 40.8 & 25 \\
\hline 128.0 & 660 & 126.7 & 281 & 53.9 & 369 & 70.8 & 1461 & 280.4 & 26 \\
\hline 128.0 & 660 & 126.7 & 281 & 53.9 & 369 & 70.8 & 1461 & 280.4 & 26 \\
\hline 128.0 & 660 & 126.7 & 281 & 53.9 & 369 & 70.8 & 1461 & 280.4 & 26 \\
\hline 128.0 & 660 & 126.7 & 281 & 53.9 & 369 & 70.8 & 1461 & 280.4 & 26 \\
\hline
\end{tabular}




\begin{tabular}{|c|c|c|c|c|c|c|c|c|c|}
\hline 128.0 & 660 & 126.7 & 281 & 53.9 & 369 & 70.8 & 1461 & 280.4 & 26 \\
\hline 128.0 & 660 & 126.7 & 281 & 53.9 & 369 & 70.8 & 1461 & 280.4 & 26 \\
\hline 128.0 & 660 & 126.7 & 281 & 53.9 & 369 & 70.8 & 1461 & 280.4 & 26 \\
\hline 128.0 & 660 & 126.7 & 281 & 53.9 & 369 & 70.8 & 1461 & 280.4 & 26 \\
\hline 128.0 & 660 & 126.7 & 281 & 53.9 & 369 & 70.8 & 1461 & 280.4 & 26 \\
\hline 6.9 & 45 & 6.8 & 30 & 4.5 & 38 & 5.7 & 107 & 16.1 & 5 \\
\hline 6.9 & 45 & 6.8 & 30 & 4.5 & 38 & 5.7 & 107 & 16.1 & 5 \\
\hline 6.9 & 45 & 6.8 & 30 & 4.5 & 38 & 5.7 & 107 & 16.1 & 5 \\
\hline 50.6 & 182 & 45.1 & 67 & 16.6 & 83 & 20.6 & 411 & 101.9 & 7 \\
\hline 50.6 & 182 & 45.1 & 67 & 16.6 & 83 & 20.6 & 411 & 101.9 & 7 \\
\hline 50.6 & 182 & 45.1 & 67 & 16.6 & 83 & 20.6 & 411 & 101.9 & 7 \\
\hline 50.6 & 182 & 45.1 & 67 & 16.6 & 83 & 20.6 & 411 & 101.9 & 7 \\
\hline 77.2 & 270 & 85.1 & 156 & 49.2 & 133 & 41.9 & 610 & 192.2 & 7 \\
\hline
\end{tabular}




\begin{tabular}{|c|c|c|c|c|c|c|c|c|c|}
\hline & & & & & & & & & Spa \\
\hline \multicolumn{9}{|c|}{ Worker Race/Ethnicity } & $\begin{array}{c}\text { Weekday } \\
\text { Span of } \\
\text { Service } \\
\text { [hours] } \\
\end{array}$ \\
\hline $\begin{array}{c}\text { Work } \\
\text { Black } \\
\text { Density }\end{array}$ & $\begin{array}{l}\text { Work } \\
\text { AIAN }\end{array}$ & $\begin{array}{c}\text { Work AIAN } \\
\text { Density }\end{array}$ & $\begin{array}{l}\text { Work } \\
\text { Asian }\end{array}$ & $\begin{array}{c}\text { Work Asian } \\
\text { Density }\end{array}$ & $\begin{array}{l}\text { Work } \\
\text { NHPI }\end{array}$ & $\begin{array}{c}\text { Work NHPI } \\
\text { Density }\end{array}$ & $\begin{array}{l}\text { Two or } \\
\text { More } \\
\text { Races }\end{array}$ & $\begin{array}{l}\text { Work Two or } \\
\text { More Races } \\
\text { Density }\end{array}$ & $\begin{array}{l}\text { Span of } \\
\text { Service }\end{array}$ \\
\hline 324.3 & 108 & 172.6 & 431 & 688.6 & 23 & 36.7 & 190 & 303.6 & 15.68 \\
\hline 8.9 & 16 & 3.9 & 119 & 28.8 & 5 & 1.2 & 34 & 8.2 & 14.72 \\
\hline 3.8 & 19 & 2.7 & 160 & 22.7 & 7 & 1.0 & 79 & 11.2 & 13.87 \\
\hline 3.8 & 19 & 2.7 & 160 & 22.7 & 7 & 1.0 & 79 & 11.2 & 13.87 \\
\hline 3.8 & 19 & 2.7 & 160 & 22.7 & 7 & 1.0 & 79 & 11.2 & 14.02 \\
\hline 14.8 & 43 & 7.5 & 204 & 35.4 & 8 & 1.4 & 110 & 19.1 & 15.92 \\
\hline 20.4 & 17 & 8.9 & 56 & 29.2 & 3 & 1.6 & 29 & 15.1 & 15.52 \\
\hline 1.7 & 29 & 1.5 & 116 & 5.8 & 3 & 0.2 & 44 & 2.2 & 15.98 \\
\hline 1.7 & 29 & 1.5 & 116 & 5.8 & 3 & 0.2 & 44 & 2.2 & 15.3 \\
\hline 63.6 & 81 & 33.4 & 297 & 122.6 & 15 & 6.2 & 137 & 56.6 & 16.35 \\
\hline 2.8 & 24 & 1.4 & 91 & 5.5 & 2 & 0.1 & 40 & 2.4 & 11 \\
\hline 18.4 & 33 & 15.9 & 127 & 61.3 & 3 & 1.4 & 61 & 29.5 & 4.28 \\
\hline 0.6 & 12 & 0.6 & 14 & 0.7 & 2 & 0.1 & 28 & 1.4 & 14.18 \\
\hline 0.6 & 12 & 0.6 & 14 & 0.7 & 2 & 0.1 & 28 & 1.4 & 14.18 \\
\hline 0.6 & 12 & 0.6 & 14 & 0.7 & 2 & 0.1 & 28 & 1.4 & 14.2 \\
\hline 0.6 & 12 & 0.6 & 14 & 0.7 & 2 & 0.1 & 28 & 1.4 & 14.2 \\
\hline
\end{tabular}




\begin{tabular}{|c|c|c|c|c|c|c|c|c|c|}
\hline 0.6 & 12 & 0.6 & 14 & 0.7 & 2 & 0.1 & 28 & 1.4 & 14.22 \\
\hline 0.6 & 12 & 0.6 & 14 & 0.7 & 2 & 0.1 & 28 & 1.4 & 14.23 \\
\hline 0.6 & 12 & 0.6 & 14 & 0.7 & 2 & 0.1 & 28 & 1.4 & 14.25 \\
\hline 13.6 & 14 & 7.9 & 68 & 38.6 & 3 & 1.7 & 24 & 13.6 & 14.23 \\
\hline 13.6 & 14 & 7.9 & 68 & 38.6 & 3 & 1.7 & 24 & 13.6 & 14.17 \\
\hline 13.6 & 14 & 7.9 & 68 & 38.6 & 3 & 1.7 & 24 & 13.6 & 14.17 \\
\hline 13.6 & 14 & 7.9 & 68 & 38.6 & 3 & 1.7 & 24 & 13.6 & 14.17 \\
\hline 13.6 & 14 & 8.0 & 68 & 38.6 & 3 & 1.7 & 24 & 13.6 & 14.17 \\
\hline 13.6 & 14 & 8.0 & 68 & 38.6 & 3 & 1.7 & 24 & 13.6 & 14.17 \\
\hline 13.6 & 14 & 8.0 & 68 & 38.6 & 3 & 1.7 & 24 & 13.6 & 14.17 \\
\hline 20.4 & 17 & 8.9 & 56 & 29.2 & 3 & 1.6 & 29 & 15.1 & 14.17 \\
\hline 20.4 & 17 & 8.9 & 56 & 29.2 & 3 & 1.6 & 29 & 15.1 & 14.17 \\
\hline 3.1 & 22 & 6.8 & 50 & 15.4 & 2 & 0.6 & 23 & 7.1 & 14.18 \\
\hline 3.1 & 22 & 6.8 & 50 & 15.4 & 2 & 0.6 & 23 & 7.1 & 14.18 \\
\hline 3.1 & 22 & 6.8 & 50 & 15.4 & 2 & 0.6 & 23 & 7.1 & 14.18 \\
\hline 3.1 & 22 & 6.8 & 50 & 15.4 & 2 & 0.6 & 23 & 7.1 & 14.18 \\
\hline 3.1 & 22 & 6.8 & 50 & 15.4 & 2 & 0.6 & 23 & 7.1 & 14.18 \\
\hline 3.1 & 22 & 6.8 & 50 & 15.4 & 2 & 0.6 & 23 & 7.1 & 14.18 \\
\hline 3.1 & 22 & 6.8 & 50 & 15.4 & 2 & 0.6 & 23 & 7.1 & 14.18 \\
\hline 3.1 & 22 & 6.8 & 50 & 15.4 & 2 & 0.6 & 23 & 7.1 & 14.18 \\
\hline
\end{tabular}




\begin{tabular}{|c|c|c|c|c|c|c|c|c|c|}
\hline 3.1 & 22 & 6.8 & 50 & 15.4 & 2 & 0.6 & 23 & 7.1 & 14.18 \\
\hline 1.7 & 29 & 1.5 & 116 & 5.8 & 3 & 0.2 & 44 & 2.2 & 14.18 \\
\hline 63.6 & 81 & 33.4 & 297 & 122.6 & 15 & 6.2 & 137 & 56.6 & 14.18 \\
\hline 63.6 & 81 & 33.4 & 297 & 122.6 & 15 & 6.2 & 137 & 56.6 & 14.27 \\
\hline 63.6 & 81 & 33.4 & 297 & 122.6 & 15 & 6.2 & 137 & 56.6 & 14.27 \\
\hline 3.7 & 42 & 2.1 & 115 & 5.8 & 5 & 0.3 & 61 & 3.1 & 6.45 \\
\hline 3.7 & 42 & 2.1 & 115 & 5.8 & 5 & 0.3 & 61 & 3.1 & 5.58 \\
\hline 63.6 & 81 & 33.4 & 297 & 122.6 & 15 & 6.2 & 137 & 56.6 & 13.15 \\
\hline 1.7 & 29 & 1.5 & 116 & 5.8 & 3 & 0.2 & 44 & 2.2 & 13.15 \\
\hline 3.3 & 14 & 2.7 & 43 & 8.2 & 1 & 0.2 & 29 & 5.6 & 13.15 \\
\hline 3.3 & 14 & 2.7 & 43 & 8.2 & 1 & 0.2 & 29 & 5.6 & 13.15 \\
\hline 3.3 & 14 & 2.7 & 43 & 8.2 & 1 & 0.2 & 29 & 5.6 & 13.15 \\
\hline 3.3 & 14 & 2.7 & 43 & 8.2 & 1 & 0.2 & 29 & 5.6 & 13.15 \\
\hline 3.3 & 14 & 2.7 & 43 & 8.2 & 1 & 0.2 & 29 & 5.6 & 13.15 \\
\hline 3.3 & 14 & 2.7 & 43 & 8.2 & 1 & 0.2 & 29 & 5.6 & 13.15 \\
\hline 3.3 & 14 & 2.7 & 43 & 8.2 & 1 & 0.2 & 29 & 5.6 & 13.15 \\
\hline 3.3 & 14 & 2.7 & 43 & 8.2 & 1 & 0.2 & 29 & 5.6 & 13.15 \\
\hline 3.3 & 14 & 2.7 & 43 & 8.2 & 1 & 0.2 & 29 & 5.6 & 13.15 \\
\hline 3.3 & 14 & 2.7 & 43 & 8.2 & 1 & 0.2 & 29 & 5.6 & 13.15 \\
\hline 3.3 & 14 & 2.7 & 43 & 8.2 & 1 & 0.2 & 29 & 5.6 & 13.15 \\
\hline
\end{tabular}




\begin{tabular}{|c|c|c|c|c|c|c|c|c|c|}
\hline 3.3 & 14 & 2.7 & 43 & 8.2 & 1 & 0.2 & 29 & 5.6 & 13.15 \\
\hline 3.3 & 14 & 2.7 & 43 & 8.2 & 1 & 0.2 & 29 & 5.6 & 13.15 \\
\hline 3.3 & 14 & 2.7 & 43 & 8.2 & 1 & 0.2 & 29 & 5.6 & 13.15 \\
\hline 3.3 & 14 & 2.7 & 43 & 8.2 & 1 & 0.2 & 29 & 5.6 & 13.15 \\
\hline 13.6 & 14 & 8.0 & 68 & 38.6 & 3 & 1.7 & 24 & 13.6 & 13.15 \\
\hline 13.6 & 14 & 8.0 & 68 & 38.6 & 3 & 1.7 & 24 & 13.6 & 13.15 \\
\hline 0.6 & 12 & 0.6 & 14 & 0.7 & 2 & 0.1 & 28 & 1.4 & 13.15 \\
\hline 0.6 & 12 & 0.6 & 14 & 0.7 & 2 & 0.1 & 28 & 1.4 & 13.15 \\
\hline 0.6 & 12 & 0.6 & 14 & 0.7 & 2 & 0.1 & 28 & 1.4 & 13.15 \\
\hline 0.6 & 12 & 0.6 & 14 & 0.7 & 2 & 0.1 & 28 & 1.4 & 13.15 \\
\hline 0.6 & 12 & 0.6 & 14 & 0.7 & 2 & 0.1 & 28 & 1.4 & 13.15 \\
\hline 0.6 & 12 & 0.6 & 14 & 0.7 & 2 & 0.1 & 28 & 1.4 & 13.15 \\
\hline 0.6 & 12 & 0.6 & 14 & 0.7 & 2 & 0.1 & 28 & 1.4 & 13.15 \\
\hline 18.3 & 33 & 15.9 & 127 & 61.3 & 3 & 1.4 & 61 & 29.4 & 13.23 \\
\hline 3.8 & 19 & 2.7 & 160 & 22.7 & 7 & 1.0 & 79 & 11.2 & 2.02 \\
\hline 3.8 & 19 & 2.7 & 160 & 22.7 & 7 & 1.0 & 79 & 11.2 & 2.03 \\
\hline 3.6 & 19 & 2.2 & 98 & 11.5 & 6 & 0.7 & 49 & 5.7 & 14.67 \\
\hline 15.9 & 17 & 7.5 & 87 & 38.4 & 7 & 3.1 & 29 & 12.8 & 14.85 \\
\hline 15.9 & 17 & 7.5 & 87 & 38.4 & 7 & 3.1 & 29 & 12.8 & 14.85 \\
\hline 68.9 & 26 & 49.8 & 67 & 128.3 & 7 & 13.4 & 35 & 67.0 & 15.22 \\
\hline
\end{tabular}




\begin{tabular}{|c|c|c|c|c|c|c|c|c|c|}
\hline 40.0 & 68 & 19.7 & 436 & 126.3 & 23 & 6.7 & 101 & 29.3 & 15.23 \\
\hline 40.0 & 68 & 19.7 & 436 & 126.3 & 23 & 6.7 & 101 & 29.3 & 15.23 \\
\hline 134.8 & 33 & 61.8 & 103 & 192.8 & 6 & 11.2 & 43 & 80.5 & 15.97 \\
\hline 2.8 & 11 & 2.4 & 26 & 5.6 & 3 & 0.6 & 13 & 2.8 & 13.58 \\
\hline 2.8 & 11 & 2.4 & 26 & 5.6 & 3 & 0.6 & 13 & 2.8 & 13.22 \\
\hline 2.8 & 11 & 2.4 & 26 & 5.6 & 3 & 0.6 & 13 & 2.8 & 13.6 \\
\hline 0.8 & 15 & 0.8 & 45 & 2.3 & 3 & 0.2 & 18 & 0.9 & 13 \\
\hline 6.9 & 46 & 4.4 & 299 & 28.9 & 9 & 0.9 & 97 & 9.4 & 13 \\
\hline 54.2 & 53 & 27.6 & 201 & 104.7 & 11 & 5.7 & 100 & 52.1 & 13 \\
\hline 324.3 & 108 & 172.6 & 431 & 688.6 & 23 & 36.7 & 190 & 303.6 & 13 \\
\hline 92.3 & 41 & 46.1 & 232 & 261.1 & 8 & 9.0 & 104 & 117.1 & 13 \\
\hline 324.3 & 108 & 172.6 & 431 & 688.6 & 23 & 36.7 & 190 & 303.6 & 14 \\
\hline 324.3 & 108 & 172.6 & 431 & 688.6 & 23 & 36.7 & 190 & 303.6 & 14 \\
\hline 54.2 & 53 & 27.6 & 201 & 104.7 & 11 & 5.7 & 100 & 52.1 & 14 \\
\hline 9.3 & 7 & 13.0 & 12 & 22.2 & 0 & 0.0 & 14 & 25.9 & 14 \\
\hline 0.8 & 15 & 0.8 & 45 & 2.3 & 3 & 0.2 & 18 & 0.9 & 14.03 \\
\hline 2.8 & 11 & 2.4 & 26 & 5.6 & 3 & 0.6 & 13 & 2.8 & 14 \\
\hline 2.8 & 11 & 2.4 & 26 & 5.6 & 3 & 0.6 & 13 & 2.8 & 14 \\
\hline 2.8 & 11 & 2.4 & 26 & 5.6 & 3 & 0.6 & 13 & 2.8 & 14 \\
\hline 0.1 & 2 & 0.1 & 4 & 0.2 & 0 & 0.0 & 1 & 0.1 & 15.05 \\
\hline
\end{tabular}




\begin{tabular}{|c|c|c|c|c|c|c|c|c|c|}
\hline 115.7 & 47 & 90.7 & 104 & 200.6 & 5 & 9.6 & 50 & 96.4 & 14 \\
\hline 5.0 & 6 & 3.0 & 29 & 14.4 & 2 & 1.0 & 21 & 10.4 & 13.75 \\
\hline 2.2 & 6 & 6.5 & 27 & 29.1 & 0 & 0.0 & 11 & 11.9 & 14.75 \\
\hline 2.2 & 6 & 6.5 & 27 & 29.1 & 0 & 0.0 & 11 & 11.9 & 14.75 \\
\hline 5.2 & 6 & 3.9 & 51 & 33.0 & 1 & 0.6 & 18 & 11.6 & 14.75 \\
\hline 5.2 & 6 & 3.9 & 51 & 33.0 & 1 & 0.6 & 18 & 11.6 & 14.75 \\
\hline 5.2 & 6 & 3.9 & 51 & 33.0 & 1 & 0.6 & 18 & 11.6 & 14.75 \\
\hline 0.4 & 3 & 0.3 & 14 & 1.5 & 2 & 0.2 & 8 & 0.8 & 14.76 \\
\hline 0.4 & 3 & 0.3 & 14 & 1.5 & 2 & 0.2 & 8 & 0.8 & 14.76 \\
\hline 0.4 & 3 & 0.3 & 14 & 1.5 & 2 & 0.2 & 8 & 0.8 & 14.75 \\
\hline 2.2 & 6 & 6.5 & 27 & 29.1 & 0 & 0.0 & 11 & 11.9 & 14.73 \\
\hline 2.2 & 6 & 6.5 & 27 & 29.1 & 0 & 0.0 & 11 & 11.9 & 14.73 \\
\hline 2.2 & 6 & 6.5 & 27 & 29.1 & 0 & 0.0 & 11 & 11.9 & 14.75 \\
\hline 2.2 & 6 & 6.5 & 27 & 29.1 & 0 & 0.0 & 11 & 11.9 & 14.75 \\
\hline 2.2 & 6 & 6.5 & 27 & 29.1 & 0 & 0.0 & 11 & 11.9 & 14.75 \\
\hline 5.0 & 6 & 3.0 & 29 & 14.4 & 2 & 1.0 & 21 & 10.4 & 14.72 \\
\hline 0.1 & 2 & 0.1 & 4 & 0.2 & 0 & 0.0 & 1 & 0.1 & 14.63 \\
\hline 1.3 & 13 & 0.7 & 48 & 2.4 & 4 & 0.2 & 22 & 1.1 & 9.1 \\
\hline 1.7 & 4 & 1.0 & 18 & 4.5 & 0 & 0.0 & 13 & 3.2 & 11 \\
\hline 1.7 & 4 & 1.0 & 18 & 4.5 & 0 & 0.0 & 13 & 3.2 & 11 \\
\hline
\end{tabular}




\begin{tabular}{|c|c|c|c|c|c|c|c|c|c|}
\hline 1.7 & 4 & 1.0 & 18 & 4.5 & 0 & 0.0 & 13 & 3.2 & 11 \\
\hline 1.7 & 4 & 1.0 & 18 & 4.5 & 0 & 0.0 & 13 & 3.2 & 11 \\
\hline 0.8 & 3 & 0.5 & 4 & 0.6 & 0 & 0.0 & 2 & 0.3 & 11 \\
\hline 0.8 & 3 & 0.5 & 4 & 0.6 & 0 & 0.0 & 2 & 0.3 & 11 \\
\hline 0.8 & 3 & 0.5 & 4 & 0.6 & 0 & 0.0 & 2 & 0.3 & 11 \\
\hline 5.0 & 28 & 5.4 & 55 & 10.6 & 6 & 1.2 & 32 & 6.1 & 11 \\
\hline 5.0 & 28 & 5.4 & 55 & 10.6 & 6 & 1.2 & 32 & 6.1 & 11 \\
\hline 5.0 & 28 & 5.4 & 55 & 10.6 & 6 & 1.2 & 32 & 6.1 & 11 \\
\hline 5.0 & 28 & 5.4 & 55 & 10.6 & 6 & 1.2 & 32 & 6.1 & 11 \\
\hline 5.0 & 28 & 5.4 & 55 & 10.6 & 6 & 1.2 & 32 & 6.1 & 11 \\
\hline 5.0 & 28 & 5.4 & 55 & 10.6 & 6 & 1.2 & 32 & 6.1 & 11 \\
\hline 5.0 & 28 & 5.4 & 55 & 10.6 & 6 & 1.2 & 32 & 6.1 & 11 \\
\hline 5.0 & 28 & 5.4 & 55 & 10.6 & 6 & 1.2 & 32 & 6.1 & 11 \\
\hline 5.0 & 28 & 5.4 & 55 & 10.6 & 6 & 1.2 & 32 & 6.1 & 11 \\
\hline 1.3 & 13 & 0.7 & 48 & 2.4 & 4 & 0.2 & 22 & 1.1 & 11 \\
\hline 1.3 & 13 & 0.7 & 48 & 2.4 & 4 & 0.2 & 22 & 1.1 & 11.03 \\
\hline 5.0 & 28 & 5.4 & 55 & 10.6 & 6 & 1.2 & 32 & 6.1 & 11.02 \\
\hline 5.0 & 28 & 5.4 & 55 & 10.6 & 6 & 1.2 & 32 & 6.1 & 11.02 \\
\hline 5.0 & 28 & 5.4 & 55 & 10.6 & 6 & 1.2 & 32 & 6.1 & 11.02 \\
\hline 5.0 & 28 & 5.4 & 55 & 10.6 & 6 & 1.2 & 32 & 6.1 & 11.02 \\
\hline
\end{tabular}




\begin{tabular}{|c|c|c|c|c|c|c|c|c|c|}
\hline 5.0 & 28 & 5.4 & 55 & 10.6 & 6 & 1.2 & 32 & 6.1 & 11 \\
\hline 5.0 & 28 & 5.4 & 55 & 10.6 & 6 & 1.2 & 32 & 6.1 & 11.02 \\
\hline 5.0 & 28 & 5.4 & 55 & 10.6 & 6 & 1.2 & 32 & 6.1 & 11 \\
\hline 5.0 & 28 & 5.4 & 55 & 10.6 & 6 & 1.2 & 32 & 6.1 & 11 \\
\hline 5.0 & 28 & 5.4 & 55 & 10.6 & 6 & 1.2 & 32 & 6.1 & 11 \\
\hline 0.8 & 3 & 0.5 & 4 & 0.6 & 0 & 0.0 & 2 & 0.3 & 11.03 \\
\hline 0.8 & 3 & 0.5 & 4 & 0.6 & 0 & 0.0 & 2 & 0.3 & 11.07 \\
\hline 0.8 & 3 & 0.5 & 4 & 0.6 & 0 & 0.0 & 2 & 0.3 & 11.12 \\
\hline 1.7 & 4 & 1.0 & 18 & 4.5 & 0 & 0.0 & 13 & 3.2 & 11 \\
\hline 1.7 & 4 & 1.0 & 18 & 4.5 & 0 & 0.0 & 13 & 3.2 & 11 \\
\hline 1.7 & 4 & 1.0 & 18 & 4.5 & 0 & 0.0 & 13 & 3.2 & 11 \\
\hline 1.7 & 4 & 1.0 & 18 & 4.5 & 0 & 0.0 & 13 & 3.2 & 11 \\
\hline 2.2 & 9 & 2.8 & 23 & 7.2 & 4 & 1.3 & 18 & 5.7 & 11 \\
\hline
\end{tabular}




\begin{tabular}{|c|c|c|c|c|c|c|c|}
\hline \multicolumn{4}{|c|}{ Routing and Scheduling } & & & & \\
\hline \multicolumn{2}{|c|}{ n and Frequency } & \multicolumn{2}{|c|}{ Stop Pairing } & \multirow{2}{*}{$\begin{array}{c}\text { ADA } \\
\begin{array}{c}\text { Mobility Device } \\
\text { Landing Pad (1 } \\
\text { = yes) }\end{array}\end{array}$} & \multicolumn{2}{|c|}{ Seating \& Shelter } & \\
\hline $\begin{array}{c}\text { \# of bus } \\
\text { trips per } \\
\text { day }\end{array}$ & $\begin{array}{l}\text { Avg. Weekday } \\
\text { Bus Frequency } \\
\text { [buses/hour] }\end{array}$ & $\begin{array}{c}\text { Bidirectional } ?(1= \\
\text { yes })\end{array}$ & $\begin{array}{l}\text { Part of a Stop } \\
\text { Pair? (1 = yes) }\end{array}$ & & Seating & $\begin{array}{l}\text { Shelter } \\
\text { [are }\end{array}$ & $\begin{array}{l}(1=\text { yes }) \\
\text { l=sqft }\end{array}$ \\
\hline $\begin{array}{c}\text { Trips Per } \\
\text { Day }\end{array}$ & Buses Per Hour & Bidirectional & Paired Stop & $\begin{array}{c}\text { ADA Landing } \\
\text { Pad }\end{array}$ & $\begin{array}{c}\text { \# of } \\
\text { benches }\end{array}$ & Shelter & Shelter Area \\
\hline 116 & 7.4 & 1 & 1 & 1 & 8 & 1 & 180 \\
\hline 43 & 2.9 & 1 & 1 & 1 & 3 & 1 & 272 \\
\hline 12 & 0.9 & 0 & 1 & 1 & 2 & 1 & 100 \\
\hline 12 & 0.9 & 0 & 1 & 1 & 4 & 1 & 60 \\
\hline 27 & 1.9 & 0 & 1 & 1 & 0 & 0 & 0 \\
\hline 27 & 1.7 & 0 & 1 & 1 & 0 & 0 & 0 \\
\hline 34 & 2.2 & 1 & 1 & 1 & 10 & 1 & 552 \\
\hline 34 & 2.1 & 1 & 1 & 1 & 2 & 1 & 52 \\
\hline 29 & 1.9 & 1 & 1 & 1 & 1 & 1 & 4200 \\
\hline 68 & 4.2 & 1 & 1 & 1 & 3 & 1 & 50 \\
\hline 23 & 2.1 & 1 & 1 & 1 & 1 & 1 & 55 \\
\hline 3 & 0.7 & 0 & 1 & 1 & 0 & 0 & 0 \\
\hline 15 & 1.1 & 0 & 1 & 0 & 0 & 0 & 0 \\
\hline 15 & 1.1 & 0 & 1 & 1 & 1 & 1 & 42 \\
\hline 15 & 1.1 & 0 & 1 & 0 & 0 & 0 & 0 \\
\hline 15 & 1.1 & 0 & 1 & 0 & 0 & 0 & 0 \\
\hline
\end{tabular}




\begin{tabular}{|c|c|c|c|c|c|c|c|}
\hline 15 & 1.1 & 0 & 1 & 1 & 1 & 1 & 54 \\
\hline 15 & 1.1 & 0 & 1 & 1 & 1 & 1 & 42.9 \\
\hline 15 & 1.1 & 0 & 1 & 1 & 0 & 0 & 0 \\
\hline 15 & 1.1 & 0 & 1 & 1 & 1 & 1 & 22.1 \\
\hline 15 & 1.1 & 0 & 1 & 1 & 1 & 1 & 32 \\
\hline 15 & 1.1 & 0 & 1 & 1 & 1 & 0 & 0 \\
\hline 15 & 1.1 & 0 & 1 & 1 & 1 & 0 & 0 \\
\hline 15 & 1.1 & 0 & 1 & 1 & 1 & 0 & 0 \\
\hline 15 & 1.1 & 0 & 1 & 1 & 1 & 1 & 38.7 \\
\hline 15 & 1.1 & 0 & 1 & 1 & 1 & 1 & 40.9 \\
\hline 15 & 1.1 & 0 & 1 & 1 & 1 & 0 & 0 \\
\hline 15 & 1.1 & 0 & 1 & 1 & 1 & 1 & 22.3 \\
\hline 15 & 1.1 & 0 & 1 & 1 & 1 & 1 & 28 \\
\hline 15 & 1.1 & 0 & 1 & 1 & 1 & 1 & 32 \\
\hline 15 & 1.1 & 0 & 1 & 1 & 1 & 0 & 0 \\
\hline 15 & 1.1 & 0 & 1 & 1 & 1 & 0 & 0 \\
\hline 15 & 1.1 & 0 & 1 & 1 & 1 & 0 & 0 \\
\hline 15 & 1.1 & 0 & 1 & 1 & 0 & 0 & 0 \\
\hline 15 & 1.1 & 0 & 1 & 0 & 1 & 0 & 0 \\
\hline 15 & 1.1 & 0 & 1 & 0 & 1 & 0 & 0 \\
\hline
\end{tabular}




\begin{tabular}{|c|c|c|c|c|c|c|c|}
\hline 15 & 1.1 & 0 & 0 & 0 & 1 & 0 & 0 \\
\hline 15 & 1.1 & 0 & 1 & 0 & 0 & 0 & 0 \\
\hline 15 & 1.1 & 0 & 1 & 0 & 0 & 0 & 0 \\
\hline 27 & 1.9 & 0 & 1 & 0 & 0 & 0 & 0 \\
\hline 27 & 1.9 & 0 & 1 & 1 & 1 & 1 & 50 \\
\hline 3 & 0.5 & 0 & 1 & 1 & 1 & 0 & 0 \\
\hline 2 & 0.4 & 0 & 1 & 1 & 1 & 0 & 0 \\
\hline 26 & 2.0 & 0 & 1 & 0 & 1 & 1 & 0 \\
\hline 14 & 1.1 & 0 & 1 & 0 & 1 & 1 & 165 \\
\hline 14 & 1.1 & 0 & 1 & 0 & 1 & 0 & 0 \\
\hline 14 & 1.1 & 0 & 1 & 1 & 1 & 1 & 50 \\
\hline 14 & 1.1 & 0 & 1 & 1 & 1 & 0 & 0 \\
\hline 14 & 1.1 & 0 & 1 & 1 & 1 & 0 & 0 \\
\hline 14 & 1.1 & 0 & 1 & 1 & 1 & 1 & 32 \\
\hline 14 & 1.1 & 0 & 1 & 1 & 1 & 0 & 0 \\
\hline 14 & 1.1 & 0 & 1 & 1 & 1 & 1 & 60 \\
\hline 14 & 1.1 & 0 & 1 & 1 & 1 & 1 & 40 \\
\hline 14 & 1.1 & 0 & 1 & 1 & 1 & 1 & 26.4 \\
\hline 14 & 1.1 & 0 & 1 & 1 & 1 & 0 & 0 \\
\hline 14 & 1.1 & 0 & 1 & 1 & 1 & 1 & 47.5 \\
\hline
\end{tabular}




\begin{tabular}{|c|c|c|c|c|c|c|c|}
\hline 14 & 1.1 & 0 & 1 & 1 & 1 & 0 & 0 \\
\hline 14 & 1.1 & 0 & 1 & 1 & 1 & 0 & 0 \\
\hline 14 & 1.1 & 0 & 1 & 1 & 1 & 0 & 0 \\
\hline 14 & 1.1 & 0 & 1 & 1 & 1 & 0 & 0 \\
\hline 14 & 1.1 & 0 & 1 & 0 & 0 & 0 & 0 \\
\hline 14 & 1.1 & 0 & 1 & 0 & 0 & 0 & 0 \\
\hline 14 & 1.1 & 0 & 1 & 1 & 1 & 1 & 48.6 \\
\hline 14 & 1.1 & 0 & 1 & 1 & 1 & 1 & 48.6 \\
\hline 14 & 1.1 & 0 & 1 & 1 & 0 & 0 & 0 \\
\hline 14 & 1.1 & 0 & 1 & 1 & 1 & 1 & 43.2 \\
\hline 14 & 1.1 & 0 & 1 & 0 & 0 & 0 & 0 \\
\hline 14 & 1.1 & 0 & 1 & 1 & 3 & 1 & 55.2 \\
\hline 14 & 1.1 & 0 & 1 & 1 & 1 & 0 & 0 \\
\hline 17 & 1.3 & 0 & 1 & 1 & 0 & 0 & 0 \\
\hline 5 & 2.5 & 0 & 1 & 1 & 2 & 1 & 40 \\
\hline 5 & 2.5 & 0 & 1 & 1 & 2 & 1 & 40.5 \\
\hline 33 & 2.2 & 1 & 1 & 1 & 3 & 1 & 57.5 \\
\hline 33 & 2.2 & 1 & 1 & 1 & 1 & 1 & 88 \\
\hline 33 & 2.2 & 1 & 1 & 1 & 2 & 1 & 62.5 \\
\hline 28 & 1.8 & 1 & 1 & 1 & 1 & 1 & 65 \\
\hline
\end{tabular}




\begin{tabular}{|c|c|c|c|c|c|c|c|}
\hline 29 & 1.9 & 1 & 1 & 0 & 1 & 0 & 0 \\
\hline 29 & 1.9 & 1 & 1 & 1 & 3 & 1 & 85 \\
\hline 31 & 1.9 & 1 & 1 & 1 & 3 & 0 & 150 \\
\hline 16 & 1.2 & 0 & 1 & 1 & 1 & 1 & 52.5 \\
\hline 14 & 1.1 & 0 & 1 & 1 & 1 & 1 & 51.8 \\
\hline 16 & 1.2 & 0 & 1 & 0 & 1 & 0 & 0 \\
\hline 14 & 1.1 & 0 & 1 & 0 & 0 & 0 & 0 \\
\hline 14 & 1.1 & 0 & 1 & 1 & 1 & 1 & 75 \\
\hline 14 & 1.1 & 0 & 1 & 1 & 1 & 1 & 42.5 \\
\hline 14 & 1.1 & 0 & 1 & 1 & 1 & 0 & 0 \\
\hline 14 & 1.1 & 0 & 1 & 1 & 1 & 0 & 0 \\
\hline 16 & 1.1 & 0 & 1 & 1 & 1 & 0 & 0 \\
\hline 14 & 1.0 & 0 & 1 & 1 & 1 & 0 & 0 \\
\hline 14 & 1.0 & 0 & 1 & 1 & 1 & 1 & 49 \\
\hline 14 & 1.0 & 0 & 1 & 1 & 1 & 1 & 35 \\
\hline 15 & 1.1 & 0 & 1 & 0 & 0 & 0 & 0 \\
\hline 15 & 1.1 & 0 & 1 & 1 & 1 & 0 & 0 \\
\hline 15 & 1.1 & 0 & 1 & 0 & 1 & 0 & 0 \\
\hline 15 & 1.1 & 0 & 1 & 1 & 1 & 1 & 49.5 \\
\hline 44 & 2.9 & 1 & 1 & 1 & 4 & 1 & 96 \\
\hline
\end{tabular}




\begin{tabular}{|c|c|c|c|c|c|c|c|}
\hline 28 & 2.0 & 0 & 1 & 1 & 1 & 0 & 0 \\
\hline 15 & 1.1 & 0 & 1 & 1 & 1 & 0 & 0 \\
\hline 16 & 1.1 & 0 & 1 & 0 & 0 & 0 & 0 \\
\hline 16 & 1.1 & 0 & 0 & 0 & 1 & 0 & 0 \\
\hline 16 & 1.1 & 0 & 0 & 0 & 1 & 0 & 0 \\
\hline 16 & 1.1 & 0 & 0 & 0 & 1 & 0 & 0 \\
\hline 16 & 1.1 & 0 & 0 & 1 & 1 & 1 & 55 \\
\hline 12 & 0.8 & 0 & 0 & 1 & 1 & 0 & 0 \\
\hline 12 & 0.8 & 0 & 0 & 0 & 1 & 0 & 0 \\
\hline 12 & 0.8 & 0 & 0 & 0 & 1 & 0 & 0 \\
\hline 12 & 0.8 & 0 & 0 & 0 & 1 & 0 & 0 \\
\hline 12 & 0.8 & 0 & 0 & 0 & 0 & 0 & 0 \\
\hline 12 & 0.8 & 0 & 0 & 0 & 1 & 0 & 0 \\
\hline 12 & 0.8 & 0 & 0 & 0 & 1 & 0 & 0 \\
\hline 16 & 1.1 & 0 & 1 & 0 & 1 & 0 & 0 \\
\hline 16 & 1.1 & 0 & 1 & 1 & 1 & 0 & 0 \\
\hline 29 & 2.0 & 0 & 1 & 0 & 1 & 1 & 48 \\
\hline 8 & 0.9 & 1 & 1 & 1 & 3 & 0 & 0 \\
\hline 5 & 0.5 & 0 & 1 & 0 & 1 & 0 & 0 \\
\hline 5 & 0.5 & 0 & 1 & 0 & 0 & 0 & 0 \\
\hline
\end{tabular}




\begin{tabular}{|c|c|c|c|c|c|c|c|}
\hline 5 & 0.5 & 0 & 1 & 1 & 0 & 0 & 0 \\
\hline 5 & 0.5 & 0 & 1 & 0 & 0 & 0 & 0 \\
\hline 5 & 0.5 & 0 & 1 & 0 & 0 & 0 & 0 \\
\hline 5 & 0.5 & 0 & 1 & 0 & 0 & 0 & 0 \\
\hline 5 & 0.5 & 0 & 1 & 0 & 1 & 0 & 0 \\
\hline 5 & 0.5 & 0 & 1 & 0 & 1 & 0 & 0 \\
\hline 5 & 0.5 & 0 & 1 & 0 & 0 & 0 & 0 \\
\hline 5 & 0.5 & 0 & 1 & 0 & 0 & 0 & 0 \\
\hline 5 & 0.5 & 0 & 1 & 0 & 1 & 0 & 0 \\
\hline 5 & 0.5 & 0 & 1 & 1 & 2 & 0 & 0 \\
\hline 5 & 0.5 & 0 & 1 & 0 & 0 & 0 & 0 \\
\hline 5 & 0.5 & 0 & 1 & 0 & 1 & 0 & 0 \\
\hline 5 & 0.5 & 0 & 1 & 0 & 1 & 0 & 0 \\
\hline 5 & 0.5 & 0 & 1 & 1 & 0 & 0 & 0 \\
\hline 5 & 0.5 & 0 & 1 & 0 & 1 & 0 & 0 \\
\hline 5 & 0.5 & 0 & 1 & 1 & 1 & 0 & 0 \\
\hline 5 & 0.5 & 0 & 1 & 0 & 0 & 0 & 0 \\
\hline 5 & 0.5 & 0 & 1 & 0 & 1 & 0 & 0 \\
\hline 5 & 0.5 & 0 & 1 & 0 & 1 & 0 & 0 \\
\hline 5 & 0.5 & 0 & 1 & 0 & 1 & 0 & 0 \\
\hline
\end{tabular}




\begin{tabular}{|c|c|c|c|c|c|c|c|}
\hline 5 & 0.5 & 0 & 1 & 0 & 0 & 0 & 0 \\
\hline 5 & 0.5 & 0 & 1 & 0 & 1 & 0 & 0 \\
\hline 5 & 0.5 & 0 & 1 & 1 & 1 & 1 & 36 \\
\hline 5 & 0.5 & 0 & 1 & 1 & 1 & 0 & 0 \\
\hline 5 & 0.5 & 0 & 1 & 1 & 3 & 1 & 30 \\
\hline 5 & 0.5 & 0 & 1 & 0 & 1 & 0 & 0 \\
\hline 5 & 0.5 & 0 & 1 & 0 & 1 & 0 & 0 \\
\hline 5 & 0.4 & 0 & 1 & 0 & 1 & 0 & 0 \\
\hline 5 & 0.5 & 0 & 1 & 0 & 1 & 0 & 0 \\
\hline 5 & 0.5 & 0 & 1 & 0 & 1 & 0 & 0 \\
\hline 5 & 0.5 & 0 & 1 & 0 & 1 & 0 & 0 \\
\hline 5 & 0.5 & 0 & 1 & 0 & 0 & 0 & 0 \\
\hline 5 & 0.5 & 0 & 0 & 0 & 1 & 0 & 0 \\
\hline
\end{tabular}




\begin{tabular}{|c|c|c|c|c|c|}
\hline \multicolumn{6}{|c|}{ Bus Stop Amenities } \\
\hline Bike & \multicolumn{4}{|c|}{ Waste } & Signage \\
\hline $\begin{array}{l}\text { Bike rack or bike } \\
\text { storage }(1=\text { yes })\end{array}$ & \multicolumn{4}{|c|}{ Trash and Recycle Receptacles } & $\begin{array}{c}\% \text { of Routes } \\
\text { serving stop } \\
\text { indicated that } \\
\text { serve stop }\end{array}$ \\
\hline BikeRack & Trash Can & \# of Trash & Recycle & $\begin{array}{c}\text { \# of } \\
\text { Recycle }\end{array}$ & $\begin{array}{l}\% \text { routes } \\
\text { Indicated }\end{array}$ \\
\hline 1 & 1 & 1 & 0 & 0 & $100 \%$ \\
\hline 1 & 1 & 1 & 0 & 0 & $100 \%$ \\
\hline 0 & 1 & 1 & 1 & 1 & $100 \%$ \\
\hline 0 & 1 & 1 & 1 & 1 & $100 \%$ \\
\hline 0 & 0 & 0 & 0 & 0 & $67 \%$ \\
\hline 0 & 0 & 0 & 0 & 0 & $100 \%$ \\
\hline 1 & 1 & 3 & 0 & 0 & $100 \%$ \\
\hline 1 & 1 & 2 & 0 & 0 & $100 \%$ \\
\hline 1 & 1 & 1 & 0 & 0 & $100 \%$ \\
\hline 1 & 1 & 1 & 0 & 0 & $100 \%$ \\
\hline 0 & 1 & 1 & 0 & 0 & $100 \%$ \\
\hline 0 & 0 & 0 & 0 & 0 & $100 \%$ \\
\hline 0 & 0 & 0 & 0 & 0 & $100 \%$ \\
\hline 1 & 1 & 1 & 0 & 0 & $100 \%$ \\
\hline 0 & 0 & 0 & 0 & 0 & $100 \%$ \\
\hline 0 & 0 & 0 & 0 & 0 & $100 \%$ \\
\hline
\end{tabular}




\begin{tabular}{|c|c|c|c|c|c|}
\hline 0 & 0 & 0 & 0 & 0 & $100 \%$ \\
\hline 0 & 1 & 1 & 0 & 0 & $100 \%$ \\
\hline 0 & 0 & 0 & 0 & 0 & $100 \%$ \\
\hline 0 & 0 & 0 & 0 & 0 & $100 \%$ \\
\hline 0 & 1 & 1 & 0 & 0 & $100 \%$ \\
\hline 0 & 0 & 0 & 0 & 0 & $100 \%$ \\
\hline 0 & 0 & 0 & 0 & 0 & $100 \%$ \\
\hline 0 & 0 & 0 & 0 & 0 & $100 \%$ \\
\hline 0 & 1 & 1 & 0 & 0 & $100 \%$ \\
\hline 0 & 1 & 1 & 0 & 0 & $100 \%$ \\
\hline 0 & 0 & 0 & 0 & 0 & $100 \%$ \\
\hline 0 & 1 & 1 & 0 & 0 & $100 \%$ \\
\hline 0 & 1 & 1 & 0 & 0 & $100 \%$ \\
\hline 0 & 1 & 1 & 0 & 0 & $100 \%$ \\
\hline 0 & 0 & 0 & 0 & 0 & $100 \%$ \\
\hline 0 & 1 & 1 & 0 & 0 & $100 \%$ \\
\hline 0 & 0 & 0 & 0 & 0 & $100 \%$ \\
\hline 0 & 0 & 0 & 0 & 0 & $100 \%$ \\
\hline 0 & 0 & 0 & 0 & 0 & $100 \%$ \\
\hline 0 & 0 & 0 & 0 & 0 & $100 \%$ \\
\hline
\end{tabular}




\begin{tabular}{|c|c|c|c|c|c|}
\hline 0 & 0 & 0 & 0 & 0 & $100 \%$ \\
\hline 0 & 0 & 0 & 0 & 0 & $100 \%$ \\
\hline 0 & 0 & 0 & 0 & 0 & $100 \%$ \\
\hline 0 & 0 & 0 & 0 & 0 & $100 \%$ \\
\hline 0 & 1 & 1 & 0 & 0 & $100 \%$ \\
\hline 0 & 0 & 0 & 0 & 0 & $100 \%$ \\
\hline 0 & 0 & 0 & 0 & 0 & $100 \%$ \\
\hline 0 & 1 & 1 & 0 & 0 & $100 \%$ \\
\hline 0 & 1 & 1 & 0 & 0 & $100 \%$ \\
\hline 0 & 0 & 0 & 0 & 0 & $100 \%$ \\
\hline 0 & 1 & 1 & 0 & 0 & $100 \%$ \\
\hline 0 & 0 & 0 & 0 & 0 & $100 \%$ \\
\hline 0 & 0 & 0 & 0 & 0 & $100 \%$ \\
\hline 0 & 1 & 1 & 0 & 0 & $100 \%$ \\
\hline 0 & 0 & 0 & 0 & 0 & $100 \%$ \\
\hline 0 & 1 & 1 & 0 & 0 & $100 \%$ \\
\hline 0 & 0 & 0 & 0 & 0 & $100 \%$ \\
\hline 0 & 1 & 1 & 0 & 0 & $100 \%$ \\
\hline 0 & 0 & 0 & 0 & 0 & $100 \%$ \\
\hline 0 & 1 & 1 & 0 & 0 & $100 \%$ \\
\hline
\end{tabular}




\begin{tabular}{|c|c|c|c|c|c|}
\hline 0 & 0 & 0 & 0 & 0 & $100 \%$ \\
\hline 0 & 0 & 0 & 0 & 0 & $100 \%$ \\
\hline 0 & 1 & 1 & 0 & 0 & $100 \%$ \\
\hline 0 & 0 & 0 & 0 & 0 & $100 \%$ \\
\hline 0 & 0 & 0 & 0 & 0 & $100 \%$ \\
\hline 0 & 0 & 0 & 0 & 0 & $100 \%$ \\
\hline 0 & 0 & 0 & 0 & 0 & $100 \%$ \\
\hline 0 & 0 & 0 & 0 & 0 & $100 \%$ \\
\hline 0 & 0 & 0 & 0 & 0 & $100 \%$ \\
\hline 0 & 1 & 1 & 0 & 0 & $100 \%$ \\
\hline 0 & 0 & 0 & 0 & 0 & $100 \%$ \\
\hline 1 & 1 & 1 & 0 & 0 & $100 \%$ \\
\hline 0 & 0 & 0 & 0 & 0 & $100 \%$ \\
\hline 0 & 0 & 0 & 0 & 0 & $100 \%$ \\
\hline 0 & 1 & 1 & 1 & 1 & $100 \%$ \\
\hline 1 & 1 & 1 & 1 & 1 & $100 \%$ \\
\hline 1 & 1 & 1 & 0 & 0 & $100 \%$ \\
\hline 1 & 1 & 1 & 0 & 0 & $100 \%$ \\
\hline 1 & 1 & 2 & 0 & 0 & $100 \%$ \\
\hline 0 & 1 & 1 & 0 & 0 & $100 \%$ \\
\hline
\end{tabular}




\begin{tabular}{|c|c|c|c|c|c|}
\hline 0 & 1 & 1 & 0 & 0 & $0 \%$ \\
\hline 0 & 1 & 1 & 0 & 0 & $0 \%$ \\
\hline 1 & 1 & 1 & 0 & 0 & $0 \%$ \\
\hline 0 & 1 & 1 & 0 & 0 & $100 \%$ \\
\hline 0 & 1 & 1 & 0 & 0 & $100 \%$ \\
\hline 0 & 1 & 1 & 0 & 0 & $100 \%$ \\
\hline 0 & 0 & 0 & 0 & 0 & $0 \%$ \\
\hline 0 & 1 & 1 & 0 & 0 & $100 \%$ \\
\hline 0 & 1 & 1 & 0 & 0 & $100 \%$ \\
\hline 0 & 0 & 0 & 0 & 0 & $100 \%$ \\
\hline 0 & 1 & 1 & 0 & 0 & $0 \%$ \\
\hline 0 & 0 & 0 & 0 & 0 & $0 \%$ \\
\hline 0 & 1 & 1 & 0 & 0 & $100 \%$ \\
\hline 0 & 1 & 1 & 0 & 0 & $100 \%$ \\
\hline 0 & 1 & 1 & 0 & 0 & $100 \%$ \\
\hline 0 & 0 & 0 & 0 & 0 & $0 \%$ \\
\hline 0 & 1 & 1 & 0 & 0 & $100 \%$ \\
\hline 0 & 1 & 1 & 0 & 0 & $100 \%$ \\
\hline 0 & 1 & 1 & 0 & 0 & $100 \%$ \\
\hline 0 & 1 & 2 & 1 & 2 & $100 \%$ \\
\hline
\end{tabular}




\begin{tabular}{|c|c|c|c|c|c|}
\hline 0 & 0 & 0 & 0 & 0 & $50 \%$ \\
\hline 0 & 1 & 1 & 0 & 0 & $100 \%$ \\
\hline 0 & 0 & 0 & 0 & 0 & $100 \%$ \\
\hline 0 & 0 & 0 & 0 & 0 & $100 \%$ \\
\hline 0 & 0 & 0 & 0 & 0 & $100 \%$ \\
\hline 0 & 1 & 1 & 0 & 0 & $100 \%$ \\
\hline 0 & 1 & 1 & 0 & 0 & $100 \%$ \\
\hline 0 & 0 & 0 & 0 & 0 & $100 \%$ \\
\hline 0 & 0 & 0 & 0 & 0 & $100 \%$ \\
\hline 0 & 1 & 1 & 0 & 0 & $100 \%$ \\
\hline 0 & 1 & 1 & 0 & 0 & $100 \%$ \\
\hline 0 & 0 & 0 & 0 & 0 & $100 \%$ \\
\hline 0 & 0 & 0 & 0 & 0 & $100 \%$ \\
\hline 0 & 0 & 0 & 0 & 0 & $100 \%$ \\
\hline 0 & 0 & 0 & 0 & 0 & $100 \%$ \\
\hline 0 & 1 & 1 & 0 & 0 & $100 \%$ \\
\hline 0 & 1 & 1 & 0 & 0 & $100 \%$ \\
\hline 0 & 1 & 1 & 1 & 1 & $100 \%$ \\
\hline 0 & 0 & 0 & 0 & 0 & $100 \%$ \\
\hline 0 & 0 & 0 & 0 & 0 & $100 \%$ \\
\hline
\end{tabular}




\begin{tabular}{|c|c|c|c|c|c|}
\hline 0 & 0 & 0 & 0 & 0 & $100 \%$ \\
\hline 0 & 0 & 0 & 0 & 0 & $100 \%$ \\
\hline 0 & 0 & 0 & 0 & 0 & $100 \%$ \\
\hline 0 & 0 & 0 & 0 & 0 & $100 \%$ \\
\hline 0 & 0 & 0 & 0 & 0 & $100 \%$ \\
\hline 0 & 0 & 0 & 0 & 0 & $100 \%$ \\
\hline 0 & 0 & 0 & 0 & 0 & $100 \%$ \\
\hline 0 & 0 & 0 & 0 & 0 & $100 \%$ \\
\hline 0 & 0 & 0 & 0 & 0 & $100 \%$ \\
\hline 0 & 0 & 0 & 0 & 0 & $100 \%$ \\
\hline 0 & 0 & 0 & 0 & 0 & $100 \%$ \\
\hline 0 & 0 & 0 & 0 & 0 & $100 \%$ \\
\hline 0 & 0 & 0 & 0 & 0 & $100 \%$ \\
\hline 0 & 0 & 0 & 0 & 0 & $100 \%$ \\
\hline 0 & 0 & 0 & 0 & 0 & $100 \%$ \\
\hline 0 & 0 & 0 & 0 & 0 & $100 \%$ \\
\hline 0 & 0 & 0 & 0 & 0 & $100 \%$ \\
\hline 0 & 0 & 0 & 0 & 0 & $100 \%$ \\
\hline 0 & 0 & 0 & 0 & 0 & $100 \%$ \\
\hline 0 & 0 & 0 & 0 & 0 & $100 \%$ \\
\hline
\end{tabular}




\begin{tabular}{|c|c|c|c|c|c|}
\hline 0 & 0 & 0 & 0 & 0 & $100 \%$ \\
\hline 0 & 0 & 0 & 0 & 0 & $100 \%$ \\
\hline 0 & 0 & 0 & 0 & 0 & $100 \%$ \\
\hline 0 & 0 & 0 & 0 & 0 & $100 \%$ \\
\hline 1 & 1 & 1 & 0 & 0 & $100 \%$ \\
\hline 0 & 0 & 0 & 0 & 0 & $100 \%$ \\
\hline 0 & 0 & 0 & 0 & 0 & $100 \%$ \\
\hline 0 & 0 & 0 & 0 & 0 & $100 \%$ \\
\hline 0 & 0 & 0 & 0 & 0 & $100 \%$ \\
\hline 0 & 0 & 0 & 0 & 0 & $100 \%$ \\
\hline 0 & 0 & 0 & 0 & 0 & $100 \%$ \\
\hline 0 & 0 & 0 & 0 & 0 & $100 \%$ \\
\hline 0 & 0 & 0 & 0 & 0 & $100 \%$ \\
\hline
\end{tabular}

